Universidade de São Paulo

Instituto DE FÍsicA

Thaciana Valentina Malaspina Fileti

Estabilidade isomérica e ligações de hidrogênio em agregados e líquidos moleculares 



\title{
Estabilidade isomérica e ligações de hidrogênio em agregados e líquidos moleculares
}

\author{
Thaciana Valentina Malaspina Fileti
}

Orientador: Prof. Dr. Sylvio Roberto Accioly Canuto

\section{Comissão Examinadora:}

Prof. Dr. Sylvio R. A. Canuto - (USP)

Profa. Dra. Lucy V. C. Assali - (USP)

Prof. Dr. Francisco B. C. Machado - (ITA)

Prof. Dr. Roberto Rivelino M. Moreno - (UFBA)

Prof. Dr. João Bosco P. da Silva - (UFPE)

Tese de doutoramento apresentada ao Instituto de Física para a obtenção do título de Doutor em Ciências 


\section{FICHA CATALOGRÁFICA}

Preparada pelo Serviço de Biblioteca e Informação do Instituto de Física da Universidade de São Paulo

Fileti, Thaciana Valentina Malaspina

Estabilidade isomérica e ligações de hidrogênio em agregados e líquidos moleculares. São Paulo, 2006

Tese (Doutorado) Universidade de São Paulo. Instituto de Física - Depto. de Física dos Materiais e Mecânica.

Orientador: Prof. Dr. Sylvio Roberto Accioly Canuto Área de Concentração: Física

\section{Unitermos}

1. Física do estado líquido;

2. Líquidos moleculares;

3. Física do estado gasoso;

4. Agregados moleculares;

5. Estrutura molecular (Física moderna).

USP/IF/SBI - 052/2006 


\section{Agradecimentos}

Muitas pessoas foram fundamentais durante os quatro anos de doutorado que resultaram nesta tese. Todas elas foram importantes, mas algumas foram imprescindíveis.

Na classe das importantes estão os amigos que fiz durante todo este período no departamento, os quais sempre me suportaram (nos dois sentidos!!!) e me alavancaram para cima. Vocês meus amigos, têm uma boa parcela de "culpa" para a conclusão desta tese. Agradeço aos colegas de sala, pela ótima convivência, o que certamente influenciou neste trabalho.

Na classe dos imprescindíveis estão meu orientador, a quem eu sempre chamei e vou continuar chamando por muito tempo de meu "pai científico", professor Sylvio Canuto, que soube durante todos estes sete anos de convivência (adaptação matemática $\rightarrow$ física, mestrado e doutorado) conduzir-me na ciência com muita paciência, dedicação e amizade. Sou muito grata, por ter feito parte de seu seleto grupo de alunos, e com isso ter tido a chance de aprender com ele não só sobre a física, mas sobre ética na vida científica e sobre a vida de um modo geral. Também na classe dos imprescindíveis está a professora Kaline, que sempre influenciou os trabalhos de todos do grupo de forma construtiva e enriquecedora, a quem também sou muito grata pela enorme amizade. Espero poder contar com os dois por muitos anos à frente.

Ao CNPq pelo suporte financeiro direto e à FAPESP pelas máquinas sem as quais nada disso seria possível. 



\section{Resumo}

Neste trabalho, estamos interessados na descrição da estabilidade isomérica de moléculas isoladas e em agregados, assim como em propriedades eletrônicas de agregados moleculares em fase gasosa e estruturas com ligação de hidrogênio em fase líquida. Na primeira investigação, estabilidade isomérica, estudamos a estabilidade relativa dos isômeros $\mathrm{C}_{2 v}, \mathrm{C}_{3 v}$ e $\mathrm{C}_{s}$ da molécula de $\mathrm{AlP}_{3}$ isolada. Analisamos tanto a estrutura conformacional, quanto a energética dos três isômeros e depois de submetermos as estruturas mais estáveis a cálculos sofisticados de química quântica, extrapolamos os resultados obtidos para as energias dos isômeros ao limite de base completa. Chegamos à conclusão que o isômero $\mathrm{C}_{3 v}$ é o menos estável dos três investigados, e que os isômeros $\mathrm{C}_{2 v}$ e $\mathrm{C}_{s}$ apresentam-se como estados quase-degenerados com uma diferença de energia de $\sim 1,6 \mathrm{kcal} / \mathrm{mol}$. Ainda pensando na estabilidade isomérica, investigamos os agregados $\mathrm{HCN} \cdots \mathrm{HOH}$ e $\mathrm{H}_{2} \mathrm{O} \cdots \mathrm{HCN}$, também em fase gasosa. Através de cálculos ab initio obtivemos a estrutura e energética dos dois agregados. Comparamos a energia dos dois agregados depois de obtermos, através de métodos altamente acurados de correlação eletrônica no limite de base completa, e obtivemos que o agregado $\mathrm{H}_{2} \mathrm{O} \cdots \mathrm{HCN}$ é o mais estável por $\sim 1,5 \mathrm{kcal} / \mathrm{mol}$. Na segunda parte de nosso trabalho, investigamos as modificações sofridas em agregados moleculares quando estes são formados em diferentes ambientes, o gasoso e o líquido. Primeiro, analisamos as diferenças nos agregados de pirazina $\left(\mathrm{N}_{2} \mathrm{C}_{4} \mathrm{H}_{4}\right)$ e água (1:1 e 1:2), através de comparação da estrutura e propriedades eletrônicas obtidas em fase gasosa através de otimização de geometria e em fase líquida, obtidos da simulação computacional Monte Carlo Metropolis. Para as estruturas 1:1 comparamos os resultados nos dois ambientes através da estrutura, energia e momento de dipolo. Para os agregados 1:2 comparamos adicionalmente as contribuições energéticas de muitos corpos e a cooperatividade nos dois ambientes. Todos os resultados nos mostram que os agregados em fase gasosa são cerca de $30 \%$ mais estáveis que os agregados do líquido, tanto para os agregados 1:1 quanto para os agregados 1:2. Ao final do trabalho, analisamos as modificações sofridas no espectro eletrônico do formaldeído $\left(\mathrm{H}_{2} \mathrm{CO}\right)$ quando este se encontra em ambiente aquoso. Analisamos especificamente o deslocamento da banda de energia referente à transição $n \rightarrow \pi^{*}$ deste espectro quando consideramos 1,2 e 3 moléculas de água solvatando o formaldeído e também quando incluímos toda a primeira camada de solvatação, 18 moléculas de água, todas inclusas explicitamente no cálculo quântico. Adicionalmente, fizemos estimativas para a contribuição da dispersão de London e da relaxação da ligação $C=O$ no deslocamento da banda $n \rightarrow \pi^{*}$ do formaldeído solvatado. 



\section{Conteúdo}

1 Introdução 1

2 Tratamentos Clássicos $\quad \mathbf{5}$

2.1 Monte Carlo Metropolis . . . . . . . . . . . . . . . . . . . 6

2.2 Potencial de Interação . . . . . . . . . . . . . . . . . . 10

2.3 Função Distribuição Radial de Pares . . . . . . . . . . . . . . . . 11

2.4 Função de Auto-correlação da Energia . . . . . . . . . . . . . . . 13

3 Tratamentos Quânticos $\quad 15$

3.1 Aproximação de Born-Oppenheimer . . . . . . . . . . . . . 15

3.2 Hartree-Fock . . . . . . . . . . . . . . . . . . . . . 18

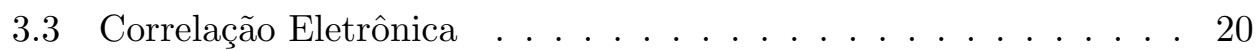

3.4 Teoria de Perturbação Møller-Plesset . . . . . . . . . . . . . . . . 21

3.5 Coupled Cluster . . . . . . . . . . . . . . . . . . 24

3.6 Teoria do Funcional da Densidade . . . . . . . . . . . . 27

3.6.1 Time Dependent-DFT . . . . . . . . . . . . . . 29

3.7 Conjunto de Funções-Base . . . . . . . . . . . . . . . . . . . 30

3.7.1 Limite de Base Completa . . . . . . . . . . . . . . . 32

3.7 .2 Superposição de Base . . . . . . . . . . . . . . . . 34

3.8 Ligação de Hidrogênio . . . . . . . . . . . . . . . . . . . . . . 35

3.8.1 Cooperatividade na Ligação de Hidrogênio ..... 39

3.9 A Metodologia S-MC/QM . . . . . . . . . . . . . . . . 41

4 Resultados $\quad 43$

4.1 Estabilidade Relativa de Isômeros . . . . . . . . . . . . . . . . . . 43

$4.1 .1 \quad \mathrm{AlP}_{3} \ldots \ldots \ldots \ldots \ldots \ldots \ldots$

$4.1 .2 \mathrm{HCN} \cdots \mathrm{HOH}$ e $\mathrm{H}_{2} \mathrm{O} \cdots \mathrm{HCN} \ldots \ldots . \ldots . \ldots . . \ldots 52$

4.2 Ligação de Hidrogênio Pirazina-Água . . . . . . . . . . . . . . . . 62

4.2.1 Estrutura 1:1, Gás e Líquido . . . . . . . . . . 70 
4.2 .2 Estrutura 1:2, Gás e Líquido . . . . . . . . . . . . 74

4.2.3 Propriedades Eletrônicas das Estruturas Pirazina-Água $1: 1$ e $1: 2 \ldots \ldots \ldots \ldots \ldots \ldots \ldots$

4.3 Formaldeído-Água: Agregados e Líquido . . . . . . . . . . . . . . 82

4.3.1 Ligação de Hidrogênio e Cooperatividade nos Agregados Formaldeído-Água . . . . . . . . . . . . . . . 84

4.3.2 Transição Eletrônica $\mathrm{n} \rightarrow \pi^{*}$ do Formaldeído em Solução Aquosa ........................... 92

5 Conclusões 


\begin{abstract}
In this work, we study the isomeric stability of isolated molecules and molecular clusters. We study the change of some electronic properties of molecular clusters in gas and liquid phases. The first application is the relative isomeric stability of isolated $A_{1} P_{3}$ in $C_{2 v}, C_{3 v}$ and $C_{s}$ symmetries. We analyze the conformational structure and the total energy of the three isomers using sophisticated quantum chemistry calculations and using $C C S D(T) / c c-p V X Z$ $(X=2,3,4$ and 5) level and extrapole to the infinite basis set limit. The locations of the two states on the potential energy hyper-surface are obtained and show that they represent well-defined and stable isomers. We also investigate the $\mathrm{HCN} \cdots \mathrm{HOH}$ and $\mathrm{H}_{2} \mathrm{O} \cdots \mathrm{HCN}$ clusters in gas phase, using ab initio calculations to obtain the optimized structure of these two molecular clusters. We present a systematic study of the stability of the $\mathrm{H}_{2} \mathrm{O} \cdots \mathrm{HCN}$ and HCN $\cdots H O H$ complexes calculating the binding energy of both systems using the aug-cc-pVXZ basis sets with $X=2,3,4$ and extending the results to the infinite limit. At the best theoretical level, $\mathrm{CCSD}(\mathrm{T})$, the $\mathrm{H}_{2} \mathrm{O} \cdots \mathrm{HCN}$ cluster is more stable than $H C N \cdots H O H$ by $\sim 1.5 \mathrm{kcal} / \mathrm{mol}$. In the second part of our work, we investigate the electronic modifications in molecular clusters due to the different environments of these clusters, the gas and the liquid phases. We analyze the pyrazine-water clusters (1:1 and 1:2) obtained in gas and liquid phases and compare the structure and electronic clusters properties. For the 1:1 pyrazine-water clusters we compare the structures, total energy and dipole moments. For the 1:2 pyrazine-water clusters we analyze the many-body contributions to the interaction energy and cooperativity. All results show that the gas phase clusters have interaction energies that are around $30 \%$ of the liquid clusters. Finally, we analyze the absorption electronic spectrum of formaldehyde in liquid water. We specifically analyze the shift of the $n \rightarrow \pi^{*}$ electronic transition. We consider 1, 2, 3 and 18 water molecules solvating the formaldehyde, all explicitaly included in the TD-DFT calculations. Additionally, we make estimates of the London dispersion contribution and $C=O$ stretching effects in the shift of the $n \rightarrow \pi^{*}$ electronic transition of formaldehyde in water.
\end{abstract}





\section{Capítulo 1}

\section{Introdução}

A investigação de sistemas moleculares, seja em fase gasosa ou em fase líquida, tem despertado o interesse de pesquisadores das áreas de química, física e biologia, há várias décadas [1-8]. Desde o advento da física quântica, a resolução da equação de Schrödinger tem fornecido resultados para as propriedades microscópicas de sistemas em fase gasosa. A qualidade e a precisão destes resultados dependem das aproximações utilizadas na resolução da equação de Schrödinger [9-14]. Neste sentido existe um compromisso entre o tamanho do sistema e o nível teórico a ser usado. Quando o sistema é composto por uma quantidade muito grande de átomos, milhares deles, como no caso das proteínas, é inviável a aplicação de metodologias sofisticadas como Coupled Cluster [15,16] e Full-CI $[11,13,14,17]$ devido ao esforço computacional envolvido na resolução da equação de Schrödinger para um sistema como esse. Porém, se o sistema é composto por algumas dezenas de átomos, é computacionalmente possível resolver a equação de Schrödinger referente a estes sistemas, com métodos bastante sofisticados.

Neste contexto, no tratamento quântico de sistemas moleculares, nos dedicamos nesta tese a dois tipos distintos de problemas. O primeiro é a elucidação de estabilidade relativa com uma aplicação para molécula isolada e uma aplicação para agregados isolados. A molécula isolada que investigamos foi a molécula de $\mathrm{AlP}_{3}$ que desperta o interesse devido a sua composição atômica por elementos com características de semicondutores [18-20]. Esta molécula ainda não foi observada experimentalmente, e a caracterização da si- 
metria mais estável ainda suscitava dúvidas segundo a literatura atual [21-25]. Assim, uma caracterização acurada da localização energética relativa das duas simetrias $\mathrm{C}_{s}$ e $\mathrm{C}_{2 v}$ para o estado singleto da molécula de $\mathrm{AlP}_{3}$ ainda é objeto de investigações teóricas e experimentais. Investigamos através de cálculos quânticos sofisticados a energética da molécula de $\mathrm{AlP}_{3}$ no estado singleto nas simetrias $\mathrm{C}_{s}, \mathrm{C}_{2 v}$ e $\mathrm{C}_{3 v}$ e ao final utilizamos técnicas de extrapolação consolidadas na literatura $[26,27]$ para obtermos a energia da molécula nas simetrias $\mathrm{C}_{s}$ e $\mathrm{C}_{2 v}$ no limite de base completa [28]. Na segunda aplicação para estabilidade relativa, fazemos um estudo similar, mas agora aumentando a complexidade do problema de uma molécula para um agregado com duas moléculas, HCN e $\mathrm{H}_{2} \mathrm{O}$ [29-31]. O HCN é a molécula mais simples do grupo nitrila e juntamente com a molécula de água, podem formar dois agregados moleculares distintos, um onde o cianeto de hidrogênio atua como doador de prótons $\left(\mathrm{H}_{2} \mathrm{O} \cdots \mathrm{HCN}\right)$ e outro agregado onde a água atua como doadora de prótons ( $\mathrm{HCN} \cdots \mathrm{HOH})$. $\mathrm{O}$ primeiro destes agregados, $\mathrm{H}_{2} \mathrm{O} \cdots \mathrm{HCN}$, foi obtido teoricamente através de métodos semi-empírico e ab initio por Turi e Dannenberg [32]. Já o agregado $\mathrm{HCN} \cdots \mathrm{HOH}$ foi obtido experimentalmente por espectrocopia de microondas por Gutowsky e coautores [33]. Em artigos mais recente [31,34], estes dois agregados foram investigados tanto teórica quanto experimentalmente. Então, caracterizamos os dois agregados, tanto estrutural quanto energeticamente e depois submetemos as duas estruturas otimizadas a cálculos pontuais para obtenção de energias em níveis mais sofisticados de correlação eletrônica, e com base nestes resultados, extrapolamos a energia de ligação dos dois agregados ao limite de base completa [35].

Na segunda parte da tese, nos dedicamos ao estudo de sistemas moleculares em fase líquida, para os quais diversas peculiaridades devem ser levadas em conta na busca das propriedades microscópicas deste tipo de sistema. A primeira peculiaridade é a grande quantidade de átomos ou moléculas, no mímino muitas centenas, que devem ser levadas em conta para uma descrição mais realista possível do sistema. Além disso um líquido não pode ser representado por uma única estrutura como acontece no caso de sistemas em fase gasosa, em que a resolução da equação de Schrödinger nos fornece uma única conformação 
e suas várias propriedades microscópicas. O líquido porém, é dotado de natureza intrinsecamente estatística, são necessárias várias configurações estruturais para representar um sistema em fase líquida. Sendo assim, foi preciso pensar em metodologias alternativas para o tratamento a nível microscópico de sistemas em fase líquida. As primeiras tentativas de descrição quântica de sistemas em fase líquida foram os métodos de campo de reação [36], onde a parte mais relevante do sistema líquido, por exemplo o soluto, é tratada quanticamente e as moléculas de solvente são substituídas pela constante dielétrica do solvente. Neste tipo de tratamento, cria-se uma cavidade tridimensional onde o soluto fica localizado e ao redor da cavidade a constante dielétrica do solvente induz modificações no soluto. Porém, esta metodogia traz consigo uma grande limitação que é o fato de não tratar de forma clara as interações específicas entre soluto e solvente. Para contemplar este aspecto do líquido, surgiu mais tarde a metodologia QM/MM (Quantum Mechanics/Molecular Mechanics) [37,38], onde parte do sistema, geralmente o soluto e algumas moléculas de solvente, são tratados quanticamente e a outra parte do sistema composta pelas moléculas de solvente mais externas são tratadas por mecânica clássica. Através desta metodologia, as interações específicas entre soluto e solvente são contempladas pelo cálculo quântico, mas o procedimento é computacionalmente muito caro, haja visto que o sistema é tratado quântica e classicamente quase simultaneamente. Para driblar o custo computacional do QM/MM tradicional surgiu uma vertente denominada S-MC/QM - sequential-Monte Carlo/Quantum Mechanics $[39,40]$ onde o sistema líquido é tratado seqüencialmente, primeiro de forma clássica através de simulação computacional Monte Carlo, e depois de forma quântica.

Aplicando a metodologia S-MC/QM, investigamos as interações sofridas em agregados moleculares de pirazina $\left(\mathrm{N}_{2} \mathrm{C}_{4} \mathrm{H}_{4}\right)$ e água, tanto em fase gasosa, quanto em fase líquida. Os agregados em fase gasosa foram obtidos através de otimização de geometria. Em fase líquida, através de simulação Monte Carlo Metropolis selecionamos estruturas onde aplicamos critérios de formação de ligação de hidrogênio e obtivemos então configurações do líquido estruturalmente compararáveis aos agregados otimizados em fase gasosa. Assim, 
em fase líquida não temos apenas uma, mas várias estruturas moleculares que satisfazem as exigências dos critérios para formação de ligação de hidrogênio. Portanto, as propriedades obtidas são uma média sobre uma amostragem obtida no líquido. Comparamos então as propriedades obtidas em fase gasosa e em fase líquida para os dois tipos de estruturas (1:1 e 1:2) e para aqueles que continham uma molécula de pirazina e duas moléculas de águas (1:2), analisamos também as contribuições energéticas de dois e três corpos na energia total do sistema, tanto em fase gasosa, quanto em fase líquida.

Por último investigamos e comparamos algumas propriedades de agregados gasosos e de estruturas do líquido obtidas com as moléculas de formaldeído $\left(\mathrm{H}_{2} \mathrm{CO}\right)$ e água. O formaldeído é a menor molécula contendo um grupo carbonila $(\mathrm{C}=\mathrm{O})$, o que faz dele um ótimo protótipo para moléculas de grande porte que contenham o grupo carbonila e que sejam de difícil abordagem em tratamentos quânticos. Neste contexto, a interação do formaldeído com outras moléculas tem sido investigada [41-46]. Em particular, o agregado formaldeído-água tem recebido alguma atenção, já que este é o mais simples sistema envolvendo uma molécula do grupo carbonila e a água $[43,44,47-49]$. Investigamos as propriedades eletrônicas, assim como estrutura, momento de dipolo, energia de ligação e as contribuições energéticas de dois e três corpos nos agregados de fase gasosa obtidos via otimização de geometria. Com o sistema obtido em fase líquida analisamos a influência das moléculas de água nos espectros eletrônicos do formaldeído em água, obtido através da metodologia S-MC/QM. 


\section{Capítulo 2}

\section{Tratamentos Clássicos}

O tratamento acurado das propriedades eletrônicas de sistemas em fase líquida ainda é um tema relativamente complexo, devido a duas características sempre presentes em sistemas em fase líquida: o grande número de partículas (átomos ou moléculas) que compõe o líquido e o grande número de configurações estruturais possíveis destas partículas a uma determinada temperatura. Neste contexto, tornam-se necessárias metodologias capazes de descrever os sistemas em fase líquida.

Uma metodologia matemática eficaz para o tratamento das inúmeras partículas presentes num líquido é a simulação computacional. Através da simulação computacional é possível tratar os sistemas líquidos de maneira estatística, produzindo resultados estatisticamente convergidos, dentro da incerteza devido ao tamanho finito da simulação [50-53]. Para este tipo de tratamento computacional, existem duas grandes vertentes largamente utilizadas que são a Dinâmica Molecular [51] e o método Monte Carlo [54].

Em poucas palavras, a Dinâmica Molecular é um processo determinístico, onde as forças que atuam em cada partícula são obtidas a partir de um potencial de interação entre as partículas, $F(\mathbf{r})=-d U(\mathbf{r}) / d r$. Desta maneira, as equações de movimento são resolvidas e evoluem por um determinado intervalo de tempo, de modo que as posições sucessivas das partículas são calculadas, gerando configurações que além de representarem o líquido, mostram a evolução temporal do sistema e de suas propriedades. Já o método Monte Carlo tem como característica mais marcante o fato do sistema ser tratado 
estocasticamente. Isto significa que as posições das partículas são obtidas de maneira aleatória, sem vínculo entre duas estruturas sucessivas. Atualmente, existe um grande número de variações distintas do método Monte Carlo. Como exemplo destas variações, podemos citar, Monte Carlo Cinético, Monte Carlo Reverso [55] e Monte Carlo Metropolis clássico [56,57] ou Quântico [58].

Nos trabalhos realizados nesta tese, utilizamos o método Monte Carlo Metropolis para a realização das simulações computacionais. A escolha deste método foi feita baseada em seu baixo custo computacional comparado aos métodos de simulação equivalentes e na sua eficácia comprovada para gerar estruturas supermoleculares que representem um líquido molecular a uma dada temperatura [59-62].

\subsection{Monte Carlo Metropolis}

Devido a seu baixo custo computacional e à produção de resultados confiáveis, o método Monte Carlo implementado com o algoritmo de Metropolis [57] (MCM) é utilizado em diversos ramos da pesquisa científica. Como exemplo, podemos citar, transporte de radiação na atmosfera terrestre [63], sistemas caóticos [64] e transições de fase [65].

Em uma simulação Monte Carlo (MC) o sistema é representado por um número $N$ de partículas confinadas em uma caixa poliédrica [66], geralmente cúbica. Uma partícula na caixa percebe a presença de outra através do potencial de interação $U$, que deve ser cuidadosamente escolhido. O conjunto das posições de todas as partículas confinadas na caixa, $\mathbf{r}=\left(\vec{r}_{1}, \vec{r}_{2}, \cdots, \vec{r}_{N}\right)$, definem uma configuração do líquido, que denotamos por $\Gamma_{i}(\mathbf{r})$. Todas estas configurações do líquido geradas pela simulação MC pertencem ao espaço de configurações $\Gamma_{i}(\mathbf{r})$.

O método de simulação Monte Carlo Metropolis é um processo ergódico [67]. Isto significa que significa que a probabilidade do sistema sair de uma configuração $\Gamma_{i}$ para uma configuração $\Gamma_{j}$ é sempre diferente de zero, quaisquer que sejam os estados $i$ e $j$ em que o sistema se encontra. Uma outra maneira de entender este conceito é pensar que todos os pontos do espaço de 
configurações podem ser visitados durante a simulação MC. Sendo assim, se realizarmos uma simulação infinita, todas as configurações $\Gamma_{i}(\mathbf{r})$ pertencentes ao espaço de configurações $\Gamma_{i}(\mathbf{r})$ serão visitadas pelo menos uma vez durante a simulação.

Um pré-requisito do método Monte Carlo Metropolis é que o sistema possa ser descrito por uma função densidade de probabilidade [57]. Assim, quando o sistema encontra-se em equilíbrio térmico, podemos gerar configurações que obedeçam a distribuição de probabilidades de Gibbs-Boltzmann $[68,69]$, dada por:

$$
P\left(\Gamma_{i}\right)=\frac{\varrho\left(\Gamma_{i}\right)}{Z}=\frac{e^{-U\left(\Gamma_{i}\right) / k T}}{Z},
$$

onde $\varrho\left(\Gamma_{i}\right)$ é a densidade de probabilidade, $Z$ é a função de partição do sistema, $k$ é a constante de Boltzmann e $T$ é a temperatura em que se encontra o sistema.

Por outro lado, temos da Mecânica Estatística que a média de uma propriedade qualquer do sistema pode ser obtida como:

$$
\langle f\rangle=\frac{1}{Z} \sum_{i}^{M} f\left(\Gamma_{i}\right) e^{\left(-\frac{U\left(\Gamma_{i}\right)}{k T}\right)} .
$$

De 2.1 e 2.2 podemos escrever, para um número $M$ de configurações a média de $f$ como:

$$
\langle f\rangle=\frac{1}{M} \sum_{i}^{M} f\left(\Gamma_{i}\right),
$$

que é uma boa estimativa para a média da propriedade $f$.

O fato da função de partição $Z$ não precisar ser conhecida, é uma das características mais importantes do método Monte Carlo Metropolis. Somente as probabilidades relativas das diferentes configurações que correspondem ao uso da função de partição devem ser conhecidas para aplicação desta técnica. Este fato, torna a simulação Monte Carlo Metropolis, uma metodologia barata computacionalmente, devido à simplificação nos cálculos dentro do algoritmo de Metropolis.

Assim, o problema se reduz a gerar as configurações $\Gamma_{i}$ com probabilidade $P\left(\Gamma_{i}\right)$, o que pode ser feito através do procedimento de amostragem ponderada. Este procedimento consiste em gerar configurações aleatórias $\Gamma_{i}$ 
pertencentes ao espaço de configurações $\Gamma_{i}$, de modo que ao final da simulação cada configuração tenha ocorrido em sua devida proporção. Utilizando este procedimento da amostragem ponderada gera-se uma cadeia de Markov [54]. Em um processo Markoviano é possível construir uma trajetória aleatória de configurações $\Gamma_{i}$, através do espaço de configurações $\Gamma_{i}$, independente de uma lei dinâmica que dite o comportamento físico do sistema. Assim, a configuração a ser gerada depende unicamente da configuração atual do sistema.

Na cadeia de Markov as configurações $\Gamma_{i}$ e $\Gamma_{j}$ estão relacionadas pela matriz de transição $\pi$, que satisfaz a condição de reversibilidade microscópica, o que significa que, partindo de qualquer configuração $\Gamma_{i}$ pode-se chegar à configuração $\Gamma_{j}$. Podemos então construirmos a matriz de transição $\pi_{i j}$ tal que:

$$
\pi_{i j} P_{j}=\pi_{j i} P_{i}
$$

onde segundo Metropolis:

$$
\pi_{i j}=\left\{\begin{array}{c}
1 \text { se } P_{i} \leq P_{j} \text { para } i \neq j \\
\frac{P_{j}}{P_{i}} \text { se } P_{i}>P_{j} \text { para } i \neq j \\
1-\sum_{i \neq j} P_{i j} \text { para } i=j
\end{array}\right.
$$

desta forma a matriz de transição satisfaz todas as propriedades gerais de uma matriz estocástica, isto é, $\pi_{i j} \geq 0$ e $\sum_{i} \pi_{i j}=1$ para todo $j$.

Utilizando um determinado ensemble, como o $N V T$, no qual o número de partículas $N$, o volume $V$ e a temperatura $T$ são mantidos fixos, podemos obter uma amostragem sobre a qual realizamos cálculos dos valores médios das propriedades em que estamos interessados. Para realizar a simulação MCM, neste ensemble, partimos de uma configuração inicial que consiste de um arranjo aleatório das $N$ partículas em uma caixa cúbica a volume e temperatura constantes. Replicamos esta caixa cúbica por todo o espaço e com isso, evitamos que as partículas na caixa central sejam submetidas a efeitos de borda. Utilizamos também o método das imagens, no qual uma partícula que se movimenta na caixa original tem todas as suas imagens movidas pelo mesmo caminho em todas as outras caixas. Caso uma partícula deixe a caixa original, uma de suas imagens entra pelo lado oposto gerando assim condição periódica de contorno. 
Para contornar esta periodicidade introduzida pela réplica das caixas por todo espaço, utilizamos o raio de corte $r_{c}$, que numericamente corresponde à metade do lado da caixa, com isso, uma partícula só pode interagir com partículas que estejam a uma distância menor que $r_{c}$ e desta forma, evitamos que uma partícula interaja com outra partícula e sua imagem simultaneamente, como ilustrado na figura 2.1 .

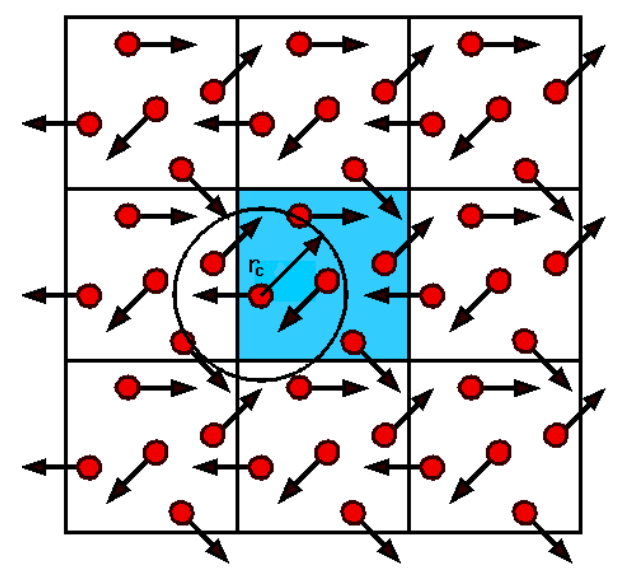

Figura 2.1: Ilustração da condição periódica de contorno, onde $\mathrm{r}_{c}$ é o raio de corte que evita que uma partícula interaja com a imagem de outra partícula.

A simulação se desenvolve através da realização de movimentos sucessivos das partículas dentro da caixa. Estes movimentos das partículas, podem aumentar ou diminuir a energia total do sistema. Com os valores da energia total do sistema antes, $U_{a}$, e depois do movimento, $U_{d}$, utilizamos a probabilidade de existência de configurações que, segundo a distribuição de Boltzmann, pode ser expressa por $P_{a}=e^{\left(-U_{a} / k T\right)}$. Após um movimento aleatório das partículas na caixa, esta probabilidade passa a ser expressa por $P_{d}=e^{\left(-U_{d} / k T\right)}$, de modo que

$$
\frac{P_{d}}{P_{a}}=e^{\left[-\frac{\left(U_{d}-U_{a}\right)}{k T}\right]}=e^{\left(-\frac{\Delta U}{k T}\right)} .
$$

Deste modo, submetemos o sistema ao teste de aceitação/rejeição que consiste em analisar a variação da energia $(\Delta U)$ do sistema: se $\Delta U \leq 0$ (a energia do sistema diminui), permitimos o movimento, e todas as partículas são levadas para suas novas posições correspondentes à nova energia. Se $\Delta U>0$ (a energia do sistema aumenta), permite-se o movimento com a probabilidade 
$P$ em 2.6. Para isso, geramos um número aleatório uniforme, $0<\xi<1$ e comparamos este número à probabilidade na equação 2.6. Se $\xi<e^{\left(-\frac{\Delta U}{k T}\right)}$, então movemos a partícula para sua nova posição e se $\xi>e^{\left(-\frac{\Delta U}{k T}\right)}$ deixamos a partícula na sua posição original, anterior ao movimento. Repetimos este procedimento de aceitação/rejeição até que a $N$-ésima partícula da caixa passe pelo teste de aceitação/rejeição.

Para que haja uma razão em torno de 0,5 desta aceitação/rejeição dos movimentos das partículas, utilizamos o critério de auto-ajuste do deslocamento. Este procedimento é usualmente utilizado e proporciona uma boa razão entre o tempo de processamento e o número de passos para se obter configurações descorrelacionadas [54].

Quando uma única partícula do sistema é submetida ao teste de aceitação/rejeição, dizemos que foi realizado um passo $M C$ e depois que todas as partículas da caixa foram submetidas ao teste de aceitação/rejeição, a configuração é armazenada. Este procedimento é repetido até um número total de passos fixados previamente na simulação, que geralmente é da ordem de $10^{8}$ passos MC.

\subsection{Potencial de Interação}

A escolha do potencial de interação a ser usado na simulação computacional é algo que requer cuidado já que o potencial escolhido se reflete na energia do sistema. Existe na literatura uma grande variedade de potenciais de interação formulados especificamente para cada tipo de sistema, como por exemplo sistemas iônicos, amorfos, sistemas vítreos e líquidos simples. Dentre esta variedade, um potencial que tem se mostrado eficaz para a descrição das interações em sistemas líquidos é composto pelos potencial Lennard-Jones (LJ) [70] adicionado de um termo de Coulomb, dado por:

$$
U\left(r_{i j}\right)=4 \varepsilon_{i j}\left[\left(\frac{\sigma_{i j}}{r_{i j}}\right)^{12}-\left(\frac{\sigma_{i j}}{r_{i j}}\right)^{6}\right]+\frac{q_{i} q_{j}}{r_{i j}} .
$$

Neste potencial de interação temos três parâmetros atômicos para cada átomo $i, \varepsilon_{i}: \sigma_{i}$ e $q_{i}$, que são combinados através de média geométrica, para gerar os 
parâmetros de pares $\varepsilon_{i j}=\left(\varepsilon_{i} \varepsilon_{j}\right)^{1 / 2}$ e $\sigma_{i j}=\left(\sigma_{i} \sigma_{j}\right)^{1 / 2}$. Na expressão do potencial, equação $2.7, r_{i j}$ corresponde a uma distância qualquer entre os átomos $i$ e $j, \sigma_{i j}$ corresponde à distância entre os átomos $i$ e $j$ para qual a energia potencial é zero e o parâmetro $\varepsilon_{i j}$ corresponde à energia clássica da ligação entre os átomos $i$ e $j$. Os parâmetros $q_{i}$ e $q_{j}$ são as cargas dos átomos $i$ e $j$ centradas em cada sítio atômico. Estes três tipos de parâmetros necessários para a utilização do potencial $U\left(r_{i j}\right)$ são obtidos para cada tipo de molécula ou constituinte químico e podem ser encontrados na literatura. Os parâmetros utilizados no potencial para cada sistema específico são obtidos realizando-se um número finito de simulações até que estes parâmetros sejam capazes de reproduzir propriedades termodinâmicas obtidas experimentalmente para o sistema em questão.

Na expressão 2.7 observamos que o potencial LJ é composto por dois termos, um termo tem dependência com $r^{-12}$ e descreve a repulsão e outro termo tem dependência com $r^{-6}$ e descreve a atração entre duas partículas $i$ e $j$. Este segundo termo no potencial LJ faz com que a energia assuma valores que tendem a zero quando $r$ vai ao infinito. O terceiro termo que compõe o potencial de interação, descreve as interações eletrostáticas e é de fundamental importância para a correta descrição, das interações tipo dipolo-dipolo e dipoloquadrupolo, por exemplo.

Utilizamos em nosso trabalho, o método Monte Carlo Metropolis e o potencial de interação da maneira como expostos acima, implementados no programa DICE [71].

\subsection{Função Distribuição Radial de Pares}

A estrutura de líquidos moleculares pode ser caracterizada através de funções de distribuição que baseiam-se na distância ou ângulos entre átomos, centros de massa ou ligações de moléculas distintas. Através do uso desta classe de funções, podemos avaliar a probabilidade de se encontrar um par de partículas separadas por uma distância $r$ determinada, tendo como referência a probabilidade esperada para uma distribuição completamente uniforme, isto é, para um 
gás ideal de densidade $N / V$.

Uma das funções de distribuição mais utilizadas para análise da estrutura de líquidos moleculares é a função distribuição radial de pares, G(r), ilustrada na figura 2.2 .

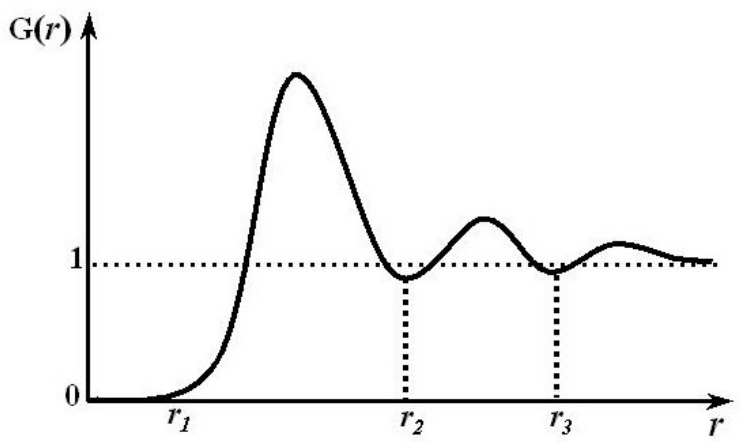

Figura 2.2: Ilustração de uma função distribuição radial de pares, típica de um sistema líquido.

Experimentalmente, pode-se obter a $\mathrm{G}(\mathrm{r})$, indiretamente, através das técnicas de difração de raios-X e de nêutrons $[72,73]$ e espalhamento de raio-X [74]. Para calcular a G(r) realizamos uma integração numérica sobre a função distribuição configuracional das posições de todos os átomos, exceto sobre o par que está sendo utilizado para definir a distância $r$ de referência. Podemos escrever [54]:

$$
G\left(\mathbf{r}_{1}, \mathbf{r}_{2}\right)=\frac{N(N-1)}{\rho^{2} Z} \int \exp \left(-\frac{U\left(\mathbf{r}_{1}, \mathbf{r}_{2}, \cdots, \mathbf{r}_{N}\right)}{k T}\right) d \mathbf{r}_{3} d \mathbf{r}_{4} \cdots d \mathbf{r}_{N},
$$

onde $\rho$ é a densidade e $Z$ é a função de partição.

Da figura 2.2, que ilustra de forma qualitativa uma $G(r)$ típica de sistemas líquidos, podemos observar que a probabilidade de se encontrar partículas (átomos ou moléculas) à pequenos valores de $r$ é nula. Isto se deve à repulsão existente entre as partículas, imposta pelo termo $r^{-12}$ do potencial Lennard-Jones. O intervalo formado entre $r_{1}$ (distância mínima para interação entre dois sítios) e $r_{2}$ determina a primeira camada de solvatação, da mesma forma que o intervalo entre $r_{2}$ e $r_{3}$ determina a segunda camada de solvatação. Para $r>>r_{3}$ a função distribuição radial tende a 1, o que significa que a grandes 
distâncias as partículas não sentem mais a presença das partículas ao seu redor e comportam-se como um gás ideal. A integração numérica da $G(r)$ nos fornece uma estimativa para o número de vizinhos da partícula de referência, também conhecido como número de coordenação. Através do número de coordenação, sabemos a quantidade de partículas presentes em cada camada de solvatação. Em muitos casos estas super-estruturas definidas pelas camadas de solvatação são submetidas a cálculos quânticos para análise de propriedades que sofrem influência quando o sistema está atingindo porporções de bulk.

\subsection{Função de Auto-correlação da Energia}

Um dos maiores problemas do tratamento teórico realístico de moléculas em solução, é lidar com as milhares de configurações que representam o líquido molecular a uma dada temperatura. Sabemos que grande parte destas configurações são estruturalmente muito semelhantes, e não trazem consigo nenhuma informação estatística relevante do sistema líquido. Em paralelo a isso, tem-se mostrado que a realização de médias sobre centenas de configurações sucessivas geradas por uma simulação Monte Carlo fornece o mesmo resultado numérico que médias realizadas sobre somente algumas configurações estatisticamente descorrelacionadas $[39,61,62,75]$.

Uma maneira usual de selecionarmos dentre as milhares de configurações produzidas pela simulação, aquelas que apresentam baixa correlação estatística é utilizando a função de auto-correlação da energia, $C(i)$, que pode ser matematicamente definida como:

$$
C(i)=\frac{\left\langle\delta U_{l} U_{l+i}\right\rangle}{\left\langle\delta U^{2}\right\rangle}=\frac{\sum_{l}\left(U_{l}-\langle U\rangle\right)\left(U_{l+i}-\langle U\rangle\right)}{\sum_{l}\left(U_{l}-\langle U\rangle\right)^{2}},
$$

onde $U_{l}$ é a energia da configuração $l$ e $U_{l+i}$ é a energia da configuração gerada depois de $i$ passos MC.

Para processos markovianos é conhecido que $C(i)$ obedece um decaimento exponencial $C(i)=e^{-i / \tau}[76]$ e representa a correlação estatística entre configurações separadas por $i$ passos MC.

$$
\tau=\int_{0}^{\infty} C(i) d i
$$


Desta forma, se $i=0 \Rightarrow C(i)=1$, temos configurações $100 \%$ correlacionadas. Por outro lado, tomando-se $i=\infty$, as configurações são estatisticamente descorrelacionadas. Na prática porém, é impossível tomarmos $i=\infty$ como intervalo de seleção de estruturas. Então consideramos que as configurações estejam estatisticamente descorrelacionadas se $i \sim 2 \tau$, onde $\tau$ é conhecido como passo de correlação e é definido abaixo.

Em simulações de líquidos moleculares é comum descrever $C(i)$ através de uma soma de duas funções exponenciais [77]

$$
C(i)=c_{1} e^{-\frac{i}{\tau_{1}}}+c_{2} e^{-\frac{i}{\tau_{2}}}
$$

onde $\tau_{1}>\tau_{2}$. Substituindo a equação 2.11 em 2.10 e integrando de 0 a $\infty$, obtem-se que $\tau=c_{1} \tau_{1}+c_{2} \tau_{2}$, onde $c_{1}, \tau_{1}, c_{2}$ e $\tau_{2}$ são obtidos através de ajustes exponenciais. A utilização do passo de correlação $\tau$ diminui drasticamente a quantidade de configurações a serem utilizadas na obtenção de médias estatísticas, sem que isso altere a média [61].

Neste trabalho, utilizamos $C(i)$ com $i \sim 2 \tau$ nos estudos de fase líquida, para selecionarmos estruturas supermoleculares consecutivas com correlação estatística abaixo de $15 \%$. 


\section{Capítulo 3}

\section{Tratamentos Quânticos}

Nosso interesse neste capítulo é descrever as metodogias quânticas utilizadas neste trabalho para uma descrição das propriedades eletrônicas de sistemas moleculares. Começamos pelo método Hartree-Fock e passamos a uma rápida discussão sobre o significado e a importância da inclusão dos efeitos de correlação eletrônica em cálculos quânticos de sistemas moleculares multi-eletrônicos. Adiante, discutimos a Teoria de Perturbação Møller Plesset, em especial com correção até segunda ordem (MP2), métodos Coupled Cluster (CC) e seguimos com a Teoria do Funcional da Densidade (DFT), dando ênfase à Time Dependent-DFT. Também neste capítulo, discorremos sobre as ligações de hidrogênio e efeito cooperativo devido a interação entre moléculas.

\subsection{Aproximação de Born-Oppenheimer}

Quando estamos interessados em descrever detalhadamente a distribuição eletrônica de um sistema atômico ou molecular qualquer, devemos utilizar a mecânica quântica, já que a mecânica clássica não se mostra capaz de descrever adequadamente as propriedades eletrônicas de tais sistemas. Em um tratamento mecânico-quântico de sistemas microscópicos, o que precisamos basicamente é resolver a equação de Schrödinger para estados estacionários:

$$
H \Psi=E \Psi
$$

Esta equação pode ser resolvida exatamente e com facilidade para o átomo de hidrogênio, que contém um único elétron. Para sistemas multi-eletrônicos a 
resolução desta equação é uma tarefa difícil de ser executada. Sendo assim, surge a necessidade do uso de aproximações que tornem viável a resolução da equação 3.1.

A primeira e mais comum das aproximações utilizadas na resolução da equação de Schrödinger para sistemas moleculares é a aproximação de BornOppenheimer $[78,79]$. A inspiração para a aproximação de Born-Oppenheimer vem do fato de que os espectros eletrônico e nuclear de um sistema molecular serem completamente distintos. Devido a essa distinção espectroscópica, muitas vezes traduzida como diferenças entre as massas dos elétrons e dos núcleos, podemos fazer a separação de Born-Oppenheimer que consiste no tratamento em separado dos movimentos eletrônico e nuclear. Assim, podemos reescrever a equação 3.1 de maneira mais específica, em função das coordenadas dos núcleos e elétrons do sistema, assim:

$$
\mathcal{H}(\mathbf{r}, \mathbf{R}) \Psi(\mathbf{r}, \mathbf{R})=\mathcal{E}(\mathbf{r}, \mathbf{R}) \% P \operatorname{si}(\mathbf{r}, \mathbf{R})
$$

Nesta equação, tanto o operador $\mathcal{H}$ quanto a função de onda $\Psi$ dependem das coordenadas de todos os núcleos $(\mathbf{R})$ e de todos os elétrons $(\mathbf{r})$ presentes no sistema. Na prática, para de fato resolvermos a equação 3.2 para um sistema multi-eletrônico qualquer, precisamos reescrever esta equação de modo a deixar explícito os termos de $\mathcal{H}(\mathbf{r}, \mathbf{R})$ e $\Psi(\mathbf{r}, \mathbf{R})$. Para o Hamiltoniano, desprezamos todos os termos relativísticos, devido às pequenas massas dos núcleos, e assim temos:

$$
\mathcal{H}(\mathbf{r}, \mathbf{R})=\sum_{A} T_{A}+\sum_{A<B} \frac{Z_{A} Z_{B} e^{2}}{R_{A B}}+\sum_{i} T_{i}+\sum_{i<j} \frac{e^{2}}{r_{i j}}-\sum_{i} \sum_{A} \frac{Z_{A} e^{2}}{r_{i A}} .
$$

Os termos de $\mathcal{H}(\mathbf{r}, \mathbf{R})$, na ordem em que aparecem na equação 3.3 , são a energia cinética dos núcleos, a repulsão eletrostática referente aos núcleos, a energia cinética dos elétrons, a repulsão eletrônica e a energia de atração elétron-núcleo.

Visando a resolução da equação 3.2 , aproximamos $\Psi(\mathbf{r}, \mathbf{R})$ por um produto tal que um dos fatores tenha uma dependência paramétrica das coordenadas nucleares, ou seja,

$$
\Psi(\mathbf{r}, \mathbf{R})=\psi(\mathbf{r} ; \mathbf{R}) \phi(\mathbf{R})
$$


onde $\psi$ depende parametricamente das coordenadas dos núcleos, $\mathbf{R}$, e representa a função de onda eletrônica do sistema, e $\phi$ representa a função de onda nuclear. Essas funções de onda são determinadas através da resolução das equações eletrônica e nuclear do sistema:

$$
\begin{aligned}
\mathcal{H}_{e l}(\mathbf{r}, \mathbf{R}) \psi_{e l}(\mathbf{r} ; \mathbf{R}) & =E_{e l}(\mathbf{r}, \mathbf{R}) \psi_{e l}(\mathbf{r} ; \mathbf{R}) \\
\mathcal{H}_{n}(\mathbf{R}) \phi_{n}(\mathbf{R}) & =E \phi_{n}(\mathbf{R}),
\end{aligned}
$$

onde

$$
\begin{aligned}
\mathcal{H}_{e l}(\mathbf{r}, \mathbf{R}) & =\sum_{i} T_{i}+\sum_{i<j} \frac{e^{2}}{r_{i j}}-\sum_{i} \sum_{A} \frac{Z_{A} e^{2}}{r_{i A}}+\sum_{A<B} \frac{Z_{A} Z_{B} e^{2}}{R_{A B}} \mathrm{e} \\
\mathcal{H}_{n}(\mathbf{R}) & =\sum_{A} T_{A}+E_{e l}(\mathbf{R}) .
\end{aligned}
$$

Esta separação do hamiltoniano em duas partes distintas, uma eletrônica e outra nuclear, é conhecida como aproximação de Born-Oppenheimer [79]. A possibilidade de separação dos movimentos eletrônico e nuclear se deve ao fato de que os elétrons têm menor inércia e podem ajustar seus movimentos quase que instantaneamente, a qualquer rearranjo das posições dos núcleos. A aproximação de Born-Oppenheimer geralmente permite que se obtenha a geometria nuclear de equilíbrio, assim como as energias eletrônica e vibracional de sistemas multi-eletrônicos, mas é válida somente quando a equação 3.4 fornece uma boa aproximação para as soluções da equação 3.1.

Tomando a função de onda eletrônica $\psi_{e l}(\mathbf{r} ; \mathbf{R})$, e sabendo que esta é dependente das coordenadas de todos os elétrons, se for possível obtermos um conjunto completo ortonormal de funções de onda de muitos elétrons $\psi_{i}$, podemos expandir $\psi_{e l}(\mathbf{r} ; \mathbf{R})$ em termos deste conjunto. Assim,

$$
\psi_{e l}(\mathbf{r} ; \mathbf{R})=\sum_{i} \psi_{i} c_{i},\left\langle\psi_{i} \mid \psi_{j}\right\rangle=\delta_{i j} .
$$

Pelo princípio de exclusão de Pauli [80], $\psi_{e l}(\mathbf{r} ; \mathbf{R})$ é antissimétrica com respeito a qualquer troca de coordenadas dos elétrons, isto é,

$$
\psi_{e l}\left(\mathbf{r}_{1}, \mathbf{r}_{2}, \ldots, \mathbf{r}_{i}, \ldots, \mathbf{r}_{k}, \ldots ; \mathbf{R}\right)=-\psi_{e l}\left(\mathbf{r}_{1}, \mathbf{r}_{2}, \ldots, \mathbf{r}_{k}, \ldots, \mathbf{r}_{i}, \ldots ; \mathbf{R}\right)
$$

Desta forma, para um sistema molecular de camada fechada, um conjunto de funções multi-eletrônicas conveniente é um conjunto de determinantes de Slater. 
Estes determinantes são formados por um conjunto completo de spin-orbitais $\varphi_{i}(j ; \mathbf{R})$ e podem ser expressos por

$$
\psi_{e l}(1,2, \ldots, N ; \mathbf{R})=\frac{1}{\sqrt{N !}}\left|\begin{array}{cccc}
\varphi_{a}(1 ; \mathbf{R}) & \varphi_{b}(1 ; \mathbf{R}) & \cdots & \varphi_{n}(1 ; \mathbf{R}) \\
\varphi_{a}(2 ; \mathbf{R}) & \varphi_{b}(2 ; \mathbf{R}) & \cdots & \varphi_{n}(2 ; \mathbf{R}) \\
\vdots & \vdots & \ddots & \vdots \\
\varphi_{a}(N ; \mathbf{R}) & \varphi_{b}(N ; \mathbf{R}) & \cdots & \varphi_{n}(N ; \mathbf{R})
\end{array}\right|
$$

onde $N$ é o número de elétrons do sistema e $\varphi_{i}(j ; \mathbf{R})$ é o spin-orbital do elétron $j$.

\subsection{Hartree-Fock}

Teoricamente, podemos obter uma solução exata para a função de onda eletrônica, $\psi_{e l}(\mathbf{r} ; \mathbf{R})$, através dos determinantes de Slater. Na prática porém, o número infinito de termos presentes na expansão (3.7) dificulta a obtenção da $\psi_{e l}(\mathbf{r} ; \mathbf{R})$. Para contornar esta dificuldade substituímos o problema da determinação de uma função de $N$ elétrons pela determinação de $N$ funções de um elétron. Assim, através do princípio variacional, escolhe-se um único determinante de Slater que produza a melhor aproximação para a função de onda eletrônica no estado fundamental

$$
\psi_{e l}(\mathbf{r} ; \mathbf{R}) \approx \psi_{0}
$$

Este determinante de Slater ótimo, $\psi_{0}$, é obtido usando-se o método variacional, o que minimiza a energia do sistema.

A determinação das $N$ funções de um elétron é feita através do uso das equações de Hartree-Fock [81-84]

$$
\mathcal{F}(1) \varphi_{i}(1 ; \mathbf{R})=\varepsilon_{i} \varphi_{i}(1 ; \mathbf{R})
$$

onde $\mathcal{F}$ é chamado operador de Fock, definido por:

$$
\mathcal{F}(1)=h_{i}+\sum_{l}\left[J_{l}(1)+K_{l}(1)\right],
$$

onde

$$
h_{i}=T_{i}-\sum_{A} \frac{Z_{A} e^{2}}{r_{i A}}
$$




$$
J_{l}(1) \varphi_{i}=\left[\int \varphi_{l}^{*}(2) \frac{1}{r_{12}} \varphi_{l}(2) d \mathbf{r}_{2}\right] \varphi_{i}
$$

é o operador de Coulomb e

$$
K_{l}(1) \varphi_{i}=\left[\int \varphi_{l}^{*}(2) \frac{1}{r_{12}} \varphi_{i}(2) d \mathbf{r}_{2}\right] \varphi_{l}
$$

é o operador de troca.

$\mathrm{Na}$ prática para resolver as equações de Hartree-Fock utilizamos o método de campo auto-consistente, (Self Consistent Field-SCF), e a aproximação algébrica LCAO (Linear Combination of Atomic Orbitals) [85].

No método de campo auto-consistente, geramos um conjunto de spin-orbitais $\varphi_{i}^{(0)}$ com o qual resolvemos a equação de Hartree-Fock, equação 3.11. Desta resolução obtemos um novo conjunto de spin-orbitais $\varphi_{i}^{(1)}$ que é novamente inserido na equação 3.11 e estas equações são novamente resolvidas e dão origem a outro novo conjunto de spin-orbitais $\varphi_{i}^{(2)}$. Estas iterações se repetem até que o conjunto de spin-orbitais de entrada seja equivalente ao de saída, depois da resolução das equações de Hartree-Fock.

Já a aproximação LCAO consiste na expansão do conjunto de orbitais moleculares $\varphi_{i}$ numa base finita de orbitais atômicos $\chi_{\alpha}$, isto é,

$$
\varphi_{i}=\sum_{\alpha} \chi_{\alpha} c_{\alpha i}
$$

Utilizando o método de campo auto-consistente e a aproximação LCAO na resolução das equações de Hartree-Fock, vamos obter um resultado aproximado (aproximação Hartree-Fock - Self Consistent Field - Linear Combination of Atomic Orbitals) que é tão próximo da solução exata HF quanto maior for o número de funções $\chi_{\alpha}$, e atinge o limite HF muito antes do conjunto $\chi_{\alpha}$ ser completo. Embora a energia obtida no procedimento HF-SCF-LCAO seja única, os spin-orbitais obtidos nesta resolução não são únicos. Por isso, durante a resolução das equações de Hartree-Fock escolhemos, convenientemente, o conjunto de spin-orbitais que diagonaliza a matriz $\varepsilon_{\mathbf{i}}$ na equação de Hartree-Fock, que é conhecido como conjunto de spin-orbitais canônicos.

Interpretando fisicamente a equação 3.11, dizemos que esta é uma equação de Schrödinger para um elétron movendo-se simultaneamente no campo 
criado pelos núcleos e no campo médio criado por todos os outros elétrons. Embora a equação de Hartree-Fock seja formalmente uma equação de um único elétron, ela depende de todos os outros elétrons devido aos operadores de Coulomb e de troca, presentes no operador de Fock.

\subsection{Correlação Eletrônica}

A energia obtida pelo método Hartree-Fock é a melhor energia que se pode obter partindo de um único determinante de Slater. O tratamento HF, obtém grande parte da energia eletrônica total não-relativística de um sistema multieletrônico. Uma limitação deste método é que ele não leva em conta o movimento correlacionado dos elétrons, isto é, não há um tratamento específico de tal forma que o movimento de um elétron esteja correlacionado ao movimento de todos os outros elétrons. Esta interação elétron-elétron é tratada de forma média, como uma interação autoconsistente [86]. Assim, no tratamento Hartree-Fock, uma pequena parte da energia total do sistema não é obtida, mesmo utlizando o melhor determinante de Slater. Esta pequena parte da energia total do sistema corresponde à energia de correlação eletrônica, e é definida como a diferença entre a energia exata e a melhor energia que se pode obter com o método HF:

$$
E_{\text {corr }}=E_{\text {exata }}-E_{H F} .
$$

Esta contribuição na energia total do sistema é necessária para uma descrição mais detalhada de processos físicos e químicos para estados estacionários de sistemas multi-eletrônicos [87]. Uma maneira de obter a energia de correlação eletrônica é utilizando métodos que vão além da aproximação Hartree-Fock, conhecidos como métodos Pós-HF. Como exemplos destes métodos podemos citar o método de Interação de Configurações (CI) e a Teoria de Perturbação Møller-Plesset (MPPT). 


\subsection{Teoria de Perturbação Møller-Plesset}

Um modo muito usual de se obter energias que incluam a energia de correlação eletrônica é utilizando a Teoria de Perturbação de Muitos Corpos. Nesta teoria, o Hamiltoniano do sistema é escrito pela soma de dois termos distintos:

$$
\mathcal{H}=H_{0}+H^{\prime}
$$

onde $H_{0}$ tem auto-valores e auto-vetores conhecidos. Na prática é usual tomarmos o hamiltoniano Hartree-Fock e $H^{\prime}$ é uma pequena perturbação introduzida no problema. A energia exata $E$ é expressa como a soma das contribuições envolvendo $H^{\prime}$ na equação:

$$
\mathcal{H}|\Psi\rangle=E|\Psi\rangle
$$

A resolução da equação 3.19 pode nos fornecer uma energia que pode até ser mais baixa que a energia exata, já que este não é um processo variacional. Contudo, a teoria de perturbação é extensiva, o que significa que a energia obtida varia linearmente com o número de partículas do sistema.

Para tratamentos quânticos de sistemas multi-eletrônicos, a seperação de Møller-Plesset como uma particularidade da teoria de perturbação de muitos corpos é largamente utilizada e dá origem à conhecida Teoria de Perturbação de Møller-Plesset-MPPT [88]. Neste tratamento, o sistema é descrito através de um hamiltoniano composto por dois termos: um é hamiltoniano de referência $H_{0}$ (não-perturbado) e outro é o hamiltoniano de perturbação, $H^{\prime}$, como definidos na equação 3.18. A peculiaridade é que a perturbação deve ser pequena quando comparada à referência, para facilitar a convergência do método. Deste modo, a equação de Schrödinger a ser resolvida é a equação 3.19 .

Como na teoria de perturbação de muitos corpos, no tratamento MPPT supomos que a equação de Schrödinger para o hamiltoniano não perturbado,

$$
H_{0} \psi^{(0)}=E^{(0)} \psi^{(0)},
$$

pode ser resolvida exatamente. Supomos também, que a função de onda de 
referência $\psi^{(0)}$ seja não degenerada e normalizada, e ainda que o hamiltoniano $H_{0}$ seja hermiteano [13].

Para que a equação 3.20 tenha solução exata é preciso fazer a escolha adequada do hamiltoniano não perturbado $H_{0}$ e da perturbação $H^{\prime}$. Sabemos que o determinante Hartree-Fock $\Phi_{0}$ é auto-função do operador de Fock, com auto-valores $\sum_{i} \varepsilon_{i}$, onde a soma se estende sobre os orbitais ocupados, o que torna conveniente escolher o hamiltoniano não perturbado como:

$$
H_{0}=\sum_{i} \mathcal{F}(i)
$$

Podemos, então escrever a perturbação como:

$$
H^{\prime}=\mathcal{H}-H_{0}=\sum_{i} h(i)+\sum_{i<j} \frac{1}{r_{i j}}-\sum_{i} \mathcal{F}(i)=\sum_{i<j} \frac{1}{r_{i j}}-\sum_{i} \nu^{H F}(i),
$$

onde

$$
\nu^{H F}(i)=\sum_{j}\left[J_{j}(i)-K_{j}(i)\right]
$$

Esta escolha do hamiltoniano Hartree-Fock como sendo o hamitoniano não perturbado foi feita pela primeira vez por C. Møller e M. S. Plesset [88]. Assim, a equação 3.20 torna-se:

$$
H_{0} \Phi_{0}=E_{0}^{(0)} \Phi_{0}
$$

onde $H_{0}$ é a soma dos operadores de Fock, $\Phi_{0}$ é a função de onda $H F$ e $E^{(0)}$ é a soma das energias orbitais HF. Para que a solução da equação 3.18 seja única, utilizamos a normalização intermediária, $\left\langle\Phi_{0} \mid \psi\right\rangle=1$ [86].

Daí, podemos obter a energia em primeira ordem, dada por:

$$
E^{(1)}=\sum_{i} \varepsilon_{i}-\frac{1}{2} \sum_{i, j}\langle i j \| i j\rangle=E_{H F}
$$

onde

$$
\langle i j|| i j\rangle=\left\langle\Phi_{0}\left|\nu^{H F}(i)\right| \Phi_{0}\right\rangle .
$$

Isso mostra que a energia obtida através do método Hartree-Fock é correta até primeira ordem e que a correlação eletrônica só tem influência na energia total do sistema a partir da segunda ordem. 
A correção para a energia em segunda ordem é dada por:

$$
E^{(2)}=\sum_{n \neq 0} \frac{\left|\left\langle\Phi_{0}\left|H^{\prime}\right| \Phi_{n}\right\rangle\right|^{2}}{E^{(0)}-E_{n}^{(0)}},
$$

onde $E_{n}^{(0)}$ representa a soma das energias orbitais para as auto-funções $\Phi_{n}$ dadas por

$$
\Phi_{n}=\Phi_{0}+\sum_{i, a} C_{i}^{a} \Phi_{i}^{a}+\sum_{i<a, a<b} C_{i j}^{a b} \Phi_{i j}^{a b}+\cdots,
$$

onde $\Phi_{0}$ é o determinante do estado de referência que contém os spin-orbitais ocupados $\Phi_{i}, \Phi_{j}, \Phi_{k}, \cdots$. A configuração $\Phi_{i}^{a}$ é obtida através da substituição do spin-orbital ocupado $\Phi_{i}$ pelo spin-orbital desocupado $\Phi_{a}$, chamada de substituição simples. O spin-orbital $\Phi_{i j}^{a b}$ é obtido realizando-se uma substituição dupla, isto é, substituindo-se os spin-orbitais ocupados $\Phi_{i}$ e $\Phi_{j}$ pelos spin-orbitais desocupados $\Phi_{a}$ e $\Phi_{b}$, e assim sucessivamente.

Pelo teorema de Brillouin [13,86], $\left\langle\Phi_{0}\left|H^{\prime}\right| \Phi_{i}^{a}\right\rangle=0$, vemos que as substituições simples não contribuem para a soma na energia em segunda ordem. As substituições triplas e de ordem mais alta também não dão nenhuma contribuição no somatório, já que $H^{\prime}$ contém somente operadores de uma e duas partículas. Desta forma, somente as substituições duplas contribuem na expressão para a correção da energia em segunda ordem, que pode agora ser reescrita de modo simplificado como:

$$
E^{(2)}=\sum_{i<j, a<b} \frac{\langle i j \| a b\rangle\langle a b \| i j\rangle}{\varepsilon_{i}+\varepsilon_{j}-\varepsilon_{a}-\varepsilon_{b}} .
$$

De modo análogo, podemos obter as expressões para os termos da energia de ordens mais altas.

Neste ponto da descrição do tratamento MPPT, é importante salientar o problema da extensividade. No tratamento MPPT observamos que alguns termos são proporcionais a $n^{2}, n^{3}, \cdots$, o que faz com que estes sejam termos não extensivos. Pensando no problema da extensividade, Brueckner [89] demonstrou o cancelamento destes termos não-físicos para as ordens mais baixas de energia. Dois anos mais tarde Goldstone [90] demonstrou que este cancelamento dos termos não-físicos se dá em todas as ordens de energia. Assim, 
podemos dizer que a energia obtida pelo tratamento MPPT é extensiva ordem a ordem, o que possibilita o truncamento da energia na ordem em que se desejar.

\subsection{Coupled Cluster}

Coupled Cluster-CC é um método físico usado para tratamento de sistemas de muitos corpos. Este método foi desenvolvido inicialmente por Fritz Coester e Hermann Kümmel, na década de 50 para estudar fenômenos nucleares. Mais tarde, Jiři Čížek [91] e Josef Paldus [92] reformularam o método para cálculos de correlação eletrônica em átomos e moléculas, o que tornou o método mais utilizado. Hoje em dia, é um dos métodos que incluem a correlação eletrônica, mais respeitados em química quântica computacional. A idéia principal do método Coupled Cluster é incluir todos os tipos de correção até ordem infinita [93]. O formalismo deste método envolve o tratamento de sistema de muitos elétrons, como pequenos sistemas de poucos elétrons, clusters, e acopla as soluções separadas em uma única solução, o que deu origem ao nome do método, Coupled Cluster.

Matematicamente, escrevemos a função de onda CC como:

$$
\begin{gathered}
\Psi_{C C}=e^{\mathbf{T}} \Phi_{0} \\
\mathbf{T}=\mathbf{T}_{1}+\mathbf{T}_{2}+\mathbf{T}_{3}+\cdots+\mathbf{T}_{N} .
\end{gathered}
$$

O operador $\mathbf{T}$ é chamado de operador de cluster e, quando atua sobre a função de onda de referência Hartree-Fock, $\Phi_{0}$, gera os determinantes de Slater referentes a todas as excitações eletrônicas possíveis. Assim,

$$
\begin{gathered}
\mathbf{T}_{1} \Phi_{0}=\sum_{i}^{o c c} \sum_{a}^{v i r} t_{i}^{a} \Phi_{i}^{a}, \\
\mathbf{T}_{2} \Phi_{0}=\sum_{i<j}^{o c c} \sum_{a<b}^{v i r} t_{i j}^{a b} \Phi_{i j}^{a b}, \ldots
\end{gathered}
$$

onde os coeficientes reais $t$ são chamados de amplitudes de cluster.

Substituindo a expansão para o operador T na exponencial em 3.30 
temos:

$e^{\mathbf{T}}=\mathbf{1}+\mathbf{T}_{1}+\left(\mathbf{T}_{2}+\frac{1}{2} \mathbf{T}_{1}^{2}\right)+\left(\mathbf{T}_{3}+\mathbf{T}_{2} \mathbf{T}_{1}+\frac{1}{6} \mathbf{T}_{1}^{3}\right)+\left(\mathbf{T}_{4}+\mathbf{T}_{3} \mathbf{T}_{1}+\frac{1}{2} \mathbf{T}_{2}^{2}+\frac{1}{24} \mathbf{T}_{1}^{4}\right)+\cdots$

Na equação 3.32, o primeiro termo gera o estado de referência Hartree-Fock e o segundo termo gera todos os estados referentes às excitações simples. O primeiro termo gera todos os estados referentes às excitações duplas, que podem ser conexos, quando dois elétrons interagentes são excitados simultamente, $\mathbf{T}_{2}$, ou excitações duplas desconexas, quando dois elétrons nãointeragentes são excitados um de cada vez, gerando ao final uma excitação dupla, $\mathbf{T}_{1}^{2}$. O segundo termo gera todos os estados triplamente excitados, onde novamente podemos ter estados de excitações triplas conexas, $\mathbf{T}_{3}$, ou estados em que o produto final é uma excitação tripla, $\mathbf{T}_{2} \mathbf{T}_{1}$ e $\mathbf{T}_{1}^{3}$. Da mesma forma, os estados quadruplamente excitados são gerados pelo quarto termo, onde temos um termo referente aos estados de quatro elétrons interagentes excitados simultaneamente, mais quatro termos referentes aos produtos de excitações de elétrons não-interagentes que ao final fornecem estados quadruplamente excitados.

Para o caso geral, a função de onda coupled cluster deve satisfazer a equação de Schrödinger

$$
\mathbf{H} e^{\mathbf{T}}\left|\Phi_{0}\right\rangle=E e^{\mathbf{T}}\left|\Phi_{0}\right\rangle
$$

Partindo da equação 3.33 podemos considerar os determinantes que compõe a função de onda CC e assim, definirmos as excitações que estão sendo levadas em conta na energia de correlação obtida. Na prática, não é possível a inclusão de operadores de clusters referentes a todas as ordens de excitações eletrônicas em um cálculo coupled cluster. Assim, o que fazemos é truncar a expansão de $\mathbf{T}$ em $\mathbf{T}_{x} \operatorname{com} x$ pequeno [86].

Se multiplicarmos a equação 3.33 por $\Phi_{0}^{*}$ à esquerda, integrarmos e depois expandirmos a exponencial $e^{\mathbf{T}}$, lembrando que o operador hamiltoniano só contém operadores de um e dois elétrons, chegaremos à seguinte expressão 
para a energia coupled cluster:

$$
E_{C C}=E_{0}+\sum_{i}^{o c c} \sum_{a}^{v i r} t_{i}^{a}\left\langle\Phi_{0}|H| \Phi_{i}^{a}\right\rangle+\sum_{i<j}^{o c c} \sum_{a<b}^{v i r}\left(t_{i j}^{a b}+t_{i}^{a} t_{j}^{b}-t_{i}^{b} t_{j}^{a}\right)\left\langle\Phi_{0}|H| \Phi_{i j}^{a b}\right\rangle
$$

Se os orbitais utilizados na construção dos determinantes de Slater são os orbitais Hartree-Fock, então, o primeiro elemento da matriz é nulo (teorema de Brillouin). O segundo elemento da matriz corresponde às integrais de dois elétrons dos orbitais moleculares. Portanto, a energia de correlação coupled cluster só depende das amplitudes simples e duplas e das integrais de dois elétrons dos orbitais moleculares.

A inclusão dos termos $\mathbf{T}_{i}$ na expansão do operador de cluster é o que vai definir a aproximação coupled cluster em questão. A aproximação mais simples do método coupled cluster é aquela em que somente o termo $\mathbf{T}_{2}$ é incluso no operador de cluster. Esta aproximação tem sua relevância, devido ao fato de que somente as contribuições duplas, interagem com o determinante Hartree-Fock (teorema de Brillouin) Coupled Cluster Double-CCD. Apesar disso, as substituições simples, triplas, quádruplas etc, também contribuem para a energia de correlação indiretamente, através de interações com as duplas, sugerindo que as contribuições referentes às substituições duplas são de fato as mais relevantes no método coupled cluster. Originalmente esta aproximação foi chamada de coupled-pair many-electron theory-CPMET no artigo em que Jiři Č́ízek propõe o método [94]. Apesar de CCD apresentar contribuições na energia de correlação referentes às substituições duplas, quádruplas etc, que mostram-se melhores até que $\operatorname{MBPT}(4)$, o CCD não inclui em sua energia de correlação substituições simples e triplas que também tem papel fundamental na boa descrição da energia de um sistema multieletrônico.

A um preço computacional mais alto que CCD, a aproximação CCSD inclui no operador de cluster contribuições referentes às substituições simples através dos termos $\mathbf{T}_{1}$ e $\mathbf{T}_{2}$ inclusos no operador de cluster. Apesar da inclusão explícita somente de $\mathbf{T}_{1}$ e $\mathbf{T}_{2}$, os termos desconexos incluem contribuições indiretas de substituições triplas, quádruplas etc. Comparando MBPT(4)e CCSD vemos que a diferença são os termos conexos provenientes de $\mathbf{T}_{3}$ que não estão inclusos em CCSD e aparecem em MBPT(4) e este termo é 
geralmente o termo dominante para as substituições triplas. Devido a essa importância do termo conexo $\mathbf{T}_{3}$, Urban et al [95] propuseram uma aproximação para a inclusão das substituições triplas em CCSD utilizando a expressão da contribuição da substituições triplas em MBPT(4). Por isso, é comum dizermos que nesta aproximação, $\operatorname{CCSD}(\mathrm{T})$, as substituições triplas são inclusas de modo perturbativo em CCSD. A inclusão dos termos $\mathbf{T}_{1}, \mathbf{T}_{2}$ e $\mathbf{T}_{3}$ no operador de cluster foi desenvolvida e implementada por Noga e Bartlett [96]. Esta aproximação é correta quando comparada a MBPT(4) e inclui todos os termos presentes em $\mathrm{MBPT}(5)$ com exceção dos termos conexos devido a $\mathbf{T}_{4}$, o que faz do CCSDT uma aproximação conceitualmente muito atraente, porém altamente dispendiosa no que diz respeito ao seu custo computacional.

\subsection{Teoria do Funcional da Densidade}

No final dos anos 20 L. H. Thomas [97] e E. Fermi [98], afirmaram que considerações estatísticas podem ser utilizadas como uma aproximação para a distribuição de elétrons em um átomo. Com isso, eles plantaram a semente para que nos anos 60 P. Hohenberg, W. Kohn e J. Sham [99,100] propusessem a estrutura teórica que conhecemos hoje como Teoria do Funcional da Densidade.

Em contraste ao método Hartree-Fock, que fornece a descrição de elétrons individuais interagindo com os núcleos e no campo médio criado por todos os outros elétrons do sistema, a Teoria do Funcional da Densidade (DFT) considera o sistema eletrônico como um todo. A idéia básica da DFT é que a energia de um sistema eletrônico pode ser escrita em termos da densidade de probabilidade eletrônica, $\rho$ [99-102]. Esta densidade é entendida como uma grandeza que tem dependência somente com as três coordenadas de uma determinada região. Para um sistema com $n$ elétrons, $\rho(\mathbf{r})$ denota a densidade eletrônica total a uma distância $\mathbf{r}$. A energia $E$ é um funcional da densidade eletrônica, denotada por $E[\rho]$, onde para uma dada função $\rho(\mathbf{r})$ existe um único valor de energia $E[\rho]$ correspondente. Se $E[\rho]$ é conhecido, podemos trocar o problema de determinar a energia e a densidade eletrônica do estado fundamental em um dado potencial externo pela minimização do funcional $E[\rho]$ da 
função densidade tridimensional $\rho(\mathbf{r})$.

Computacionalmente, para aplicação desta teoria, é conveniente representar a função densidade eletrônica em termos dos orbitais ocupados, $\psi_{i}$,

$$
\rho(\mathbf{r})=\sum_{i}\left|\psi_{i}(\mathbf{r})\right|^{2}
$$

e, deste modo fazer a minimização do funcional de energia $E[\rho]$ em termos destes orbitais. Esta aproximação resulta nas equações de Kohn-Sham de uma partícula [100],

$$
\hat{h}_{K S} \psi_{i}=\varepsilon \psi_{i}
$$

que são semelhantes às equações de Hartree-Fock. Kohn e Sham propuseram o uso de um sistema não-interagente auxiliar, sistema Kohn-Sham, para avaliar a densidade de um sistema interagente. $\hat{h}_{K S}$ é o operador de Kohn-Sham, composto de termos para descrever as interações do sistema tratado, o que nos possibilita escrever a energia como:

$$
E[\rho]=T[\rho]+V[\rho]+C[\rho]+X C[\rho]
$$

onde $T[\rho]$ é a energia cinética do gás e $V[\rho]$ é o potencial de atração dos núcleos. A energia elétron-elétron é descrita por dois termos: A repulsão Coulombiana clássica, $C[\rho]$, e a energia de troca e correlação $X C[\rho]$ onde estão inclusos todos os efeitos quânticos de muitos corpos. A densidade eletrônica para o estado fundamental é obtida pela minimização da energia e a decomposição da energia feita desta forma é formalmente exata. Porém, as expressões para as interações de troca e correlação de muitos corpos são desconhecidas e sua acurácia depende do funcional empregado na sua determinação. Assim, é preciso fazer aproximações para se obter o termo $X C[\rho(\mathbf{r})]$.

Dependendo do problema a ser tratado, a aproximação utilizada poderá fornecer uma acurácia maior para o termo $X C[\rho(\mathbf{r})]$ e conseqüentemente para o cálculo da propriedade de interesse. A primeira aproximação para o termo $X C[\rho(\mathbf{r})]$ é a aproximação LDA-Local Density Aproximation. Nesta aproximação a densidade é tratada localmente como a densidade de um gás de elétrons uniforme e $\rho(\mathbf{r})$ varia suavemente nas proximidades de $\mathbf{r}$. Se 
a densidade eletrônica $\rho(\mathbf{r})$ for altamente não-uniforme, então a aproximação LDA não é uma boa opção. Esta aproximação foi então refinada em termos do gradiente da densidade de carga total, conhecida como expansão generalizada em termos de gradientes GGA-Generalized Gradient Aproximation. Existe na atualidade uma variedade de propostas para a aproximação GGA, e as mais utilizadas baseiam-se nos trabalhos de Lee-Yang-Parr-Becke [103], Perdew [104] e Becke [105]. Existem ainda os funcionais chamados de funcionais híbridos e levam este nome por misturarem o funcional de troca Hartree-Fock no funcional de troca DFT, como é o caso dos funcionais B3LYP $[103,106]$, B3PW91 [106,107] e B972 [108], utilizados nesta tese.

\subsubsection{Time Dependent-DFT}

A formulação original da teoria do Funcional da Densidade (DFT), aplica-se para sistemas eletrônicos a temperatura zero com estado fundamental nãodegenerado. Uma extensão mais generalizada da DFT convencional foi introduzida por Runge e Gross $[109,110]$ que inspirados pelo teorema de HohenbergKohn introduziram a idéia de uma equação de Schrödinger com dependência temporal conhecida como Time Dependent-DFT (TDDFT). Na verdade, dois trabalhos anteriores já utilizaram a idéia de uma DFT com dependência temporal $[111,112]$, mas foram Runge e Gross que em 1984 sistematizaram a TDDFT como utilizada atualmente. O alcance da generalização TDDFT inclui cálculo de espectros de fotoabsorção, ou de modo mais geral, interação de campos eletromagnéticos com a matéria. A teoria também contempla a descrição de experimentos de espalhamento com dependência temporal [113].

A equação de Kohn-Sham dependente do tempo para um sistema não interagente é definida como:

$$
i \frac{\partial}{\partial t} \phi_{i}(\mathbf{r}, t)=\left[-\frac{1}{2} \nabla^{2}+v_{k s}[\rho](\mathbf{r}, t) \phi_{i}(\mathbf{r}, t)\right]
$$

onde o potencial de Kohn-Sham local,

$$
v_{k s}[\rho]=v_{e f f}[\rho](\mathbf{r}, t)=v(t)+\int \frac{\rho\left(\mathbf{r}^{\prime}, t\right)}{\left|\mathbf{r}-\mathbf{r}^{\prime}\right|} d \mathbf{r}^{\prime}+v_{x c}[\rho](\mathbf{r}, t)
$$

é composto de um termo, $v(t)$, referente à perturbação imposta ao sistema (campo aplicado) e os outros dois termos referentes ao campo auto-consistente. 
O potencial de troca e correlação, $v_{x c}[\rho](\mathbf{r}, t)$, é dado como um funcional derivado de uma ação de troca e correlação $A_{x c}$, de tal forma que:

$$
v_{x c}[\rho](\mathbf{r}, t)=\frac{\delta A_{x c}[\rho]}{\delta \rho(\mathbf{r}, t)} \approx \frac{\delta E_{x c}\left[\rho_{t}\right]}{\delta \rho_{t}(\mathbf{r})}=v_{x c}\left[\rho_{t}\right](\mathbf{r})
$$

de modo que o funcional de ação desconhecido $A_{x c}$, dependente do espaço e do tempo em que o sistema se encontra, é substituído pelo funcional $E_{x c}$ que tem dependência espacial a um tempo $t$ fixo. Esta aproximação é comumente chamada de aproximação adiabática e é geralmente utilizada para estados excitados de baixa valência, conjuntamente com funcionais padrão.

Para sistemas inicialmente no estado fundamental, o efeito da perturbação introduzida em 3.38 em primeira ordem é:

$$
\delta v_{e f f}(\mathbf{r}, t)=\delta v(t)+\delta v_{S C F}(\mathbf{r}, t)
$$

onde $\delta v_{S C F}(\mathbf{r}, t)$ é a resposta linear do campo auto-consistente a partir da densidade de carga dada, em termos das freqüencias, por:

$$
\delta \rho(\mathbf{r}, \omega)=\sum_{a i} \delta P_{a i}(\omega) \psi_{a}(\mathbf{r}) \psi_{i}^{*}(\mathbf{r})+\sum_{i a} \delta P_{i a}(\omega) \psi_{i}(\mathbf{r}) \psi_{a}^{*} .
$$

As partes da resposta linear $\delta P_{i a}$ (partícula-buraco) e $\delta P_{a i}$ (buraco-partícula) relacionam-se através de uma conjugação complexa, onde $i, j$ referem-se aos orbitais moleculares ocupados, $a, b$ aos virtuais e $s, t$ aos orbitais gerais. Usando resultados elementares da teoria de perturbação dependente do tempo, podemos escrever a resposta linear da matriz densidade KS/HF para um campo aplicado como:

$$
\delta P_{s t}(\omega)=\frac{\Delta n_{s t}}{\left(\epsilon_{s}-\epsilon_{t}\right)-\omega} \delta v_{s t}^{e f f}(\omega),
$$

onde $\delta P_{s t}$ é a resposta linear da matriz densidade Kohn-Sham/Hartree-Fock (KS/HF) na base dos orbitais moleculares não-perturbados e $\Delta n_{s t}$ é a diferença nos números de ocupação, 1 para $s t=a i$ e -1 para $s t=i a$.

\subsection{Conjunto de Funções-Base}

A maior parte dos tratamentos quânticos necessitam de um conjunto de funçõesbase $\chi_{\alpha}$ para expandir os orbitais moleculares $\varphi_{i}$, equação 3.16. Sendo assim, a 
escolha do conjunto de funções-base adequado é essencial para que os cálculos quânticos forneçam resultados confiáveis.

Hoje em dia encontra-se disponível um vasta variedade de conjuntos de funções. Um dos conjuntos de funções centradas nos núcleos atômicos é conhecido como orbitais tipo Slater-STO, apresentam um decaimento exponencial do tipo $e^{-\zeta r}$, onde $r$ é a distância ao núcleo e $\zeta$ é uma constante previamente definida. É bastante usual substituir as funções STO por funções tipo gaussianas [114]. A diferença entre esses dois tipos de função é que as gaussianas decaem exponencialmente com o quadrado da distância ao núcleo atômico, $e^{-\zeta r^{2}}$, o que aumenta a rapidez de resolução das integrais que aparecem durante a resolução das equações de Hartree-Fock, já que é mais fácil calcular $e^{-\zeta r^{2}}$ que $e^{-\zeta r}$. Por isso, é comum nos cálculos quânticos atuais o uso de conjuntos de funções-base compostos exclusivamente por funções do tipo gaussianas.

Outro conjunto de funções base largamente utilizado pela comunidade científica atual, são os conjuntos de funções-base tipo correlated consistentcc [115] com double $-\zeta$,triple $-\zeta$, quadruple $-\zeta$, etc. Estes conjuntos são construídos de modo que cada orbital atômico é desdobrado em dois orbitais $($ double $-\zeta)$, três orbitais (triple $-\zeta)$, quatro orbitais (quadruple $-\zeta)$ e assim por diante. Estes desdobramentos são referentes a todos os orbitais do sistema, sejam eles referentes a elétrons de camada interna ou de valência.

Uma prática usual em tratamentos quânticos, é a adição de funções extras aos conjuntos de função-base primitivos. As funções de polarização auxiliam na descrição das distorções da nuvem eletrônica em moléculas ou agregados moleculares. Estas funções são importantes na descrição das ligações químicas. Um outro tipo de funções extras que costumeiramente são adicionadas aos conjuntos de função-base primitivos são as funções difusas. Estas funções são normalmente necessárias para o cálculo de propriedades de ânions, onde a nuvem eletrônica apresenta uma tendência à expansão.

Neste trabalho, utilizamos os conjuntos de funções-base: $6-31+\mathrm{G}(\mathrm{d})$ [116-119], 6-311++G(d,p) [120,121], e as correlated consistent-cc-pVXZ, com $\mathrm{X}=\mathrm{D}[122], \mathrm{T}$ [123], Q [115] e 5 [124]. Para a maioria dos sistemas aqui tra- 
tados, adicionamos funções de polarização, e funções difusa aos conjuntos de função-base mínimos. Para exemplificar estas notações, tomamos dois conjunto de funções-base gaussianas, 6-31+G(d) e aug-cc-pVDZ. O conjunto de funçõesbase $6-31+\mathrm{G}(\mathrm{d})$ apresenta seis funções gaussianas primitivas para descrever os orbitais mais internos dentro do caroço, o número 3 indica que três funções gaussianas foram utilizadas na construção dos orbitais das camadas internas fora do caroço, 1 indica que uma função gaussiana foi utilizada para os orbitais da camada de valência, o + indica uma função difusa adicionada e o $d$ indica uma função de polarização adicionada, ambas, centradas nos átomos não hidrogênicos do sistema. Já na base $a u g-c c-p V D Z$, o aug representa uma função difusa adicionada ao conjunto de funções base $c c-p V D Z$ que por definição, já inclui função de polarização.

\subsubsection{Limite de Base Completa}

Dentro das aproximações várias vezes utilizadas na resolução da equação de Schrödinger sabemos que o conjunto de funções-base de um-elétron é um conjunto finito e que a descrição das interações dos N-elétrons no espaço de Fock é incompleta [125]. Idealmente, o que se deseja em um cálculo de química é poder utilizar base completa em um método de interação de configuração completo. Porém, para a grande maioria dos sistemas moleculares estes cálculos são computacionalmente inviáveis. Neste contexto começaram a surgir alternativas que propõe esquemas de extrapolação tanto para os métodos quanto para os conjuntos de função-base para a obtenção da energia de correlação eletrônica com um alto nível de acurácia. Para as funções-base sabemos que é possível construir um conjunto base no qual a energia de correlação eletrônica seja sistemática e uniformemente convergente, a partir das bases desenvolvidas por Dunning [115], cc-pVXZ, onde X é o número cardinal empregado na base. Assim, os esquemas de extrapolação para o limite de base infinita, que em sua grande maioria utilizam as bases Dunning, sugerem que se obtenha a energia de correlação eletrônica neste limite de base completa sem que contudo sejam feitos cálculos com uma base efetivamente completa.

Os primeiros trabalhos publicados propondo um esquema de extra- 
polação para o limite de base infinita baseiam-se num modelo de convergência exponencial para a energia de correlação [126,127], dado pela seguinte fórmula:

$$
E_{X}=E_{\infty}+A e^{-B X}
$$

onde $E_{\infty}$ é a energia de correlação no limite de base completa. Porém, a formulação exponencial neste modelo impõe que $E_{X}$ tenda ao limite de base infinita mais rápido do que ocorre na realidade provocando um inadequada convergência da energia de correlação eletrônica [125].

Mais tarde, observou-se que a energia de correlação eletrônica apresenta convergência de acordo com a série de potência em $X^{-3}$,

$$
E_{X}=E_{\infty}+A X^{-3}
$$

Esta formulação logo em seguida foi testada e modificada por vários autores [26,128-134], e pode ser expressa de modo geral em função do expoente inteiro $k$ e do parâmetro $\gamma$,

$$
E_{X}=E_{\infty}+A(X+\gamma)^{-k}
$$

Esta formulação geral mostra um comportamento numericamente convergente de acordo com $k$ e $\gamma$ utilizados, porém não há um concenso na literatura sobre quais expoentes e parâmetros são os melhores para a obtenção da energia de correlação no limite de base infinita.

Dentre os esquemas que se enquadram na formulação 3.46 , podemos citar o modelo de extrapolação proposto por Truhlar [132] que se destaca por fornecer valores extrapolados para o limite de base infinita tanto para a energia de correlação quanto para a energia Hartree-Fock, cuja formulação final proposta é:

$$
E_{\infty}^{\text {tot }}=\frac{3^{\alpha}}{3^{\alpha}-2^{\alpha}} E_{3}^{H F}-\frac{2^{\alpha}}{3^{\alpha}-2^{\alpha}} E_{2}^{H F}+\frac{3^{\beta}}{3^{\beta}-2^{\beta}} E_{3}^{\text {corr }}-\frac{2^{\beta}}{3^{\beta}-2^{\beta}} E_{2}^{c o r r} .
$$

Neste esquema, os parâmetros otimizados $\alpha$ e $\beta$ são fornecidos para os modelos teóricos MP2, CCSD e CCSD(T). Uma exigência deste esquema é que sejam feitos cálculos para obtenção de energias com os números cardinais 2 e 3.

Um outro esquema de extrapolação para a energia de correlação no limite de base infinita que se enquadra na formulação 3.46, foi proposto por 
Varandas [26] e permite o uso de números cardinais variados, como pode ser visto na expressão 3.48 .

$$
E_{\infty}^{c o r r}=E_{X}^{c o r r} /\left(1-2,4 X^{-3}\right)
$$

Especificamente para MP2, CCSD e $\operatorname{CCSD}(\mathrm{T})$ há na literatura diversas prescrições para extrapolar ao limite de base infinita $[26,132,135,136]$. Porém a única referência que permite a extrapolação para o limite de base infinita a partir de resultados DFT foi proposta por Cabral e Canuto [137] e é dada por:

$$
E_{X}=E_{\infty}+A_{3} X^{-3}+A_{5} X^{-5}
$$

Em nosso trabalho, utilizamos dois dos esquemas de extrapolação expostos, o proposto por Varandas [26] nos resultados obtidos com MP2, CCSD e $\operatorname{CCSD}(\mathrm{T})$ e o esquema proposto por Cabral e Canuto [137] para resultados obtidos com métodos DFT.

\subsubsection{Superposição de Base}

É comum observar-se erros devido à superposição de base na maioria dos cálculos quânticos de agregados com ligação de hidrogênio e agregados moleculares no geral. Estes erros surgem porque a base gerada para um agregado molecular é maior que as bases geradas para as moléculas isoladas, mesmo utilizando o mesmo conjunto de funções-base nas duas situações. Assim, as moléculas isoladas se estabilizam menos do que deveriam quando comparadas ao agregado, gerando um artefacto de cálculo conhecido como erro de superposição do conjunto base-BSSE. Os efeitos do BSSE mostram-se menores com o aumento do conjunto de funções-base e tendem a desaparecer quando a base atinge o limite de base infinita [138].

Uma maneira conceitualmente simples de amenizar o BSSE é aumentar o conjunto de funções-base $[17,35]$. Porém esse aumento do conjunto de funções-base até o limite de base infinita é algo computacionalmente impossível de ser feito. Para corrigir os efeitos causados pelo BSSE, é comum a utilização do método de correção de counterpoise [139]. Para exemplificar o que de fato acontece na correção de counterpoise, consideremos duas moléculas $A$ e 
$B$, cada uma delas descrita por conjuntos de função-base, denotados por $a$ e $b$, centradas nos núcleos das moléculas $A$ e $B$. Consideremos também o agregado $A B$, descrito por um conjunto combinado de funções-base, $a b$. Temos então a expressão para a energia de complexação (ou de aglomeração), dada por:

$$
\Delta E_{\text {complexo }}=E(A B)_{a b}^{*}-E(A)_{a}-E(B)_{b},
$$

onde a geometria do agregado é designada pela notação $(*)$. Partindo da geometria do agregado, calculamos a energia da molécula $A$ com a função-base $a b$, localizando a função-base $b$ na posição correspondente à molécula $B$, sem que haja a presença explícita desta molécula no agregado. Usamos o mesmo procedimento para a molécula $B$. Assim, a correção de counterpoise pode ser definida por

$$
\Delta E^{C P}=E(A)_{a b}^{*}+E(B)_{a b}^{*}-E(A)_{a}^{*}-E(B)_{b}^{*}
$$

Desta forma, a energia de ligação do agregado, incluindo a correção de counterpoise, $\Delta E^{C P}$, é definida por $\Delta E_{\text {complexo }}-\Delta E^{C P}$.

\subsection{Ligação de Hidrogênio}

Uma ligação de hidrogênio é uma interação inter ou intramolecular atrativa que existe entre átomos com diferentes eletronegatividades. Embora mais fortes que a maioria das outras forças intermoleculares, a ligação de hidrogênio típica é muito mais fraca do que as ligações iônica e covalente. A presença de ligações de hidrogênio dentro de macromoléculas tais como proteínas e ácidos nucleicos é bastante comum, e tem um papel importante na forma estrutural destas moléculas. Porém, a ligação de hidrogênio não é uma atração simples entre cargas pontuais, ela possui preferência orientacional. A compreensão das ligações de hidrogênio (LH) e de suas implicações a nível molecular é de grande interesse em física, química e biologia, devido à grande variedade de situações em que estas interações encontram-se presentes [27, 138, 140-143].

O recente progresso de técnicas como vaporização a laser e jet cooling, favoreceu a obtenção de uma rica variedade de agregados moleculares 
onde as moléculas interagem através de ligações de hidrogênio. Este fato provocou um aumento nas investigações de ligação de hidrogênio, tanto por parte dos teóricos quanto dos experimentais, em moléculas isoladas, agregados moleculares gasosos e em agregados moleculares em fase líquida [2,31,144-171]. Entretanto, a situação encontrada em um agregado molecular isolado é muito distinta daquela encontrada em um agregado em fase líquida. Isso faz com que o estudo das ligações de hidrogênio em fase líquida seja de fundamental importância para o entendimento de uma série de fenômenos biológicos conhecidos por ocorrerem somente em solução, principalmente em solução aquosa.

As ligações de hidrogênio estão intimamente relacionadas à estrutura e às propriedades da água em seus diversos estados, assim como estão relacionadas a moléculas em solução aquosa. O mais observado e talvez o mais simples exemplo de ligação do hidrogênio é encontrado entre moléculas de água. Duas moléculas de água podem formar uma ligação do hidrogênio entre elas, quando uma molécula de água compartilha o próton de um de seus hidrogênios com a outra molécula de água, que recebe este próton no par isolado de elétrons do oxigênio. Assim forma-se o dímero de água, que é freqüentemente usado como sistema protótipo para o estudo de ligações de hidrogênio [126, 172,173]. Quando mais que duas moléculas de água estiverem presentes, como é o caso da água líquida, é propício que mais ligações de hidrogênio se formem, já que o oxigênio de uma molécula de água tem dois pares isolados de elétrons, e cada um destes elétrons pode formar uma ligação de hidrogênio com hidrogênios das outras moléculas de água. Isto pode se repetir de modo que cada molécula de água esteja ligada com até quatro outras moléculas de água, formando uma rede no líquido de água.

Uma ligação de hidrogênio se forma quando duas moléculas, aceitadora e doadora de prótons atraem-se devido à diferença de eletronegatividade existente entre elas formando um sistema $R-H \cdots X$. Uma molécula doadora de prótons caracteriza-se pelo terminal positivo de hidrogênio $R-H$ e a molécula chamada de aceitadora de próton é caracterizada pela presença de um sítio eletronegativo $X$, geralmente $X=O, N, F$, onde verifica-se a presença de elétrons não comprometidos em ligações covalentes. A atração sofrida pelos 
dois sítios, faz com que as moléculas se aproximem de modo que os elétrons da molécula aceitadora de prótons sejam atraídos na direção do hidrogênio da molécula doadora de prótons. Podemos observar em uma mesma molécula sítios doador e receptor de prótons que interajam entre si formando ligações de hidrogênio na molécula. Um exemplo deste tipo de ligação de hidrogênio intermolecular pode ser visto entre as bases que compõe o DNA e no ácido benzóico e são responsáveis pelas suas conformações espaciais. Outro exemplo interessante e não-convencional de ligação de hidrogênio pode ser observado entre a nuvem $\pi$ da molécula de benzeno (aceitadora de prótons) e a molécula de água (doadora de prótons) [174].

As ligações de hidrogênio provocam diversas alterações nas moléculas envolvidas neste tipo de interação. Geometricamente, observa-se que na molécula doadora de prótons a distância entre o hidrogênio que participa da ligação de hidrogênio e o átomo ligado a ele covalentemente é geralmente alongada levando a um efeito de red-shift. Porém, em agregados que apresentam blue-shift esta distância entre o hidrogênio que participa da ligação de hidrogênio e o átomo ligado a ele covalentemente é encurtada [175]. Pode-se também prever a direção da ligação de hidrogênio quando existe apenas um próton e um par isolado de elétrons envolvidos na ligação de hidrogênio, que tendem a manter-se colineares à ligação covalente $R-H$ [142]. A ligação de hidrogênio também provoca uma redistribuição de cargas nas moléculas doadora e receptora de prótons. Para verificar esta redistribuição de cargas, podemos comparar o potencial eletrostático na região da molécula doadora de prótons antes e depois da formação da ligação de hidrogênio. Outro modo de verificar estes rearranjos na densidade eletrônica, é analisando a direção e o módulo do momento de dipolo do agregado molecular.

Quando o sistema a ser tratado é composto por um único agregado molecular, a inspeção da formação de ligação de hidrogênio, não é uma tarefa difícil de ser executada com sucesso. Porém, quando o sistema em questão é um líquido molecular obtido de forma teórica através de simulação computacional, é natural esperar que com o passar do tempo ou dos passos de simulação, o líquido apresente a formação de mais que um agregado molecular. Daí a necessidade 
de se adotar critérios que determinem com acurácia a formação de ligação de hidrogênio em agregados moleculares obtidos em fase líquida.

As alterações na estrutura das moléculas que interagem por meio de ligações de hidrogênio em líquidos moleculares foram tomadas como critérios para formação de ligação de hidrogênio pela primeira vez por volta dos anos 60 [140]. Uma das primeiras propriedades a ser observada para caracterização de ligação de hidrogênio, é a energia de ligação do agregado, definida anteriormente na equação 3.50. A magnitude da energia da ligação de hidrogênio, em geral, pode variar de menos de $0,5 \mathrm{kcal} / \mathrm{mol}$ em casos em que a ligação é muito fraca, até $\sim 10 \mathrm{kcal} / \mathrm{mol}$ quando as moléculas interagentes são íons. O critério energético, tem um papel excludente na determinação da formação de ligação de hidrogênio, mas por si só não é capaz de garantir a formação da ligação de hidrogênio em um agregado molecular. Por isso, é preciso tomarmos critérios estruturais adicionais para garantir a formação de ligação de hidrogênio. Estes critérios estruturais levam em conta a distância em que se encontram os sítios doador e receptor de prótons na ligação de hidrogênio, o que é geralmente bem caracterizado pelas intersecções das esferas de van der Waals dos átomos envolvidos na ligação que é refletido na função de distribuição radial dos pares aceitador/doador. Por último, é preciso contemplar nos críterios de formação da ligação de hidrogênio, o caráter direcional que geralmente é observado nas ligações de hidrogênio. Este critério fica bem estruturado quando definimos um ângulo máximo formado entre os sítios $X \cdots H-O$ que mantenha a direção da ligação de hidrogênio similar à direção $H-O$ da molécula doadora de prótons.

Utilizando estes três critérios discutidos acima, energia de ligação $\left(E_{l i g}\right)$, distância entre os sítios doador e receptor de prótons $R(X \cdots H)$ e ângulo entre o sítio aceitador e a ligação covalente $H-O \theta(X \cdots H-O)$ pudemos selecionar e analisar agregados moleculares formados nos líquidos estudados neste trabalho. 


\subsubsection{Cooperatividade na Ligação de Hidrogênio}

Sabemos que a formação de uma ligação de hidrogênio provoca mudanças na disposição dos núcleos e na densidade eletrônica das moléculas envolvidas nesta interação, principalmente na região próxima ao hidrogênio doador de prótons. A estrutura eletrônica das moléculas envolvidas na ligação de hidrogênio passa por um rearranjo que pode ser observado nos espectros eletrônico e vibracional, no momento de dipolo de moléculas em agregado. Devido a estas alterações observadas em moléculas que interagem por meio desta interação, presume-se que a capacidade de formar uma segunda ligação de hidrogênio sofra alguma influência devido à presença da primeira ligação de hidrogênio já formada no agregado [138, 140-143].

Como exemplo desta influência podemos tomar um par de moléculas $A H$ e $B H$ que podem ambas ser tanto doadoras quanto receptoras de prótons. Se estas moléculas formarem uma ligação de hidrogênio do tipo $A H \cdots B H$, a densidade eletrônica de $B H$, que está concentrada primordialmente em $B$, é compartilhada com $A H$ através da ligação de hidrogênio. Porém, o próton de $B H$ ainda está disponível para formar uma ligação de hidrogênio com outra molécula, $C H$, dando origem ao trímero $A H \cdots B H \cdots C H$. Observamos que devido maior distribuição de cargas em $B H$ a ligação $B H \cdots C H$ no trímero torne-se mais forte que uma ligação similar no dímero $B H \cdots C H$. Ou seja, $B H$ apresenta-se mais atrativo como doador de prótons em uma ligação de hidrogênio com uma terceira molécula $C H$. O raciocínio análogo, leva a pensar que a molécula $B H$ seja mais aceitadora de prótons em $A H \cdots B H$ que isoladamente.

O efeito exemplificado acima reporta a natureza cooperativa das ligações de hidrogênio e é chamado de cooperatividade ou não-aditividade. Este efeito, faz com que as ligações de hidrogênio presentes em uma cadeia de moléculas sejam mais fortes que ligações existentes em cada dímero da cadeia isoladamente [31, 138, 176].

Porém, existem situações em que a formação de ligações de hidrogênio adicionais à primeira não apresentam cooperatividade de maneira ci- 
tada anteriormente e este efeito costuma ser chamado de anti-cooperatividade. A anti-cooperatividade geralmente ocorre quando uma mesma molécula atua duplamente como receptora e/ou doadora de prótons. Para entendermos a anticooperatividade, é necessário falarmos dos termos energéticos que compõem a energia de interação total de um agregado molecular formado por $N$ moléculas (monômeros), que pode ser decomposta em uma soma de termos de múltiploscorpos da seguinte forma $[29,176]$ :

$$
\Delta E_{N}=\sum_{i=1}^{N-1} \sum_{j>i}^{N} U_{2}(i, j)+\sum_{i=1}^{N-2} \sum_{j>i}^{N-1} \sum_{k>j}^{N} U_{3}(i, j, k)+\cdots,
$$

onde $U_{2}(i, j)$ são chamados de termos de dois corpos e referem-se às contribuições energéticas de duas moléculas na energia de interação total do agregado. Da mesma maneira $U_{3}(i, j, k)$ refere-se à contribuição de três corpos na energia de interação total do agregado. As contribuições de múltiplos-corpos por sua vez são obtidos recursivamente a partir da energia dos monômeros $E_{1}(i)$, dos dímeros $E_{2}(i, j)$, dos trímeros $E_{3}(i, j, k)$ etc, definidas assim:

$$
\begin{gathered}
U_{2}(i, j)=E_{2}(i, j)-\left[E_{1}(i)+E_{1}(j)\right] \\
U_{3}(i, j, k)=E_{3}(i, j, k)-\left[U_{2}(i, j)+U_{2}(j, k)+U_{2}(i, k)\right]-\left[E_{1}(i)+E_{1}(j)+E_{1}(k)\right]
\end{gathered}
$$

Quantitativamente, a cooperatividade pode ser avaliada como $\Delta E_{3}-$ $2 \Delta E_{2}[138,176]$, que pode ser traduzida como o aumento na energia de ligação do sistema devido à inclusão de uma terceira molécula na estrutura.

Para um agregado formado por $N$ moléculas ser estável $\Delta E_{N}$ deve assumir uma valor negativo, mas isso não siginifica que todos os termos de muitos corpos $U_{i}$ assumem valores negativos. Alguns dos termos $U_{i}$ podem assumir valores positivos e estes termos são considerados termos anti-cooperativos e as moléculas envolvidas pelo termo são ditas anti-cooperativas. Embora a anti-cooperatividade possa enfraquecer os termos energéticos referentes a três, quatro etc, corpos, a contribuição energética total, incluindo contribuições entrópicas, referente a todos os corpos geralmente ainda é energeticamente favorável e o agregado ou cadeia forma-se expontaneamente, fazendo com que a existência de duas ligações de hidrogênio seja mais favorável que a existência de uma única ligação. 
Geralmente, quando tomamos um agregado molecular interagindo por meio de uma ligação de hidrogênio e adicionamos a este uma terceira molécula de modo seqüencial ${ }^{1}$, todas as ligações de hidrogênio da cadeia são fortalecidas. O mesmo acontece quando adicionamos de maneira seqüencial outras moléculas na cadeia.

\subsection{A Metodologia S-MC/QM}

Até alguns anos atrás, as metodologias de mecânica quântica disponíveis eram capazes de tratar somente sistemas isolados, em vácuo. Problemas como reações químicas eram tratados teoricamente de maneira pouco realista, visto que os reagentes eram tratados quanticamente e o substrato em torno destes não era considerado nestes cálculos. Pensando em uma descrição teórica para as reações enzimáticas, Warshel e Levitt $[37,38]$ propuseram um método híbrido, em que parte do sistema é tratado por mecânica quântica, enquanto que o restante do sistema é tratado por mecânica molecular, de forma que todo o sistema é explicitamente considerado no cálculo [177]. Devido à maneira como o sistema é tratado nesta metodologia, ela é chamada de QM/MM - Quantum Mechanics/Molecular Mechanics. No tratamento híbrido QM/MM, a parte do sistema do qual queremos obter propriedades físicas específicas, é tratada quanticamente, enquanto que o restante do sistema é descrito por funções potenciais clássicas e por uma distribuição de cargas clássica.

A metodologia Sequential-Monte Carlo/Quantum Mechanics, S-MC/ QM $[39,40]$ traz consigo várias características que a tornam muito atraente. A primeira delas é que o fato de ser um metodologia seqüencial, após a simulação Monte Carlo, pode-se selecionar desta simulação somente as conformações estruturais que trazem informações estatísticas relevantes do sistema, diminuindo drasticamente o número de estruturas a serem tratadas pelo cálculo quântico de centenas de milhares para algumas dezenas, sem que com isso haja perda de informações estatísticas relevantes do sistema [61]. Outra vantagem da aplicação da metodologia S-MC/QM é que ela não limita a quantidade de moléculas de

\footnotetext{
${ }^{1}$ Em cadeias seqüenciais as moléculas centrais atuam tanto como doadora quanto doadora de prótons, como por exemplo podemos citar as cadeias de $H C N$.
} 
solvente a serem usadas nos cálculos quânticos, ou seja, se a propriedade que se quer obter do soluto é diretamente influenciada pela quantidade de moléculas de solvente ao seu redor, esta metodologia se adeqüa à resolução deste problema.

Neste trabalho, utilizamos um tratamento híbrido baseado no QM/ MM, mas que trata o sistema de forma seqüencial, primeiro através do método clássico de simulação Monte Carlo e depois através de cálculos de mecânica quântica, S-MC/MQ [39, 148]. Baseados neste tratamento, geramos as estruturas supermoleculares do líquido através de simulação computacional Monte Carlo Metropolis (MCM) e depois, para obtermos as propriedades eletrônicas dos sistemas em questão, realizamos cálculos quânticos sobre as estruturas geradas na simulação computacional. Este tratamento seqüencial, proporciona a opção de tratarmos primeiramente todos os átomos do sistema de forma clássica, e posteriormente submetermos as estruturas geradas a cálculos de mecânica quântica. Porém, a realização de cálculos quânticos sobre todas as estruturas obtidas da simulação MCM é inviável. Desta forma, podemos realizar os cálculos de mecânica quântica somente sobre as estruturas estatisticamente descorrelacionadas. Com isso, a metodologia S-MC/QM torna-se vantajosa por possibilitar uma diminuição da quantidade de cálculos quânticos a serem realizados sobre as estruturas geradas na simulação, além de garantir a convergência estatística dos resultados. Porém, determinados estudos através desta metodologia necessitam de cuidados, uma vez que certos efeitos quânticos sobre a estrutura eletrônica (tunelamento, por exemplo) não podem ser apropriadamente descritos se as interações entre as moléculas na simulaçãao forem tratadas classicamente. 


\section{Capítulo 4}

\section{Resultados}

Neste capítulo apresentamos os resultados obtidos de estudos teóricos para os seguintes sistemas moleculares: $\mathrm{AlP}_{3}$ em fase gasosa, agregados formados pelas moléculas de $\mathrm{HCN}$ e $\mathrm{H}_{2} \mathrm{O}$ em fase gasosa, pirazina-água e formadeído-água nas fases gasosa e líquida. Começamos pela estabilidade de isômeros isolados com duas aplicações distintas: A primeira para os isômeros da molécula de $\mathrm{AlP}_{3} \mathrm{e}$ a segunda para os agregados de $\mathrm{HCN}$ e $\mathrm{H}_{2} \mathrm{O}$. Adiante, investigamos as propriedade eletrônicas devido à formação de ligação de hidrogênio em dois sistemas moleculares distintos: pirazina e água, onde as propriedades eletrônicas que analisamos foram momento de dipolo, energia de ligação, energia de interação de muitos corpos e cooperatividade tanto em agregados de fase líquida quanto em agregados de fase gasosa. Por último, no sistema formaldeído-água, investigamos a energia de ligação, momento de dipolo, energia de interação de muitos corpos e cooperatividade dos agregados em fase gasosa e também o deslocamento da banda de energia $\mathrm{n} \rightarrow \pi^{*}$ da molécula de formaldeído quando embebida em água.

\subsection{Estabilidade Relativa de Isômeros}

\subsection{1 $\quad \mathrm{AlP}_{3}$}

Os materiais compostos por elementos 13-15 da tabela periódica são de grande importância tecnológica devido ao seu uso na construção de dispositivos microeletrônicos e diodos de emissão de luz. Os agregados de semicondutores 13- 
15 têm despertado bastante interesse para realização de estudos tanto teórico quanto experimentais [178-180]. Devido à aplicação destes materiais na fabricação de dispositivos, estudos detalhados das propriedades destes agregados como função do tamanho podem fornecer significativas previsões para a evolução desde o nível molecular até volumes macroscópicos, costumeiramente chamados de bulk [24]. Dentre os compostos formados pelos elementos 13-15, os agregados de $\mathrm{AlP}_{3}^{-}$destacam-se por dois motivos, têm altas freqüências vibracionais o que facilita a observação do espectro vibracional [22]. Adicionalmente, o pequeno número de elétrons presente nestes agregados viabiliza sofisticados cálculos de estrutura eletrônica destes sistemas. Neste contexto, a forma neutra da molécula de $\mathrm{AlP}_{3}$ aparece como um potencial objeto para estudos teóricos acurados.

Em um primeiro estudo sobre esta molécula, a estrutura piramidal do tripleto $\mathrm{C}_{3 v}$ foi sugerida como sendo a conformação molecular mais estável [21]. Um estudo teórico posterior sugere que no estado singleto é possível a obtenção de duas estruturas de simetrias diferentes, $\mathrm{C}_{s}$ e $\mathrm{C}_{2 v}$, com energias de estabilização muito próximas, cuja diferença é de $\sim 1,5 \mathrm{kcal} / \mathrm{mol}$ [23]. Este mesmo trabalho, declina a idéia de que a estrutura tripleto $\mathrm{C}_{3 v}$, obtida no artigo anterior [21] é a mais estável, já que esta estrutura $\mathrm{C}_{3 v}$ encontra-se energeticamente $\sim 12,6 \mathrm{kcal} / \mathrm{mol}$ acima dos outros dois estados singletos quasidegenerados, $\mathrm{C}_{2 v}$ e $\mathrm{C}_{s}$. Em uma investigação teórica isovalente, da molécula de $\mathrm{AlAs}_{3}$, o estado singleto $\mathrm{C}_{2 v}$ mostrou-se energeticamente mais estável que o estado $\mathrm{C}_{s}$ [19]. Já para a molécula de $\mathrm{GaP}_{3}$ o estado singleto de simetria $\mathrm{C}_{s}$ encontra-se cerca de $6,9 \mathrm{kcal} / \mathrm{mol}$ mais estável que o estado singleto $\mathrm{C}_{2 v}$ da mesma molécula [20]. Estudos teóricos mais recentes [24,25], reafirmaram a estrutura singleto $\mathrm{C}_{2 v}$ do $\mathrm{AlP}_{3}$ como mais estável que a estrutura singleto $\mathrm{C}_{s}$ por $\sim 2,5 \mathrm{kcal} / \mathrm{mol}$, descartando de vez a estrutura $\mathrm{C}_{3 v}$ como uma das mais estáveis para esta molécula. Portanto, uma caracterização acurada da localização energética relativa das duas simetrias $\mathrm{C}_{s}$ e $\mathrm{C}_{2 v}$ para o estado singleto da molécula de $\mathrm{AlP}_{3}$ ainda é de interesse teórico e experimental. Neste capítulo, investigamos através de sofisticados cálculos quânticos a energética da molécula de $\mathrm{AlP}_{3}$ no estado singleto nas simetrias $\mathrm{C}_{s}, \mathrm{C}_{2 v}$ e $\mathrm{C}_{3 v}$. 


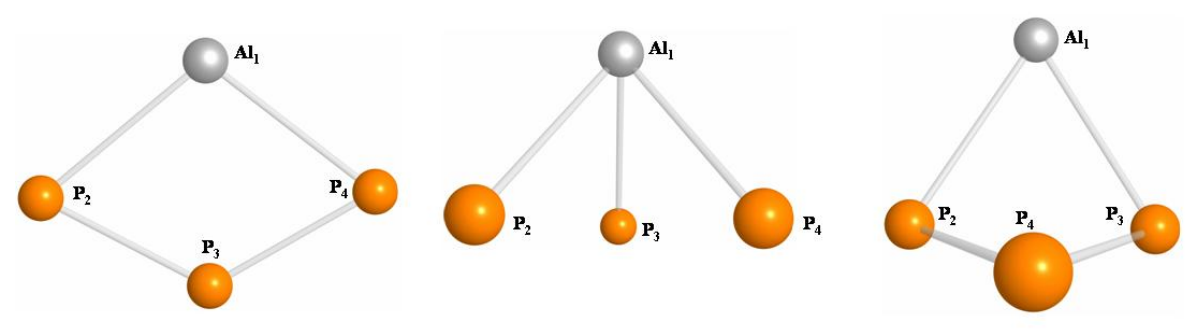

Figura 4.1: Ilustração das estruturas otimizadas do singleto $\mathrm{AlP}_{3}$ em três simetrias distintas obtidas em nível MP2/aug-cc-pVTZ. Da esquerda para a direita, apresentamos os isômeros $\mathrm{C}_{2 v}, \mathrm{C}_{3 v}$ e $\mathrm{C}_{s}$.

Para obtermos as estruturas estáveis da molécula de $\mathrm{AlP}_{3}$ singleto nas simetrias $\mathrm{C}_{3 v}, \mathrm{C}_{s}$ e $\mathrm{C}_{2 v}$, realizamos otimizações de geometria nos níveis MP2/aug-cc-pVTZ e B3LYP/aug-cc-pVTZ, utilizando o programa Gaussian 03 [181]. Todas as seis estruturas obtidas com os dois métodos de cálculo mostraram de fato estruturas de mínima energia, onde a análise vibracional apresenta todas as freqüência vibracionais. O três isômeros moleculares obtidos são ilustrados na figura 4.1 e os parâmetros geométricos que resultaram das otimizações são apresentados na tabela 4.1.

Analisando distâncias e ângulos na tabela 4.1 podemos verificar que existe uma concordância muito boa entre os valores obtidos com os dois métodos de cálculo quântico, MP2 e B3LYP. A maior diferença observada entre estes parâmetros é de $2,5 \%$ entre os ângulos $\theta\left(P_{2} P_{3} P_{4}\right)$.

Para confirmar que todos os isômeros obtidos são estruturas de mínima energia, apresentamos na tabela 4.2 as freqüências vibracionais harmônifcas obtidas nos níveis de cálculo MP2 e B3LYP, ambos com a base aug-ccpVTZ. Também nesta tabela, apresentamos os momentos de dipolo, energia de ponto zero e energia total do sistema $\left(\mathrm{E}_{t o t}\right)$ para cada um dos três isômeros.

Observamos que as freqüências vibracionais dos isômeros não sofrem mudanças significativas quando comparamos os dois métodos de cálculo. Já para os momentos de dipolo observamos que a simetria $\mathrm{C}_{s}$ mostra uma va- 


\begin{tabular}{cccc}
\hline \hline & $\mathrm{C}_{s}$ & $\mathrm{C}_{2 v}$ & $\mathrm{C}_{3 v}$ \\
\hline $\mathrm{MP} 2$ & & & \\
\hline $\mathrm{R}\left(\mathrm{Al}_{1}-\mathrm{P}_{4}\right)$ & 2,425 & 2,339 & 2,260 \\
$\mathrm{R}\left(\mathrm{P}_{2}-\mathrm{P}_{3}\right)$ & 2,118 & 2,077 & - \\
$\mathrm{R}\left(\mathrm{Al}_{1}-\mathrm{P}_{3}\right)$ & - & - & 2,260 \\
$\theta\left(\mathrm{P}_{2} \mathrm{Al}_{1} \mathrm{P}_{4}\right)$ & 60,8 & 102,6 & 57,8 \\
$\theta\left(\mathrm{P}_{2} \mathrm{P}_{3} \mathrm{P}_{4}\right)$ & 70,8 & 123,1 & 60,0 \\
\hline $\mathrm{B}_{\mathrm{L} L \mathrm{P}}$ & & & \\
\hline $\mathrm{R}\left(\mathrm{Al}_{1}-\mathrm{P}_{4}\right)$ & 2,453 & 2,303 & 2,245 \\
$\mathrm{R}\left(\mathrm{P}_{2}-\mathrm{P}_{3}\right)$ & 2,107 & 2,098 & - \\
$\mathrm{R}\left(\mathrm{Al}_{1}-\mathrm{P}_{3}\right)$ & - & - & 2,245 \\
$\theta\left(\mathrm{P}_{2} \mathrm{Al}_{1} \mathrm{P}_{4}\right)$ & 60,1 & 104,1 & 64,4 \\
$\theta\left(\mathrm{P}_{2} \mathrm{P}_{3} \mathrm{P}_{4}\right)$ & 71,3 & 120,0 & 60,0 \\
\hline \hline
\end{tabular}

Tabela 4.1: Parâmetros geométricos obtidos nos níveis de cálculo MP2/aug-cc-pVTZ e B3LYP/aug-cc-pVTZ, com distâncias em angstrom e ângulos em grau, para o singleto $\mathrm{AlP}_{3}$ nas simetrias $\mathrm{C}_{s}, \mathrm{C}_{2 v}$ e $\mathrm{C}_{3 v}$.

\begin{tabular}{cccc}
\hline \hline $\mathrm{MP} 2$ & $\mathrm{C}_{s}$ & $\mathrm{C}_{2 v}$ & $\mathrm{C}_{3 v}$ \\
\hline$\omega_{1}$ & 577 & 517 & 558 \\
$\omega_{2}$ & 364 & 364 & 365 \\
$\omega_{3}$ & 305 & 279 & 450 \\
$\omega_{4}$ & 206 & 191 & 175 \\
$\omega_{5}$ & 478 & 650 & - \\
$\omega_{6}$ & 316 & 364 & - \\
$\mathrm{ZPE}$ & 3,21 & 3,38 & 3,10 \\
$\mu$ & 1,56 & 1,84 & 4,56 \\
$\mathrm{E}_{t o t}$ & $-1264,6798919$ & $-1264,6822424$ & $-1264,6210006$ \\
\hline $\mathrm{B} 3 \mathrm{LYP}$ & $\mathrm{C}_{s}$ & $\mathrm{C}_{2 v}$ & $\mathrm{C}_{3 v}$ \\
\hline$\omega_{1}$ & 586 & 500 & 562 \\
$\omega_{2}$ & 359 & 365 & 351 \\
$\omega_{3}$ & 286 & 289 & 454 \\
$\omega_{4}$ & 197 & 195 & 168 \\
$\omega_{5}$ & 442 & 566 & - \\
$\omega_{6}$ & 260 & 354 & - \\
$\mathrm{ZPE}$ & 3,05 & 3,24 & 3,09 \\
$\mu$ & 1,10 & 2,19 & 4,38 \\
$\mathrm{E}_{t o t}$ & $-1266,6054314$ & $-1266,6065959$ & $-1266,5422662$ \\
\hline \hline
\end{tabular}

Tabela 4.2: Freqüências vibracionais $\mathrm{em}^{-1}$, ZPE em kcal $/ \mathrm{mol}$, momento de dipolo em debye e energia total do sistema corrigida de ZPE em hartree. Resultados obtidos nos níveis de cálculo MP2/aug-cc-pVTZ e B3LYP/aug-cc-pVTZ, para o singleto $\mathrm{AlP}_{3}$ nas simetrias $\mathrm{C}_{s}$, $\mathrm{C}_{2 v}$ e $\mathrm{C}_{3 v}$. 
riação de até $\sim 30 \%$ quando comparamos os resultados obtidos nos níveis MP2 e B3LYP. Também mostramos na tabela 4.2 as energias totais com correção vibracional de ponto zero, obtidas para os três isômeros com os dois métodos de cálculo utilizados anteriormente. Observamos para ambos os métodos, que a simetria $\mathrm{C}_{2 v}$ da molécula de $\mathrm{AlP}_{3}$ é energeticamente mais estável que as outras duas conformações isoméricas. A simetria $\mathrm{C}_{3 v}$ apresenta as energias mais altas para ambos os métodos de cálculo. Se compararmos as energias totais obtidas para as simetrias $\mathrm{C}_{s}$ e $\mathrm{C}_{2 v}$ em cada método de cálculo B3LYP e MP2, vamos observar diferenças de 0,73 e 1,48 kcal/mol, respectivamente, ambas em favor da maior estabilidade para a simetria $\mathrm{C}_{2 v}$.

A caracterização precisa da posição relativa da energia dos estados $\mathrm{C}_{2 v}$ e $\mathrm{C}_{s}$ ainda está sujeita à incerteza. Devido a essa pequena diferença na energia de estabilização destes dois isômeros, cálculos de alto nível e bem balanceados são agora oportunos e relevantes. Para analisarmos sistematicamente o papel dos efeitos da correlação eletrônica na energia total do sistema, submetemos os isômeros otimizados a cálculos pontuais utilizando métodos que vão aumentando a sofisticação do tratamento da correlação eletrônica, indo do método de MP2 ao $\operatorname{CCSD}(\mathrm{T})$. Também utilizamos neste trabalho, o método dos orbitais de Brueckner [182] nos níveis BD e $\mathrm{BD}(\mathrm{T})$, a teoria Gaussian 3 (G3) [183], implementada no programa Gaussian e, por fim, métodos de cálculo DFT, que utilizam funcionais híbridos com diferentes funcionais de troca e correlação, BVWN, B3LYP, B3PW91 [103, 105, 184]. Adicionalmente, realizamos um cálculo HFS, Hartree-Fock Slater [184], a fim de analisarmos como a energia HF mudaria. Em seguida, obtivemos uma diferença de energia muito acurada usando o método Coupled-Cluster CC com extrapolação para o limite de base infinita. Empregamos neste estudo, diferentes conjuntos de funções base tipo correlated-consistent [123], cc-pVXZ, onde $\mathrm{X}=2,3,4$ e 5 .

Analisamos primeiramente o papel das diferentes contribuições aos efeitos da correlação eletrônica. A tabela 4.3 mostra as energias totais obtidas para os isômeros $\mathrm{C}_{s}$ e $\mathrm{C}_{2 v}$ partindo das geometrias otimizadas em nível MP2/aug-cc-pVTZ, já incluindo correção de energia vibracional de ponto zero, ZPE. Em nível HF a estrutura $\mathrm{C}_{s}$ mostra-se mais estável que a estrutura 


\begin{tabular}{lccc}
\hline \hline E & $\mathbf{C}_{s}$ & $\mathbf{C}_{2 v}$ & $\Delta E$ \\
\hline HF & $-1264,1572171$ & $-1264,1565942$ & 0,39 \\
HFS & $-1257,3213006$ & $-1257,3214092$ & $-0,07$ \\
SP86 & $-1259,8034776$ & $-1259,8043451$ & $-0,54$ \\
BVWN & $-1269,8166008$ & $-1269,8177665$ & $-0,73$ \\
B3LYP & $-1266,6046906$ & $-1266,6057792$ & $-0,68$ \\
B3PW91 & $-1266,4103516$ & $-1266,4108774$ & $-0,33$ \\
MP2 & $-1264,6798919$ & $-1264,6822425$ & $-1,48$ \\
MP3 & $-1264,6956707$ & $-1264,6971417$ & $-0,92$ \\
MP4D & $-1264,7177077$ & $-1264,7178759$ & $-0,11$ \\
MP4DQ & $-1264,6885266$ & $-1264,6876364$ & 0,56 \\
MP4SDQ & $-1264,6955574$ & $-1264,6952812$ & 0,17 \\
MP4SDTQ & $-1264,7470860$ & $-1264,7486926$ & $-1,01$ \\
CCSD & $-1264,6946365$ & $-1264,6937698$ & 0,54 \\
CCSD(T) & $-1264,7400128$ & $-1264,7401730$ & $-0,10$ \\
BD & $-1264,6931970$ & $-1264,6922528$ & 0,59 \\
BD(T) & $-1264,7400034$ & $-1264,7402057$ & $-0,13$ \\
G3 & $-1265,933553$ & $-1265,9341183$ & $-0,36$ \\
\hline \hline
\end{tabular}

Tabela 4.3: Energias totais em hartree com correções para ZPE calculadas com a base aug-cc-pVTZ, a menos do modelo G3 emprega bases pré-estabelecidas, sobre as geometrias $\mathrm{MP} 2 /$ aug-cc-pVTZ, para os estados singleto do $\mathrm{AlP}_{3}$ nas simetrias $\mathrm{C}_{s}$ e $\mathrm{C}_{2 v} . \Delta E=E\left(C_{2 v}\right)-$ $E\left(C_{s}\right) \mathrm{em} \mathrm{kcal} / \mathrm{mol}$.

$\mathrm{C}_{2 v}$. Porém, resultados confiáveis requerem a inclusão dos efeitos da correlação eletrônica. Para todos os métodos DFT empregados neste trabalho, obtivemos a estrutura $\mathrm{C}_{2 v}$ como sendo a mais estável, o que está de acordo com os resultados obtidos em nível MP2. Agora, analisamos as ordens mais elevadas. Em quarta-ordem completa, MP4, com inclusão de todas as excitações simples, duplas, triplas e quádruplas, encontramos o estado $\mathrm{C}_{2 v}$ como sendo mais estável por 1,01 kcal/mol. Entretanto, em nível CCSD observamos o oposto. Salientamos agora a contribuição das excitações triplas. Em quarta-ordem esta contribuição é obtida como a diferença entre o resultado MP4-SDTQ completo e o resultado MP4-SDQ incompleto. A importância das excitações triplas pode ser observada na mudanca da estabilidade relativa de $0,17 \mathrm{kcal} / \mathrm{mol}$ para $-1,01$ $\mathrm{kcal} / \mathrm{mol}$, onde o sinal positivo de $\Delta E$ indica uma estabilidade maior da estrutura $\mathrm{C}_{s}$ e o sinal negativo de $\Delta E$ indica maior estabilidade da estrutura $\mathrm{C}_{2 v}$. Esta importância das excitações triplas pode também ser vista em ordens maiores onde estas excitações são também fundamentais para uma boa descrição 
da energia total de cada sistema. Por exemplo, a predição de CCSD é mudada após a inclusão das excitações triplas, em $\operatorname{CCSD}(\mathrm{T})$. Notamos um padrão similar usando o método dos orbitais de Brueckner. O isômero $\mathrm{C}_{2 v}$ é mais estável somente após a inclusão das excitações triplas. Os cálculos realizados em níveis mais altos como por exemplo, $\operatorname{CCSD}(\mathrm{T})$ ou $\mathrm{BD}(\mathrm{T})$, fornecem uma estabilidade relativa de cerca de $0,1 \mathrm{kcal} / \mathrm{mol}$ a favor da estrutura de simetria $\mathrm{C}_{2 v}$. Esta diferença de energia é certamente muito pequena, contudo, é sistemática para todos os níveis de altas ordens. Como uma outra estimativa, o resultado que obtivemos com o método G3 [183], também na tabela 4.3, é similar, com uma estabilidade relativa a favor da estrutura $\mathrm{C}_{2 v}$ de $-0,36 \mathrm{kcal} / \mathrm{mol}$. $\mathrm{O}$ valor B3PW91 é -0, 33 kcal/mol, e mostra-se bem próximo da estimativa G3. Observamos que é difícil estabelecer uma associação entre todos os resultados DFT e a hierarquia dos métodos pós HF. Mesmo assim, concluímos que os métodos de DFT favorecem a estrutura de $\mathrm{C}_{2 v}$ mesmo na aproximação LDA.

Para obtermos resultados ainda mais acurados consideramos o efeitos do aumento do conjunto de funções-base empregando métodos de extrapolação para o limite de base infinita sobre resultados obtidos com as bases correlated consistent. A tabela 4.4 mostra as energias relativas entre as estruturas $\mathrm{C}_{2 v}$ e $\mathrm{C}_{s}$, obtidas através de cálculos pontuais e de extrapolações para o limite de base infinita sobre as estruturas $\mathrm{C}_{2 v}$ e $\mathrm{C}_{s}$ otimizadas em nível B3LYP/augcc-pVTZ. Tem-se discutido que as extrapolações fornecem aproximações muito boas para as estruturas exatas a um custo computacional bem mais baixo [185]. Novamente, todos os resultados apresentados já incluem a energia vibracional de ponto zero. Para todos os modelos teóricos, observamos que o uso da base cc-pVDZ é insuficiente para uma boa descrição da energia relativa, apresentando a estrutura de simetria $\mathrm{C}_{s}$ como a de mais alta energia, ao contrário dos nossos resultados apresentados na tabela 4.3. Usando o conjunto de funçõesbase cc-pVTZ, os resultados para $\Delta E$ mudam para um sinal negativo isto é, a estrutura de $\mathrm{C}_{2 v}$ é encontrada como sendo a mais estável do que a estrutura $\mathrm{C}_{s}$, exceto para o método CCSD. A falha do método CCSD reitera que as excitações triplas são importantes na descrição acurada da energia total dos isômeros de $\mathrm{AlP}_{3}$. 
É interessante agora extrapolarmos os resultados obtidos para a base cc-pVXZ ao limite de base infinita. Para os resultados DFT extrapolamos as energias totais diretamente, através do uso do mesmo esquema empregado com sucesso anteriormente e as energias relativas obtidas com a extrapolação proposta por Cabral e Canuto [137] encontram-se no intervalo que vai de 2, 56 a $1,81 \mathrm{kcal} / \mathrm{mol}$ dependendo do funcional de troca e correlação empregado. Todos os valores de $\Delta E$ indicam o isômero na simetria $\mathrm{C}_{2 v}$ como sendo o mais estável. Os valores obtidos com o esquema de estrapolação proposto por Truhlar [132] foram menores que os valores obtidos usando a base cc-pV5Z, e por isso, não são reportados neste texto. Os valores obtidos a partir do esquema de extrapolação proposto por Varandas [26] foram baseados nos resultados obtidos com a base cc-pV5Z e são reportados na tabela 4.4 .

\begin{tabular}{cccccc}
\hline \hline$\Delta \mathbf{E ~ ( k c a l / m o l ) ~}$ & $\mathbf{X = 2}$ & $\mathbf{X = 3}$ & $\mathbf{X = 4}$ & $\mathbf{X = 5}$ & Extrapolação \\
\hline B3LYP & 1,68 & $-0,48$ & $-1,19$ & $-2,10$ & $-2,45^{a}$ \\
B3P86 & 1,12 & $-0,77$ & $-1,32$ & $-1,96$ & $-2,22^{a}$ \\
HCTX & 0,78 & $-0,94$ & $-1,86$ & $-2,10$ & $-2,56^{a}$ \\
B3PW91 & 1,34 & $-0,45$ & $-0,64$ & $-1,71$ & $-1,81^{a}$ \\
MP2 & 0,51 & $-0,97$ & $-2,06$ & $-2,39$ & $-2,43^{b}$ \\
CCSD & 3,16 & 0,61 & $-0,62$ & $-0,90$ & $-0,91^{b}$ \\
CCSD(T) & 2,15 & $-0,15$ & $-1,30$ & $-1,55$ & $-1,57^{b}$ \\
\hline \hline
\end{tabular}

Tabela 4.4: Energias relativas e energias extrapoladas incluido correção para ZPE, em $\mathrm{kcal} / \mathrm{mol}, \Delta E=E\left(C_{2 v}\right)-E\left(C_{s}\right)$ em vários níveis teóricos,obtidas a partir da geometria B3LYP/aug-cc-pVTZ. ${ }^{a}$ Esquema de extrapolação proposto na ref. [137] ${ }^{b}$ Esquema de extrapolação proposto na ref. [26].

No nível mais elevado considerado, $\operatorname{CCSD}(\mathrm{T})$, a extrapolação mostra que o estado de $\mathrm{C}_{2 v}$ é mais estável que o estado do $\mathrm{C}_{s}$ por $\sim 1,6 \mathrm{kcal} / \mathrm{mol}$. Os valores de $\Delta E$ obtidos com o método $\operatorname{CCSD}(\mathrm{T})$, em função do número cardinal X, são mostrados na figura 4.2.

A prescrição sugerida na referência [135] para a extrapolação das excitações triplas está em muito bom acordo com nossos valores calculados explicitamente.

Os resultados apresentados acima demonstram a existência de duas estruturas quasi-degeneradas, correspondendo às simetrias $\mathrm{C}_{2 v}$ e $\mathrm{C}_{s}$. Para obter uma compreensão melhor da posição dos dois estados na hiper-superfície de 


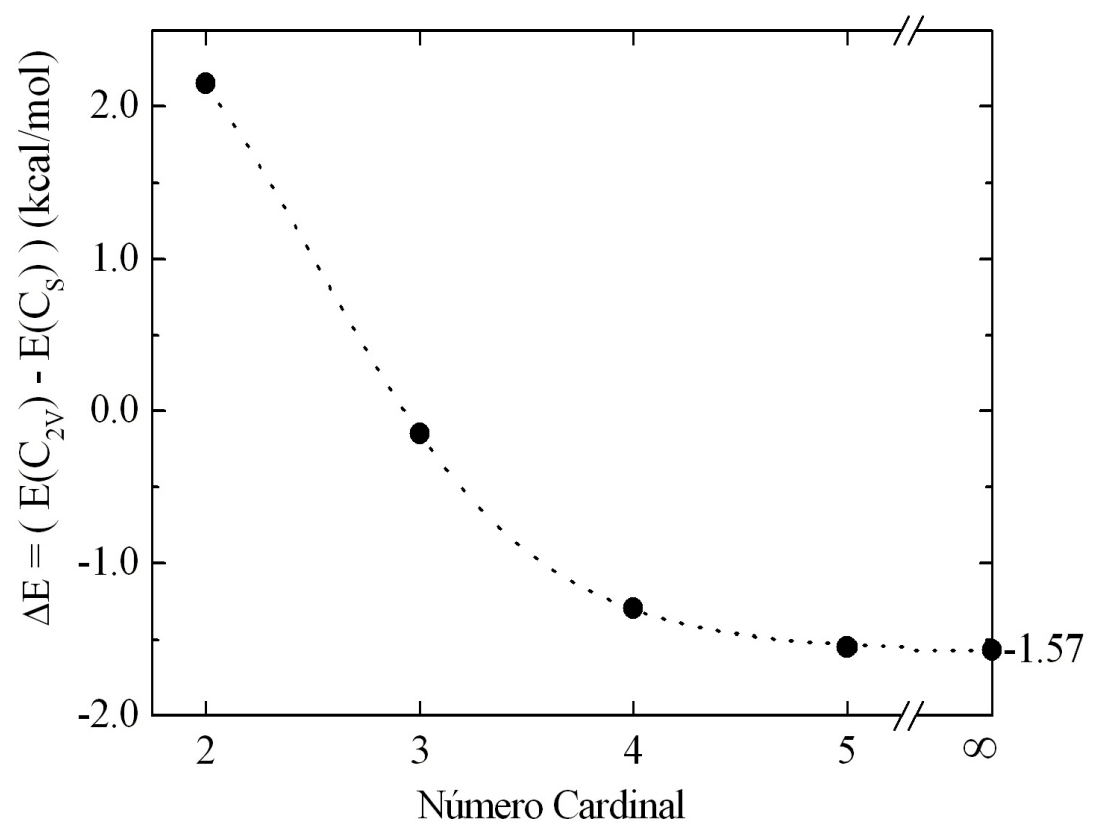

Figura 4.2: Extrapolação para o limite de base infinita da energia relativa dos dois isômeros, utilizando $\operatorname{CCSD}(\mathrm{T}) / \mathrm{cc}-\mathrm{pVXZ}$.

energia potencial obtida em nível B3LYP/6-311G(d) sobre as estruturas otimizadas em nível B3LYP/aug-cc-pVTZ, a figura 4.3 mostra a energia em função da distância $\mathrm{Al}_{1}-\mathrm{P}_{3}$ e do ângulo diedro $\mathrm{Al}_{1}-\mathrm{P}_{2}-\mathrm{P}_{4}-\mathrm{P}_{3}$. Os dois estados não se convertem simplesmente um no outro pela simples mudança direta do ângulo diedro. Eles têm as distâncias $\mathrm{Al}_{1}-\mathrm{P}_{3}$ diagonais curtas para o isômero $\mathrm{C}_{2 v}$ e longas para o isômero $\mathrm{C}_{s}$, com características oblata e prolata. Observamos que os estados são bem localizados e correspondem a dois isômeros independentes e estáveis. A barreira grande de interconversão e a diferença muito pequena da energia entre os dois mínimos fazem ambos os isômeros interessantes. Obtivemos as posições dos dois estados na hiper-superfície de energia potencial para mostrar que os dois estados são localizados e que representam isômeros estáveis e independentes.

Sumarizando, investigamos teoricamente a estabilidade relativa dos dois estados singletos mais estáveis do $A l P_{3}:{ }^{1} A_{1}$ em simetria $C_{2 v}$ e ${ }^{1} A^{\prime}$ em simetria $C_{s}$. Usando métodos altamente correlacionados com grandes conjuntos 


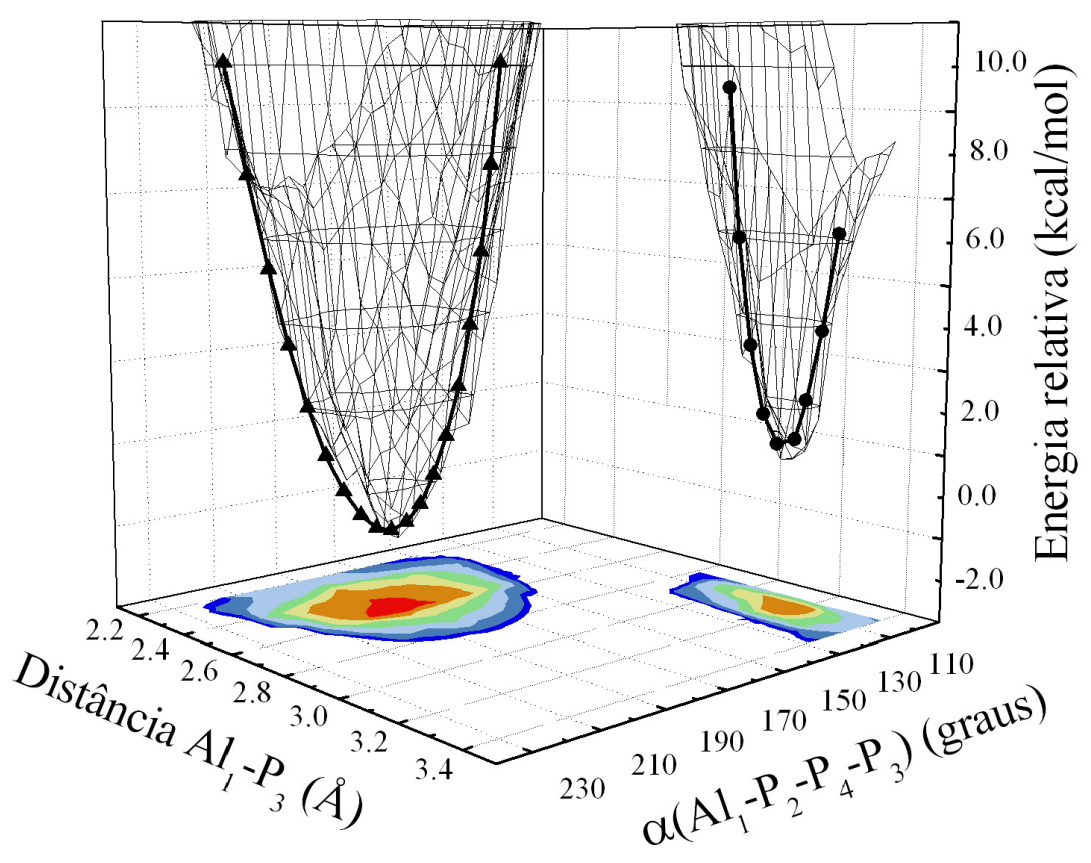

Figura 4.3: Hiper-superfície de energia potencial dos dois isômeros do singleto $\mathrm{AlP}_{3}$.

de funções base encontramos uma diferença de energia muito pequena mas sistematicamente favorável à simetria $\mathrm{C}_{2 v}$. A extrapolação ao limite de base infinita usando $\operatorname{CSSD}(\mathrm{T}) / \mathrm{cc}-\mathrm{pVXZ}(\mathrm{X}=2,3,4$ e 5) fornece uma diferença relativa de energia de 1,6 kcal/mol. Analisando as diferentes contribuições para o efeito de correlação eletrônica notamos que a estabilidade relativa depende crucialmente do tamanho do conjunto de funções base empregados e da inclusão das excitações triplas relativa ao estado Hartree-Fock de referência. As posições dos dois estados na hiper-superfície de energia potencial foram obtidas e mostram que estes estados são independentes e bem localizados representando isômeros estáveis de similar interesse [28].

\subsection{2 $\mathrm{HCN} \cdots \mathrm{HOH}$ e $\mathrm{H}_{2} \mathrm{O} \cdots \mathrm{HCN}$}

Em meados da década de 70 foi desenvolvida a técnica de Jet-cooling, que possibilita a obtenção de agregados moleculares. Esta técnica pode ser resumida da seguinte forma: primeiramente, faz-se uma expansão adiabática de um gás que é mantido à alta pressão (3 a 5 bar) e direcionado para uma câmara em 
alto vácuo através de um orifício cônico de dimensões reduzidas. Neste orifício são instaladas válvulas pulsadas que liberam o gás durante algumas dezenas de microsegundos, produzindo um jato supersônico de moléculas com baixa temperatura interna, o que se reflete numa baixa energia interna das moléculas (rotacional e vibracional) favorecendo a formação e estabilização de agregados moleculares. Teoricamente, pode-se obter agregados moleculares através de cálculos de química quântica que permitem a determinação da estrutura molecular de mínima energia. Podemos definir agregados moleculares como uma ou mais moléculas interagindo por meio de interações específicas. Dentro desta classe de interações, podemos citar as ligações de hidrogênio, que em particular, são um tópico largamente explorado tanto na área da física quanto na área da química $[1,2,138,141-143,186,187]$ e que geralmente estão presentes, definindo a interação entre moléculas em um agregado molecular.

Pensando na formação de agregados moleculares, as moléculas pertencentes ao grupo nitrila $(\mathrm{R}-\mathrm{C} \equiv \mathrm{N})$ são particularmente interessantes para serem estudadas em agregados devido a presença do par isolado de elétrons no átomo de nitrogênio, o que facilita a interação com moléculas doadoras de prótons. Neste contexto, a mais simples das nitrilas o cianeto de hidrogênio $(\mathrm{HCN})$ assim como a molécula de água $\left(\mathrm{H}_{2} \mathrm{O}\right)$ têm dupla função quando interagem com outras moléculas em agregados moleculares. Estas duas moléculas podem atuar como doadores de prótons através das extremidades formadas pelos átomos de hidrogênio, assim como podem atuar como aceitadores de prótons através dos pares isolados de elétrons presentes nos átomos de nitrogênio do $\mathrm{HCN}$ e de oxigênio do $\mathrm{H}_{2} \mathrm{O}$. Esta dupla possibilidade de atuar tanto como doadores quanto como aceitadores de prótons possibilita a formação de cadeias lineares ou cíclicas formadas por estas duas moléculas. No caso de cadeias de HCN, minuciosamente estudadas por Scheiner [138], a linearidade e a presença de um único par isolado de elétrons na molécula isolada fazem com que as cadeias lineares sejam as mais estáveis, independente do comprimento da cadeia $[138,188,189]$. O estudo de contribuições energéticas através dos termos de muitos corpos nas cadeias de HCN também foi estudado [176]. Por outro lado, oligômeros de água têm sido um sistema modelo para estudos de ligações 
de hidrogênio $[29-31,190]$.

Tomando uma molécula de água e uma de cianeto de hidrogênio, podemos formar dois agregados moleculares distintos, um agregado onde o cianeto de hidrogênio atua como doador de prótons $\left(\mathrm{H}_{2} \mathrm{O} \cdots \mathrm{HCN}\right)$ e outro agregado onde a água atua como doadora de prótons $(\mathrm{HCN} \cdots \mathrm{HOH})$. O primeiro destes agregados, $\mathrm{H}_{2} \mathrm{O} \cdots \mathrm{HCN}$, foi obtido teoricamente através de métodos semiempírico e ab initio por Turi e Dannenberg [32]. Já o agregado HCN $\cdots$ HOH foi obtido experimentalmente por espectrocopia de microondas por Gutowsky e coautores [33]. Em artigos mais recentes [31,34], estes dois agregados foram investigados tanto teórica quanto experimentalmente.

Neste trabalho, os agregados $\mathrm{HCN} \cdots \mathrm{H}_{2} \mathrm{O}$ e $\mathrm{H}_{2} \mathrm{O} \cdots \mathrm{HCN}$ são caracterizados teoricamente e sua estabilidade relativa é determinada. Para isso empregamos métodos sofisticados de química quântica. Obtivemos em todos os níveis de cálculo estruturas de mínima de energia. Obtivemos valores para a energia de ligação dos agregados, já incluindo correções para a energia vibracional de ponto zero e erro de superposição de base, utilizando o programa Gaussian 03 [181]. Posteriormente utilizamos métodos de extrapolação já citados e utilizados no estudo dos isômeros do $\mathrm{AlP}_{3}$, para obtermos estimativas para a energia de ligação dos dois agregados.

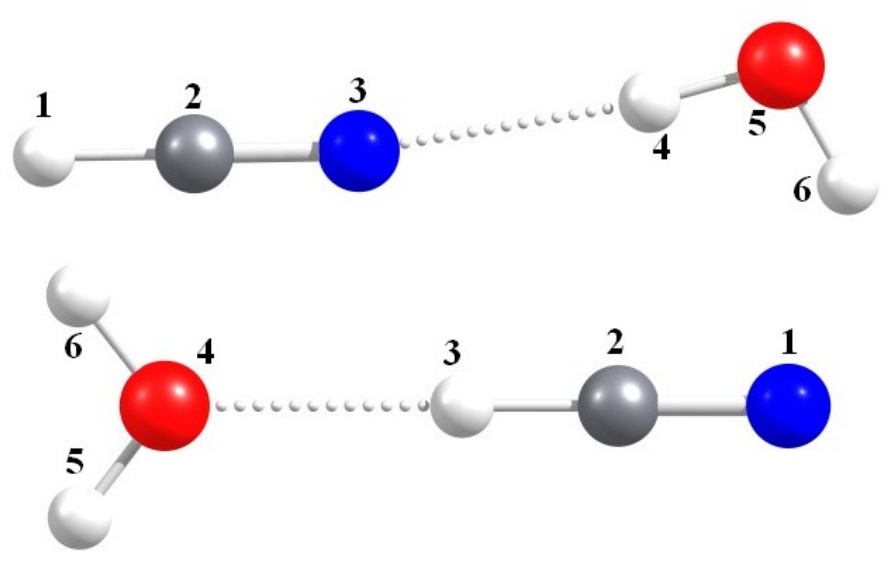

Figura 4.4: De cima para baixo, geometrias dos agregados $\mathrm{HCN} \cdots \mathrm{HOH}$ e $\mathrm{H}_{2} \mathrm{O} \cdots \mathrm{HCN}$ otimizadas em nível MP2/aug-cc-pVTZ.

Para obtermos os agregados $\mathrm{HCN} \cdots \mathrm{HOH}$ e $\mathrm{H}_{2} \mathrm{O} \cdots \mathrm{HCN}$ realiza- 
mos otimização de geometria utilizando dois funcionais de densidade, B3LYP e B3PW91 e teoria de perturbação em segunda ordem, MP2. Nestas otimizações de geometria utilizamos para os funcionais de densidade o conjunto de funçõesbase aug-cc-pVQZ, e para o método perturbativo, aug-cc-pVTZ. A figura 4.4 ilustra as geometrias dos dois isômeros obtidos a partir das otimizações de geometria em nível MP2/aug-cc-pVTZ. O isômero HCN $\cdots \mathrm{HOH}$ tem simetria $\mathrm{C}_{s}$ e o isômero $\mathrm{H}_{2} \mathrm{O} \cdots \mathrm{HCN}$, simetria $\mathrm{C}_{2 v}$. Na verdade, o agregado $\mathrm{H}_{2} \mathrm{O} \cdots \mathrm{HCN}$ tem uma estrutura interessante e tem despertado a atenção devido a sua estrutura $[31-34,191]$.

Cálculos teóricos anteriores, obtiveram que a molécula de água deste agregado encontra-se fora do plano [31,34]. Porém, experimentalmente Gutowsky e coautores [33] afirmam em seu artigo que o ângulo que leva a molécula de água para fora do plano, está em torno de $20^{\circ}$ mas que a barreira de energia formada por esse variação angular, de 0 a $20^{\circ}$ é tão baixa que o nível vibracional referente à energia de ponto zero encontra-se acima do máximo determinados pelos limites da variação angular. Devido a esse fato, realizamos cálculos pontuais em nível MP2/6-311++G(d,p) sobre a estrutura do agregado $\mathrm{H}_{2} \mathrm{O} \cdots \mathrm{HCN}$ variando o ângulo que a molécula de água forma com o $\mathrm{HCN}$. A figura 4.5 mostra um mínimo de energia em torno de $20^{\circ}$, como já havia sido enfatizado anteriormente em investigação experimental desta estrutura. Porém, a diferença de energia entre a estrutura em 0 e $20^{\circ}$ está em torno de $0,06 \mathrm{kcal} / \mathrm{mol}$ que é uma quantidade de energia inexpressiva para concluirmos que a estrutura do agregado $\mathrm{H}_{2} \mathrm{O} \cdots \mathrm{HCN}$ não tem simetria $\mathrm{C}_{2 v}$. Vale ressaltar também que o conjunto de funções-base que utilizamos em nossas otimizações de geometria é um pouco maior, que o conjunto $6-311++\mathrm{G}(\mathrm{d}, \mathrm{p})$ que utilizamos na construção do gráfico 4.5. Além disso, as freqüências vibracionais obtidas nas otimizações de geometria confirmam que as estruturas obtidas são de fato estados de mínima energia.

Na tabela 4.5 mostramos os parâmetros geométricos obtidos das otimizações dos agregados $\mathrm{HCN} \cdots \mathrm{HOH}$ e $\mathrm{H}_{2} \mathrm{O} \cdots \mathrm{HCN}$. De um modo geral, podemos observar pequenas variações nas distâncias interatômicas de ambos agregados quando comparamos os métodos de cálculo. Se tomarmos as distâncias 


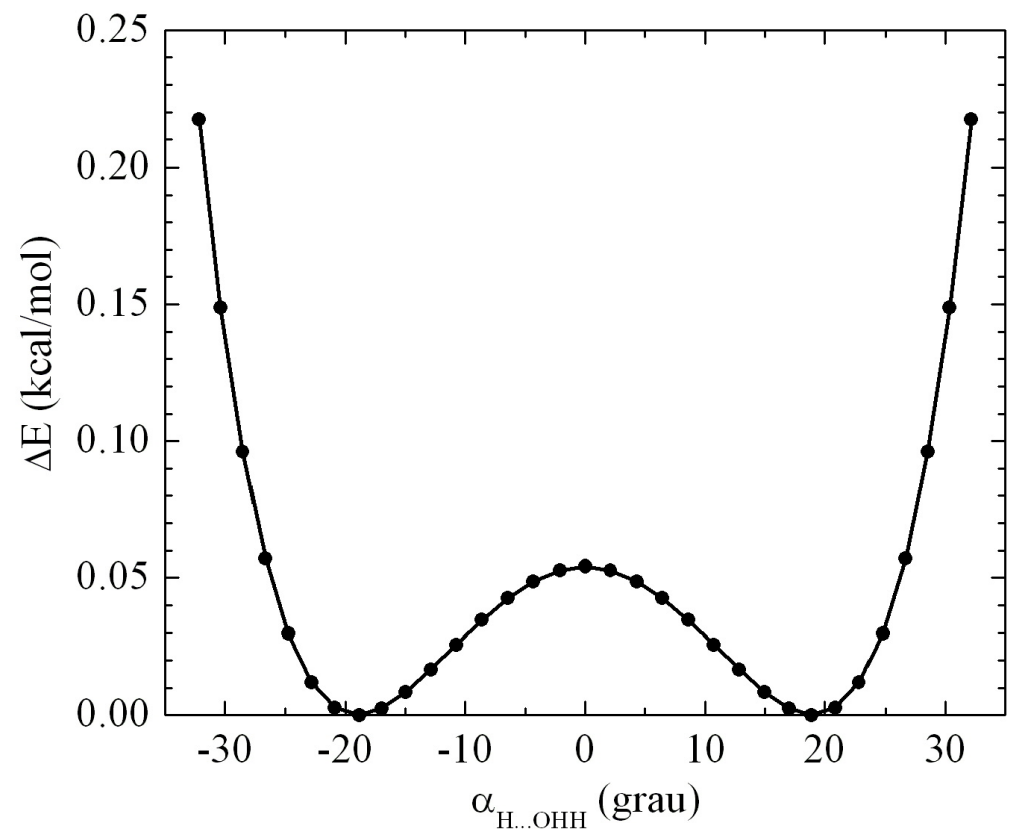

Figura 4.5: Poço duplo de energia do agregado $\mathrm{H}_{2} \mathrm{O} \cdots \mathrm{HCN}$ em função do ângulo $\alpha$ formado entre a molécula de água e o HCN. Valores obtidos em nível MP2/6-311++G(d,p). A energia de referência tem o valor de $-169,4877649$ hartree

\begin{tabular}{|c|c|c|c|}
\hline HCN $\cdots$ HOH & B3LYP & B3PW91 & MP2 \\
\hline $\mathrm{R}\left(\mathrm{H}_{1}-\mathrm{C}_{2}\right)$ & 1,066 & 1,068 & 1,065 \\
\hline $\mathrm{R}\left(\mathrm{C}_{2}-\mathrm{N}_{3}\right)$ & 1,143 & 1,144 & 1,165 \\
\hline $\mathrm{R}\left(\mathrm{N}_{3} \cdots \mathrm{H}_{4}\right)$ & 2,125 & 2,140 & 2,090 \\
\hline $\mathrm{R}\left(\mathrm{H}_{4}-\mathrm{O}_{5}\right)$ & 0,965 & 0,964 & 0,966 \\
\hline $\mathrm{R}\left(\mathrm{O}_{5}-\mathrm{H}_{6}\right)$ & 0,960 & 0,958 & 0,960 \\
\hline$\theta\left(\mathrm{C}_{2}-\mathrm{N}_{3} \cdots \mathrm{H}_{4}\right)$ & 171,3 & 171,0 & 171,4 \\
\hline$\alpha\left(\mathrm{C}_{2}-\mathrm{N}_{3} \cdots \mathrm{O}_{5}-\mathrm{H}_{6}\right)$ & 179,6 & 179,6 & 179,7 \\
\hline $\mathrm{H}_{2} \mathrm{O} \cdots \mathbf{H C N}$ & B3LYP & B3PW91 & MP2 \\
\hline $\mathrm{R}\left(\mathrm{N}_{1}-\mathrm{C}_{2}\right)$ & 1,146 & 1,146 & 1,167 \\
\hline $\mathrm{R}\left(\mathrm{C}_{2}-\mathrm{H}_{3}\right)$ & 1,074 & 1,076 & 1,072 \\
\hline $\mathrm{R}\left(\mathrm{H}_{3} \cdots \mathrm{O}_{4}\right)$ & 2,056 & 2,057 & 2,043 \\
\hline $\mathrm{R}\left(\mathrm{O}_{4}-\mathrm{H}_{5}\right)$ & 0,961 & 0,959 & 0,962 \\
\hline $\mathrm{R}\left(\mathrm{C}_{2} \cdots \mathrm{O}_{4}\right)$ & 3,130 & 3,134 & 3,116 \\
\hline$\theta\left(\mathrm{C}_{2}-\mathrm{H}_{3} \cdots \mathrm{O}_{4}\right)$ & 180,0 & 179,9 & 179,9 \\
\hline$\alpha\left(\mathrm{C}_{2}-\mathrm{H}_{3} \cdots \mathrm{O}_{4}-\mathrm{H}_{5}\right)$ & 42,0 & 42,9 & 61,2 \\
\hline
\end{tabular}

Tabela 4.5: Parâmetros geométricos obtidos para os agregados $\mathrm{HCN} \cdots \mathrm{HOH}$ e $\mathrm{H}_{2} \mathrm{O} \cdots \mathrm{HCN}$. Para os funcionais utilizamos o conjunto de funções-base aug-cc-pVQZ e para o MP2 o conjunto aug-cc-pVTZ. 
referentes às ligações de hidrogênio, observamos que os funcionais B3LYP e B3PW91 fornecem valores ligeiramente mais altos, cerca de $2 \%$ acima, dos valores obtidos com MP2. Nossos valores obtidos para a distância $\mathrm{N}_{3} \cdots \mathrm{H}_{4}$ do agregado $\mathrm{HCN} \cdots \mathrm{HOH}$, são mais acurados que o valor obtido por Heikkilä e colaboradores [34], de 2,1087 ̊ em nível MP2/6-311++G(2d,2p).

Fazendo a mesma análise sobre a distância da ligação de hidrogênio para o agregado $\mathrm{H}_{2} \mathrm{O} \cdots \mathrm{HCN}$, tabela 4.5 , observamos uma boa concordância entre os valores obtidos com DFT e uma diminuição de menos de 1\% na mesma distância obtida com MP2. Para a distância $\mathrm{OC}_{2} \cdots \mathrm{O}_{4}$ Heikkilä encontrou o valor 3,128 A em nível MP2/6-311++G(2d,2p). O valor experimental para a mesma distância $\mathrm{C}_{2} \cdots \mathrm{O}_{4}$ é de $3,152 \AA$ [33]. Os valores para esta distância que obtivemos em nossos cálculos estão entre 3,115 e 3,130 $A$, portanto em boa concordância com ambos os valores obtidos na literatura.

Ainda analisando os valores na tabela 4.5, observamos que as distâncias das ligação de hidrogênio formadas no isômero $\mathrm{H}_{2} \mathrm{O} \cdots \mathrm{HCN}$ são cerca de $5 \%$ menores que as distâncias das ligações de hidrogênio no agregado HCN $\cdots H O H$. Esse encurtamento na ligação de hidrogênio é refletido na energia de ligação do sistema, como veremos adiante. O que se observa é que existe uma correlação entre a distância dos átomos doador e receptor de prótons com a energia de ligação do agregado, quanto menor a distância de ligação, maior a estabilidade do agregado [144-146, 148, 192].

\begin{tabular}{ccc}
\hline \hline$\mu$ & $\mathrm{HCN} \cdots \mathrm{HOH}$ & $\mathrm{NCH} \cdots \mathrm{OH}_{2}$ \\
\hline B3LYP/aug-cc-pVQZ & 4,80 & 5,64 \\
B3PW91/aug-cc-pVQZ & 4,80 & 5,63 \\
MP2/aug-cc-pVTZ & 5,09 & 6,02 \\
ZPE & $\mathrm{HCN} \cdots \mathrm{HOH}$ & $\mathrm{NCH} \cdots \mathrm{OH}_{2}$ \\
\hline B3LYP/aug-cc-pVQZ & 2,45 & 2,14 \\
B3PW91/aug-cc-pVQZ & 2,42 & 2,12 \\
MP2/aug-cc-pVTZ & 1,38 & 1,14 \\
\hline \hline
\end{tabular}

Tabela 4.6: Momentos de dipolo, em debye, e ZPE, em kcal/mol, obtidos nas otimizações para os agregados $\mathrm{HCN} \cdots \mathrm{HOH}$ e $\mathrm{H}_{2} \mathrm{O} \cdots \mathrm{HCN}$.

Na tabela 4.6 mostramos os momentos de dipolo e energia vibracional de ponto zero, obtidos em cada nível de cálculo. Nesta tabela podemos 
observar que os momentos de dipolo obtidos para o agregado $\mathrm{H}_{2} \mathrm{O} \cdots \mathrm{HCN}$ são maiores que aqueles obtidos para o agregado HCN $\cdots$ HOH. Isso se deve ao fato de que no agregado $\mathrm{H}_{2} \mathrm{O} \cdots \mathrm{HCN}$ os momentos de dipolo das moléculas individuais estão em posições paralelas, o que determina o aumento do momento de dipolo do agregado $\mathrm{H}_{2} \mathrm{O} \cdots \mathrm{HCN}$. Os funcionais B3LYP e B3PW91 nos fornecem valores para o momento de dipolo muito semelhantes para cada um dos agregados. No caso do agregado $\mathrm{HCN} \cdots \mathrm{HOH}$ os valores de $\mu$ obtidos com os dois funcionais são coincidentes. Para o agregado $\mathrm{H}_{2} \mathrm{O} \cdots \mathrm{HCN}$ os momentos de dipolo obtidos são também muito semelhantes, diferindo na segunda casa decimal. Os valores de 4,8 D e $\sim 5,6 \mathrm{D}$ obtidos pelos métodos DFT para os agregados $\mathrm{HCN} \cdots \mathrm{HOH}$ e $\mathrm{H}_{2} \mathrm{O} \cdots \mathrm{HCN}$ respectivamente, estão em bom acordo com os resultados 5,85 D e 5,11 D obtidos anteriormente em nível B3LYP/6-311++G(d,p) [192]. Os momentos de dipolo obtidos em nível MP2/aug-cc-pVTZ para os dois agregados são ligeiramente maiores que os obtidos com DFT. Para o agregado HCN...HOH o resultado MP2 é cerca de $6 \%$ maior que os resultados em DFT. Já para o agregado $\mathrm{H}_{2} \mathrm{O} \cdots \mathrm{HCN}$ essa diferença é de aproximadamente $7 \%$ sendo que o maior momento de dipolo foi obtido pelo método MP2. Comparando nossos resultados em MP2 com resultados anteriores obtidos em nível MP2/6-311++G(d,p) [192], observamos uma diferença de menos de $1 \%$ para o agregado $\mathrm{H}_{2} \mathrm{O} \cdots \mathrm{HCN}$ e para o agregado HCN $\cdots$ HOH o resultado da literatura é 5\% maior que o nosso de 5, 09 D.

Ainda na tabela 4.6 observamos que as energias vibracionais de ponto zero são superestimadas por $\sim 1 \mathrm{kcal} / \mathrm{mol}$ pelos funcionais de densidade em ambos os agregados quando comparados aos valores de ZPE obtidos com MP2. Além disso, notamos que o agregado HCN $\cdots \mathrm{HOH}$ apresenta ZPE $13 \%$ maior em nível DFT e 17\% maior em nível MP2 quando comparadas às energias de ponto zero obtidas para o agregado $\mathrm{H}_{2} \mathrm{O} \cdots \mathrm{HCN}$ nos mesmos níveis de cálculo.

Na tabela 4.7 mostramos as energias de ligação dos agregados de $\mathrm{HCN}$ e $\mathrm{H}_{2} \mathrm{O}$ obtidas com cálculos pontuais sobre geometrias otimizadas. Para ambos os agregados, utilizamos a geometria otimizada com o mesmo método quântico que os utilizados nos cálculos pontuais. Assim, nos cálculos B3LYP a 


\begin{tabular}{|c|c|c|c|c|c|c|}
\hline$E_{\text {Lig }}$ & $\mathrm{X}=\mathbf{2}$ & $\mathrm{X}=\mathbf{3}$ & $X=4$ & Extrapolação & \multicolumn{2}{|c|}{ Outros } \\
\hline \multicolumn{7}{|c|}{$H C N \cdots H O H$} \\
\hline B3LYP & $-1,21$ & $-1,01$ & $-1,04$ & $-1,11^{a}$ & & \\
\hline B3PW91 & $-0,71$ & $-0,53$ & $-0,53$ & $-0,55^{a}$ & & \\
\hline MP2 & $-3,11$ & $-3,04$ & $-2,91$ & $-2,96^{b}$ & $-3,61^{c}$ & $-3,66^{d}$ \\
\hline CCSD & $-2,67$ & $-2,60$ & $-2,43$ & $-2,47^{b}$ & & $-3,27^{d}$ \\
\hline $\operatorname{CCSD}(\mathbf{T})$ & $-2,93$ & $-2,85$ & $-2,69$ & $-2,74^{b}$ & $-3,38^{c}$ & $-3,44^{d}$ \\
\hline \multicolumn{7}{|c|}{$\mathrm{H}_{2} \mathrm{O} \cdots \mathrm{HCN}$} \\
\hline B3LYP & $-2,87$ & $-2,61$ & $-2,64$ & $-2,69^{a}$ & & \\
\hline B3PW91 & $-2,38$ & $-2,17$ & $-2,16$ & $-2,17^{a}$ & & \\
\hline MP2 & $-4,46$ & $-4,34$ & $-4,16$ & $-4,17^{b}$ & $-5,36^{c}$ & $-4,71^{d}$ \\
\hline CCSD & $-4,27$ & $-4,22$ & $-4,05$ & $-4,05^{b}$ & & $-4,57^{d}$ \\
\hline $\operatorname{CCSD}(\mathbf{T})$ & $-4,46$ & $-4,35$ & $-4,17$ & $-4,17^{b}$ & $-5,17^{c}$ & $-4,63^{d}$ \\
\hline
\end{tabular}

Tabela 4.7: Energia de ligação, em kcal/mol, obtida para os agregados HCN $\cdots$ HOH e $\mathrm{H}_{2} \mathrm{O} \cdots \mathrm{HCN}$ nos níveis B3LYP, B3PW91, MP2, CCSD e CCSD(T) com o conjunto de funçõesbase aug-cc-pVXZ, $\mathrm{X}=2,3,4$ e extrapoladas para o limite de base infinita. ${ }^{a}$ Esquema de extrapolação proposto na ref. [137] ${ }^{b}$ Esquema de extrapolação proposto na ref. [26].

geometria utilizada foi a B3LYP/aug-cc-pVQZ, nos B3PW91 a geometria utilizada foi a B3PW91/aug-cc-pVQZ e para os cálculos perturbativos utilizamos a geometria MP2/aug-cc-pVTZ. As bases utilizadas foram augmented correlated consistent aug-cc-pVXZ, com $\mathrm{X}=2,3$ e 4 para todos os níveis de cálculo utilizados. Aplicamos também esquemas de extrapolação para a energia de ligação dos agregados $\mathrm{HCN} \cdots \mathrm{HOH}$ e $\mathrm{H}_{2} \mathrm{O} \cdots \mathrm{HCN}$. Estes esquemas de extrapolação foram utilizados anteriormente para o estudo dos isômeros de $\mathrm{AlP}_{3}$ e forneceram bons resultados. Todos os resultados mostrados na tabela 4.7 incluem a correção de counterpoise [139] contra o erro de superposição de base e a energia vibracional de ponto zero.

Analisando os resultados para a energia de ligação dos agregados, tabela 4.7, obtidos com os dois funcionais de densidade, observamos que as energias obtidas com a base aug-cc-pVDZ superestimam a energia de ligação para ambos os agregados. Comparando os resultados obtidos com o conjunto de função-base aug-cc-pVDZ com os resultados das extrapolações para as energias de ligação dos agregados, observamos que esta base aumenta em $8 \%$ a energia B3LYP e 22\% a energia B3PW91, ambos para o agregado HCN $\cdots$ HOH. Para o agregado $\mathrm{H}_{2} \mathrm{O} \cdots \mathrm{HCN}$ as superestimativas são de $6 \%$ com o funcional B3LYP 
e 9\% com o funcional B3PW91. Os cálculos em MP2 e Coupled Cluster, ainda utilizando a base aug-cc-pVDZ mostram valores de energia de ligação mais baixos que os valores obtidos nas extrapolações para ambos os agregados. Com isso, percebemos que para os agregados formados com as moléculas de HCN e $\mathrm{H}_{2} \mathrm{O}$, o conjunto de fuções-base aug-cc-pVDZ é insuficiente para uma boa descrição da energia dos sistemas, fornecendo valores sempre superestimados. Observamos também, para ambos os agregados, que se comparamos base a base as energias obtidas nos cálculos B3LYP com as energias correspondentes obtidas pelo funcional B3PW91 vemos que aquelas obtidas com B3LYP são maiores que as energias B3PW91 por cerca de $0,5 \mathrm{kcal} / \mathrm{mol}$.

Para os dois agregados de $\mathrm{HCN}$ e $\mathrm{H}_{2} \mathrm{O}$, notamos que o método MP2, forneceu as maiores energias de ligação, em cada nível de cálculo e também na extrapolação para o limite de base infinita, de $-2,96 \mathrm{kcal} / \mathrm{mol}$ para o agregado $\mathrm{HCN} \cdots \mathrm{HOH}$ e $-4,17 \mathrm{kcal} / \mathrm{mol}$ para o agregado $\mathrm{H}_{2} \mathrm{O} \cdots \mathrm{HCN}$. Comparando nossos valores obtidos para energia de ligação, tabela 4.7 em MP2 com valores obtidos na literatura, observamos que os nossos estão energeticamente mais baixos devido a correção vibracional de ponto zero que está inclusa em nossos cálculos. Para o agregado HCN $\cdots \mathrm{HOH}$ obtivemos $-2,96 \mathrm{kcal} / \mathrm{mol}$ como energia extrapolada ao limite de base infinita e na literatura encontramos os valores de $-3,66 \mathrm{kcal} / \mathrm{mol}$ no nível $\mathrm{MP} 2 / 6-311++\mathrm{G}(2 \mathrm{~d}, 2 \mathrm{p})$ [34] e $-3,54$ kcal/mol no nível MP2/6-311++G(d,p) obtido na referência [192]. Já para o agregado $\mathrm{H}_{2} \mathrm{O} \cdots \mathrm{HCN}$, obtivemos uma energia de ligação de $-4,17 \mathrm{kcal} / \mathrm{mol}$ em MP2 no limite de base infinita e na literatura obtivemos os valores de $-4,70$ $\mathrm{kcal} / \mathrm{mol}$ [192] e -4,71 kcal/mol [34] obtidos nos níveis MP2/6-311++G(d,p) e MP2/6-311++G(2d,2p), respectivamente. Portanto, os valores que obtivemos para a energia de ligação dos dois agregados concordam com os resultados anteriormente obtidos na literatura em nível MP2.

Fazendo a diferença das energias de ligação obtidas com $\operatorname{CCSD}(\mathrm{T})$ e CCSD podemos obter um valor numérico para a contribuição das excitações triplas na energia de ligação dos agregados. Para o agregado $\mathrm{HCN} \cdots \mathrm{HOH}$ obtivemos que as excitações triplas contribuem com 0,26, 0,25 e 0,26 kcal/mol na energia de ligação deste agregado quando utilizamos as bases aug-cc-pVXZ 
com $\mathrm{X}=2,3$ e 4 respectivamente. Para o limite de base infinita, as excitações triplas contribuem com 0,27 das $2,74 \mathrm{kcal} / \mathrm{mol}$ que é a energia de interação em nível $\operatorname{CCSD}(\mathrm{T})$. Fazendo esta mesma análise para o agregado $\mathrm{H}_{2} \mathrm{O} \cdots \mathrm{HCN}$, vemos que as excitações triplas são responsáveis por 0,19, 0,13 e 0,12 kcal/mol das energias de ligação obtidas com o método $\operatorname{CCSD}(\mathrm{T})$ nas bases aug-cc-pVXZ, $\operatorname{com} \mathrm{X}=2,3$ e 4 respectivamente. No limite de base infinita as excitações triplas contribuem com $0,12 \mathrm{kcal} / \mathrm{mol}$ das $4,17 \mathrm{kcal} / \mathrm{mol}$ da energia de ligação total obtida em nível CCSD(T). Percebemos que nas estimativs de energia de ligação no limite de base infinita, a energias referente às excitações triplas contribuem com $10 \%$ e $~ 3 \%$ das energias de ligação total dos agregados $\mathrm{HCN} \cdots \mathrm{HOH}$ e $\mathrm{H}_{2} \mathrm{O} \cdots \mathrm{HCN}$, respectivamente. Tanto o valor numérico $(0,27 \mathrm{kcal} / \mathrm{mol})$ quanto o valor percentual (10\%) nos informam que a inclusão das excitações triplas no cálculo da energia de ligação do agregado $\mathrm{HCN} \cdots \mathrm{HOH}$ são mais importantes que no agregado $\mathrm{H}_{2} \mathrm{O} \cdots \mathrm{HCN}$, onde as excitações triplas contribuem bem menos para a energia de ligação do agregado.

$\mathrm{O}$ agregado $\mathrm{H}_{2} \mathrm{O} \cdots \mathrm{HCN}$ é, em todos os níveis de cálculo, mais estável que o agregado $\mathrm{HCN} \cdots \mathrm{HOH}$. Os funcionais densidade apresentam diferenças de energia em torno de 1,6 kcal/mol, sempre em favor da estrutura $\mathrm{H}_{2} \mathrm{O} \cdots \mathrm{HCN}$. A menor diferença de energia entre os dois isômeros é observada no limite de base infinita com o método de cálculo MP2, que é de 1,21 kcal/mol. Em nosso mais acurado nível de cálculo, $\operatorname{CCSD}(\mathrm{T})$, essa diferença de energia chega a 1,43 kcal $/ \mathrm{mol}$ favorecendo o isômero $\mathrm{H}_{2} \mathrm{O} \cdots \mathrm{HCN}$. Este fato já havia sido observado anteriormente por Heikkilä e colaboradores que encontraram, em nível CCSD(T)/6-311++G(2d,2p)//MP2(FC)/6-311++G(2d,2p), uma diferença de energia de $1,26 \mathrm{kcal} / \mathrm{mol}$, indicando que o isômero $\mathrm{H}_{2} \mathrm{O} \cdots \mathrm{HCN}$ é energeticamante mais favorável que o isômero HCN $\cdots \mathrm{HOH}$. Em outro trabalho teórico [192], observou-se que o isômero $\mathrm{H}_{2} \mathrm{O} \cdots \mathrm{HCN}$ é $1,36 \mathrm{kcal} / \mathrm{mol}$ mais estável que o isômero $\mathrm{HCN} \cdots \mathrm{HOH}$.

Com isso, observamos que dentre os dois isômeros formados pelas moléculas de $\mathrm{HCN}$ e de $\mathrm{H}_{2} \mathrm{O}$ é energeticamente mais favorável o cianeto de hidrogênio doar prótons para a molécula de água. Se tomarmos nosso melhor nível de cálculo, $\operatorname{CCSD}(\mathrm{T})$ com limite de base infinita, vemos que a energia de ligação 
para o agregado $\mathrm{HCN} \cdots \mathrm{HOH}$ é de $-2,74 \mathrm{kcal} / \mathrm{mol}$ enquanto que para o agregado $\mathrm{H}_{2} \mathrm{O} \cdots \mathrm{HCN}$ a energia de ligação obtida foi de $-4,17 \mathrm{kcal} / \mathrm{mol}$ no mesmo nível de cálculo. Este fato, nos leva a afirmar que o agregado $\mathrm{H}_{2} \mathrm{O} \cdots \mathrm{HCN}$ é mais estável que o $\mathrm{HCN} \cdots \mathrm{HOH}$ por 1, $43 \mathrm{kcal} / \mathrm{mol}$. Este fato tem importantes conseqüências no equilíbrio isomérico visto que, através das contribuições termoquímicas para a energia livre de Gibbs podemos estimar a constante de equilíbrio para o isomerismo e sob condições dos experimentos de expansão ( $\mathrm{T}<$ $150 \mathrm{~K}) \mathrm{H}_{2} \mathrm{O} \cdots \mathrm{HCN}$ é essencialmente o único isômero presente [193]. Todos os nossos resultados para os agregados de $\mathrm{HCN}$ e $\mathrm{H}_{2} \mathrm{O}$ mostram-se mais acurados que os resultados anteriores obtidos na literatura. Adicionalmente, realizamos extrapolações para o limite de base infinita, o que nos forneceu valores mais exatos para a energia relativa dos dois agregados, e apontaram para o agregado $\mathrm{H}_{2} \mathrm{O} \cdots \mathrm{HCN}$ como sendo o mais estável, o que pode ser justificado pela basicidade do átomo de oxigênio da água ser maior que a basicidade do átomo de nitrogênio do HCN, fazendo com que a ligação de hidrogênio no agregado $\mathrm{H}_{2} \mathrm{O} \cdots \mathrm{HCN}$ seja maior que a ligação de hidrogênio do agregado $\mathrm{HCN} \cdots \mathrm{HOH}$.

\subsection{Ligação de Hidrogênio Pirazina-Água}

Grande parte dos processos físicos e químicos que envolvem moléculas biológicas ocorrem em ambiente aquoso, por isso a água é o solvente mais estudado tanto teórica quanto experimentalmente [194-196]. As ligações de hidrogênio formadas entre a água e as biomoléculas são um tópico importante na química e na biologia e nos últimos anos têm atraído interesse considerável também na física. Um bom protótipo para estudar a interação entre a água e moléculas biológicas é o estudo das interações da água com pequenas moléculas orgânicas [170,197-199]. Neste contexto, os azabenzenos são conhecidos como blocos constituintes de grandes moléculas de interesse biológico e sua facilidade para formar ligações de hidrogênio tem sido estudada extensivamente tanto teórica quanto experimentalmente [59, 169, 198, 200-203]. O estudo das ligações de hidrogênio entre anéis aromáticos e a molécula de água é crucial para a compreensão das propriedades das biomoléculas em ambiente aquoso [138,141,142]. 
Um esforço considerável é associado à compreensão destes agregados isolados onde as moléculas estão interagindo através de ligações de hidrogênio [150,151, 170, 198, 199, 204-207]. Porém, a situação real encontrada em um ambiente de água líquida, como acontece em diversos processos químicos e biológicos, não pode ser confundida e nem descrita por uma situação em que uma biomolécula interage com um número restrito de moléculas de água em uma única conformação espacial $[27,144]$. Neste capítulo, investigamos algumas das propriedades eletrônicas das estruturas pirazina-água tanto em fase líquida quanto em fase gasosa.

Para obtermos os agregados de fase gasosa, realizamos otimização de geometria em nível MP2/aug-cc-pVDZ. Nestas otimizações obtivemos três agregados pirazina-água, onde dois deles são formados por uma molécula de pirazina e uma molécula de água, aos quais chamamos agregados 1:1, e o terceiro deles, formado por uma molécula de pirazina e duas moléculas de água, cada uma delas formando uma ligação de hidrogênio com um dos átomos de nitrogênio da molécula de pirazina, aos quais denominamos agregados 1:2. Para estas três geometrias realizamos cálculos de freqüências vibracionais e asseguramos que as estruturas são de fato estados de mínima energia, onde todas as freqüências vibracionais são positivas.

O sistema líquido por sua vez foi obtido por meio de uma simulação Monte Carlo (MC) no ensemble canônico (NVT), implementado no programa DICE [71]. O sistema considerado consistiu em uma molécula de pirazina e 400 moléculas de água. O volume da caixa cúbica foi determinado pela densidade experimental da água [208] de 0,9966 g/ $\mathrm{cm}^{3}$ à temperatura ambiente, 298, $15 \mathrm{~K}$. As interações intermoleculares foram descritas pelo potencial Lennard-Jones incluindo o potencial de Coulomb, com três parâmetros para cada átomo $i\left(\varepsilon_{i}, \sigma_{i}\right.$ e $q_{i}$ ). Os parâmetros atômicos foram combinados por médias geométricas para gerar os parâmetros de pares $\varepsilon_{i j}=\left(\varepsilon_{i} \varepsilon_{j}\right)^{\frac{1}{2}}$ e $\sigma_{i j}=\left(\sigma_{i} \sigma_{j}\right)^{\frac{1}{2}}$. Para a molécula de pirazina utilizamos os parâmetros obtidos no potencial OPLS-AA (Optimized Potential of Liquid Systems-All Atoms) [209]. A geometria da molécula de pirazina utilizada na simulação foi obtida do agregado pirazina-água 1:1 otimizado anteriormente em nível MP2/6-31+G(d). A molécula de água foi modelada 
pelo potencial SPC (Simple Potential Charge) [210] para o qual $R_{O \cdots H}=1,000$ $\AA$ e $\alpha_{H O H}=109,47^{\circ}$. Nesta simulação todas as moléculas foram mantidas em suas geometrias rígidas. A simulação consistiu em estágio de termalização de $6 \times 10^{6}$ passos MC, seguidas por um estágio de $8 \times 10^{7}$ passos $\mathrm{MC}$, no qual as propriedades termodinâmicas foram avaliadas e as configurações de equilíbrio foram geradas.

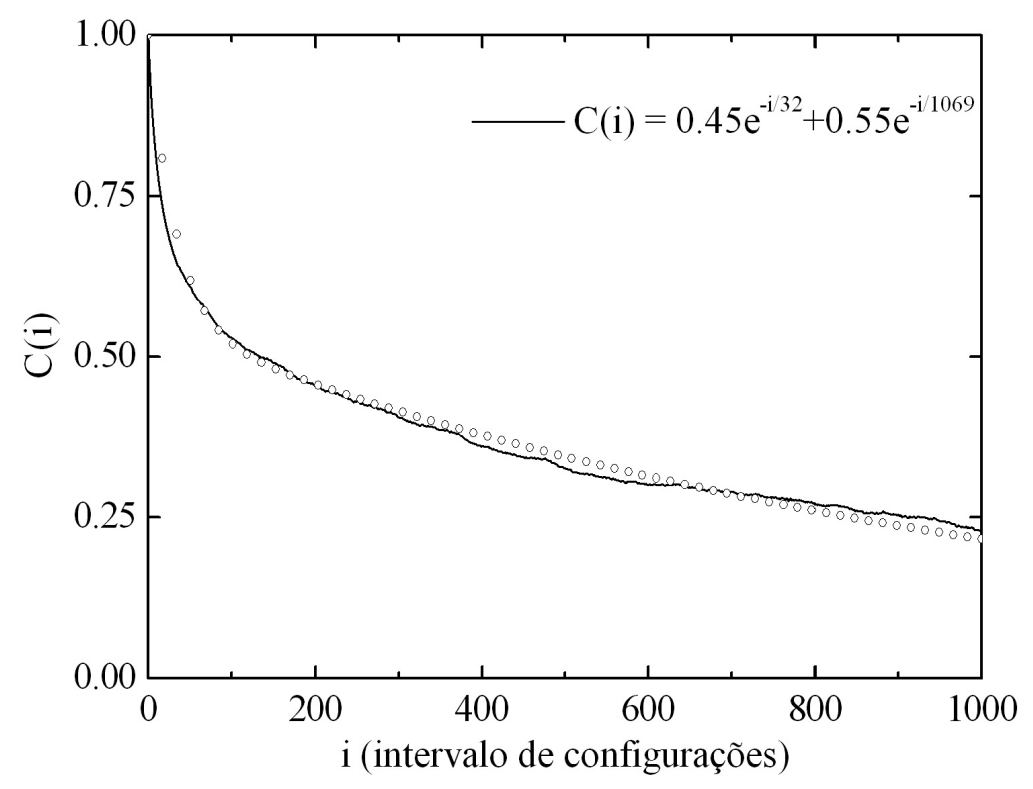

Figura 4.6: Função de auto-correlação da energia do sistema líquido pirazina-água.

A função de auto-correlação da energia, figura 4.6, foi usada para calcular o intervalo de correlação estatística, $\tau$, que nos permite selecionar somente as configurações estatisticamente relevantes geradas pela simulação MC. O uso do intervalo $\tau$ reduz drasticamente o número de configurações a serem submetidas aos cálculos quânticos. Este procedimento tem sido aplicado com sucesso e fornece valores médios estatisticamante convergidos a partir de um número mínimo de configurações [39]. Desta maneira, obtivemos um $\tau \sim 242 \times 10^{3}$ passos de MC. De trabalhos anteriores, sabemos que a utilização de $2 \tau$ como intervalo de correlação, é suficiente para obtermos configurações com baixa correlação estatística $[39,40,62,75]$. Utilizamos neste trabalho um 
intervalo de correlação de $562 \times 10^{3}$, o que nos forneceu menos de $14 \%$ de correlação entre duas estruturas consecutivas. Com isso diminuímos o número de configurações a serem utilizadas nos cálculos quânticos de $8 \times 10^{7}$ para somente 142 configurações, sem com isso perdermos informações estatísticas relevantes sobre o sistema.

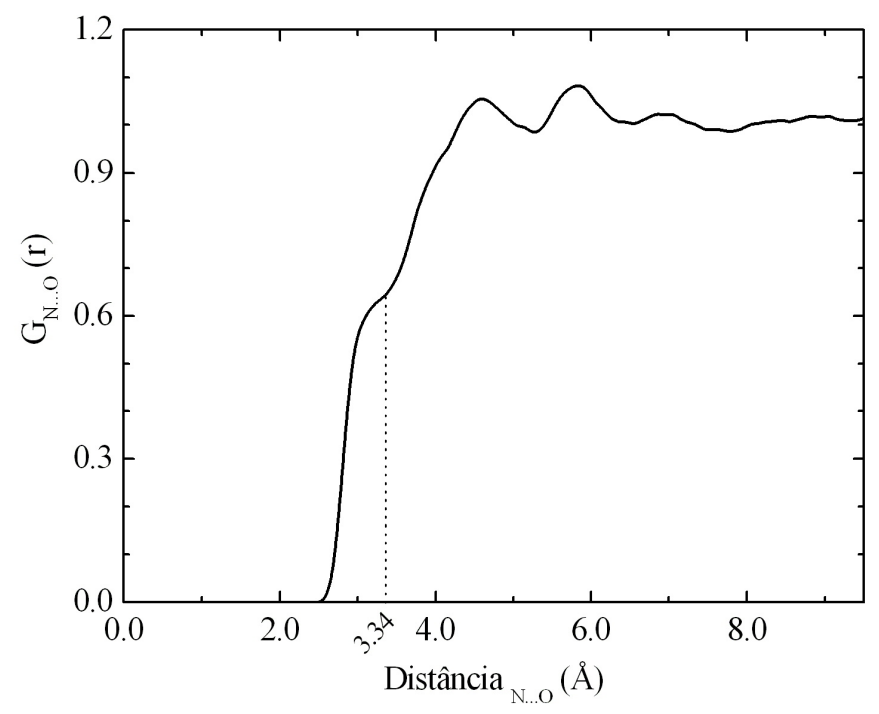

Figura 4.7: Função de distribuição radial determinada pelo átomo de nitrogênio da molécula de pirazina e átomos de hidrogênio das moléculas de água.

Para obtermos as estruturas de fase líquida retiramos da simulação as estruturas contendo ligações do hidrogênio, selecionando-as no líquido através de critérios geométricos e energéticos [144] especificamente determinados para cada sistema. Estes critérios possibilitam a seleção de agregados do líquido, onde a molécula de pirazina forma ligações de hidrogênio diretamente com as moléculas de água do solvente. Neste ponto, é importante ressaltar a existência de diversas dificuldades envolvendo a identificação de estruturas que formam ligações do hidrogênio em sistemas líquidos. Isso se deve ao fato de que um líquido contém um número muito grande de conformações estruturais possíveis a uma dada temperatura. A identificação das ligações do hidrogênio formadas no sistema líquido é, portanto, um ponto muito importante neste estudo, e será feita através do uso de parâmetros geométricos e energéticos determinados pela estrutura do líquido. 
A função de distribuição radial determinada pelo átomo de nitrogênio da pirazina e de oxigênio da água, $G_{N \ldots O}(r)$, nos fornece um dos parâmetros geométricos que compõe os critérios de ligação de hidrogênio. A figura $4.7, G_{N \ldots O}(r)$, nos mostra uma discreta elevação entre 2,55 e $3,35 \AA$ que sugere que esta distância $R_{N \ldots O}$ de $3,5 \AA$ como distância máxima para formação das ligações de hidrogênio entre pirazina e água.

Se analisarmos o gráfico da figura 4.8 podemos ver que só distância $\mathrm{R}_{N \ldots O}$ definida na $G_{N \ldots O}(r)$ é insuficiente como critério para formação de ligação de hidrogênio, pois podemos ver uma grande quantidade de agregados que respeitam o critério de distância mas não caracterizam a formação de ligação de hidrogênio devido ao fato de que suas energias clássicas de interação são positivas. Se fizermos um corte como o mostrado no gráfico 4.8 em $\mathrm{R}_{N \cdots O}=3,5 \AA$ e em $E=-2,5 \mathrm{kcal} / \mathrm{mol}$, definimos uma região interna ao corte em que todos as estruturas respeitam a distância definida pela $G_{N \ldots O}(r)$ e ao mesmo tempo apresentam energia de interação condizentes com o esperado para um agregado onde as moléculas estão interagindo por forças fracas tipo de van der Waals.

Adicionalmente, devemos levar em consideração a distribuição angular que as moléculas de água estão assumindo em torno da molécula de pirazina, uma vez que, mesmo selecionando as distâncias e energias que caracterizam ligações de hidrogênio, podemos estar tomando estruturas nas quais o ângulo $\mathrm{N} \cdots \mathrm{OH}$ não apresenta caráter direcional típico em ligações de hidrogênio [138]. Neste contexto, a figura 4.9 mostra a distribuição angular, $\theta_{N \cdots O H}$, das estruturas do líquido molecular, onde as estruturas tomadas já respeitam os critérios de distância e energia, definidos anteriormente. Analisando este gráfico, vemos que a maior ocorrência do ângulo $\theta_{N \cdots O H}$, primeiro pico do gráfico, está entre entre 0 e $\sim 45^{\circ}$. Esta análise angular, conclui a determinação dos critérios geométricos e energéticos de formação de ligação de hidrogênio no líquido molecular pirazina-água 1:400.

Assim, os critérios determinados são: distância $\mathrm{R}_{N \cdots O} \leq 3,5 \AA$ $\mathrm{E}_{\text {lig }} \geq 2,5 \mathrm{kcal} / \mathrm{mol}$ e $\theta_{N \cdots O H} \leq 45^{\circ}$. A figura 4.10 mostra a superposição de 


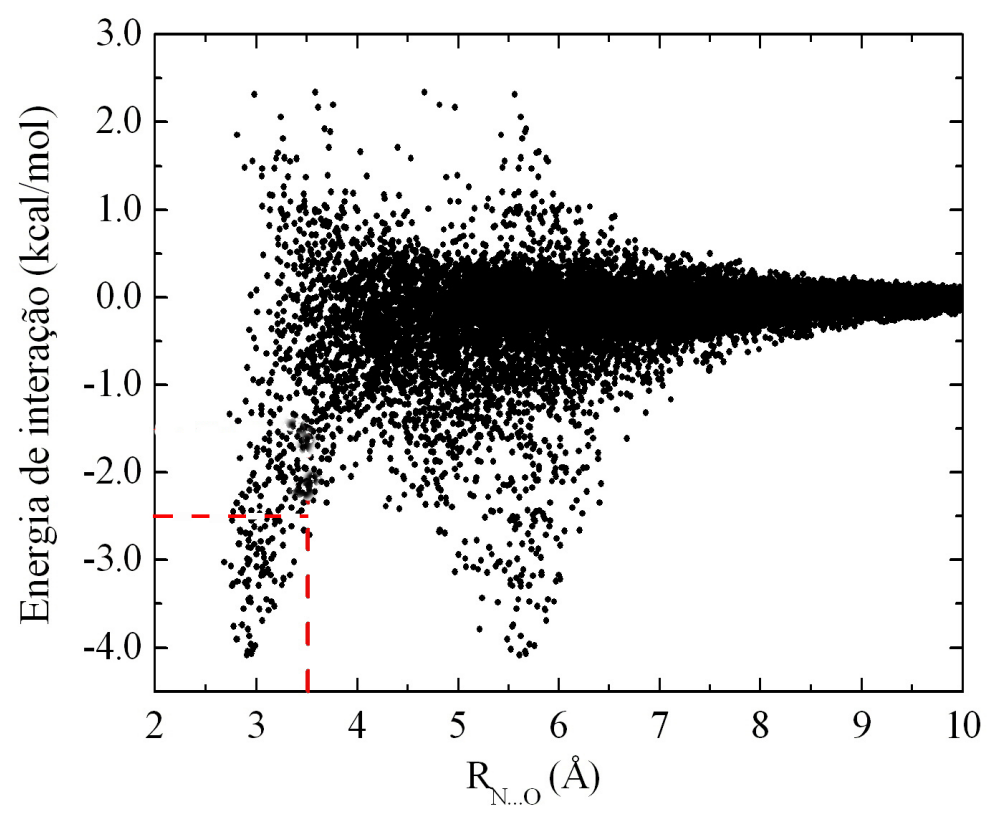

Figura 4.8: Distribuição energética das estruturas do líquido de pirazina e água. As linhas tracejadas delimitam a distância e a energia máximas que caracterizam a formação de ligação de hidrogênio no líquido.

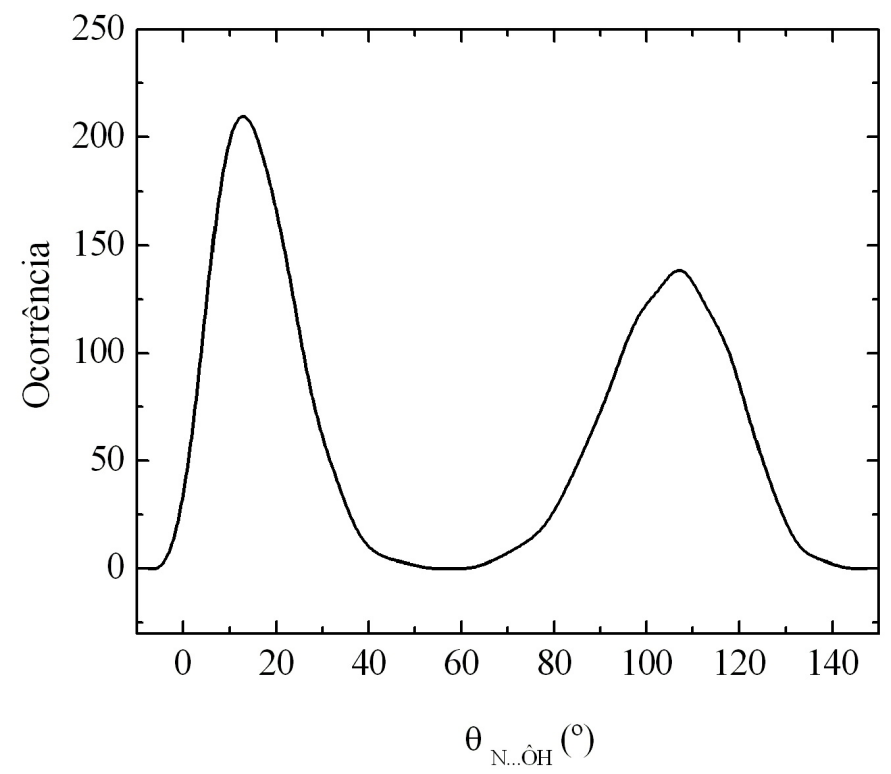

Figura 4.9: Distribuição do ângulo N ‥ OH nas estruturas de agregados do líquido com $\mathrm{R}_{N \cdots O} \leq 3,5 \AA$ e $\mathrm{E}_{l i g} \geq 2,5 \mathrm{kcal} / \mathrm{mol}$. 
todas as estruturas determinados através da aplicação destes critérios sobre as estruturas com baixa correlação estatística do líquido.

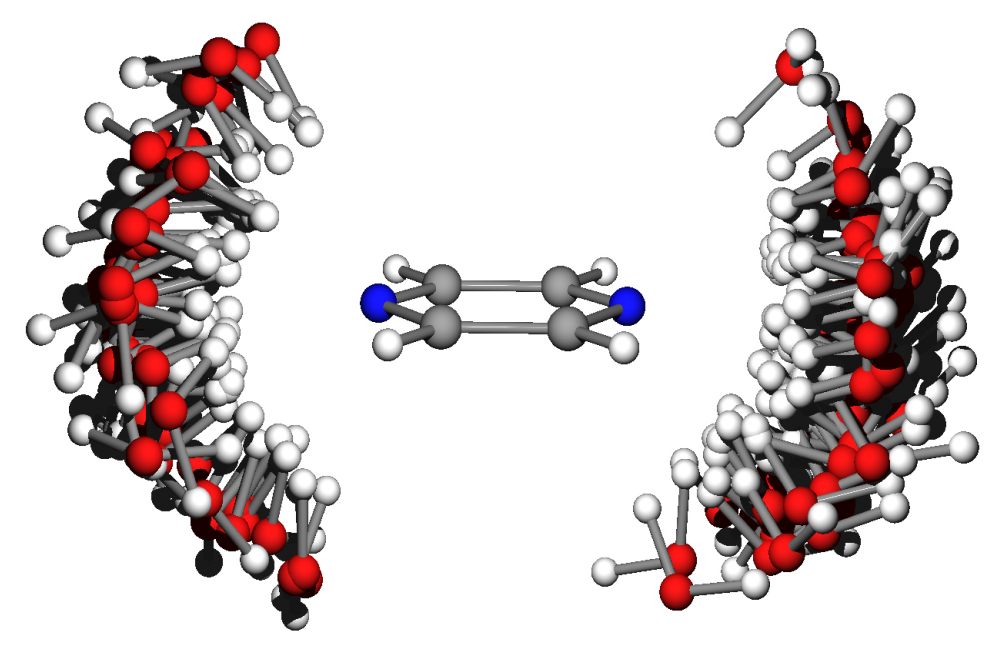

Figura 4.10: Superposição de todas as estruturas que apresentam ligação de hidrogênio no líquido pirazina-água.

Aplicando estes critérios para formação de ligação de hidrogênio no líquido molecular sobre as 142 estruturas supermoleculares separadas pelo intervalo de correlação estatística, obtivemos a estatística de ligação de hidrogênio apresentada na tabela 4.8. Como a molécula de pirazina tem dois átomos de nitrogênio em posições simétricas, podemos fazer distinção entre as ligações de hidrogênio que são formadas simultaneamente nos dois átomos de nitrogênio e aquelas que são formadas separadamente em cada átomo.

\begin{tabular}{cccccc}
\hline \hline & 0 LH & 1 LH & 2 LH & 3 LH & LH/configuração \\
\hline $\mathrm{N}_{1}$ ou $\mathrm{N}_{4}$ & 74 & 64 & 4 & 0 & 0,50 \\
$\mathrm{~N}_{1}$ e $\mathrm{N}_{4}$ & 39 & 67 & 33 & 3 & 1,0 \\
\hline \hline
\end{tabular}

Tabela 4.8: Estatística de ligações de hidrogênio (LH) formadas no líquido pirazina-água $1: 400$.

Para as duas situações, podemos observar uma ocorrência significa- 
tiva de configurações que não apresentam nenhuma ligação de hidrogênio. Na situação em que $\mathrm{N}_{1}$ ou $\mathrm{N}_{4}$ é o único aceitador de ligação de hidrogênio, obtivemos uma ocorrência expressiva de configurações com somente uma ligação de hidrogênio, $\sim 45 \%$ das configurações. O número de configurações onde aparecem duas e três ligações de hidrogênio com $\mathrm{N}_{1}$ ou $\mathrm{N}_{4}$ como aceitador de prótons é estatisticamente inexpressiva.

Quando consideramos a possibilidade de formar ligação de hidrogênio simultaneamente nos dois átomos de nitrogênio da molécula de pirazina, a estatística obtida é um pouco diferente da anterior. Novamente observamos, que no líquido existe uma preferência para formação de estruturas com uma única ligação de hidrogênio, cerca de $47 \%$ das configurações. Para formação de três ligações de hidrogênio, não observamos uma amostragem significativa já que somente $2 \%$ das 142 configurações apresentaram a formação de 3 ligações de hidrogênio.

Analisando mais detalhadamente a estatística de duas ligações de hidrogênio no líquido, podemos ver que o número de configurações aumenta expressivamente quando os dois átomos de nitrogênio estão simultaneamente disponíveis para aceitar prótons. Este aumento na formação de duas ligações de hidrogênio de $20 \%$ ( $3 \%$ quando $\mathrm{N}_{1}$ ou $\mathrm{N}_{4}$ é o aceitador de LH para $23 \%$ quando $\mathrm{N}_{1}$ e $\mathrm{N}_{4}$ são simultaneamente aceitadores de LH) pode ser explicado pela presença simultânea de dois sítios aceitadores de prótons. Quando impomos que somente um dos dois átomos de nitrogênio aceite prótons para formar duas ligações de hidrogênio nas estruturas, estamos impondo que o nitrogênio compartilhe com os hidrogênios da água mais que um elétron, o que não é energeticamante favorável e explica porque observamos somente $3 \%$ das estruturas apresentando duas ligações de hidrogênio quando $\mathrm{N}_{1}$ ou $\mathrm{N}_{4}$ é o aceitador de LH. Em contrapartida, quando permitimos que os dois átomos de nitrogênio, simultaneamente, aceitem prótons das moléculas de água no líquido, podemos esperar um aumento na estatística de formação de ligação de hidrogênio, por dois motivos: primeiro é óbvio que se aumentamos a quantidade de sítios aceitadores de ligação de hidrogênio, observaremos uma maior quantidade de ligações se formando. Mas pensando desta forma, este aumento deveria ser linear, pas- 
sando de $3 \%$ para $6 \%$ do número total de configurações. Porém, observamos um aumento de $20 \%$ do número de configurações formando duas ligações de hidrogênio, de $3 \%$ para $23 \%$. Acreditamos que este aumento no número de configurações formando duas ligações de hidrogênio seja devido ao efeito cooperativo [138], onde a tendência observada é a formação de mais que uma ligação de hidrogênio em cada estrutura, o que para o sistema pirazina-água pode ser traduzido como uma ligação de hidrogênio em cada sítio aceitador da pirazina.

As estruturas com ligação de hidrogênio foram submetidas ao procedimento S-MC/QM [39,148,211]. Através de cálculos quânticos ab initio em nível MP2/6-31+G(d), as propriedades eletrônicas como energia da ligação de hidrogênio, momento de dipolo, cooperatividade e energia de interação de muitos corpos foram obtidas tanto para os agregados em fase gasosa quanto para as estruturas em fase líquida. Analisamos e comparamos estas propriedades eletrônicas obtidas para as estruturas nas duas fases, líquida e gasosa. Todos os cálculos quânticos foram feitos com o programa Gaussian 98 [212] e a simulação Monte Carlo com o programa DICE [71]. A escolha do método quântico para tratamento dos sistemas foi feita devido ao fato de que MP2 é um dos modelos teóricos confiáveis para estudos da ligação de hidrogênio [153,213].

\subsubsection{Estrutura 1:1, Gás e Líquido}

Nesta seção tratamos as estruturas de pirazina e água formadas por uma molécula de água e uma molécula de pirazina (1:1), obtidas nas fases líquida e gasosa. Um dos agregados que obtivemos em fase gasosa foi observado experimentalmente por Caminati et al [171] e mostra a molécula de água no mesmo plano do anel aromático, a qual chamamos daqui por diante de agregado 1:1A.

O segundo agregado formado por uma molécula de pirazina e uma molécula de água, agregado 1:1B, mostra a água fazendo ligações do hidrogênio simultaneamente com os dois átomos do nitrogênio do anel. Nesta estrutura a molécula de água assume uma posição fixa com o hidrogênio da água que aponta para os átomos de nitrogênio da molécula de pirazina. Obtivemos estes dois 

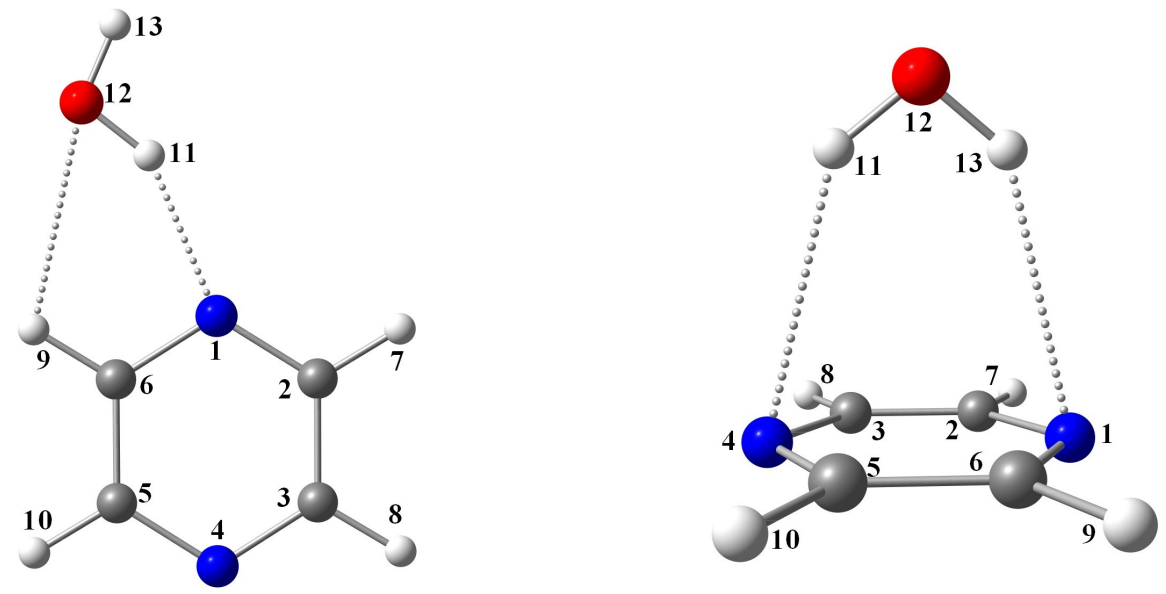

Figura 4.11: Da esquerda para a direita, estruturas otimizadas em nível MP2/aug-cc-pVDZ dos agregados pirazina-água, planar, agregado 1:1A e não-planar, agregado 1:1B.

agregados através de otimização de geometria em nível MP2/aug-cc-pVDZ. A figura 4.11 ilustra estas duas estruturas otimizadas e a tabela 4.9 apresenta os parâmetros geométricos mais importantes das duas estruturas 1:1 do agregado pirazina-água obtidos em fase gasosa [152].

Para o agregado 1:1A (planar), a distância experimental $\mathrm{N}_{4} \cdots \mathrm{H}_{11}$ da ligação do hidrogênio é de $(1,94 \pm 0,02) \AA$, que concorda muito bem com a distância que obtivemos em nossos cálculos quânticos de 1,98 $\AA$. O parâmetro geométrico mais característico desta estrutura é o ângulo $\mathrm{N}_{4} \cdots \mathrm{H}_{11}-\mathrm{O}_{12}$. Este ângulo foi obtido experimentalmente [171] como $(152 \pm 4)^{\circ}$, e em nosso cálculo obtivemos o valor de $151^{\circ}$, novamente em bom acordo. A planaridade desta estrutura é confirmada atraves do ângulo diedral $\mathrm{C}_{6} \mathrm{~N}_{1} \mathrm{O}_{12} \mathrm{H}_{13}$, que pode ser visto na tabela 4.9. Nesta tabela mostramos também a distância que o oxigênio da água faz com o hidrogênio do anel, de 2,638 $\AA$. Através da análise desta distância podemos supor a existência de uma interação entre os átomos de oxigênio da água e o hidrogênio da pirazina. Analisando a distribuição de cargas de Mülliken das moléculas de pirazina e água isoladas e comparando com as cargas no agregado pirazina-água vemos que existem variações significativas nas cargas do oxigênio da água, assim como do hidrogênio e do carbono da pirazina 
envolvidos nesta interação. Esta variação de carga aliada à pequena distância $\mathrm{O}_{12} \mathrm{H}_{7}$ são fortes indicativos de que o átomo de oxigênio está interagindo com a molécula de pirazina. Este tipo de conformação com uma segunda ligação de hidrogênio entre as mesmas moléculas foi observado também em agregados de formaldeído e água [47, 49], formaldeído e ácido fluorídrico [42]. Com isso explicamos também o porquê da ligação de hidrogênio $\mathrm{N}_{4} \mathrm{H}_{11}$ não ter o caráter direcional que comumente é observado neste tipo de interação [138, 144].

\begin{tabular}{ccc}
\hline \hline Distância [ $\AA$ ] & $1: 1 \mathrm{~A}$ & $1: 1 \mathrm{~B}$ \\
\hline $\mathrm{R}\left(\mathrm{N}_{1} \cdots \mathrm{H}_{11}\right)$ & 1,978 & 2,712 \\
$\mathrm{R}\left(\mathrm{H}_{9} \cdots \mathrm{O}_{12}\right)$ & 2,638 & - \\
$\mathrm{R}\left(\mathrm{O}_{12}-\mathrm{H}_{11}\right)$ & 0,976 & 0,967 \\
$\mathrm{R}\left(\mathrm{O}_{12}-\mathrm{H}_{13}\right)$ & 0,964 & 0,967 \\
$\left.\hat{\text { Angulos [ }}{ }^{\circ}\right]$ & & \\
\hline$\theta\left(\mathrm{H}_{11} \mathrm{O}_{12} \mathrm{H}_{13}\right)$ & 104,8 & 103,4 \\
$\theta\left(\mathrm{N}_{1} \cdots \mathrm{H}_{11} \mathrm{O}_{12}\right)$ & 150,9 & 142,6 \\
$\theta\left(\mathrm{C}_{6} \mathrm{~N}_{1} \cdots \mathrm{O}_{12} \mathrm{H}_{13}\right)$ & 180,0 & 120,1 \\
\hline \hline
\end{tabular}

Tabela 4.9: Parâmetros geométricos obtidos para os dois agregados de pirazina-água (1:1A e 1:1B segundo a figura 4.11) em nível MP2/aug-cc-pVDZ.

Na estrutura 1:1B que é a estrutura onde a molécula de água está localizada acima do plano do anel aromático, os átomos de hidrogênio da água apontam para os sítios dos nitrogênios da molécula de pirazina, e não para a nuvem $\pi$ do anel como acontece com a ligação de hidrogênio presente no sistema benzeno-água [174]. O fato dos hidrogênios apontarem para os nitrogênios impede o movimento livre de rotação da molécula de água sobre o anel, como acontece no caso benzeno-água [174,204,214,215].

A figura 4.12 mostra a variação da energia do sistema devido à rotação da molécula de água em torno da linha central que bisecciona o ângulo $\mathrm{HOH}$ da molécula de água passando pelo centro de massa da molécula de pirazina. Obtivemos esta figura realizando cálculos pontuais em nível MP2/6$31+G(d)$, onde a energia de referência utilizada no gráfico foi a que obtivemos anteriormente para a posição de equilíbrio, com $\mathrm{N} \cdots \mathrm{HOH} \cdots \mathrm{N}=0^{\circ}$. Através deste gráfico podemos observar claramente um mínimo de energia na posição de $\mathrm{N} \cdots \mathrm{HOH} \cdots \mathrm{N}$ otimizada e com isso, confirmamos que a molécula de água 


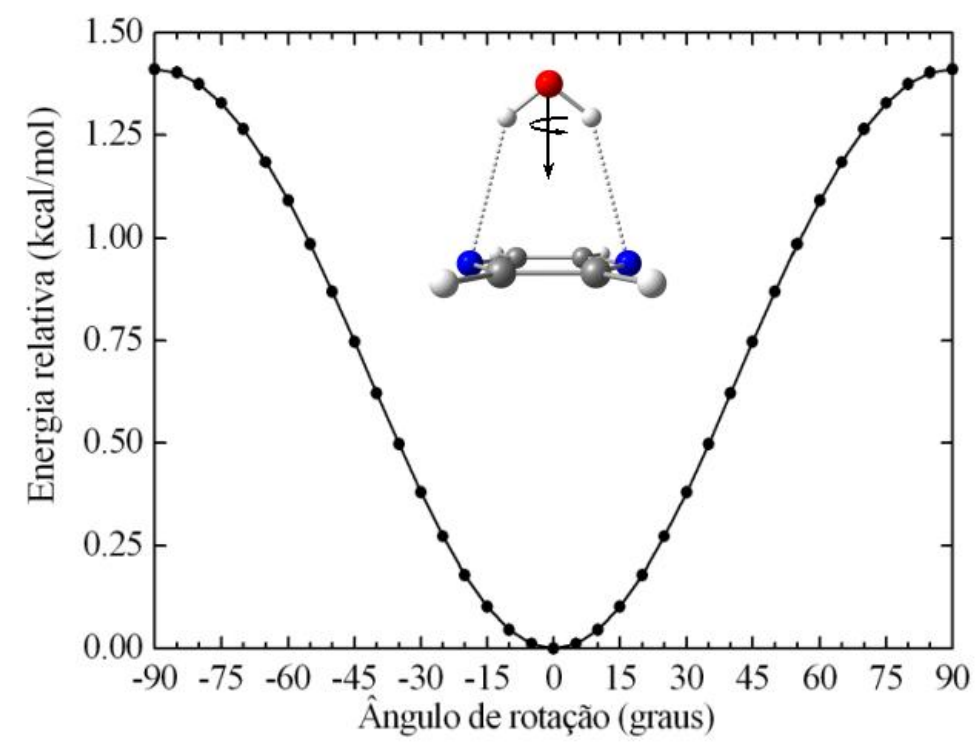

Figura 4.12: Energia relativa, em kcal/mol, calculada em nível MP2/6-31+G(d) referente a rotação da molécula de água sobre o anel.

deste agregado assume uma posição fixa sobre o anel da pirazina. Ainda sobre a estrutura 1:1B, obtivemos a distância da ligação do hidrogênio $\mathrm{N}_{4} \mathrm{H}_{11}$ de 2,712 $\AA$ e a distância do oxigênio da água ao centro do anel aromático de $3,226 \AA$. No caso do agregado benzeno-água, a distância ao centro do anel é de 3,211 $\AA$ [215], o que concorda com o valor similar obtido no agregado 1:1B.

\begin{tabular}{|c|c|c|}
\hline Aceitador na LH & $\mathbf{N}_{1}$ ou $\mathbf{N}_{4}$ & $\mathbf{N}_{1}$ e $\mathbf{N}_{4}$ \\
\hline $\mathbf{R}(\mathbf{N} \cdots \mathbf{H})$ & $\langle 2,050 \pm 0,158\rangle_{124}$ & $\langle 2,074 \pm 0,170\rangle_{67}$ \\
\hline $\mathbf{R}(\mathbf{H} \cdots \mathbf{O H})$ & $\langle 3,361 \pm 0,291\rangle_{124}$ & $\langle 3,362 \pm 0,282\rangle_{67}$ \\
\hline$\theta(\mathbf{N} \cdots \mathbf{O H})$ & $\langle 16,4 \pm 8,0\rangle_{124}$ & $\langle 16,4 \pm 8,1\rangle_{67}$ \\
\hline
\end{tabular}

Tabela 4.10: Distâncias, em angstrom, e ângulos, em grau, obtidos para os agregados 1:1 de pirazina-água do líquido obtidos em nível MP2/6-31+G(d). As incertezas são o desvio padrão das médias. Os subíndices nos valores médios indicam o número de configurações utilizados na obtenção do valor médio.

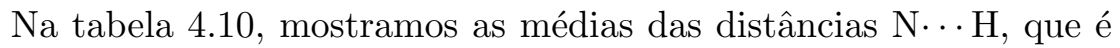
a distância da ligação de hidrogênio pirazina-água, $\mathrm{H} \cdots \mathrm{O}$ que é a distância obtida entre $\mathrm{H}_{9}$ da pirazina e o oxigênio da água e também mostramos o valor médio do ângulo $\mathrm{N} \cdots \mathrm{OH}$, todos obtidos das 67 estruturas pirazina-água 1:1 
formadas no líquido molecular. Para as duas situações em que os átomos de nitrogênio podem ser aceitadores de próton na ligação de hidrogênio, separada ou simultaneamente. Obtivemos os mesmos valores de distâncias e ângulos, se levarmos em conta o desvio padrão das médias. Vemos que a distância $\mathrm{N} \cdots \mathrm{H}$ obtida no líquido mostra uma variação de no máximo $4 \%$ quando comparamos àquela obtida no agregado 1:1A, que é de $1,978 \AA$. Como estamos comparando grandezas obtidas em fase líquida e em fase gasosa, consideramos esta como sendo uma variação menor que a esperada. Para a distância $\mathrm{H}$.. O também observamos um aumento de $21 \%$ quando comparamos o valor médio obtido das estruturas do líquido com o valor de $2,638 \AA$ obtido para o aglomerado 1:1A. A ocorrência de aumento das distâncias da ligação de hidrogênio em estruturas do líquido quando comparados com agregados otimizados era esperada e já havia sido observada para o caso das estruturas piridina-água [144]. Analisando o ângulo $\mathrm{N} \cdots \mathrm{OH}$, podemos constatar uma diminuição em seu valor médio, se comparado aos valores obtidos nos agregados otimizados com os valores das estruturas do líquido. Também observamos que, os valores médios do ângulo $\mathrm{N}$... OH obtidos no líquido encontram-se no intervalo que vai de $8,4^{\circ}$ a $24,4^{\circ}$. Esta variação no valor do ângulo $\mathrm{N}$... OH é atribuída à flutuação térmica e está presente em todos os sistemas líquidos.

\subsubsection{Estrutura 1:2, Gás e Líquido}

Obtivemos o agregado formado por uma molécula de pirazina e duas moléculas de água através de otimização de geometria em nível MP2/aug-cc-pVDZ. Neste agregado (1:2), as moléculas de água encontram-se no mesmo plano do anel, formando uma estrutura de simetria $\mathrm{D}_{2 h}$, como pode ser visto na figura 4.13.

Para podermos fazer uma comparação direta dos valores de distâncias e ângulos obtidos nas fases líquida e gasosa, realizamos uma inspeção individual nas 33 configurações de estruturas com uma molécula de pirazina e duas moléculas de água (1:2) obtidas em fase líquida. Através desta inspeção, vimos que 28 destas 33 configurações apresentam uma molécula de água doando próton para cada nitrogênio da molécula do pirazina. Nas 5 configurações restantes as duas moléculas de água estão simultaneamente interagindo com o 


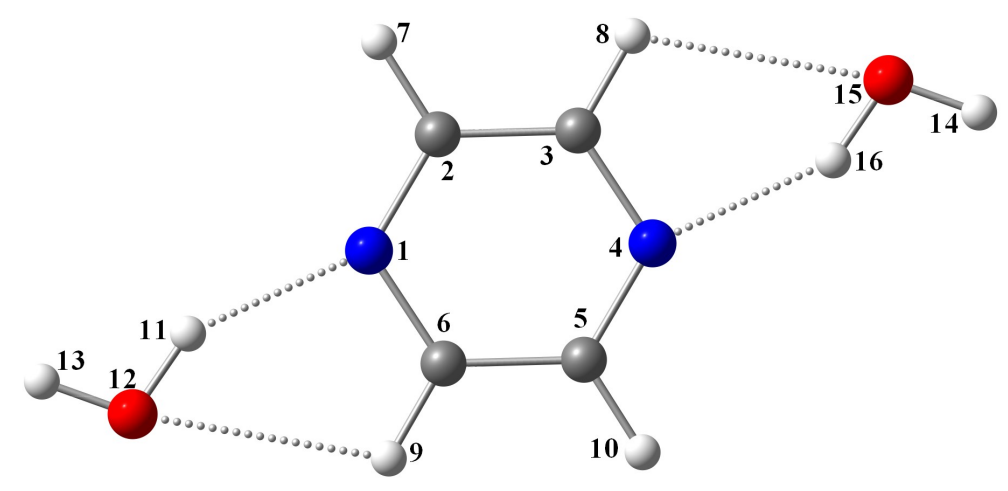

Figura 4.13: Estrutura otimizada em nível MP2/aug-cc-pVDZ do agregado pirazina-água $1: 2$.

mesmo nitrogênio da pirazina. Nas análises seguintes, consideramos somente aquelas 28 configurações onde as duas moléculas de água estão interagindo com nitrogênios distintos da pirazina.

Na tabela 4.11 mostramos os principais parâmetros geométricos dos agregados pirazina-água 1:2 obtidos em fase gasosa (otimizado) e em fase líquida. Para as distâncias e ângulos obtidos em fase líquida, os números na tabela são valores médios obtidos sobre 28 configurações com duas ligações de hidrogênio cada uma, uma água em cada sítio de nitrogênio da pirazina. Os erros associados aos valores médios são o desvio padrão de cada média.

\begin{tabular}{ccc}
\hline \hline Distância [ $\AA$ ] & $(1: 2)_{\text {gasoso }}$ & $(1: 2)_{\text {líquido }}$ \\
\hline $\mathrm{R}\left(\mathrm{N}_{1} \cdots \mathrm{H}_{11}\right)$ & 1,990 & $\langle 2,070 \pm 0,188\rangle_{56}$ \\
$\mathrm{R}\left(\mathrm{O}_{12}-\mathrm{H}_{11}\right)$ & 0,976 & - \\
$\mathrm{R}\left(\mathrm{O}_{12}-\mathrm{H}_{13}\right)$ & 0,964 & - \\
$\mathrm{R}\left(\mathrm{O}_{12} \cdots \mathrm{H}_{9}\right)$ & 2,600 & $\langle 3,362 \pm 0,317\rangle_{56}$ \\
\hline$\left.\hat{\text { Angulos [o }}{ }^{\circ}\right]$ & & \\
\hline$\theta\left(\mathrm{H}_{11} \mathrm{O}_{12} \mathrm{H}_{13}\right)$ & 104,9 & - \\
$\theta\left(\mathrm{N}_{1} \cdots \mathrm{O}_{12} \mathrm{H}_{11}\right)$ & 20,8 & $\langle 16,6 \pm 8,1\rangle_{56}$ \\
$\theta\left(\mathrm{C}_{6} \mathrm{~N}_{1} \cdots \mathrm{O}_{12} \mathrm{H}_{13}\right)$ & 180,0 & - \\
\hline \hline
\end{tabular}

Tabela 4.11: Parâmetros geométricos obtidos para a estrutura pirazina-água 1:2 onde gasoso refere-se à estrutura otimizada em nível MP2/aug-cc-pVDZ e líquido refere-se a valores médios obtidos diretamente das estruturas do líquido.

Analisando os resultados da tabela 4.11 podemos observar que a distância da ligação de hidrogênio, $\mathrm{N}_{1} \cdots \mathrm{H}_{11}$, do agregado otimizado, 1, $990 \stackrel{A}{A}$, é 
ligeiramente maior, 0,6\%, que a mesma distância no agregado 1:1A, de 1,978 . Por outro lado, a distância $\mathrm{O}_{12} \cdots \mathrm{H}_{9}$ sofreu uma leve diminuição, cerca de 1,4\%, quando comparamos esta distância nos agregados planares $1: 1 \mathrm{~A}(2,638 \AA$ ) e 1:2 $(2,600 \AA)$. Devido a estas mudanças nas distâncias de interação do agregado pirazina-água 1:2, o ângulo $\mathrm{N}_{1} \cdots \mathrm{O}_{12} \mathrm{H}_{11}$ sofreu um ligeiro aumento, passando de $19,6^{\circ}$ no agregado $1: 1 \mathrm{~A}$ para $20,8^{\circ}$ no agregado $1: 2$. Observamos que as distâncias e ângulos das moléculas de água no agregado pirazina-água 1:2 não sofreram nenhuma modificação quando comparados ao agregado pirazina-água 1:1A. Assim como no agregado 1:1A, no agregado 1:2, fica clara a existência da interação entre os átomos de oxigênio da água e os hidrogênios ligados aos carbonos da molécula de pirazina.

\subsubsection{Propriedades Eletrônicas das Estruturas Pirazina-Água $1: 1$ e $1: 2$}

Para analisarmos o efeito cooperativo nas ligações de hidrogênio formadas entre as moléculas de pirazina e água, vamos nos concentrar em duas propriedades eletrônicas dos sistemas, o momento de dipolo e a energia de ligação. Para obtenção destas duas propriedades eletrônicas, realizamos cálculos quânticos pontuais em nível MP2/6-31+G(d) sobre as estruturas de mínima energia e sobre aquelas obtidas da simulação MC.

\begin{tabular}{cc}
\hline \hline Estruturas & $\mu$ \\
\hline $\mathbf{1 : 1 A}$ & 2,27 \\
$\mathbf{1 : 1 B}$ & 2,58 \\
$\mathbf{1 : 1}$ líquido & $\langle 2,60 \pm 0,24\rangle_{67}$ \\
$\mathbf{1 : 2}$ & 0,00 \\
$\mathbf{1 : 2}$ líquido & $\langle 2,06 \pm 1,23\rangle_{28}$ \\
\hline \hline
\end{tabular}

Tabela 4.12: Momentos de dipolo, $\mu$ em debye, calculados em nível MP2/6-31+G(d) das estruturas otimizadas e do líquido. As incertezas são o desvio padrão das médias e os números subscritos indicam o número de estruturas na média.

Na tabela 4.12 apresentamos os momentos de dipolo obtidos através de cálculos pontuais ab initio em nível MP2/6-31+G(d) para os três agregados otimizados em nível MP2/aug-cc-pVDZ, 1:1A, 1:1B e 1:2 e também para as estruturas com uma e duas moléculas de água interagindo com a molécula de 
pirazina, obtidos em fase líquida.

Para o agregado 1:1A obtivemos um momento de dipolo de 2,27 D e para o agregado 1:1B $\mu=2,58 \mathrm{D}$. Ambos os valores de $\mu$ estão próximos do momento de dipolo obtido em mesmo nível teórico para a molécula de água isolada que é de 2,35 D. As pequenas diferenças existentes entre os dipolos dos dois agregados 1:1A e 1:1B e o dipolo da água, 0,08D e 0,23 D, respectivamente, são atribuídas ao momento de dipolo induzido pela água na molécula de pirazina dos agregados. Observamos que o momento de dipolo do agregado 1:1B é cerca de $0,31 \mathrm{D}$ maior que o obtido no agregado 1:1A. Este aumento do momento de dipolo justifica-se pela distância $\mathrm{N} \cdots \mathrm{H}$ no agregado 1:1B ser maior que a mesma distância no agregado 1:1A e pela própria conformação do agregado 1:1B, com a água acima do anel, o que favorece o aparecimento de um dipolo maior neste agregado. A figura 4.14 mostra a distribuição do momento de dipolo calculado para as 67 estruturas pirazina-água 1:1 obtidas no líquido molecular. Embora as estruturas de líquido e de gás sejam distintas, o valor médio obtido para o dipolo das estruturas 1:1 do líquido está em boa concordância com os valores obtidos para os agregados isolados, como podemos ver na tabela 4.12.

Ainda na tabela 4.12, vemos que o dipolo do agregado 1:2 otimizado é nulo. Isto porque este agregado mantém os dipolos das duas moléculas de água em posições antiparalelas, fazendo com que o dipolo total do agregado 1:2 seja nulo. Já para as 28 estruturas 1:2 do líquido, vemos que o valor médio do $\mu=2,06 \pm 1,23 \mathrm{D}$ reflete a flutuação térmica presente no líquido molecular. As diferentes conformações espaciais assumidas pelas moléculas de água nas estruturas 1:2 do líquido, fazem com que o momento de dipolo total seja significativo quando comparado ao agregado otimizado que tem dipolo nulo.

Na tabela 4.13 apresentamos as energias de ligação das estruturas 1:1, $\Delta E_{2}$, e 1:2, $\Delta E_{3} \mathrm{em} \mathrm{kcal} / \mathrm{mol}$. Obtivemos estas energias realizando cálculos pontuais em nível MP2/6-31+G(d) sobre as estruturas do líquido e sobre as estruturas otimizadas em nível MP2/aug-cc-pVDZ. Todas as energias de ligação nesta tabela incluem a correção de counterpoise [139] para eliminação do erro de superposição de base de nossos resultados. Na figura 4.15 apresentamos a con- 


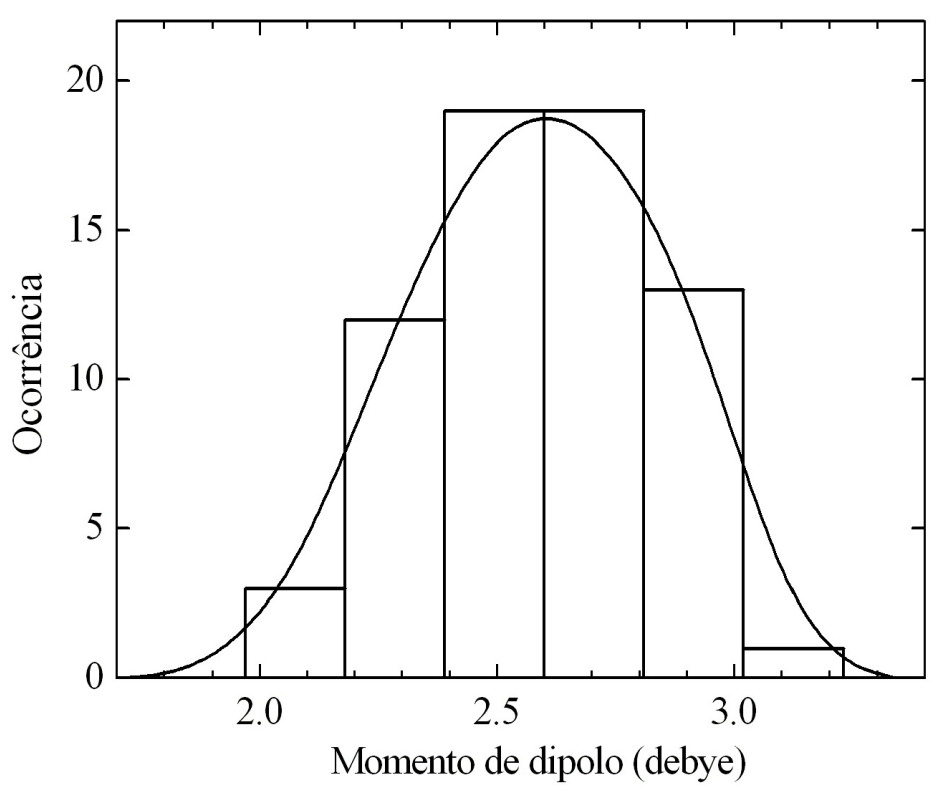

Figura 4.14: Histograma dos momentos de dipolo calculados em nível MP2/6-31+G(d) das 67 estruturas 1:1 do líquido.

\begin{tabular}{cc}
\hline \hline Estrutura & $\boldsymbol{\Delta} \mathbf{E}_{2}(\mathrm{kcal} / \mathbf{m o l})$ \\
\hline $\mathbf{1 : 1 A}$ & $-7,19$ \\
$\mathbf{1 : 1 B}$ & $-3,08$ \\
$\mathbf{1 : \mathbf { 1 } _ { \text { líquido } }}$ & $\langle-5,20 \pm 1,14\rangle_{67}$ \\
\hline & $\boldsymbol{\Delta} \mathbf{E}_{3}(\mathrm{kcal} / \mathbf{m o l})$ \\
\hline $\mathbf{1 : 2}$ & $-14,34$ \\
$\mathbf{1 : 2}$ & $\langle-9,74 \pm 1,65\rangle_{28}$ \\
\hline \hline
\end{tabular}

Tabela 4.13: Energias de ligação, calculadas em nível MP2/6-31+G(d) sobre as estruturas otimizadas e do líquido. As incertezas são o desvio padrão das médias e os subscritos indicam o número de estruturas na média. 

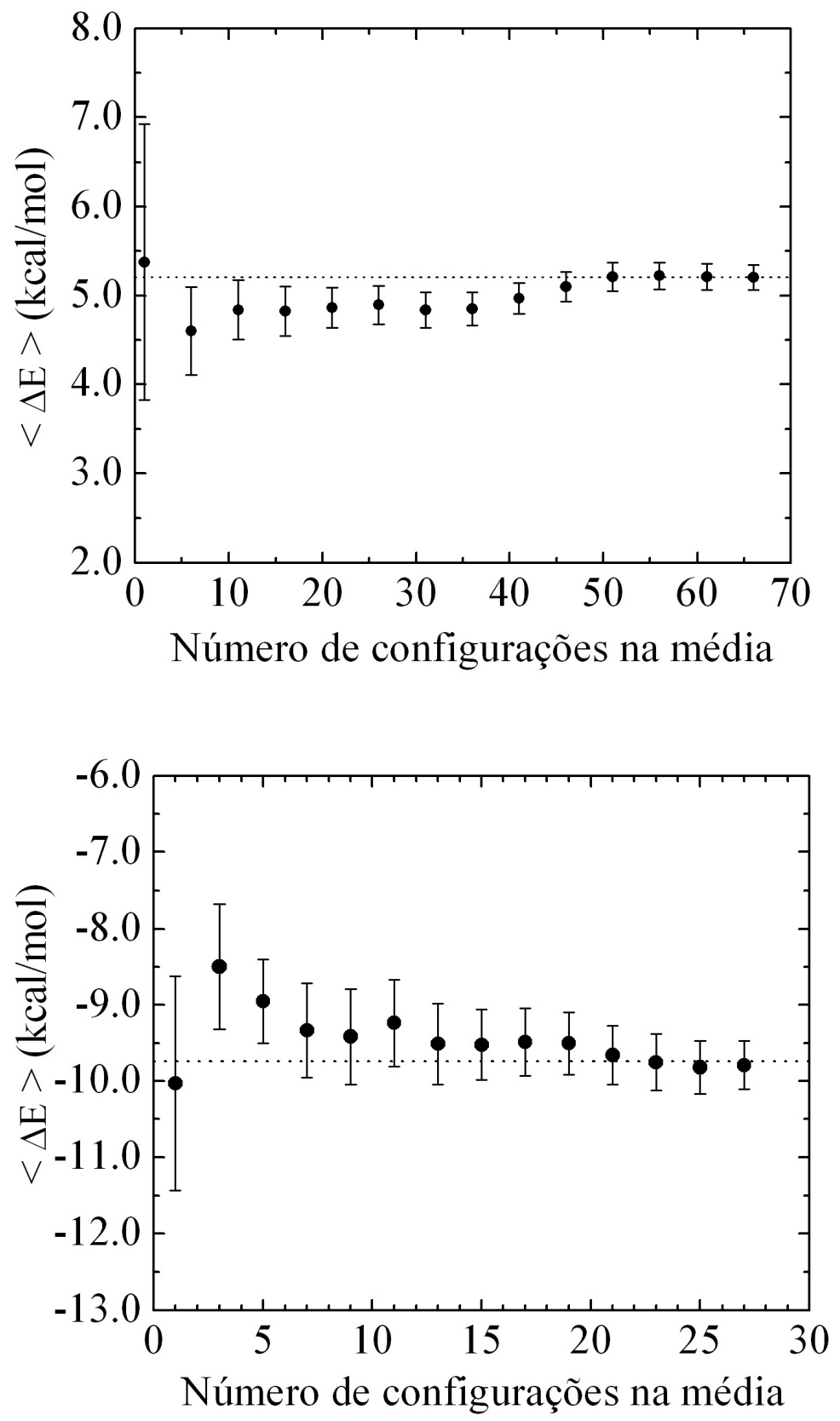

Figura 4.15: Convergência estatística das médias da energia de ligação obtidas das estruturas 1:1 (acima) e 1:2 (abaixo) do líquido. As barras de erro apresentadas correspondem ao erro estatístico presente nas médias. 
vergência estatística das médias das energias de ligação obtidas das estruturas 1:1 e 1:2 do líquido.

Analisando os resultados na tabela 4.13, vemos que no agregado 1:1A a molécula de água está mais fortemente ligada à pirazina que no agregado $1: 1 \mathrm{~B}$, por $\sim 4,11 \mathrm{kcal} / \mathrm{mol}$. No agregado 1:1A as moléculas de pirazina e água atuam tanto como doadoras quanto como aceitadoras de prótons. Já no agregado 1:1B a molécula de água atua somente como doadora e a molécula de pirazina somente como receptora de prótons. A dupla atuação das moléculas de água e pirazina como aceitadora e doadora de prótons no agregado 1:1A faz com que as moléculas se aproximem mais que no agregado 1:1B o que favorece que a energia de ligação do agregado 1:1A seja maior que no agregado 1:1B. Comparando a média da energia de ligação obtida para as 67 estruturas do líquido com a energia do agregado 1:1A, observamos que a energia de ligação obtida em fase gasosa é cerca de $28 \%$ maior que a obtida em fase líquida. Podemos fazer esta mesma comparação para as energias de ligação das estruturas pirazina-água 1:2 e observamos que, novamente, o agregado obtido em fase gasosa mostra-se mais estável que as estruturas do líquido por aproximadamente $4,6 \mathrm{kcal} / \mathrm{mol}$, o que equivale a $32 \%$ da energia de interação do agregado $1: 2$ isolado.

Esta relação entre as energias de fase líquida e gasosa já havia sido observada anteriormente para o sistema piridina-água [144], onde a magnitude da energia obtida em fase líquida é $\sim 1 / 3$ menor que a energia de ligação obtida em fase gasosa. Esta situação pode ser explicada pelo fato de que em fase gasosa as interações entre as moléculas de pirazina e água tornam-se mais fortes porque elas estão isoladas do meio e só podem interagir entre si. Em fase líquida o que acontece é que existe uma rede de moléculas de água doando e aceitando prótons simultaneamente entre si e com a molécula de pirazina, o que acaba por enfraquecer as interações específicas entre as moléculas de água que estão formando ligação de hidrogênio com a pirazina. Isso corrobora o fato de que as situações encontradas em fase líquida e gasosa para um mesmo sistema molecular são distintas. 
Outra análise que podemos fazer com os dados da tabela 4.13 é sobre a cooperatividade na ligação de hidrogênio. Avaliando os agregados gasosos, vemos que do agregado 1:2 para o agregado 1:1A a anti-cooperatividade é de $0,04 \mathrm{kcal} / \mathrm{mol}$. Fazendo o mesmo cálculo para as estruturas 1:2 e 1:1 do líquido obtemos uma anti-cooperatividade de 0,66 kcal/mol. Embora a fórmula $\Delta E_{3}-2 \Delta E_{2}$ nos forneça um número para quantificar a capacidade de formação de ligações de hidrogênio subsequentes a primeira, em nosso sistema, o que observamos é somente uma tendência e não um efeito cooperativo ou anti-cooperativo propriamente dito, devido à pequena quantidade de moléculas que temos em nossas estruturas.

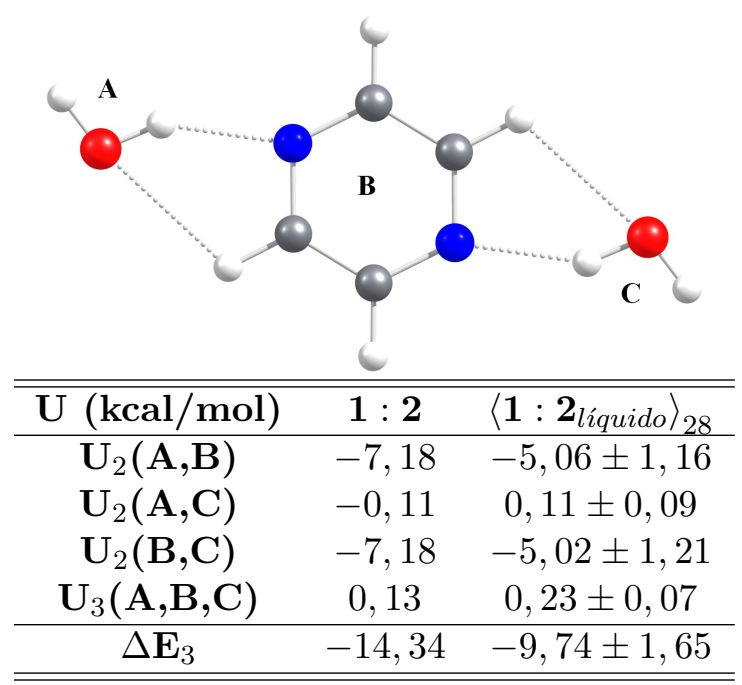

Tabela 4.14: Energias de interação de três e dois corpos para as estruturas pirazina-água 1:2 em fase gasosa e líquida. A figura acima identifica as moléculas A, B e C.

Na tabela 4.14 apresentamos as energias de interação de dois e três corpos para as estruturas pirazina-água 1:2 obtidos nas fases gasosa e líquida. De um modo geral, as energias de interação de dois corpos do agregado isolado mostram uma estabilidade energética maior que nas estruturas do líquido. As energias $U_{2}(\mathrm{~A}, \mathrm{~B})$ e $U_{2}(\mathrm{~B}, \mathrm{C})$ mostram-se cerca de $30 \%$ mais baixas para o agregado isolado que na média das estruturas do líquido. Já para a energia $U_{2}(\mathrm{~A}, \mathrm{C})$ que é a energia de interação das duas águas das estruturas 1:2, observamos que no agregado isolado ela assume um valor negativo de $-0,11 \mathrm{kcal} / \mathrm{mol}$. Este 
valor negativo de $U_{2}(\mathrm{~A}, \mathrm{C})$ nos diz que a presença de uma segunda molécula de água no agregado 1:2 isolado tende a estabilizar este agregado. Este mesmo comportamento não foi observado nas estruturas 1:2 do líquido, onde a $U_{2}(A, C)$ assume um valor positivo de $0,11 \mathrm{kcal} / \mathrm{mol}$, o que mostra que as duas moléculas de água tendem a aumentar a energia total das estruturas 1:2 em fase líquida. Embora as energias de interação do par água-água das estruturas 1:2 mostrem comportamentos distintos quando isolados ou em líquido, devemos lembrar que em módulo estas energias são muito pequenas e por isso contribuem muito pouco para a energia de interação total das estruturas. Este comportamento de energia de pares pequena para as moléculas mais distantes em agregados de três corpos foi observado também para o agregado $(H C N)_{3}[176]$.

Para as energias de interação de três corpos, $U_{3}(\mathrm{~A}, \mathrm{~B}, \mathrm{C})$, vemos que tanto no agregado gasoso quanto na média das estruturas do líquido, temos contribuições positivas que diferem entre si por $0,10 \mathrm{kcal} / \mathrm{mol}$. Porém, ainda observamos a tendência anterior de que no agregado isolado a energia de ligação seja mais alta em módulo que nas estruturas do líquido. Fazendo agora a soma das energias de interação de pares $U_{2}$ com a energia de interação de três corpos $U_{3}$, temos a energia de ligação total do sistema de três corpos, $\Delta E_{3}[138,176]$. Comparando os valores de $\Delta E_{3}$ para os agregados isolado e líquido, vemos novamente que o agregado 1:2 isolado é mais estável que as agregados do líquido por aproximadamente $4,60 \mathrm{kcal} / \mathrm{mol}$, o que corresponde a $32 \%$ da energia de ligação total do agregado 1:2 isolado.

\subsection{Formaldeído-Água: Agregados e Líquido}

Os compostos carbonílicos como acetona, acetaldeído e formaldeído são muito importantes em diversas áreas da química [60,146,216-218]. Especificamente, a molécula de formaldeído $\left(\mathrm{H}_{2} \mathrm{C}=\mathrm{O}\right)$ tem sido alvo de diversos estudos tanto teóricos quanto experimentais $[45,46,216,217,219-226]$. A atenção dedicada ao formaldeído é explicada por ser esta a menor molécula contendo um grupo carbonila $(\mathrm{C}=\mathrm{O})$, o que faz do formaldeído um ótimo protótipo para moléculas de grande porte que contenham o grupo carbonila e que sejam de difícil abor- 
dagem em tratamentos quânticos. Neste contexto, a interação do formaldeído com outras moléculas tem sido investigada [41-46]. Em particular, o agregado formaldeído-água tem recebido alguma atenção, já que este é o mais simples sistema envolvendo uma molécula do grupo carbonila e a água [43,44,47-49]. As modificações das propriedades eletrônicas do formaldeído devido às interações com as moléculas de água são de interesse tanto em agregados moleculares quanto em ambiente aquoso.

O aprimoramento das técnicas experimentais, o avanço computacional e o desenvolvimento de métodos ab initio atualmente são suficientemente capazes de predizer estrutura, energia e propriedades eletrônicas de moléculas isoladas com alto nível de precisão [218]. Devido à dificuldade em se tratar quanticamente os sistemas moleculares em fase líquida, diversos estudos são direcionados à investigação de sistemas microsolvatados [41-44] como uma tentativa de descrever o sistema em fase líquida. Outra tentativa de obter propriedades eletrônicas de líquidos moleculares vem sendo feita através do uso de modelos de solvente contínuo, onde as moléculas de solvente são substituídas por uma constante dielétrica e as mudanças devido ao solvente são observadas na molécula de soluto [36, 227, 228]. Embora estes dois tipos de tratamento, microsolvatação e solvente contínuo, sejam válidos a título de estimativa, eles não retratam de maneira realista as propriedades eletrônicas de um sistema em fase líquida. Hoje em dia, graças ao grande avanço computacional alcançado nos últimos anos, a inclusão de moléculas explícitas de solvente nos cálculos quânticos tornou-se não só possível como cada vez mais comum, embora ainda seja computacionalmente muito dispendioso. Tratamentos teóricos como Método Monte Carlo Quântico, Dinâmica Molecular Quântica e, especificamente, a metodologia S$\mathrm{MC} / \mathrm{MQ}$ tornam o tratamento eletrônico de sistemas em fase líquida cada vez mais realista.

Neste trabalho investigamos duas propriedades eletrônicas do formaldeído, a energia de ligação, momento de dipolo, energia de interação de muitos corpos e cooperatividade obtidos das estruturas formados com a água em fase gasosa. Também investigamos as modificações no espectro eletrônico do formaldeído devido à presença de água, tanto em agregados isolados quanto 
em ambiente aquoso.

Os agregados isolados foram obtidos através de otimização de geometria em nível MP2/aug-cc-pVDZ utilizando o programa Gaussian 03 [181]. Para o estudo do espectro eletrônico do formaldeído solvatado em água utilizamos o método S-MC/MQ $[39,40]$. Obtivemos primeiramente o líquido molecular via simulação Monte Carlo Metropolis implementado no programa DICE [71], selecionamos estruturas supermoleculares descorrelacionadas e submetemos estas estruturas a cálculos quânticos Time Dependent-DFT para obteção do espectro eletrônico do formaldeído solvatado, onde nosso interesse particular é a primeira transição eletrônica deste espectro, a transição $n \rightarrow \pi^{*}$.

\subsubsection{Ligação de Hidrogênio e Cooperatividade nos Agregados Formaldeído-Água}

Obtivemos em nível MP2/aug-cc-pVDZ três estruturas de mínima energia, um agregado formado por uma molécula de formaldeído e uma de água, agregado 1:1, e dois agregados formados por uma molécula de formaldeído e duas moléculas de água, 1:2A e 1:2B, figura 4.16. Nos três agregados obtidos, tanto a molécula de formaldeído quanto as moléculas de água recebem e doam prótons nas ligações de hidrogênio. Num trabalho recente, Karpfen e Kryachko [42] reportaram um estudo sobre agregados de formaldeído e fluoreto de hidrogênio, $\mathrm{H}_{2} \mathrm{CO} \cdots(\mathrm{HF})_{1 \leq n \leq 4}$, onde os agregados obtidos com uma e duas moléculas de HF são muito semelhantes a dois dos agregados de formaldeído-água que obtivemos em nosso estudo. Na tabela 4.15 apresentamos os principais parâmetros geométricos obtidos das otimizações de geometria.

No agregado 1:1 a molécula de formaldeído faz duas ligações de hidrogênio com a molécula de água, em uma ligação de hidrogênio atuando como aceitadora de próton, $\mathrm{O}_{1} \cdots \mathrm{H}_{5}$, e na outra doando próton, $\mathrm{H}_{4} \cdots \mathrm{O}_{6}$ formando uma estrutura $\mathrm{C}_{s}$ contida no plano do formaldeído. Este agregado foi obtido anteriormente por Ramelot e colaboradores [47] em nível CCSD/TZ2P+diff. Uma estrutura similar de $\mathrm{H}_{2} \mathrm{CO} \cdots \mathrm{HF}$ com a mesma simetria onde o formaldeído atua tanto como doador quanto aceitador de prótons também foi obtida por Karpfen e Kryachko [42]. 


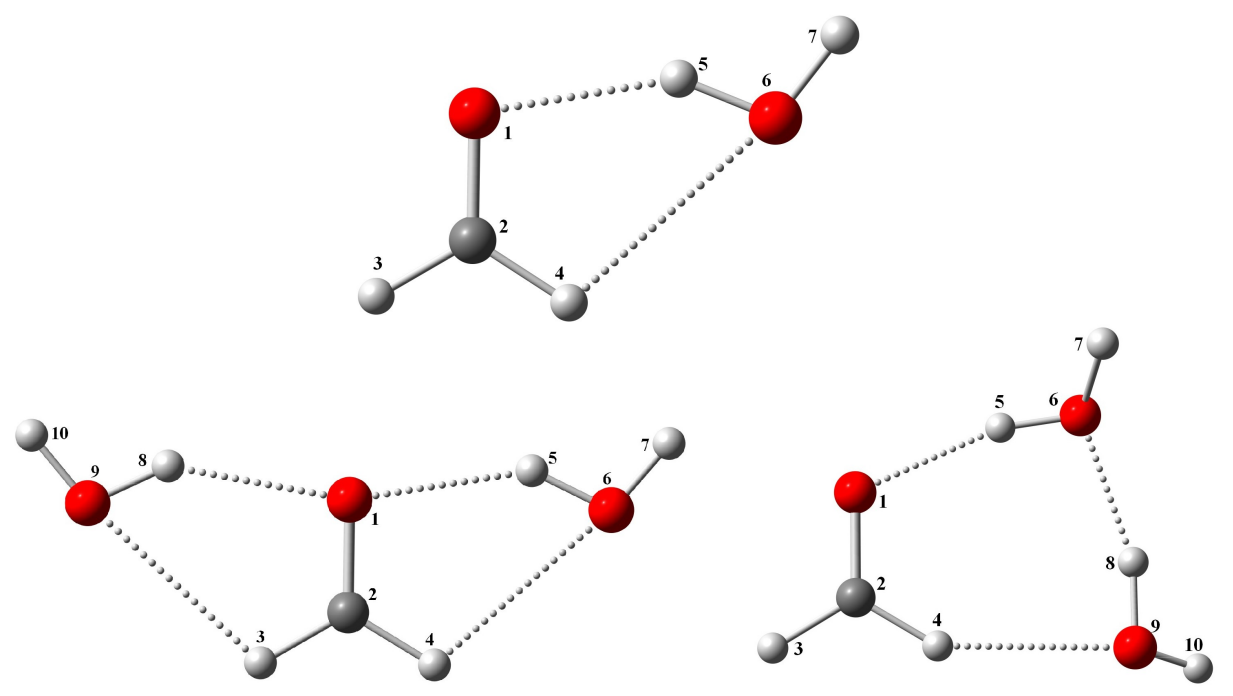

Figura 4.16: Agregados formaldeído-água otimizados em nível MP2-aug-cc-pVDZ. Acima, agregado 1:1, formaldeído e uma água interagindo por duas ligações de hidrogênio. Abaixo da esquerda para a direita, agregado 1:2A, formaldeído e duas águas interagindo por meio de quatro ligações de hidrogênio e agregado 1:2B, formaldeído e duas águas interagindo por meio de três ligações de hidrogênio.

\begin{tabular}{ccccc}
\hline \hline & isolada & $\mathbf{1 : 1}$ & $\mathbf{1 : 2 A}$ & $\mathbf{1 : 2 B}$ \\
\hline $\mathrm{R}\left(\mathrm{C}_{2}=\mathrm{O}_{1}\right)$ & 1,224 & 1,228 & 1,232 & 1,232 \\
$\mathrm{R}\left(\mathrm{C}_{2}-\mathrm{H}_{4}\right)$ & 1,112 & 1,108 & 1,106 & 1,107 \\
$\mathrm{R}\left(\mathrm{O}_{1} \cdots \mathrm{H}_{5}\right)$ & - & 1,987 & 2,021 & 1,880 \\
$\mathrm{R}\left(\mathrm{H}_{4} \cdots \mathrm{O}_{6 / 9}\right)$ & - & 2,619 & 2,575 & 2,272 \\
$\mathrm{R}\left(\mathrm{O}_{6} \cdots \mathrm{H}_{8}\right)$ & - & - & - & 1,866 \\
$\theta\left(\mathrm{O}_{1}=\mathrm{C}_{2}-\mathrm{H}_{4}\right)$ & 121,6 & 121,2 & 120,6 & 121,5 \\
$\theta\left(\mathrm{H}_{5}-\mathrm{O}_{6}-\mathrm{H}_{7}\right)$ & 103,9 & 104,7 & 104,8 & 104,8 \\
$\alpha\left(\mathrm{C}_{2}=\mathrm{O}_{1} \cdots \mathrm{H}_{5}-\mathrm{O}_{6}\right)$ & - & 0,0 & 0,0 & $-5,9$ \\
$\alpha\left(\mathrm{C}_{2}-\mathrm{H}_{4} \cdots \mathrm{O}_{6}-\mathrm{H}_{7}\right)$ & - & 0,0 & $-0,4$ & $-74,8$ \\
$\alpha\left(\mathrm{C}_{2}-\mathrm{H}_{4} \cdots \mathrm{O}_{9}-\mathrm{H}_{8}\right)$ & - & - & $-0,3$ & 10,8 \\
$\alpha\left(\mathrm{C}_{2}-\mathrm{H}_{4} \cdots \mathrm{O}_{9}-\mathrm{H}_{10}\right)$ & - & - & $-0,3$ & 128,3 \\
\hline \hline
\end{tabular}

Tabela 4.15: Distâncias em angstrom e ângulos em grau, obtidos em nível MP2/aug-ccpVDZ para as moléculas de formaldeído e água isoladas e para os agregados formaldeído-água $1: 1,1: 2 \mathrm{~A}$ e $1: 2 \mathrm{~B}$. 
Comparando as distâncias das ligações de hidrogênio obtidas aqui com as distâncias obtidas por Ramelot e colaboradores, vemos que existe uma concordância muito boa entre elas. Observamos uma diferença de menos de $1 \%$ no caso da distância $\mathrm{O}_{1} \cdots \mathrm{H}_{5}$ para a qual obtivemos o valor de $1,987 \AA$ e cerca de $3 \%$ para a distância $\mathrm{H}_{4} \cdots \mathrm{O}_{6}$ para a qual obtivemos o valor de 2,619 $\AA$. Comparando as distâncias $\mathrm{C}=\mathrm{O}$ obtidas para o formaldeído isolado e para o formaldeído no agregado 1:1, observamos que a ligação de hidrogênio formada entre os átomos $\mathrm{O}_{1} \cdots \mathrm{H}_{5}$ causa um alongamento da ligação $\mathrm{C}_{2}=\mathrm{O}_{1}$ de 0,004 $\AA$. Para a distância $\mathrm{C}_{2}-\mathrm{H}_{4}$, observamos um encurtamento de $0,004 \AA$ no formaldeído do agregado 1:1 quando comparado com o formaldeído isolado, essa diferença significa menos de $1 \%$ da ligação $\mathrm{C}-\mathrm{H}$ no formaldeído isolado. O ângulo $\mathrm{O}_{1} \mathrm{C}_{2} \mathrm{H}_{4}$ do formaldeído no agregado 1:1 também mostra uma pequena diminuição de $0,4^{\circ}$ quando comparado ao mesmo ângulo na molécula de formaldeído isolada. Este leve fechamento do ângulo $\mathrm{O}_{1} \mathrm{C}_{2} \mathrm{H}_{4}$ e o alongamento da distância $\mathrm{C}_{2}=\mathrm{O}_{1}$ mostram o efeito das ligações de hidrogênio formadas entre os átomos $\mathrm{O}_{1} \cdots \mathrm{H}_{5}$ e $\mathrm{H}_{4} \cdots \mathrm{O}_{6}$ obrigando a molécula de formaldeído a reestruturar sua geometria devido a presença da molécula de água no agregado 1:1. Adicionalmente a molécula de água também passa por uma reestruturação geométrica devido à presença do formaldeído no agregado formaldeído-água 1:1. Comparando a molécula de água no agregado 1:1 com a molécula de água obtida isoladamente no mesmo nível de cálculo, vimos que a distância $\mathrm{O}_{6} \mathrm{H}_{5}$ sofre um alongamento de 0,007 $\AA$ no agregado 1:1 e o ângulo $\mathrm{H}_{5} \mathrm{O}_{6} \mathrm{H}_{7}$ também aumenta cerca de $1^{o}$ no agregado formaldeído-água 1:1. Neste agregado as moléculas de formaldeído e água estão contidas no mesmo plano como pode ser visto através dos ângulos $\mathrm{C}_{2} \mathrm{O}_{1} \cdots \mathrm{H}_{5} \mathrm{O}_{6}$ e $\mathrm{C}_{2} \mathrm{H}_{4} \cdots \mathrm{O}_{6} \mathrm{H}_{7}$. A planaridade deste agregado é justificada pela interação dipolo-dipolo que ocorre entre as moléculas de formaldeído e água [48].

$\mathrm{O}$ agregado $1: 2 \mathrm{~A}$, figura 4.16, mantém a simetria $\mathrm{C}_{2 v}$ e a planaridade da molécula de formaldeído isolada. Neste agregado, a molécula de formaldeído faz com as duas moléculas de água um total de quatro ligações de hidrogênio, nas quais a molécula de formaldeído aceita, no átomo de oxigênio, dois prótons um de cada uma das moléculas de água, e cada uma das moléculas 
de água aceita um próton dos hidrogênios do formaldeído. Já no agregado 1:2B as moléculas de formaldeído e água também atuam como aceitadora e doadora de prótons, porém, em uma conformação cíclica onde as duas moléculas de água fazem uma ligação de hidrogênio entre si. Também para esta conformação, existe um agregado similar formado por um formaldeído e dois fluoretos de hidrogênio [42], porém neste agregado todas as moléculas estão contidas no mesmo plano atuando tanto como doadores como receptores de prótons. Esta conformação cíclica, de simetria $\mathrm{C}_{s}$ do agregado formaldeído-água 1:2B, obriga as as ligações $\mathrm{O}_{6}-\mathrm{H}_{7}$ e $\mathrm{O}_{9}-\mathrm{H}_{10}$ das moléculas de água a saírem do plano do formaldeído para que a ligação de hidrogênio $\mathrm{O}_{6} \cdots \mathrm{H}_{8}$ aconteça, privilegiando energeticamente a interação do par isolado de elétrons do oxigênios da água receptora com o hidrogênio da água doadora de próton. Observamos na tabela 4.15 que as distâncias $\mathrm{O}_{1}=\mathrm{C}_{2}$ e $\mathrm{C}_{2}-\mathrm{H}_{4}$ dos agregados 1:2A e 1:2B são praticamente iguais nos dois agregados e que, assim como ocorreu com o agregado 1:1, as ligações de hidrogênio $\mathrm{O}_{1} \cdots \mathrm{H}_{5}$ e $\mathrm{H}_{4} \cdots \mathrm{O}_{6}$ provocam o alongamento de 0,03 $\AA$ e de $\sim 0,01 \AA$ nas ligações covalentes $\mathrm{O}_{1}=\mathrm{C}_{2}$ e $\mathrm{C}_{2}-\mathrm{H}_{4}$, respectivamente. Comparando as distâncias das ligações de hidrogênio dos três agregados vemos que a menor distância de ligação $\mathrm{O}_{1} \cdots \mathrm{H}_{5}$ ocorre no agregado 1:2B, de 1,880 $\AA$. O agregado 1:1 apresenta um ligação de hidrogênio 5,7\% maior, enquanto que o agregado 1:2A, apresenta a mesma ligação 7,5\% maior, ambas comparadas ao agregado 1:2B. Fazendo a mesma análise para a ligação de hidrogênio $\mathrm{H}_{4} \cdots \mathrm{O}_{6}$ vemos que no agregado 1:2A, os átomos de oxigênio da água e hidrogênio do formaldeído estão 0,044 $\AA$ mais próximos que no agregado 1:1 onde esta distância é de $2,619 \AA$.

Analisando detalhadamente cada uma das ligações de hidrogênio do agregado 1:2B, vemos que estas são mais curtas que as ligações similares nos outros agregados. É esperado que em agregados cíclicos as distâncias de ligação de hidrogênio sejam mais curtas que em agregados onde todas as moléculas estejam contidas no mesmo plano [138]. Em outras palavras, a distorção angular sofrida pelas moléculas em um agregado cíclico, como o agregado 1:2B, é compensada por um encurtamento das ligações de hidrogênio [138]. Na situação em que o formaldeído é doador de hidrogênio no agregado 1:2B, a ligação $\mathrm{H}_{4} \cdots \mathrm{O}_{9}$, 


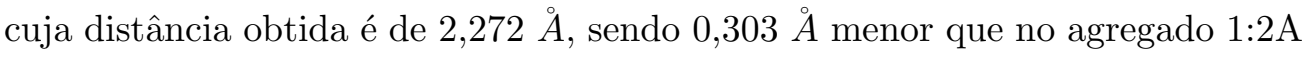
e 0,345 $\AA$ menor que no agregado 1:1. Vale ressaltar que embora nestes três agregados a molécula de formaldeído seja a doadora de prótons na ligação de hidrogênio em questão, $\mathrm{H}_{4} \cdots \mathrm{O}_{9}$, nos agregados 1:1 e 1:2A a doação de próton pelo formaldeído ocorre com a mesma molécula de água da qual o formaldeído recebe um próton no átomo de oxigênio. No agregado 1:2B o formaldeído doa próton para a segunda molécula de água do agregado, o que contribui para a diminuição da distância $\mathrm{H}_{4} \cdots \mathrm{O}_{9}$ no agregado 1:2B.

\begin{tabular}{rccc}
\hline \hline & $\mu$ & $Z P E$ & $\mathbf{\Delta E}$ \\
\hline $\mathbf{1 : 1}$ & 1,23 & 2,17 & $-3,66$ \\
$\mathbf{1 : 2 A}$ & 0,79 & 3,99 & $-7,34$ \\
$\mathbf{1 : 2 B}$ & 0,75 & 4,51 & $-10,45$ \\
\hline \hline
\end{tabular}

Tabela 4.16: Momentos de dipolo em debye, energias vibracionais de ponto zero em $\mathrm{kcal} / \mathrm{mol}$ e energias de ligação em kcal/mol corrigidas contra o erro de superposição de base e ZPE, obtidas em nível MP2/aug-cc-pVDZ para os agregados formaldeído-água 1:1, 1:2A e 1:2B.

O momento de dipolo das moléculas de formaldeído e água, obtidos isoladamente em nível MP2/aug-cc-pVDZ são iguas a 2,41 e 1,88 D, respectivamente. Observamos na tabela 4.16 que os momentos de dipolo dos três agregados investigados são menores que os dipolos das moléculas de formaldeído e água isoladas. No agregado 1:1, observamos que as moléculas de formaldeído e água estão com os momentos de dipolo em uma posição quase anti-paralela, ou seja, enquanto o dipolo do formaldeído aponta numa direção, o dipolo da água aponta no sentido contrário praticamente na mesma direção do dipolo do formaldeído, levando o dipolo do agregado $1: 1, \mu=1,23 \mathrm{D}$ a um valor menor que os dipolos de cada uma das moléculas isoladas. No agregado 1:2A as duas moléculas de água estão localizadas uma de cada lado do formaldeído também em posições anti-paralelas diminuindo ainda mais o momento de dipolo do agregado, que é de 0,79 D. Já no agregado 1:2B as moléculas de água saem do plano em que se encontra o formaldeído e com isso maximizam a interação entre os dipolos das moléculas no agregado, levando o dipolo do agregado 1:2B a um valor pequeno de $0,75 \mathrm{D}$.

Ainda na tabela 4.16 apresentamos as energias vibracionais de ponto 
zero para cada um dos agregados. Também apresentamos nesta tabela, as energias de ligação dos agregados formaldeído-água já incluindo a correção de counterpoise, contra o erro de superposição de base, e ZPE. Para o agregado 1:1 obtivemos uma energia de ligação de $-3,66 \mathrm{kcal} / \mathrm{mol}$. Sem a inclusão da energia vibracional de ponto zero na energia de ligação deste agregado, obtemos um valor de $-5,83 \mathrm{kcal} / \mathrm{mol}$ que concorda relativamente bem com o valor obtido para este mesmo agregado em nível CCSD/DZP de -5, $46 \mathrm{kcal} / \mathrm{mol}$ por Ramelot et al [47]. No mais alto nível reportado nesta mesma referência [47], CCSD/TZ2P+diff, a energia de ligação obtida para o agregado, já incluindo energia vibracional de ponto zero, foi de $-3,19 \mathrm{kcal} / \mathrm{mol}$, novamente em boa concordância com nosso resultado de $-3,66 \mathrm{kcal} / \mathrm{mol}$. Para o agregado formaldeído-água 1:2A, obtivemos uma energia de ligação de $-7,34 \mathrm{kcal} / \mathrm{mol}$, incluindo correções de ZPE e counterpoise contra BSSE. Já para o a agregado 1:2B obtivemos uma energia de ligação de $-10,45 \mathrm{kcal} / \mathrm{mol}$, cerca de 3,11 $\mathrm{kcal} / \mathrm{mol}$ mais baixa que a energia do agregado 1:2A. Essa diferença de energia de $3,11 \mathrm{kcal} / \mathrm{mol}$ entre os agregados 1:2 mostra o resultado já esperado de que os agregados cíclicos são os mais estáveis. Outra evidência que corrobora esta maior estabilidade do agregado 1:2B é o encurtamento das distâncias das ligações de hidrogênio quando comparadas às distâcias de ligação no agregado $1: 2 \mathrm{~A}$.

Uma outra análise que pode ser feita com as enegias de ligação obtidas para estes três agregados é uma estimativa da energia de ligação por número de ligações de hidrogênio feitas em cada um dos agregados. No agregado 1:1 as moléculas de formaldeído e água interagem através de duas ligações de hidrogênio, com uma energia de ligação total de $-3,66 \mathrm{kcal} / \mathrm{mol}$, o que nos leva a pensar que cada ligação de hidrogênio formada neste agregado contribui com 1, $829 \mathrm{kcal} / \mathrm{mol}$ da energia de interação do agregado. Fazendo a mesma análise para o agregado 1:2A, ou seja dividindo a energia de ligação total do agregado pelo número de ligações de hidrogênio, $(7,34 \mathrm{kcal} / \mathrm{mol} \div 4 \mathrm{LH})$, vamos obter o valor de 1, $832 \mathrm{kcal} / \mathrm{mol}$. Acreditamos que estes valores muito próximos obtidos na energia de interação por ligação de hidrogênio para os agregados 1:1 e 1:2A não sejam uma coincidência, já que no agregado 1:2A a segunda 
molécula de água assume um posicionamento similar aquele observado no agregado 1:1. Podemos elucidar este mesmo fato calculando a cooperatividade existente entre estes dois agregados, que matematicamente pode ser expressa por $\Delta E_{3}-2 \Delta E_{2}[138]$. Aplicando os valores de energia de ligação do agregado 1:1, $\Delta E_{2}=-3,66 \mathrm{kcal} / \mathrm{mol}$ e do agregado $1: 2 \mathrm{~A}, \Delta E_{3}=-7,34 \mathrm{kcal} / \mathrm{mol}$ na fórmula da cooperatividade obtemos o valor de $-0,02 \mathrm{kcal} / \mathrm{mol}$ como sendo a cooperatividade presente entre os agregados formaldeído-água 1:1 e 1:2A que mesmo sendo negativo é um valor de magnitude muito pequena e só podemos afirmar que a segunda molécula de água tende a estabilizar discretamente o sistema.

A energia de interação por ligação de hidrogênio do agregado 1:2B nos fornece um valor absoluto de $3,48 \mathrm{kcal} / \mathrm{mol}$, mais alto que os obtidos para os agregados 1:1 e 1:2A, ou seja, cada ligação de hidrogênio no agregado 1:2B contribui com 3,48 kcal/mol da energia de estabilização total do sistema, que é de $-10,45 \mathrm{kcal} / \mathrm{mol}$. Isso mostra novamente, que o agregado 1:2B é o mais estável dentre os agregados que obtivemos. Calculando a cooperatividade existente entre os agregados 1:1 e 1:2B obtivemos um valor de $-3,13 \mathrm{kcal} / \mathrm{mol}$, o que indica uma alta cooperatividade entre os dois agregados. Comparando a cooperatividade obtida, partindo do agregado 1:1, nos dois agregados 1:2A e 1:2B, vemos que quando a segunda molécula de água entra no agregado fazendo ligação de hidrogênio com a água e o formaldeído simultaneamente, o sistema fica mais estável que quando a segunda água entra em uma posição simétrica à água existente no agregado, fazendo ligação de hidrogênio somente com o formaldeído.

Na tabela 4.17 apresentamos as energias de interação de dois e três corpos obtidas em nível MP2/aug-cc-pVDZ para os agregados com uma molécula de formaldeído e duas moléculas de água, 1:2A e 1:2B. Estas energias incluem correção de counterpoise contra o BSSE, mas não incluem o valor da energia vibracional de ponto zero. Analisando a energia de interação de dois corpos, $\mathrm{U}_{2}$, observamos que no agregado 1:2A as moléculas de formaldeído e água estão mais fortemente ligadas que no agregado 1:2B. As diferenças de energia são de $-0,58 \mathrm{kcal} / \mathrm{mol}$ no caso de $\mathrm{U}_{2}(\mathrm{~A}, \mathrm{~B})$ e $-0,78 \mathrm{kcal} / \mathrm{mol}$ no caso 


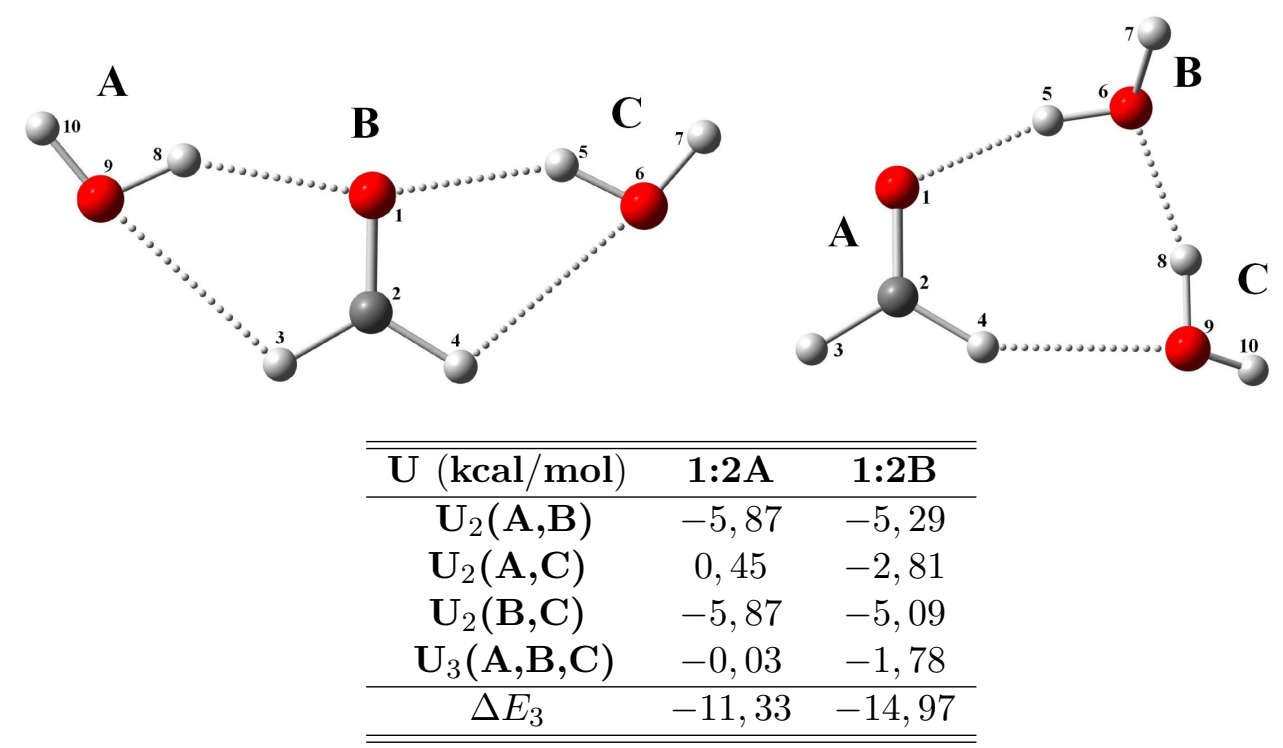

Tabela 4.17: Energias de interação de dois e três corpos, obtidas em nível MP2/aug-ccpVDZ, para os agregados formaldeído-água 1:2A e 1:2B. As figuras acima identificam as moléculas A, B e C em cada agregado.

$\mathrm{U}_{2}(\mathrm{~B}, \mathrm{C})$, onde $\mathrm{A}, \mathrm{B}$ e $\mathrm{C}$ referem-se à nomenclatura apresentada na figura logo acima da tabela. Estas interações mais fortes ente o formaldeído e as águas no agregado 1:2A podem ser explicadas pelo fato de que neste agregado as moléculas de água compartilham prótons e elétrons unicamente com a molécula de formaldeído, o que não acontece com as moléculas de água do agregado 1:2B que formam uma ligação de hidrogênio entre si. O fato de as moléculas de água do agregado 1:2A não compartilharem prótons e elétrons entre si maximiza a distribuição de cargas entre estas moléculas e o formaldeído, aumentando a energia de interação entre formaldeído e água neste agregado. Já a interação entre as moléculas de água mostra-se claramente mais forte no agregado 1:2B, onde $\mathrm{U}_{2}(\mathrm{~A}, \mathrm{C})=-2,81 \mathrm{kcal} / \mathrm{mol}$, chegando a um valor de energia positiva no agregado 1:2A. Este valor positivo de $0,45 \mathrm{kcal} / \mathrm{mol}$ obtido para a interação entre as moléculas de água do agregado 1:2A é justificado pelo fato das duas moléculas não interagirem diretamente uma com a outra, por isso a energia de interação entre elas se torna repulsiva, o que é representada pela energia de interação positiva. 
$\mathrm{O}$ valor da energia de interação de três corpos $\mathrm{U}_{3}$ pode ser entendido como a quantidade de interação simultânea existente entre três moléculas dentro de um agregado molecular. Logo, como era esperado, as três moléculas do agregado 1:2B apresentam uma energia de interação de três corpos significativamente maior que as moléculas do agregado 1:2A. Enquanto que $\mathrm{U}_{3}$ do agregado 1:2B é $-1,78 \mathrm{kcal} / \mathrm{mol}$, no agregado 1:2A $\mathrm{U}_{3}$ assume o valor de $-0,03$ $\mathrm{kcal} / \mathrm{mol}$. O motivo para essa baixa energia de interação no agregado 1:2A é que as moléculas de água não compartilham prótons ou elétrons entre si, o que contribui para uma diminuição do valor absoluto da energia de interação das três moléculas do agregado 1:2A. Além disso, este baixo valor de $\mathrm{U}_{3}$ aliado ao valor positivo da energia de interação entre as moléculas de água no agregado 1:2A contribuem para uma diminuição do valor absoluto da energia de ligação do agregado 1:2A, como também pode ser visto em $\Delta E_{3}$, na tabela 4.17.

As energias de ligação totais dos agregados 1:2A e 1:2B apresentam uma diferença de $3,64 \mathrm{kcal} / \mathrm{mol}$ em favor de uma maior estabilização da estrutura 1:2B. Essa diferença de energia evidencia mais uma vez o fato de que uma conformação cíclica onde as moléculas sofrem torções angulares para fora do plano leva de fato a uma maior estabilidade conformacional que estruturas onde as moléculas permanecem todas no mesmo plano [42,138].

\subsubsection{Transição Eletrônica $n \rightarrow \pi^{*}$ do Formaldeído em Solução Aquosa}

As transições eletrônicas moleculares ocorrem quando os elétrons ganham energia suficiente para serem promovidos a níveis de energia mais elevados, ou seja, acontece uma excitação eletrônica. A mudança da energia associada com esta transição fornece informações sobre a estrutura da molécula e determina muitas propriedades moleculares, como por exemplo sua cor. Em compostos orgânicos, as transições eletrônicas referentes à absorção podem ser determinadas por espectroscopia ultravioleta visível (UV/VIS). Dentre os compostos orgânicos, as moléculas do grupo carbonila têm, há muitas décadas, despertado o interesse de teóricos e experimentais no que diz respeito estudo do espectro destas moléculas tanto em fase gasosa, quanto em meio solvente. Dentre os compostos car- 
bonílicos, a acetona e o formaldeído têm seus espectros de absorção bastante investigados em ambiente de solvatação. O espectro experimental do formaldeído solvado em água, foi obtido por Becker e colaboradores em 1972 [45] porém foi necessário neste experimento uma alta concentração de formaldeído devido à grande facilidade para formação de agregados existente entre as moléculas de água e formaldeído. Sendo assim, o espectro da molécula de acetona solvatada em água $[60,146,218,229]$ é muitas vezes usado como protótipo para o espectro do formaldeído em ambiente aquoso. Teoricamente porém, é possível obter informações referentes aos espectros de absorção e emissão do formaldeído, em qualquer solvente desejado, e com isso obter também as diferenças de energia referentes às transições eletrônicas nestes espectros. Neste contexto, o espectro do formaldeído solvatado em água, foi largamente estudado através de abordagens como a microsolvatação [41-44,47-49], modelos de solvente contínuo [230,231], e solvatação com moléculas explícitas [148,211,232-234]. Estamos interessados nesta parte do trabalho em investigar o deslocamento da banda de energia referente a transição eletrônica $n \rightarrow \pi^{*}$ do formaldeído em solução aquosa. Em um trabalho anterior do grupo [148], esta mesma transição do formaldeído em água foi estudada através da metodologia S-MC/QM onde os cálculos quânticos foram realizados com o modelo semi-empírico INDO-S/CIS e os cáculos apontaram para um deslocamento da banda de energia referente à transição $\mathrm{n} \rightarrow \pi^{*}$ de $\sim 2200 \mathrm{~cm}^{-1}$. Nossa proposta agora é fazer um estudo similar, através da metodologia S-MC/QM, porém utilizando time dependent-DFT para o tratamento quântico das supermoléculas geradas no líquido molecular.

Para gerar o líquido molecular de formaldeído em água, realizamos com o programa DICE [71] uma simulação Monte Carlo Metropolis no ensemble NVT, com uma molécula de formaldeído embebida em 400 moléculas de água, à temperatura de 298,15 K, à densidade experimental da água [208] de 0,9966 $\mathrm{g} / \mathrm{cm}^{3}$. A geometria do formaldeído utilizada na simulação foi otimizada isoladamente em nível MP2/aug-cc-pVDZ com o programa Gaussian 03 [181], já a geometria da água utilizada foi a do potencial SPC [210], onde $\mathrm{R}(\mathrm{O}-\mathrm{H})=1,00$ $\AA$ e $\alpha(\mathrm{HOH})=109,47^{\circ}$. Todas as distância e ângulos intramoleculares foram mantidas fixos durante toda a simulação MC. Utilizamos os parâmetros de po- 
tencial SPC para modelar a água [210] e para o formaldeído utilizamos as cargas obtidas em nível HF/6-31+G(d) por Blair et al [232] e os parâmetros para o potencial Lennard-Jones foram obtidos da literatura [235].

O líquido molecular passou por um estágio de termalização de $6 \times 10^{6}$ passos MC e, depois do sistema ter entrado em equilíbrio termodinâmico, realizamos mais $2 \times 10^{8}$ passos de MC. Utilizamos a função de auto-correlação da energia, figura 4.17, para selecionarmos estruturas do líquido com baixa correlação estatística. O uso desta função nos permite utilizar um número menor de estrururas nos cálculos de macânica quântica, sem perda de informações estatísticas relevantes do sistema. Através do uso de $\mathrm{C}(i)$ obtivemos $\tau \simeq 600$, e utilizando $2 \tau$ diminuímos o número de estruturas a serem submetidas aos cálculos quânticos de $2 \times 10^{8}$ para 416 estruturas com correlação estatística de $\sim 16 \%$ entre duas estruturas consecutivas.

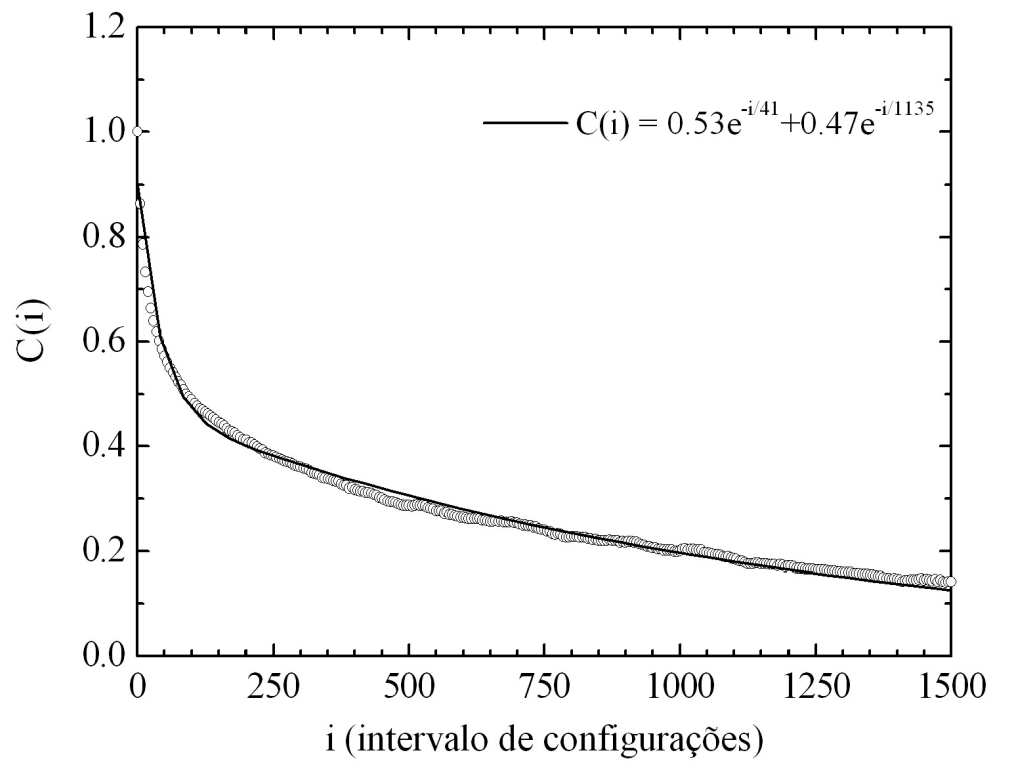

Figura 4.17: Função de auto-correlação da energia para o de líquido formaldeído em água.

Após esta seleção das 416 estruturas do líquido, determinamos os critérios para a formação das ligações de hidrogênio no líquido. Estes critérios são determinados com base na distância entre os átomos de oxigênio do formaldeído e oxigênio da água, $\mathrm{R}(\mathrm{O} \cdots \mathrm{O})$, no ângulo da ligação de hidrogênio 
$\theta(\mathrm{O} \cdots \mathrm{OH})$ e na energia clássica de interação do formaldeído com a água. Através da análise da função de distribuição radial $\mathrm{G}_{O \ldots O}(r)$, figura 4.18 , determinada pela distância entre os átomos de oxigênio do formaldeído e da água temos uma indicação das distâncias em que provavelmente estão se formando as ligações de hidrogênio no líquido.

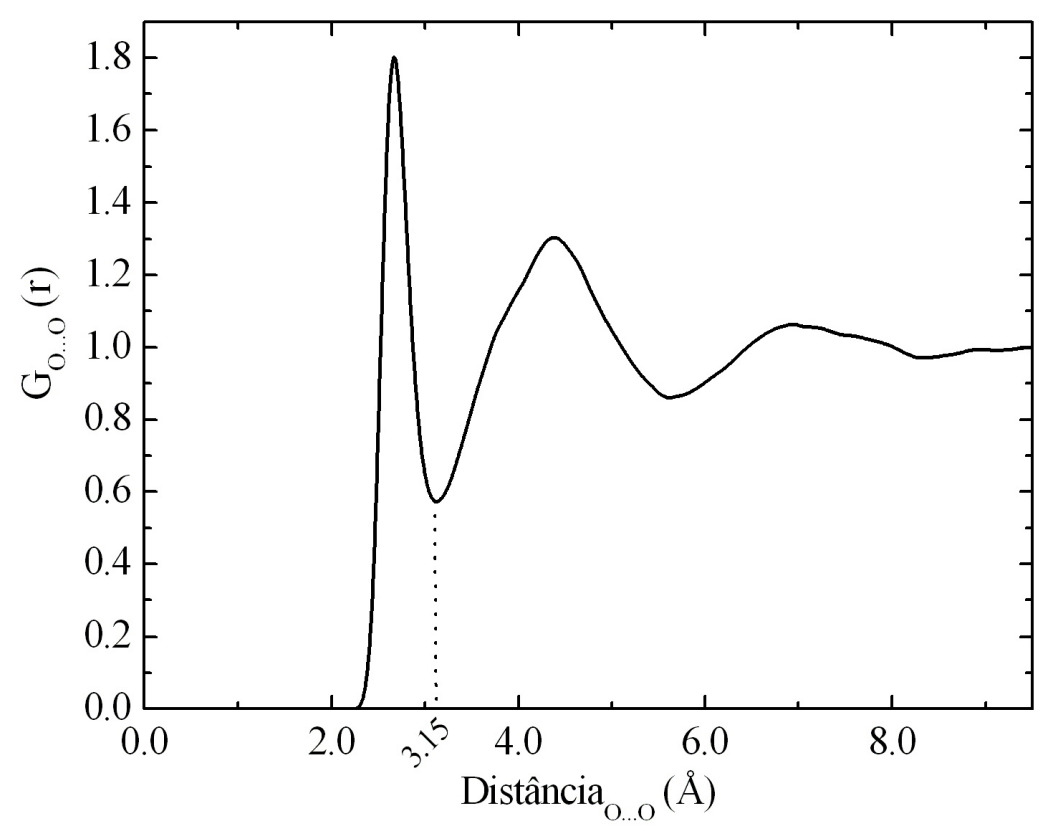

Figura 4.18: Função de distribuição radial determinada pelas distâncias entre os átomos de oxigênio do formaldeído e das moléculas de água no líquido.

O gráfico da energia de interação em função da distância $\mathrm{R}(\mathrm{O} \cdots \mathrm{O})$, figura 4.19 nos dá uma visão geral da energética do sistema líquido. Vemos através deste gráfico que tomando energias de ligação maiores que $-4,0 \mathrm{kcal} / \mathrm{mol}$ e distâncias $\mathrm{O} \cdots \mathrm{O}$ menores que $3,5 \AA$, estaremos tomando somente estruturas onde o formaldeído e a água estão de fato interagindo por meio de ligação de hidrogênio. Outro indicativo de presença das ligações de hidrogênio pode ser vista na mesma figura 4.19 no gráfico menor. Este gráfico mostra a ocorrência das energias de interação no sistema, e o ombro formado entre $-8,0 \mathrm{kcal} / \mathrm{mol}$ e $-4,0 \mathrm{kcal} / \mathrm{mol}$ é característico de formação de ligações de hidrogênio em sistemas líquidos.

Adicionalmente, devemos levar em consideração a distribuição an- 


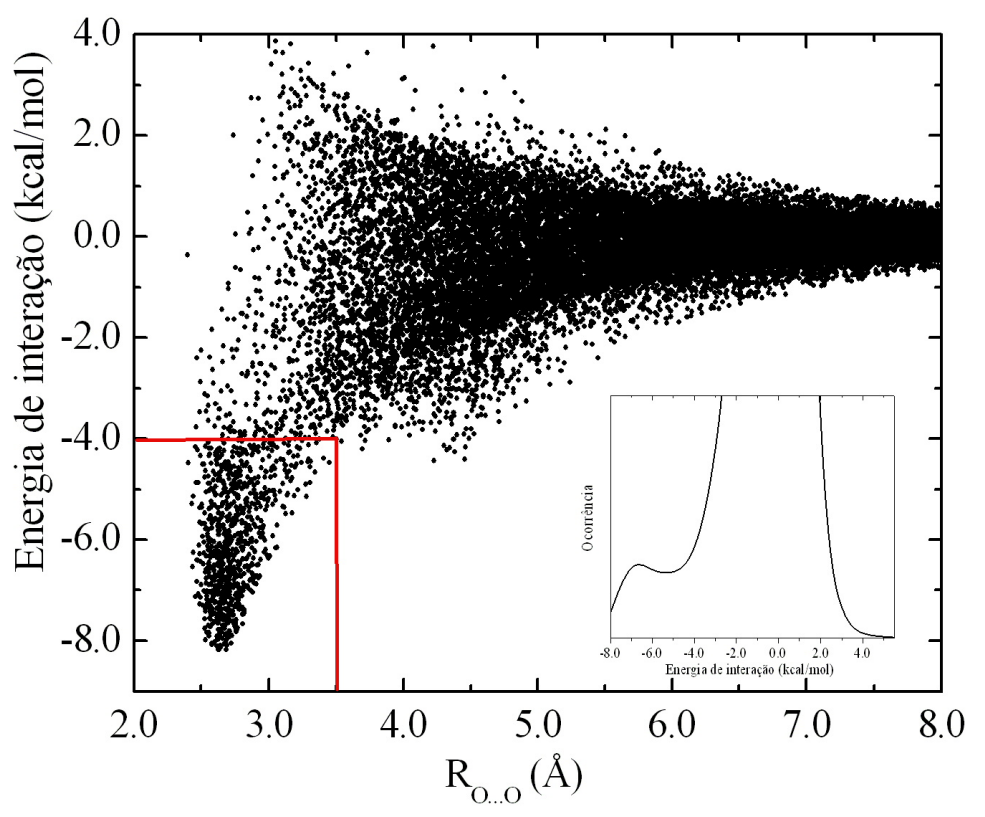

Figura 4.19: Energia de interação em função da distância O $\cdots$ O formaldeído-água no líquido. O gráfico em menor escala mostra o histograma de ocorrência da energia clássica de interação formaldeído-água.

gular das moléculas de água em torno do formaldeído durante a formação das ligações de hidrogênio. Neste contexto, a figura 4.20 mostra a distribuição angular, $\theta(\mathrm{O} \cdots \mathrm{OH})$, nas estruturas do líquido molecular, neste gráfico as estruturas tomadas já respeitam os critérios de distância e energia, definidos anteriormente. Analisando este gráfico, vemos que a maior ocorrência do ângulo $\theta(\mathrm{O} \cdots \mathrm{OH})$, primeiro pico do gráfico, está entre entre 0 e $\sim 40^{\circ}$. Sendo assim, determinamos como ângulo máximo para formação de ligação de hidrogênio o ângulo $\theta(\mathrm{O} \cdots \mathrm{OH}) \leq 40^{\circ}$.

Baseado nos critérios de formação para ligação de hidrogênio obtidos, $\mathrm{R}(O \cdots \mathrm{O}) \leq 3,5 \AA$ A $, \mathrm{E}_{\text {interação }} \leq-4,0 \mathrm{kcal} / \mathrm{mol}$ e $\theta(\mathrm{O} \cdots \mathrm{OH}) \leq 40^{\circ}$, obtivemos das 416 estruturas estatisticamante descorrelacionadas do líquido de formaldeído em água. A estatística de ligações de hidrogênio formadas no líquido é apresentada na tabela 4.18. Esta estatística nos mostra uma clara preferência do formaldeído em formar duas ligações de hidrogênio com as moléculas de água, visto que 272 estruturas, cerca de $65 \%$ das estruturas selecionadas, apresenta- 


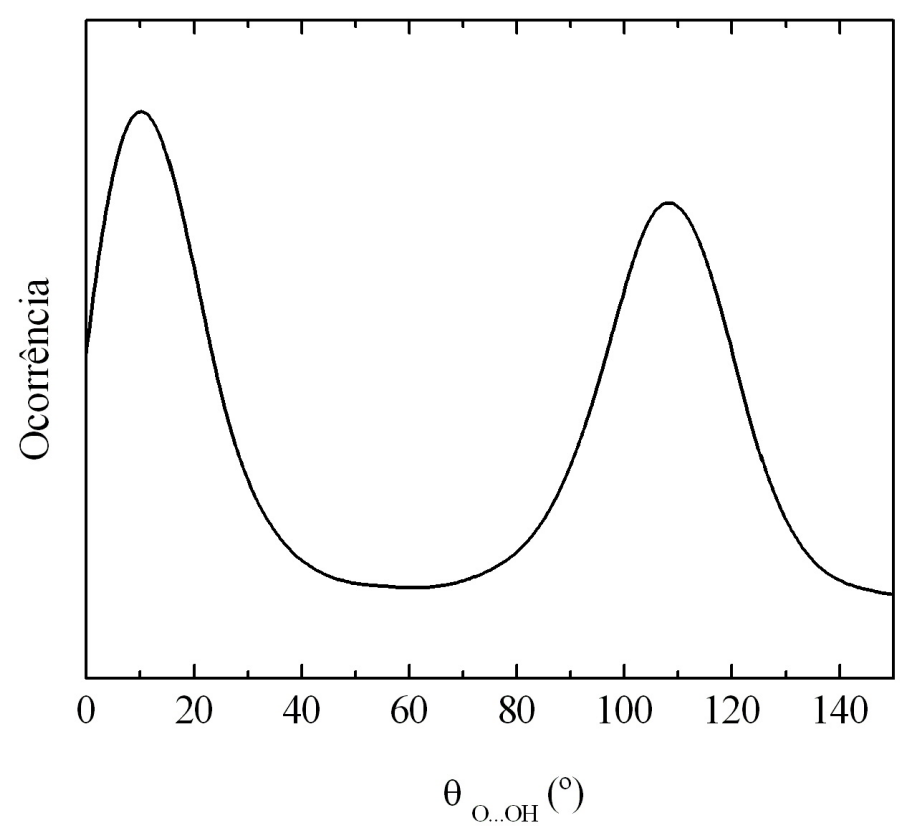

Figura 4.20: Distribuição do ângulo $\theta(\mathrm{O} \cdots \mathrm{OH})$ nas estruturas de agregados do líquido formaldeído-água, com $\mathrm{R}_{O \ldots O} \leq 3,5 \AA$ e $\mathrm{E}_{\text {interação }} \leq-4,0 \mathrm{kcal} / \mathrm{mol}$.

\begin{tabular}{cc}
\hline \hline $\mathbf{N}^{o}$ de LH & $\mathbf{N}^{o}$ de configurações \\
\hline 0 & 4 \\
1 & 82 \\
2 & 272 \\
3 & 56 \\
4 & 2 \\
\hline $\mathbf{1 , 9 3} \mathbf{L H} /$ configuração \\
\hline \hline
\end{tabular}

Tabela 4.18: Estatística de ligações de hidrogênio formadas no líquido formaldeído-água $1: 400$. 
ram a formação de duas ligações de hidrogênio nas estruturas de formaldeído e água. Este fato pode ser facilmente entendido se lembrarmos que o oxigênio, que é o átomo eletronegativo que participa da ligação de hidrogênio, tem um par isolado de elétrons que se satura recebendo dois hidrogênios. Observamos também que em $20 \%$ das estruturas (82 estruturas) o formaldeído e a água forma apenas uma ligação de hidrogênio e $\sim 13 \%$ das estruturas apresentam a formação de três ligações de hidrogênio entre o formaldeído e as moléculas de água no líquido. Uma porcentagem muito pequena das estruturas selecionadas apresentou zero ou quatro ligações de hidrogênio, $1 \%$ e $0,5 \%$ respectivamente. A estatística mostrada na tabela 4.18 também nos diz qual o número médio de ligações de hidrogênio que se formam no líquido por estrutura. Para o líquido de formaldeído e água é esperado que esse número médio esteja em torno de 2 LH/configuração já que o átomo aceitador de ligação de hidrogênio, no caso o oxigênio do formaldeído, pode aceitar até duas ligações de hidrogênio simultaneamente. Utilizando os critérios para formação de ligação de hidrogênio acima, obtivemos 1,93 LH/configuração, o que concorda muito bem com a média obtida em trabalho anterior de 1,9 LH/configuração [148].

Selecionadas as estruturas que apresentam ligações de hidrogênio no líquido de formaldeído e água, submetemos estas estruturas a cálculos quânticos para obtenção da energia referente à transição $n \rightarrow \pi^{*}$. Realizamos cálculos quânticos Time Dependent-DFT com os funcionais B3LYP e B972, ambos com o conjunto de funções base 6-311++G(d,p) sobre as estruturas com uma, duas e três ligações de hidrogênio selecionadas no líquido.

Na figura 4.21, apresentamos os gráficos da convergência estatística das médias para o deslocamento da banda de energia referente à transição $\mathrm{n}$ $\rightarrow \pi^{*}$ do formaldeído solvatado pelas ligações de hidrogênio que se formaram no líquido. As barras de erros apresentadas nos gráficos são o desvio padrão referentes às médias. Observamos que o funcional B3LYP forneceu valores de 10 a $13 \%$ maiores que os valores obtidos com o funcional B972 para os deslocamentos das bandas de energia da transição $\mathrm{n} \rightarrow \pi^{*}$ do formaldeído. Nos três gráficos observamos que os valores médios estão estatisticamente convergidos, com $\sim 70$ cálculos nas estruturas com uma molécula de água, com $\sim 240$ 

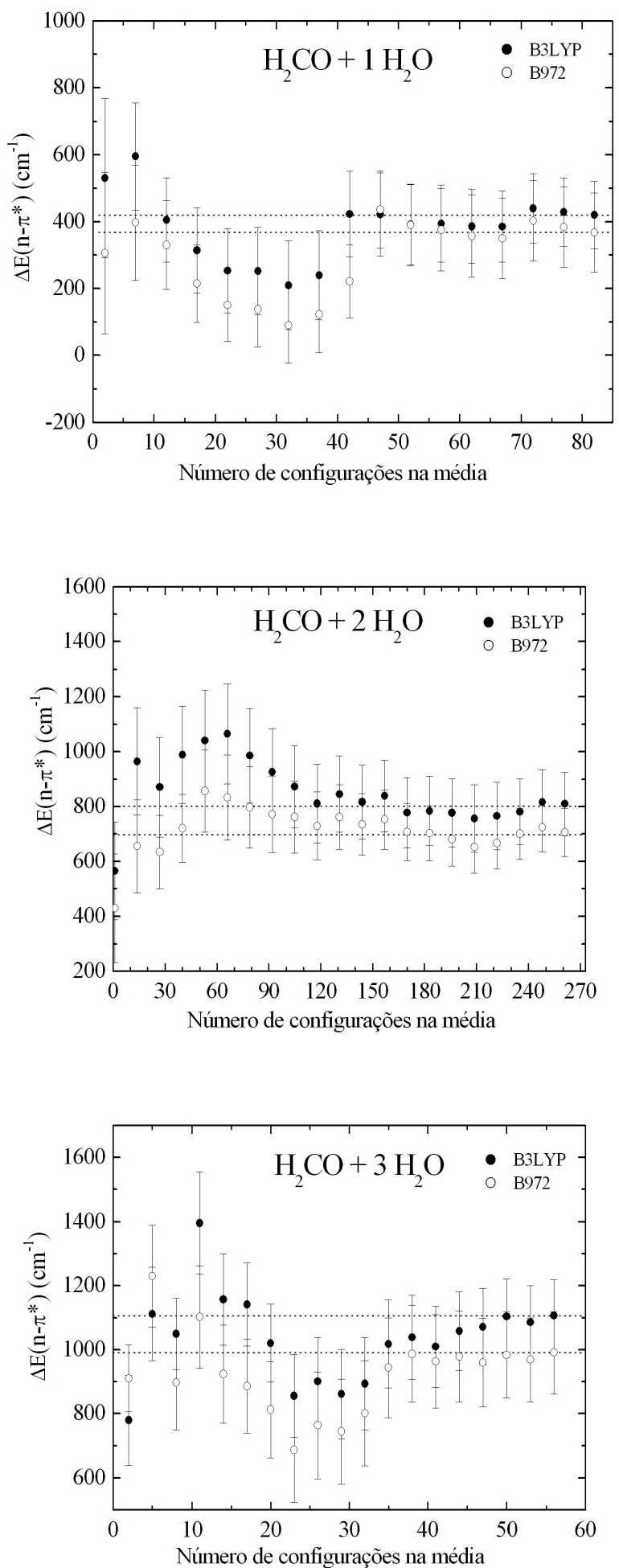

Figura 4.21: $\Delta E$ da transição $\mathrm{n} \rightarrow \pi^{*}$ do formaldeído em agregados do líquido contendo uma, duas e três moléculas de água fazendo ligação de hidrogênio, obtidas com os funcionais B3LYP e B972, ambos com a base 6-311++G(d,p). As barras de erro são o desvio padrão das médias. 
cálculos quânticos nas estruturas com duas moléculas de água e com $\sim 50$ cálculos na média para as estruturas com três moléculas de água.

\begin{tabular}{ccc}
\hline \hline$\Delta E\left(n \rightarrow \pi^{*}\right)\left(\mathrm{cm}^{-1}\right)$ & B3LYP & B972 \\
\hline$\left\langle\mathbf{1} \mathbf{H}_{2} \mathbf{O}\right\rangle_{82}$ & $420 \pm 101$ & $368 \pm 118$ \\
$\left\langle\mathbf{2} \mathbf{H}_{2} \mathbf{O}\right\rangle_{272}$ & $802 \pm 114$ & $697 \pm 86$ \\
$\left\langle\mathbf{3} \mathbf{H}_{2} \mathbf{O}\right\rangle_{56}$ & $1106 \pm 112$ & $991 \pm 128$ \\
& & \\
\hline$\delta E_{i}$ & $\mathbf{B 3 L Y P}$ & $\mathbf{B 9 7 2}$ \\
\hline$\left\langle\delta E_{1}\right\rangle_{82}$ & 420 & 368 \\
$\left\langle\delta E_{2}\right\rangle_{272}$ & 401 & 349 \\
$\left\langle\delta E_{3}\right\rangle_{56}$ & 369 & 330 \\
\hline \hline
\end{tabular}

Tabela 4.19: Valores médios do $\Delta E$ da transição $\mathrm{n} \rightarrow \pi^{*}$ para as estruturas com uma, duas e três ligações de hidrogênio no líquido. Contribuição média de molécula de água para o deslocamento da banda de energia da transição $\mathrm{n} \rightarrow \pi^{*}$, onde $\delta E_{i}=\Delta E / i \operatorname{com} i=N^{o}$ de moléculas de água.

Na tabela 4.19 mostramos os valores médios obtidos para o deslocamento da banda $\mathrm{n} \rightarrow \pi^{*}$ para o formaldeído solvatado pelas ligações de hidrogênio obtidas no líquido. Estes valores foram obtidos pela diferença entre as energias da transição $\mathrm{n} \rightarrow \pi^{*}$ do formaldeído solvatado nas estruturas com ligação de hidrogênio e isolado, $\Delta E=E_{\text {solvatado }}-E_{\text {isolado }}$. Como já era esperado, em todos os casos na tabela 4.19 obtivemos valores positivos para o deslocamento da banda, o que também é bastante conhecido como deslocamento para a região do azul. Em um artigo recente [43], Mikkelsen e colaboradores calcularam a energia da transição $\mathrm{n} \rightarrow \pi^{*}$ do formaldeído microsolvatado com uma, duas e quatro moléculas de água. Neste trabalho eles encontraram em nível CCSD/aug-cc-pVTZ deslocamentos de 1515 e $1415 \mathrm{~cm}^{-1}$ para a banda $\mathrm{n}$ $\rightarrow \pi^{*}$ do formaldeído microsolvatado por uma e duas moléculas de água, respectivamente. Em nível CC2/aug-cc-pVTZ, os mesmo autores encontraram 1453 e $1255 \mathrm{~cm}^{-1}$ para o mesmo deslocamento da banda $\mathrm{n} \rightarrow \pi^{*}$ do formaldeído, novamente microsolvatado por uma e duas moléculas de águas respectivamente. Estes valores são muito altos quando pensamos no valor esperado para este deslocamento quando o formaldeído está solvatado em bulk de água que está em torno de $1900 \mathrm{~cm}^{-1}$ [45], porém a uma alta concentração de formaldeído. Quando comparamos os valores obtidos na referência [43] aos valores que obti- 
vemos aqui, vemos que a microsolvatação majora o valor do deslocamento da banda $\mathrm{n} \rightarrow \pi^{*}$, nas estruturas com uma água em pelo menos $1047 \mathrm{~cm}^{-1}$ e nas estruturas com duas águas em pelo menos $558 \mathrm{~cm}^{-1}$. Se tomarmos as estruturas otimizadas das estruturas de formaldeído com uma e duas moléculas de água e fizermos sobre estas estruturas, cálculos TD-DFT com os funcionais B3LYP e B972 e base 6-311++G(d,p), ou seja, usando o mesmo nível de cálculo adotado para as estruturas do líquido, vamos obter valores para $\Delta E$ da transição $\mathrm{n} \rightarrow \pi^{*}$ do formaldeído de 1105 e $1103 \mathrm{~cm}^{-1}$, respectivamente, para o agregado com uma água. Para as estruturas com duas moléculas de água, obtivemos 1275 e $1278 \mathrm{~cm}^{-1}$ seguindo o mesmo procedimento anterior. Com isso temos uma clara indicação de que a microsolvatação, ou seja o uso de estruturas otimizadas e com um número pequeno de moléculas de solvente, superestima a energia da transição $\mathrm{n} \rightarrow \pi^{*}$ do formaldeído. O que não acontece se tomarmos configurações de líquido onde o formaldeído, embora esteja solvatado por um número pequeno de moléculas de água, apresenta um deslocamento condizente com o esperado devido à quantidade de moléculas de água presentes nas configurações. Portanto, uma análise interessante seria analisar numericamente a contribuição de cada molécula de água na energia da transição $\mathrm{n} \rightarrow \pi^{*}$ do formaldeído solvatado.

Uma maneira de analisarmos quantitativamente a contribuição de cada molécula de água no deslocamento da banda de energia da transição $\mathrm{n}$ $\rightarrow \pi^{*}$ do formaldeído em solução, dividimos o valor de $\Delta E$ pelo número de moléculas de água nas estruturas, tabela 4.19. Analisando os valores médios nesta tabela, vemos que, para os dois funcionais, o valor da contribuição de cada molécula de água no deslocamento da banda de energia da transição $\mathrm{n} \rightarrow \pi^{*}$ diminui à medida que aumentamos o número de moléculas de água no agregado, como era esperado. Tomando os valores obtidos com o funcional B3LYP observamos uma diminuição de $5 \%$ quando comparamos $\delta E_{1} \operatorname{com} \delta E_{2}$. Fazendo a mesma comparação entre os deslocamentos obtidos para as estruturas com duas e três moléculas de água, com o mesmo funcional (B3LYP), observamos uma saturação ainda maior, com uma diminuição de $8 \%$ entre os valores de $\delta E_{i}$. Para o funcional B972 observamos a mesma tendência à saturação, porém 
com diferenças de $\delta E_{i}$ menores, de 5,1 e 5,4\%. Assim, podemos afirmar que existe de fato uma tendência à saturação do deslocamento da banda quando acrescentamos moléculas de água as estruturas de formaldeído e água. Resta saber qual o valor do deslocamento da banda $n \rightarrow \pi^{*}$ quando o formaldeído estiver completamento solvatado pelas moléculas de água. Para isso, precisamos ir além da análise com as estruturas de ligação de hidrogênio, que tem por característica um número pequeno de moléculas de água. Analisamos então a função distribuição radial dos pares C $\cdots \mathrm{O}$, das moléculas de formaldeído e água, figura 4.22. Nesta $\mathrm{G}_{C \ldots O}(\mathrm{r})$ vemos definidas duas camadas de solvatação que se formam em torno da molécula de formaldeído. A primeira camada de solvatação, ilustrada na figura 4.23, mostra um líquido bem estruturado, com pico definido entre 2,65 e $5,15 \AA$. Na camada subseqüente, vemos que o líquido perde a estrutura observada na primeira camada de solvatação, mas ainda assim, podemos definir um vale em 8,65 $\AA$ onde a segunda camada de solvatação termina. Por conveniência, uma terceira camada de solvatação foi tomada até o limite da caixa em torno de $11,45 \stackrel{\AA}{A}$.

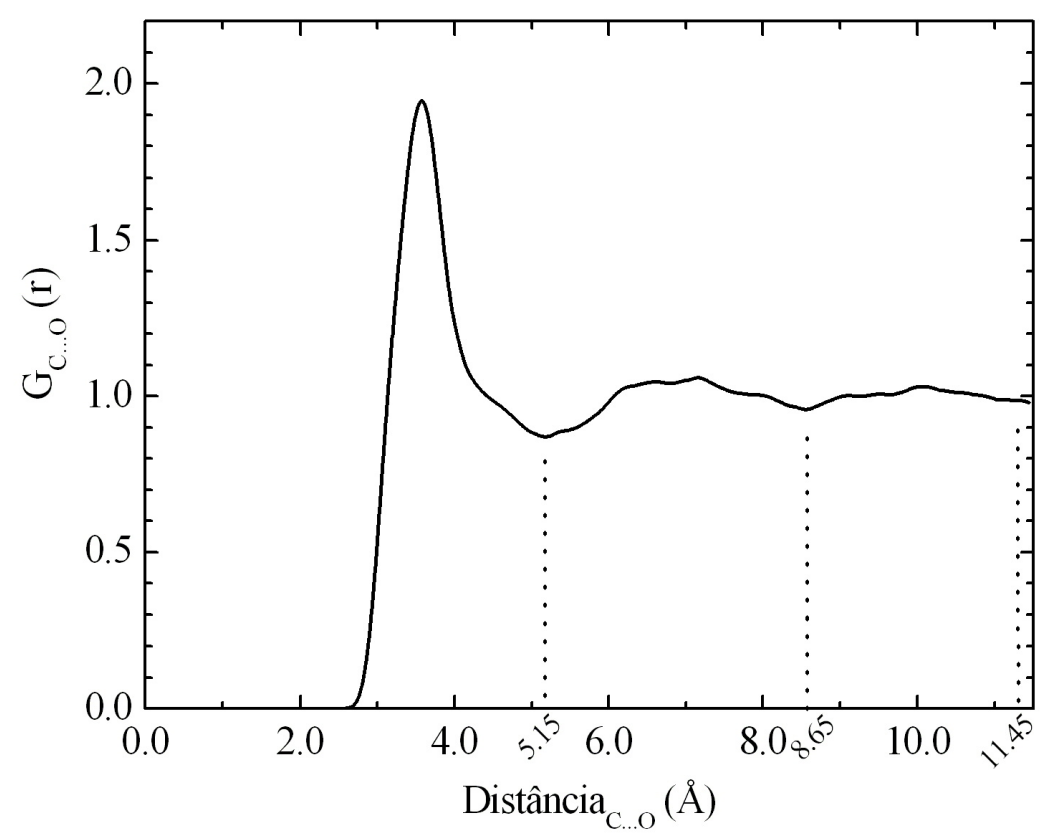

Figura 4.22: Função distribuição radial de pares determinada entre os átomos de carbono do formaldeído e oxigênio da água no líquido. 
A integração numérica das camadas de solvatação, nos fornece o número de coordenação de cada uma delas, o que significa a quantidade de moléculas em torno da molécula de referência. Integrando as três camadas de solvatação definidas na figura 4.22, encontramos 18, 90 e 210 moléculas de água em torno da molécula de formaldeído até a $1^{\mathrm{a}}, 2^{\mathrm{a}}$ e $3^{\mathrm{a}}$ camada de solvatação, respectivamente.

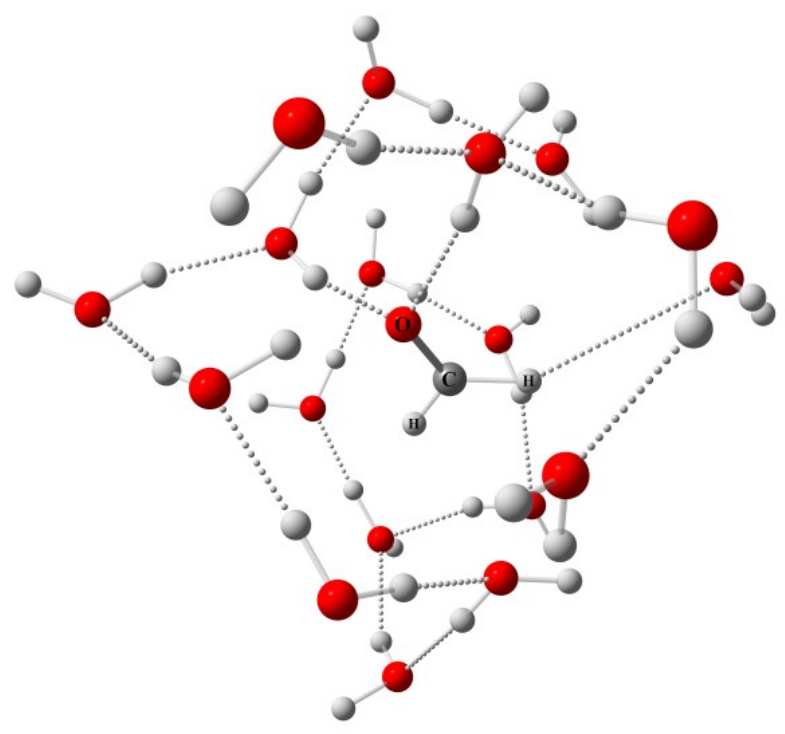

Figura 4.23: Ilustração da primeira camada de solvatação em torno do formaldeído em solução aquosa.

Definidas as estruturas referentes às camadas de solvatação do formaldeído em água, realizamos cálculos quânticos TD-DFT sobre as estruturas de primeira camada com a molécula de formaldeído envolta por 18 moléculas de água. Utilizamos novamente dois funcionais, B3LYP e B972, mas agora com bases distintas para cada tipo de molécula. Mantivemos a base $6-311++\mathrm{G}(\mathrm{d}, \mathrm{p})$ para o formaldeído a fim de tentar manter a coerência quanto ao tamanho da base utilizada no caso gasoso, que é utilizado para a obtenção do deslocamento da banda. Porém, manter este mesmo conjunto de funções-base para todas as 18 moléculas de água nas inúmeras estuturas do líquido torna os cálculos quânticos inviáveis, por isso utilizamos o conjunto de funções-base 6-31G nas moléculas de água nos cálculos com a primeira camada de solvatação.

A figura 4.24, mostra a convergência estatística das médias obtidas 


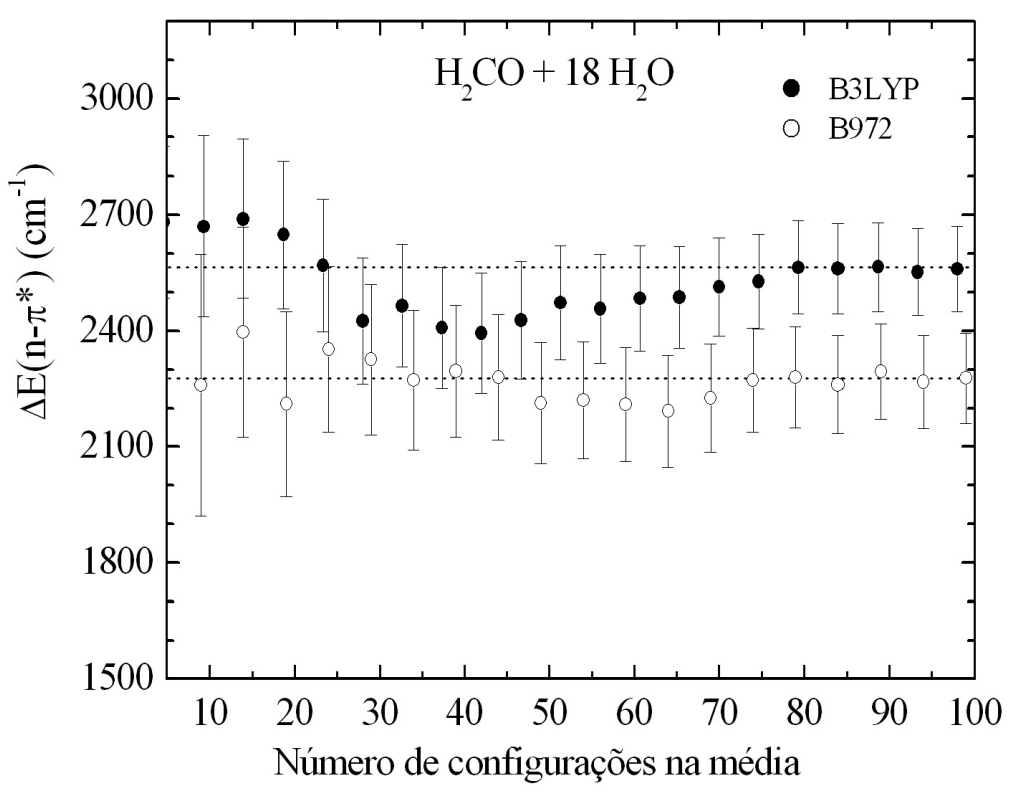

Figura 4.24: Convergência estatística do deslocamento da banda $\mathrm{n} \rightarrow \pi^{*}$ do formaldeído na primeira camada de solvatação.

incluindo 100 valores para o deslocamentos da banda de energia da transição $n$ $\rightarrow \pi^{*}$ do formaldeído envolto por 18 moléculas de água. Novamente notamos que as médias obtidas com o funcional B3LYP superestima o valor do deslocamento da banda $\mathrm{n} \rightarrow \pi^{*}$ do formaldeído no líquido de água. Comparando os valores obtidos com B3LYP e B972, observamos que o funcional B3LYP fornece um valor médio de $2564 \pm 108 \mathrm{~cm}^{-1}$, que é $11 \%$ maior que o valor fornecido pelo funcional B972 para o mesmo deslocamento da banda $n \rightarrow \pi^{*}$, que foi de $2277 \pm 117 \mathrm{~cm}^{-1}$. Também observamos no gráfico que, para os dois funcionais utilizados, com aproximadamente 75 cálculos inclusos na média já obtemos valores estatisticamente convergidos. Ambos os valores obtidos estão bem acima dos valores esperados para o deslocamento desta banda de energia, que está em torno de $1900 \mathrm{~cm}^{-1}[45]$.

Em um trabalho relativamente recente, Mikkelsen e colaboradores [233] investigaram a transição $\mathrm{n} \rightarrow \pi^{*}$ do formaldeído em água. Estes pesquisadores encontraram para o deslocamento da banda de energia da transição $\mathrm{n} \rightarrow \pi^{*} 2803 \pm 46 \mathrm{~cm}^{-1}$ usando CCSD/aug-cc-pVTZ com um potencial pola- 
rizável para a água. O resultado correspondente, desprezando-se a polarização explícita é de $2139 \pm 45 \mathrm{~cm}^{-1}$. Estes dois resultados também são superestimativas para o valor experimental esperado, de $1900 \mathrm{~cm}^{-1}$. Os autores atribuem esta superestimativa a diversos fatores. Dentre eles estão: a negligência quanto aos efeitos de mudança estrutural sofrida pelo formaldeído quando solvatado em água, ineficiência do campo de forças utilizado na simulação e por fim, à ausência de dispersão e a repulsão de curto alcance nos cálculos combinados Coupled Cluster/Molecular Mechanics utilizados no trabalho. Ao final os autores também reportam que não é coerente a comparação direta entre os resultados obtidos por eles e o resultado experimental de $\sim 1900 \mathrm{~cm}^{-1}$ devido à alta concentração de formaldeído em que foi feito o experimento, portanto o valor experimental serve apenas como um indicativo do deslocamento da transição.

\begin{tabular}{ccc}
\hline \hline$\Delta E\left(n \rightarrow \pi^{*}\right)$ & B3LYP & B972 \\
\hline molécula explícita & & \\
\hline $\mathbf{1}^{a}$ camada 100 estruturas & $2564 \pm 108$ & $2277 \pm 117$ \\
& & \\
\hline carga pontual & & \\
\hline $\mathbf{1}^{a}$ camada 100 estruturas & $2030 \pm 334$ & $1828 \pm 333$ \\
$\mathbf{2}^{a}$ camada 100 estruturas & $2249 \pm 352$ & $2047 \pm 351$ \\
$\mathbf{3}^{a}$ camada 100 estruturas & $2288 \pm 352$ & $2086 \pm 351$ \\
& & \\
\hline Mikkelsen $[233]$ & & \\
\hline CCSD/aug-cc-pVTZ polarizado & $2803 \pm 46$ \\
CCSD/aug-cc-pVTZ não polarizado & $2139 \pm 45$ \\
\hline \hline
\end{tabular}

Tabela 4.20: Valores médios do deslocamento da banda referente à transição $\mathrm{n} \rightarrow \pi^{*}$ do formaldeído em água, em $\mathrm{cm}^{-1}$ obtidos com TD-DFT para os funcionais B3LYP e B972 nas bases 6-311++G(d,p) para o formaldeído e 6-31G para as moléculas de água inclusas explicitamente nos cálculos quânticos.

Na figura 4.25 apresentamos os histogramas referentes aos deslocamentos da banda de energia da transição $\mathrm{n} \rightarrow \pi^{*}$ obtidas para a primeira camada de solvatação com os funcionais B3LYP e B972, nas bases 6-311++G(d,p) para o formaldeído e 6-31G para as 18 moléculas de água.

Na tabela 4.20 apresentamos os valores do deslocamento da banda $\mathrm{n} \rightarrow \pi^{*}$ que obtivemos com os funcionais B3LYP e B972, utilizando a base 6-311++G(d,p) para o formaldeído e diferentes tratamentos para as moléculas 

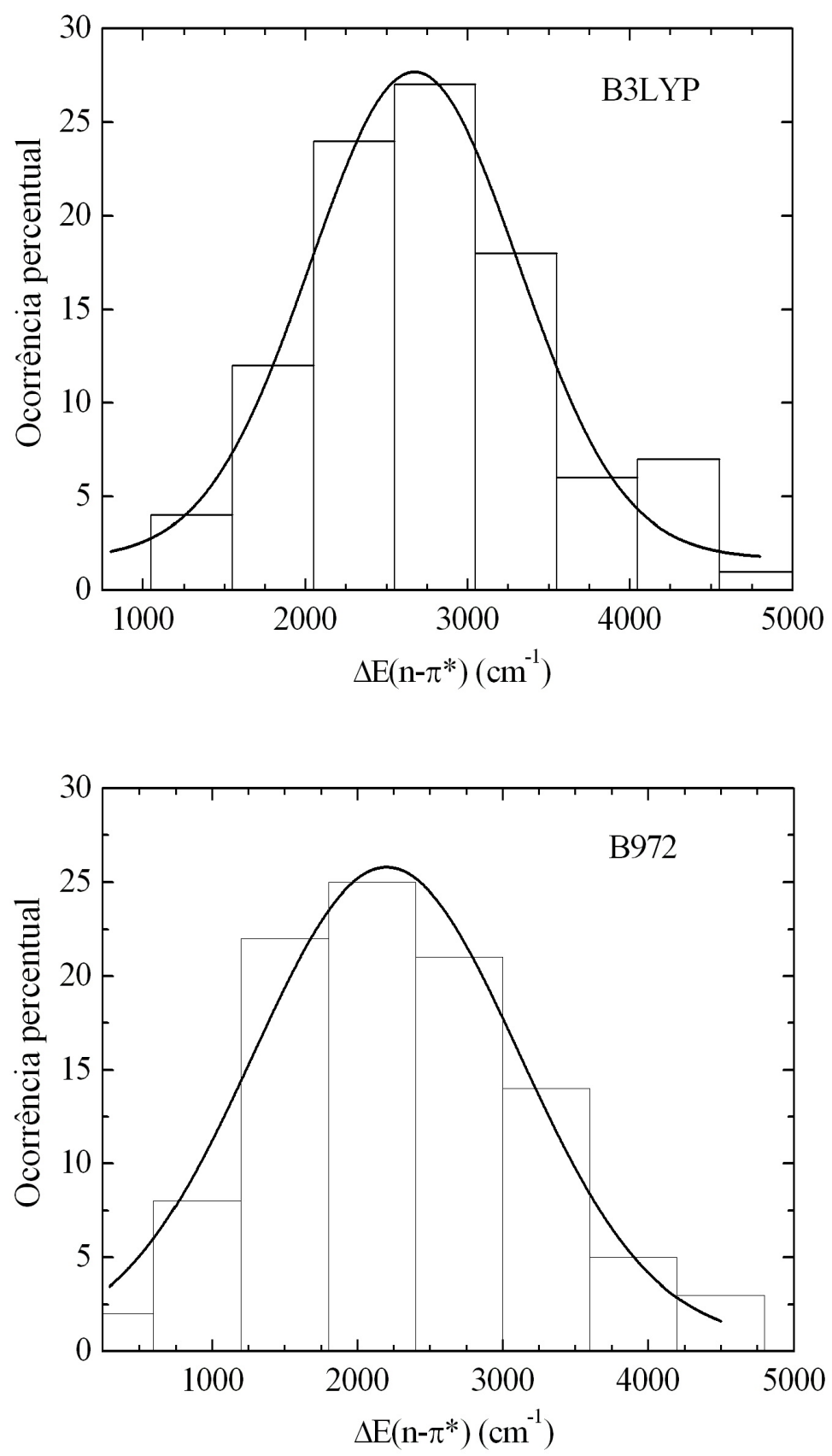

Figura 4.25: Histograma dos deslocamentos das bandas referentes à transição $\mathrm{n} \rightarrow \pi^{*}$ obtidos com os funcionais B3LYP e B972, com as bases 6-311++G(d,p) para o formaldeído e 6-31G para as 18 moléculas de água inclusas explicitamente no cálculo quântico. 
de água. Os valores designados por molécula explícita nesta tabela, foram obtidos incluindo as 18 moléculas de água nos cálculos quânticos explicitamente, utilizando-se a base 6-31G para estas moléculas. Nesta situação, assim como aconteceu com as estruturas de ligações de hidrogênio, o funcional B3LYP forneceu valores mais altos, cerca de $12 \%$ maiores, para o deslocamento da banda de energia $n \rightarrow \pi^{*}$ quando comparamos ao valor fornecido pelo funcional B972. Comparando aos valores obtidos por Mikkelsen e colaboradores [43], observamos que nossos valores para o deslocamento da banda estão ambos, bem abaixo do valor de $2803 \pm 46 \mathrm{~cm}^{-1}$ obtido com o potencial SPC polarizado para a água. Este é um bom indicativo para nossos resultados visto que não levamos em consideração a polarização nas moléculas de água do líquido. Se compararmos os mesmos valores de $\Delta E\left(n \rightarrow \pi^{*}\right)$ que obtivemos agora com o valor obtido por Mikkelsen utilizando o potencial não polarizado TIP3P, observamos que o funcional B3LYP ainda fornece um valor superestimado para a $\Delta E\left(n \rightarrow \pi^{*}\right)$, porém o funcional B972 fornece um valor médio semelhante ao valor obtido por Mikkelsen de $2139 \mathrm{~cm}^{-1}$. Vale a pena ressaltar que os valores médios obtidos na referência [233] incluem 145 moléculas de água no cálculo quântico, o que equivale a um raio de corte de $10 \AA$ A. Já em nossos cálculos para obtenção dos valores médios de $\Delta E\left(n \rightarrow \pi^{*}\right)$ o raio de corte foi de $5,15 \AA$, o que determina um número de coordenação de 18 moléculas de água. Sentimos então a necessidade de incluir mais moléculas de água em nossos cálculos quânticos. Porém, incluir moléculas de água de forma explícita seria computacionalmente inviável, já que cada cálculo com 18 moléculas de água explícitas leva em média 5 horas de $\mathrm{CPU}^{1}$. Sendo assim, submetemos estruturas com 18, 90 e 210 moléculas de água à cálculos quânticos onde as moléculas de água foram inclusas com cargas parciais que preservam a distribuição espacial das moléculas de água no líquido. Na tabela 4.20 apresentamos os valores médios de $\Delta E\left(n \rightarrow \pi^{*}\right)$ obtidos com as cargas pontuais das moléculas de água nas estruturas com 18, 90 e 210 moléculas de solvente. Se compararmos os valores obtidos com 18 moléculas de água com os obtidos com 210 moléculas de água inclusas nos cálculos quânticos, vemos que a inclusão de 192 moléculas de águas causou, coincidentemente, um

${ }^{1}$ Tempo de CPU relativo a uma máquina Athlon XP 2400. 
aumento de $258 \mathrm{~cm}^{-1}$ no $\Delta E\left(n \rightarrow \pi^{*}\right)$ com ambos os funcionais. Esse valor de $258 \mathrm{~cm}^{-1}$ equivale a um aumento de menos de $12 \%$ no deslocamento da banda de energia da transição $n \rightarrow \pi^{*}$ e significa o efeito da polarização sofrida pelo formaldeído devido às 192 moléculas de água a mais em torno do formaldeído.

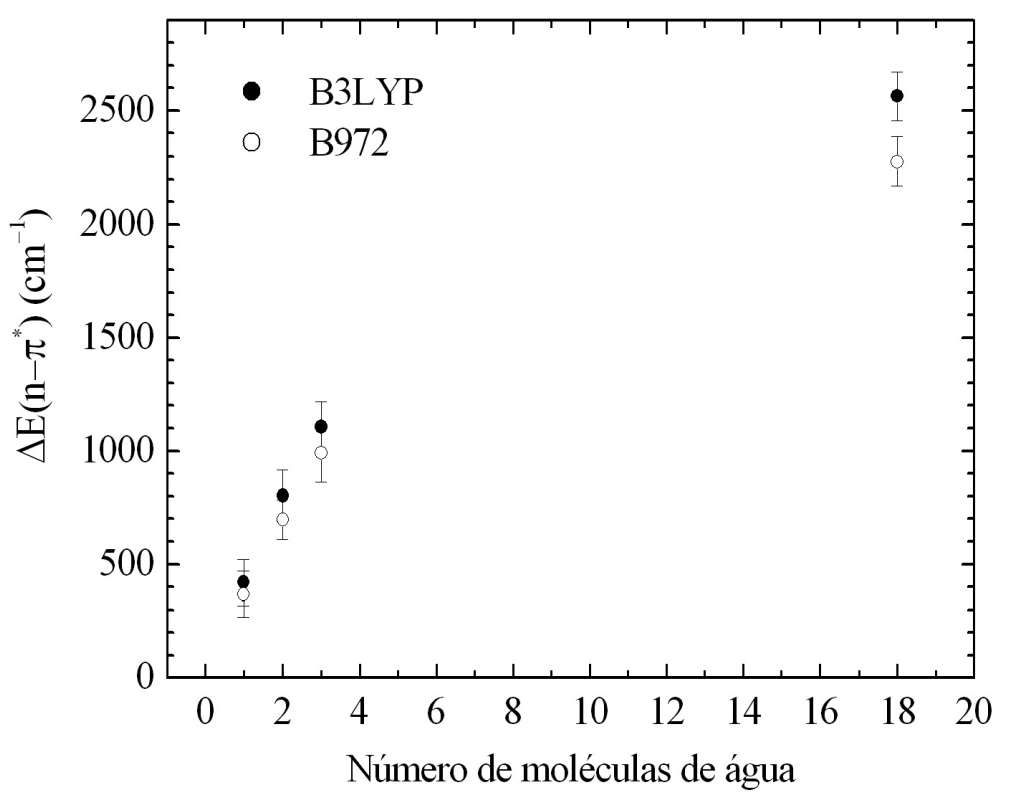

Figura 4.26: Saturação dos deslocamentos das bandas referentes à transição $\mathrm{n} \rightarrow \pi^{*}$ do formaldeído em água, em função do número de moléculas de água inclusas explicitamente no cálculo quântico. Valores obtidos com os funcionais B3LYP e B972, com as bases 6$311++\mathrm{G}(\mathrm{d}, \mathrm{p})$ para o formaldeído e $6-31 \mathrm{G}$ para as moléculas de água. As barras de erro representam o desvio padrão das médias obtidas.

Uma preocupação pertinente nesta fase do trabalho é saber quantas moléculas de água são necessárias para que haja uma saturação do deslocamento da banda $\mathrm{n} \rightarrow \pi^{*}$ do formaldeído em água. Como não é computacionalmente viável, utilizando a metodologia TD-DFT, a inclusão de um número maior que 18 moléculas de água explicitamente nos cálculos quânticos, podemos obter uma indicação da convergência do $\Delta E\left(n \rightarrow \pi^{*}\right)$ colocando os valores já obtidos quanticamente em um gráfico de $\Delta E\left(n \rightarrow \pi^{*}\right)$ em função do número de moléculas de água inclusas nos cálculos quânticos. A figura 4.26 nos sugere a tendência a um comportamento monotônico de $\Delta E\left(n \rightarrow \pi^{*}\right)$ com relação 
ao número de moléculas de água em torno do formaldeído. Podemos perceber também que somente com a primeira camada de solvatação (18 moléculas de água), ainda não podemos afirmar que o valor médio obtido para o deslocamento da banda reflete um valor saturado. Na tabela 4.20, podemos ver os valores de $\Delta E\left(n \rightarrow \pi^{*}\right)$ obtidos com as cargas pontuais das moléculas de água, e percebemos uma clara saturação do deslocamento como função do número de moléculas de água, já com 90 moléculas de água (segunda camada de solvatação) presentes em torno do formaldeído. Além disso, os valores obtidos na tabela 4.20 mostram que a inclusão da terceira camada de solvatação, que equivale a 210 moléculas de água em torno do formaldeído, não altera o valor médio para o deslocamento da banda $\mathrm{n} \rightarrow \pi^{*}$ do formaldeído em água.

Outra análise importante que deve ser feita diz respeito à influência do estiramento da ligação $\mathrm{C}=\mathrm{O}$ do formaldeído na transição eletrônica $\mathrm{n} \rightarrow \pi^{*} \mathrm{e}$ consequentemente, no deslocamento da banda referente a esta transição quando o formaldeído está solvatado em água. Na simulação Monte Carlo da qual obtivemos as configurações do líquido molecular, tanto o formaldeído quanto as moléculas de água permaneceram com suas coordenadas internas constantes, ou seja, permaneceram com geometria rígida, durante toda a simulação. A geometria do formaldeído utilizada na simulação foi obtida de uma otimização isolada, onde a ligação $\mathrm{C}=\mathrm{O}$ não sofreu nenhum estiramento. Em um trabalho anterior [148] desenvolvido em nosso grupo de pesquisa, a geometria do formaldeído inserida na simulação foi primeiramente otimizada na presença de uma molécula de água. Devido à ligação de hidrogênio que se formou entre o formaldeído e a água, a ligação $\mathrm{C}=\mathrm{O}$ sofreu um estiramento que pode ser observado comparando a distância de ligação $\mathrm{C}=\mathrm{O}$ no formaldeído nas duas situações, com e sem a molécula de água. Para ver o efeito do estiramento da ligação $\mathrm{C}=\mathrm{O}$ no deslocamento da banda de energia da transição $\mathrm{n} \rightarrow \pi^{*}$ do formaldeído isolado, realizamos uma sequência de 10 cálculos pontuais onde calculamos a energia da transição $\mathrm{n} \rightarrow \pi^{*}$ do formaldeído com a ligação $\mathrm{C}=\mathrm{O}$ sendo estirada de 0,001 $\AA$, variando a distância de ligação de 1,223 $\AA$ que é a distância otimizada isoladamente a $1,232 \AA$, que é a distância da ligação $\mathrm{C}=\mathrm{O}$ otimizada na presença da água. Estes cálculos TD-DFT foram realizados com 
os funcionais B3LYP e B972 na base 6-311++G(d,p), e a figura 4.27 apresenta os valores do deslocamento da banda $\mathrm{n} \rightarrow \pi^{*}$ para o formaldeído isolado em função da variação da distância $\mathrm{C}=\mathrm{O}$.

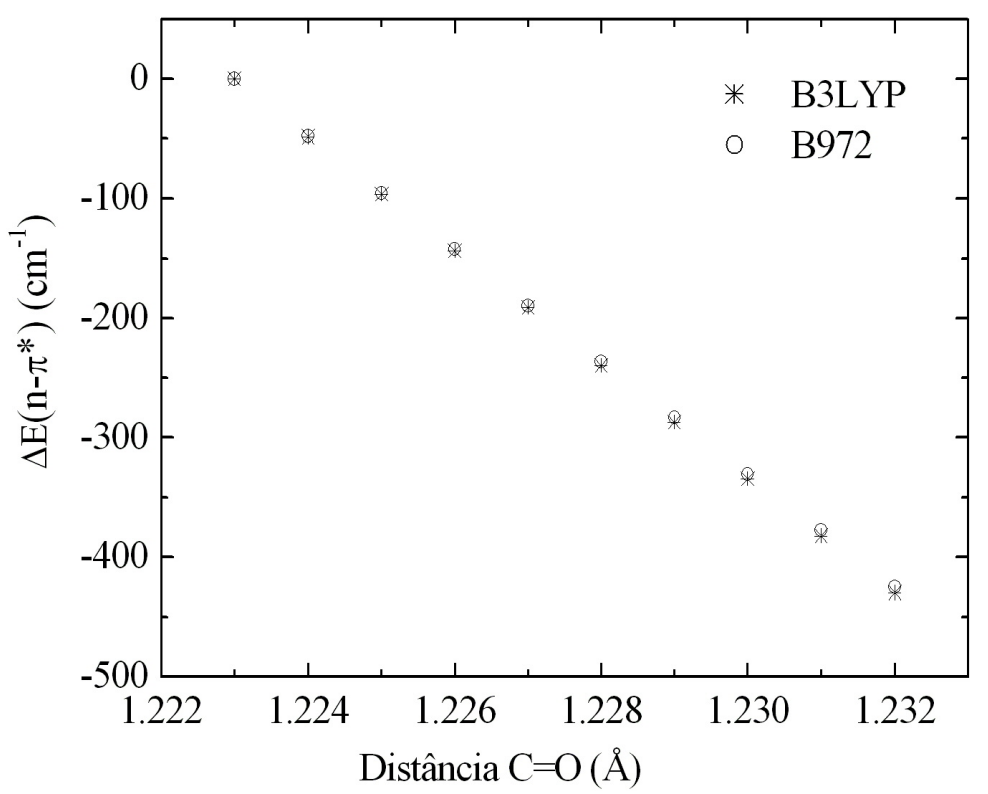

Figura 4.27: Deslocamento da banda de energia da transição $\mathrm{n} \rightarrow \pi^{*}$ em função do estiramento da ligação $\mathrm{C}=\mathrm{O}$ do formaldeído isolado. Cálculos pontuais realizados com os funcionais B3LYP e B972 na base 6-311++G(d,p).

Observamos na figura 4.27, como era esperado, que o estiramento da ligação $\mathrm{C}=\mathrm{O}$ do formaldeído causa um deslocamento pro vermelho na energia da transição $\mathrm{n} \rightarrow \pi^{*}$, ou seja, diminui a energia da transição eletrônica por cerca de $430 \mathrm{~cm}^{-1}$. Sendo assim, podemos levantar a hipótese de que nossos resultados para o deslocamento da banda de energia da transição $\mathrm{n} \rightarrow \pi^{*}$ possam estar superestimados por $\sim 430 \mathrm{~cm}^{-1}$, já que tanto na simulação quanto na referência para obtenção de $\Delta E$ o formaldeído não tem a ligação $\mathrm{C}=\mathrm{O}$ estirada.

Na figura 4.28 mostramos a saturação do deslocamento da banda $\mathrm{n} \rightarrow \pi^{*}$ do formaldeído em água obtidos em nível B3LYP/6-311++G(d,p). Nestes cálculos, as moléculas de água não foram inclusas explicitamente, mas como cargas pontuais em cada átomo das moléculas de água. Da esquerda para a direita os pontos mostram a inclusão de 15, 35, 80, 180 e 210 moléculas de 
água nos cálculos quânticos.

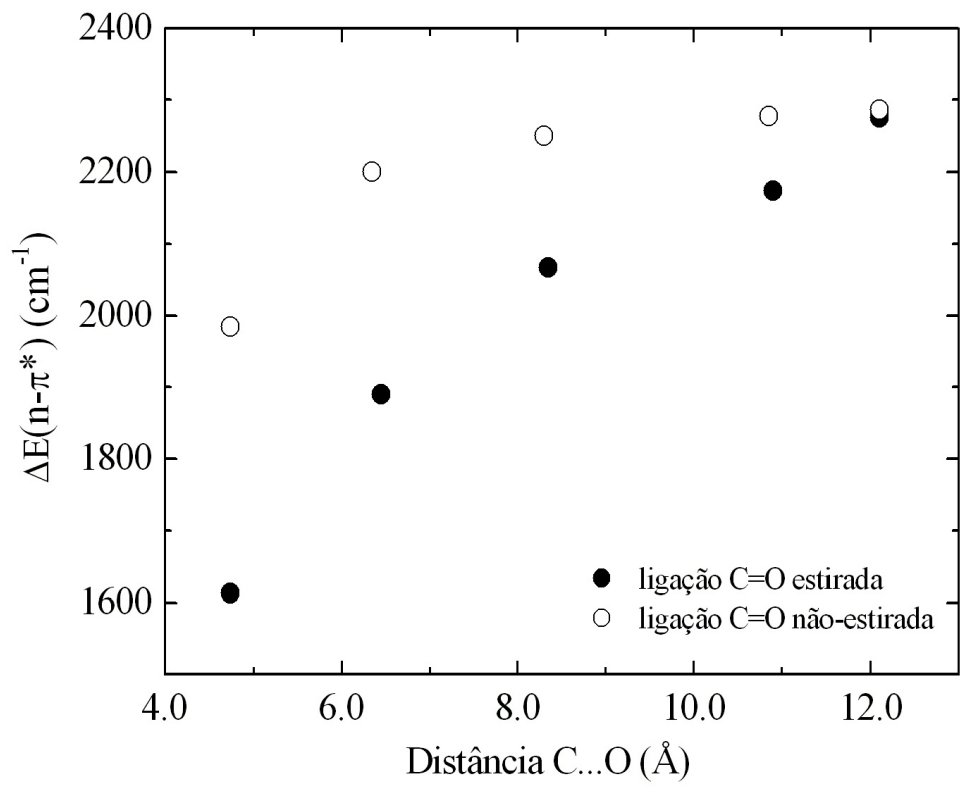

Figura 4.28: Saturação do deslocamento da banda de energia da transição $\mathrm{n} \rightarrow \pi^{*}$ em função da distância entre o átomo de carbono do formaldeído e o oxigênio da água. Cálculos pontuais realizados em nível B3LYP/6-311++G(d,p), as moléculas de água entraram nos cáculos como cargas pontuais nos átomos. Da esquerda para a direita, os pontos incluem as cargas pontuais de $15,35,80,180$ e 210 moléculas de água.

Comparando os pontos cheios, que referem-se a ligação $\mathrm{C}=\mathrm{O}$ estirada, com os pontos vazios, ligação $\mathrm{C}=\mathrm{O}$ não estirada, podemos notar que o fato da ligação $\mathrm{C}=\mathrm{O}$ do formaldeído não estar estirada provoca um aumento no $\Delta E\left(n \rightarrow \pi^{*}\right)$, de $371,311,183$ e $103 \mathrm{~cm}^{-1}$. Este aumento tem como referência os $\Delta E\left(n \rightarrow \pi^{*}\right)$ obtidos com a ligação $\mathrm{C}=\mathrm{O}$ do formaldeído estirada, obtidos de trabalho anterior desenvolvido no grupo [148]. A tendência à saturação do $\Delta E\left(n \rightarrow \pi^{*}\right)$ com respeito ao estiramento da ligação $\mathrm{C}=\mathrm{O}$ é constatada quando incluímos 210 moléculas de água nos cálculos quânticos. Nesta situação, a diferença entre os deslocamentos obtidos com e sem estiramento da ligação $\mathrm{C}=\mathrm{O}$ é de $\sim 11 \mathrm{~cm}^{-1}$. Assim, podemos afirmar que quando o sistema atinge proporções de bulk o estiramento da ligação $\mathrm{C}=\mathrm{O}$ do formaldeído não afeta o deslocamento da banda $\mathrm{n} \rightarrow \pi^{*}$ para o formaldeído solvatado em água.

Vimos a partir de nossos resultados, que o funcional B3LYP forne- 
ceu valores superestimados comparados ao funcional B972, para $\Delta E\left(n \rightarrow \pi^{*}\right)$ independente da quantidade de moléculas de água inseridas explicitamente nos cálculos quânticos, e o maior valor obtido com B3LYP é de $2564 \pm 108 \mathrm{~cm}^{-1}$ incluindo toda a primeira camada de solvatação. Já o valor para $\Delta E\left(n \rightarrow \pi^{*}\right)$ incluindo a primeira camada de solvatação, obtido com o funcional B972, de $2277 \pm 177 \mathrm{~cm}^{-1}$. Isso mostra que a utilização da metodologia TD-DFT requer cuidados com a escolha do funcional a ser utilizado, visto que em nosso trabalho os dois funcionais apresentaram valores distintos para as mesma diferença de energia, chegando a quase $300 \mathrm{~cm}^{-1}$ de diferença entre os valores obtidos com os dois funcionais.

\begin{tabular}{ccc}
\hline \hline & Método & $\boldsymbol{\Delta E}\left(\mathrm{cm}^{-1}\right)$ \\
\hline Kawashima et al [236] & QM/MMpol-vib/CAV (CASSCF) & 2690 \\
Fukunaga e Morokuma [237] & Supermolécula (SCF /EHP) & 3150 \\
Bader [238] & Modelo contínuo & 3500 \\
Canuto e Coutinho [148] & Supermolécula (INDO/CIS) & 2200 \\
Mennucci [239] & PCM (MCSCF) & 595 \\
Ten-no [240] & RISM-SCF (SCF /AM1) & 1210 \\
Blair [232] & QM/MM (SCF) & 1900 \\
Martin [241] & AESP/MD (CASSCF) & 1470 \\
Naka [242] & RISM-SCF (CASSCF) & 1998 \\
Thompson [243] & QM/MMpol (MNDO) & 1150 \\
Kongsted et al [233] & QM/MM (CCSD/MD) & 2139 \\
\hline \hline
\end{tabular}

Tabela 4.21: Valores para do deslocamento da banda referente à transição $\mathrm{n} \rightarrow \pi^{*}$ do formaldeído em água, em $\mathrm{cm}^{-1}$ obtidos na literatura.

Se compararmos estes dois valores, B3LYP de $2564 \pm 108 \mathrm{~cm}^{-1}$ e B972 de $2277 \pm 177 \mathrm{~cm}^{-1}$ com aqueles obtidos na literatura 4.21, vemos que os nossos valores estão dentro do intervalo que vai de $595 \mathrm{~cm}^{-1}$ [239] a 3500 $\mathrm{cm}^{-1}$ [238] para a mesma transição eletrônica do formaldeído em água. Vemos também na tabela 4.21 que de acordo com o modelo teórico utilizado pode obter resultados muito distintos e que a ausência de resultados experimentais do espectro eletrônico do formaldeído em água faz com que exista na literatura esta vasta variedade de resultados teóricos distintos.

Acreditamos que nossos resultados obtido com os funcionais B3LYP e B972 para o deslocamento $\Delta E\left(n \rightarrow \pi^{*}\right)$ de $2564 \pm 108 \mathrm{~cm}^{-1}$ e $2277 \pm 177$ 
$\mathrm{cm}^{-1}$ respectivamente, sejam boas estimativas para a diferença de energia da transição eletrônica $\left(\mathrm{n} \rightarrow \pi^{*}\right.$ ) já que são resultados próximos ao estimado para o sistema acetona-água de $\sim 1900 \mathrm{~cm}^{-1}$. Porém, a inclusão de somente 18 moléculas de água referentes a primeira camada de solvatação nos cálculos quânticos é insuficiente para garantir a saturação de $\Delta E$ da banda $\mathrm{n} \rightarrow \pi^{*}$ com a quantidade de moléculas de água solvatando o formaldeído. 


\section{Capítulo 5}

\section{Conclusões}

Nosso enfoque principal nesta tese foi o estudo de propriedades estruturais e eletrônicas de isômeros e agregados moleculares isolados e também estruturas obtidas em fase líquida. Especificamente, estudos da estabilidade isomérica de moléculas ou agregados moleculares mostram-se ainda bastante atuais e necessários, já que desta forma são propostas teoricamente estruturas moleculares que ainda não foram obtidas através de técnicas experimentais. Por outro lado, o estudo de sistemas em fase líquida e das modificações observadas em uma molécula de referência devido a interação desta com o meio são alvo de investigações tanto teóricas quanto experimentais. Particularmente, as soluções aquosas despertam muito interesse graças às diversas peculiaridades que envolvem a água. Tanto em agregados moleculares quanto em soluções onde a molécula de água se faz presente, a formação de ligações de hidrogênio é geralmente observada. Em nosso trabalho fizemos aplicações que nos deram a oportunidade de investigar sistemas isolados onde focamos a estabilidade relativa de isômeros e agregados moleculares, assim como investigamos modificações das propriedade eletrônicas e estruturais de moléculas orgânicas devido à interação destas moléculas com o meio aquoso em que estavam inseridas. Destas aplicações, pudemos tirar algumas conclusões que estão expostas a seguir.

Em nossa primeira aplicação, para a estabilidade isomérica de três estados singletos distintos da molécula de $\mathrm{AlP}_{3}\left(\mathrm{C}_{2 v}, \mathrm{C}_{s}\right.$ e $\left.\mathrm{C}_{3 v}\right)$, utilizamos métodos altamente correlacionados com grandes conjuntos de funções base e encontramos uma diferença de energia muito pequena entre as estruturas $\mathrm{C}_{2 v}$ 
e $\mathrm{C}_{s}$, porém, sistematicamente favorável à simetria $\mathrm{C}_{2 v}$. A extrapolação ao limite de base infinita usando $\operatorname{CSSD}(\mathrm{T}) / \mathrm{cc}-\mathrm{pVXZ}(\mathrm{X}=2,3,4$ e 5$)$ forneceu uma diferença relativa de energia de $1,6 \mathrm{kcal} / \mathrm{mol}$. Analisando as diferentes contribuições energéticas para o efeito de correlação eletrônica notamos que a estabilidade relativa depende crucialmente do tamanho do conjunto de funções base empregados e da inclusão das excitações triplas relativa ao estado HartreeFock de referência. As posições dos dois estados mais estáveis na hiper-superfície de energia potencial obtida mostram que estes estados são independentes e bem localizados representando isômeros estáveis e igualmente prováveis de serem obtidos em uma abordagem experimental.

Nossa segunda aplicação, para os agregados de $\mathrm{HCN}$ e $\mathrm{H}_{2} \mathrm{O}$, vimos que o agregado $\mathrm{H}_{2} \mathrm{O} \cdots \mathrm{HCN}$ é, em todos os níveis de cálculo, mais estável que o agregado $\mathrm{HCN}$... HOH. Dentre as duas estruturas formadas pelas moléculas de $\mathrm{HCN}$ e de $\mathrm{H}_{2} \mathrm{O}$ é energeticamante mais favorável o cianeto de hidrogênio doar prótons para a molécula de água, o que pode ser explicado pela maior basicidade do átomo de oxigênio da água em relação ao átomo de nitrogênio do HCN, fazendo com que a ligação de hidrogênio formada no agregado $\mathrm{H}_{2} \mathrm{O} \cdots \mathrm{HCN}$ seja mais forte que a ligação de hidrogênio formada no agregado $\mathrm{HCN} \cdots \mathrm{HOH}$. Em nosso melhor nível de cálculo, $\operatorname{CCSD}(\mathrm{T})$ no limite de base infinita, vemos que a energia de ligação do agregado $\mathrm{HCN} \cdots \mathrm{HOH}$ é de $-2,74 \mathrm{kcal} / \mathrm{mol}$ enquanto que para o isômero $\mathrm{H}_{2} \mathrm{O} \cdots \mathrm{HCN}$ é de $-4,17 \mathrm{kcal} / \mathrm{mol}$, no mesmo nível de cálculo, fornecendo uma estabilidade relativa entre os agregados de 1,43 $\mathrm{kcal} / \mathrm{mol}$. Essa diferença de energia de 1,43 kcal/mol influencia diretamente o equilíbrio isomérico e se reflete na abundância dos agregados em uma possível observação experimental.

Podemos afirmar com base nos dois sistemas estudados que níveis teóricos sofisticados aliados a esquemas de extrapolação para o limite de base completa, são eficientes e fornecem resultados confiáveis para a energia total do sistema. Porém a inclusão das excitações triplas também se mostraram de fundamental importância para um correta descrição do sistema.

Do estudo do sistema molecular formado por pirazina e água nas 
fases gasosa e líquida vimos que de um modo geral, as energias de ligação dos agregados isolados mostram uma estabilidade energética maior que nas estruturas do líquido. A diferença entre a energia de ligação das estruturas com a mesma quantidade de moléculas em fase gasosa e líquida nos mostra que no líquido, as estruturas estão com energia cerca de $30 \%$ mais fracas que nos agregados gasosos. Já para a energia de moléculas que não interagem diretamente no agregado a energia mostra um um valor negativo de $-0,11 \mathrm{kcal} / \mathrm{mol}$, o que significa que a presença de uma segunda molécula de água no agregado 1:2 isolado tende a estabilizar ligeiramente este agregado. Embora as energias de interação do par água-água dos agregados 1:2 mostrem comportamentos distintos quando isolados ou em líquido, devemos salientar que a magnitude destas energias são muito pequenas e por isso contribuem muito pouco para a energia de interação total das estruturas. Para as energias de interação de três corpos, $U_{3}$, vemos que tanto no agregado gasoso quanto nas estruturas do líquido, temos contribuições positivas que diferem entre si por apenas0, $10 \mathrm{kcal} / \mathrm{mol}$. Porém, ainda observamos a tendência anterior na qual o agregado isolado é energeticamente mais estável que as estruturas do líquido. Podemos dizer que existe cooperatividade em fase gasosa, mas nada podemos afirmar sobre a cooperatividade em fase líquida. Comparando os valores de $\Delta E_{3}$ que é a soma de todas as contribuições de dois e três corpos, vemos novamente que o agregado 1:2 isolado é mais estável que as estruturas do líquido por aproximadamente 4,60 $\mathrm{kcal} / \mathrm{mol}$, o que corresponde a $32 \%$ da energia de ligação total do agregado 1:2 isolado. Como já havia sido observado anteriormente para outros sistemas moleculares, as estruturas de líquido tem uma interação 30\% menor comparadas a agregados isolados e isto se deve ao fato de que no líquido a rede de ligações de hidrogênio formada entre todas as moléculas de água enfraquece a interação soluto-solvente.

Nos agregados de formaldeído e água, onde o formaldeído e a água atuam tanto como aceitadores como doadores de prótons, observamos um fortalecimento das ligações no agregado cíclico comparado ao agregado planar. Isto se deve ao fato de que no agregado cíclico, todas as moléculas interagem entre si, enquanto que no agregado planar as moléculas de água não interagem entre 
si, o que significa que estas moléculas não contribuem para a estabilização total do agregado.

Para a transição $\mathrm{n} \rightarrow \pi^{*}$ do formaldeído solvatado em água, podemos afirmar que quando o sistema atinge proporções de bulk o estiramento da ligação $\mathrm{C}=\mathrm{O}$ do formaldeído parece não afetar o deslocamento da banda $\mathrm{n} \rightarrow \pi^{*}$ do espectro eletrônico. Os funcionais B3LYP e B972, forneceram valores superestimados para $\Delta E\left(n \rightarrow \pi^{*}\right)$ quando comparamos com o deslocamento experimental da mesma banda no espectro eletrônico da acetona em água, cerca de $1900 \mathrm{~cm}^{-1}$. O valor obtido com o funcional B3LYP é de $2564 \pm 108 \mathrm{~cm}^{-1}$ e com o funcional B972, de $2277 \pm 177 \mathrm{~cm}^{-1}$, incluindo toda a primeira camada de solvatação de forma explícita. A utilização da metodologia TD-DFT requer cuidados com a escolha do funcional, visto que em nosso trabalho os dois funcionais apresentaram valores distintos para as mesma diferença de energia, chegando a diferir por quase $300 \mathrm{~cm}^{-1}$. Acreditamos que os resultados obtidos para $\Delta E\left(n \rightarrow \pi^{*}\right)$ sejam bons resultados por estarem perto da estimativa prevista experimentalmente no espectro eletrônico da acetona em água. Além disso mostram-se em bom acordo com resultados obtidos anteriormente. Porém, a inclusão de somente 18 moléculas de água, referentes a primeira camada de solvatação, é insuficiente para mostrar uma saturação no valor de $\Delta E$ da banda $\mathrm{n} \rightarrow \pi^{*}$. Portanto um número maior de moléculas de água deve ser levado em conta nos cálculos quânticos, o que não foi possível ser feito neste trabalho devido ao custo computacional associado à metodologia TD-DFT. 


\section{Bibliografia}

[1] H. Weber, editor, Structure and dynamics of weakly bound molecular complexes, Reidel, Dordrecht, The Netherlands, 1987.

[2] P. Hobza e R. H. Zahradnik, Intermolecular Complexes. The Role of Van der Waals Systems in Physical Chemistry and Biodisciplines, Elsevier, Amsterdam, 1988.

[3] G. Scoles, editor, The chemical physics of atomic and molecular clusters, North-Holland, Amsterdam, 1990.

[4] E. R. Bernstein, editor, Atomic and molecular clusters, Elsevier, Amsterdam, 1990.

[5] K. E. Drexler, Nanosystems: Molecular Machinery, Manufacturing, and Computation, John Wiley and Sons Inc., New York, 1992.

[6] J. Leszczynski, Computational Molecular Biology (Theoretical and Computational Chemistry), Elsevier Science B. V., Amsterdam, 1999.

[7] S. Bromberg e K. A. Dill, Molecular Driving Forces: Statistical Thermodynamics in Chemistry and Biology, Garland Science, New York, 2003.

[8] G. A. Mansoori, Principles of Nanotechnology: Molecular-based Study of Condensed Matter in Small Systems, World Scientific Publishing Co. Pte. Ltd., London, 2005.

[9] J. C. Slater, Quantum Theory of Molecular and Solids. Vol. 4: The SelfConsistent Field for Molecular and Solids, McGraw-Hill, New York, 1974. 
[10] W. J. Hehre, L. Radom, P. V. R. Schleyer e J. A. Pople, Ab initio molecular orbital theory, John Wiley, New York, 1986.

[11] R. McWeeny, Methods of molecular quantum mechanics, Academic Press, London, 1989.

[12] B. T. Sutcliffe, Computational techniques in quantum chemistry; Fundamentals of computational quantum chemistry, Oxford University Press, New York, 1989.

[13] A. Szabo e N. S. Ostlund, Modern quantum chemistry. Introduction to advanced electronic structure theory, Dover, New York, 1982.

[14] P. W. Atkins e R. S. Friedman, Molecular quantum mechanics, Oxford University Press, Oxford, 1997.

[15] R. F. Bishop, U. Kaldor, H. Kummel e D. Mukherjee, The Coupled Cluster Approach to Quantum Many-Particle Systems, Springer-Verlag, New York, 2003.

[16] R. J. Bartlett, Recent Advances in Coupled-Cluster Methods (Recent Advances in Computational Chemistry, Vol. 3, World Scientific Publishing Company, New York, 1997.

[17] I. N. Levine, Quantum Chemistry, Prentice Hall, New Jersey, 2000.

[18] S. C. O'Brien, Y. Liu, Q. L. Zhang, J. R. Heath, F. K. Tittel, R. F. Curl e R. E. Smalley, Supersonic cluster beams of III-V semiconductors: $\mathrm{Ga}_{X} \mathrm{As}_{y}$, J. Chem. Phys. 84, 4074 (1986).

[19] H. K. Quek, Y. P. Feng e C. K. Ong, Tight binding molecular dynamics studies of $\mathrm{Ga}_{m} \mathrm{As}_{m}$ and $\mathrm{Al}_{m} \mathrm{As}_{n}$ clusters, Z. Phys. D 42, 309 (1997).

[20] E. F. Archibong e E. N. Mvula, An ab initio and density functional study of $\mathrm{GaP}_{3}^{-}$and $\mathrm{GaP}_{3}$, Chem. Phys. Lett. 391, 325 (2004).

[21] P. Y. Feng e K. Balasubramanian, Electronic states of $\mathrm{Al}_{3} \mathrm{P}$ and $\mathrm{AlP}_{3}$ and their positive ions, Chem. Phys. Lett. 301, 458 (1999). 
[22] H. Gomez, T. R. Taylor e D. M. Neumark, Anion photoelectron spectroscopy of aluminum phosphide clusters, J. Phys. Chem. A 105, 6886 (2001).

[23] E. F. Archibong, S. K. Goh e D. S. Marynick, Electronic structure of $\mathrm{AlP}_{3}$ and $\mathrm{AlP}_{3}^{-}$, Chem. Phys. Lett. 361, 214 (2002).

[24] H. Wu, L. Guo e Z. Jin, First principles study of the structure, electronic state and stability of $\mathrm{Al}_{n} \mathrm{P}_{m}^{-}$anions, J. Mol. Struct. (THEOCHEM) 683, 43 (2004).

[25] L. Guo, H. Wu e Z. Jin, Ab initio investigation of structures and stability of $\mathrm{Al}_{n} \mathrm{P}_{m}$ clusters, J. Mol. Struct. (THEOCHEM) 684, 67 (2004).

[26] A. J. C. Varandas, Basis-set extrapolation of the correlation energy, J. Chem. Phys. 113, 8880 (2000).

[27] S. Canuto, K. Coutinho e J. C. Cabral, Hydrogen bonding and the energetics of homolytic dissociation in solution. A sequential Monte Carlo/Quantum Mechanics approach, in: Fundamental world of quantum chemistry. A tribute volume to the memory of Per-Olov Löwdin,vol 3, pp. 581-599, E. Brändas and E. Kryachko, Klüwer, 2004.

[28] T. Malaspina, K. Coutinho e S. Canuto, The relative stability of the two isomers of $\mathrm{AlP}_{3}$, Chem. Phys. Lett. 411, 14 (2005).

[29] S. S. Xantheas, Ab initio studies of cyclic clusters $\left(\mathrm{H}_{2} \mathrm{O}\right)_{n}, \mathrm{n}=1-6$. Analysis of many-body interactions, J. Chem. Phys. 100, 7523.

[30] S. S. Xantheas, On the importance of the fragment relaxation energy terms in the estimation of the basis set superposition error correction to the intermolecular interaction energy, J. Chem. Phys. 104, 8821 (1996).

[31] R. Rivelino e S. Canuto, An ab initio study of the hydrogen bonded $\mathrm{HCN} \cdots \mathrm{H}_{2} \mathrm{O}$ and $\mathrm{H}_{2} \mathrm{O} \cdots \mathrm{HCN}$ isomers, Chem. Phys. Lett. 322, 207 (2000). 
[32] L. Turi e J. J. Dannenberg, Molecular orbital studies of C-H ․ O hydrogen-bonded complexes, J. Chem. Phys. 97, 7899 (1993).

[33] H. S. Gutowsky, T. C. Germann, J. D. Augspurger e C. E. Dykstra, Structure and dynamics of the $\mathrm{H}_{2} \mathrm{O} \cdots \mathrm{HCN}$ dimer, J. Chem. Phys. 96, 5808 (1992).

[34] A. Heikkilä, M. Pettersson, J. Lundell, L. Khriachtchev e M. Räsänen, Matrix isolation and ab initio studies of 1:1 hydrogen-bonded complexes $\mathrm{HCN} \cdots \mathrm{H}_{2} \mathrm{O}$ and $\mathrm{HNC} \cdots \mathrm{H}_{2} \mathrm{O}$ produced by photolysis of formaldoxime, J. Phys. Chem. A 103, 2945 (1999).

[35] F. Jensen, Introduction to computational chemistry, John Wyley, New York, 1999.

[36] O. Tapia e O. Goscinski, Self-consistent reaction field-theory of solvent effects, Mol. Phys. 29, 1653 (1975).

[37] A. Warshel e M. Levitt, Theoretical studies of enzymatic reactions - Dielectric, electrostatic and steric stabilization of carbonium-ion in reaction of lysozyme, J. Mol. Biol. 103, 227 (1976).

[38] A. Warshel, Calculations of chemical processes in solutions, J. Phys. Chem. 83, 1640 (1979).

[39] K. Coutinho e S. Canuto, Solvent effects from a sequential Monte Carloquantum mechanical approach, Adv. Quantum Chem. 28, 89 (1997).

[40] K. Coutinho, S. Canuto e M. C. Zerner, A Monte Carlo-quantum mechanics study of the solvatochromic shift of the lowest excited state of benzene, J. Chem. Phys. 112, 9874 (2000).

[41] R. D. Parra, S. Bulusu e X. C. Zeng, Cooperative effects in twodimensional ring-like networks of three-center hydrogen bonding interactions, J. Chem. Phys. 122, 184325 (2005). 
[42] A. Karpfen e E. S. Kryachko, Strongly blue-shifted C-H stretches: Interaction of formaldehyde with hydrogen fluoride clusters, J. Phys. Chem. A 109, 8930 (2005).

[43] J. Kongsted, A. Osted, T. B. Pedersen e K. V. Mikkelsen, The $n-\pi^{*}$ electronic transition in microsolvated formaldehyde. A coupled cluster and combined Coupled Cluster/Molecular Mechanics study, J. Phys. Chem. A 108, 8624 (2004).

[44] M. Dupuis, M. Aida, Y. Kawashima e K. Hirao, A polarizable mixed Hamiltonian model of electronic structure for micro-solvated excited states. I. Energy and gradients formulation and aplication to formaldehyde $\left({ }^{1} \mathrm{~A}_{2}\right)$, J. Chem. Phys. 117, 1242 (2002).

[45] T. Bercovici, J. King e R. S. Becker, Formaldehyde: Comprehensive spectral investigation as a function of solvent and temperature, J. Chem. Phys. 56, 3956 (1972).

[46] C. A. Cantrell, J. A. Davidson, A. H. M. Daniel, R. E. Shetter e J. G. Calvert, Temperature-dependent formaldehyde cross sections in the nearultraviolet spectral region, J. Phys. Chem. 94, 3902 (1990).

[47] T. A. Ramelot, C. H. Hu, J. E. Fowler, B. J. DeLeeuw e H. F. Schaefer III, Carbonyl-water hydrogen bonding: The $\mathrm{H}_{2} \mathrm{CO}-\mathrm{H}_{2} \mathrm{O}$ prototype, J. Chem. Phys. 100, 4347 (1994).

[48] R. J. Vos, R. Hendriks e F. B. V. Duijneveldt, SCF, MP2 and CEPA1 calculations on the $\mathrm{OH} \cdots \mathrm{O}$ hydrogen bonded complexes $\left(\mathrm{H}_{2} \mathrm{O}-\mathrm{H}_{2} \mathrm{O}\right)_{2}$ and $\left(\mathrm{H}_{2} \mathrm{CO}-\mathrm{H}_{2} \mathrm{O}\right)$, J. Comp. Chem. 11, 1 (1990).

[49] R. A. Kumpf e J. R. Damewood Jr., Interaction of formaldehyde with water, J. Phys. Chem. 93, 4478 (1989).

[50] J. M. Haile, Molecular Dynamics Simulation: Elementary Methods, Wiley, New York, USA, 1992.

[51] D. C. Rapaport, The art of molecular dynamics, Cambridge University Press, Cambridge, 1995. 
[52] D. Frenkel e B. Smit, Understanding molecular simulation, Academic Press, San Diego, USA, 2002.

[53] D. M. Heyes, The liquid state. Applications of molecular simulations, John Wiley, New York, 1998.

[54] M. P. Allen e D. J. Tildesley, Computer simulation of liquids, Clarendon Press, Oxford, 1987.

[55] D. P. Landau e K. Binder, A guide to Monte Carlo simulations in statistical physics, Cambridge University Press, Cambridge, UK, 2000.

[56] N. Metropolis e S. Ulam, The Monte Carlo method, J. Am. Stat. Ass. 44, 335 (1949).

[57] N. Metropolis, A. W. Rosenbluth, M. N. Rosenbluth, A. H. Teller e E. Teller, Equation of state calculations by fast computing machines, J. Chem. Phys. 21, 1087 (1953).

[58] M. P. Nightingale e C. J. Umrigar, editors, Quantum Monte Carlo methods in physics and chemistry, Kluwer Academic Publishers, New York, USA, 1999.

[59] S. Canuto, K. Coutinho e M. C. Zerner, Including dispersion in configuration interaction-singles calculations for the spectroscopy of chromophores in solution, J. Chem. Phys. 112, 7293 (2000).

[60] K. Coutinho e S. Canuto, The sequential Monte Carlo-quantum mechanics methodology. Application to the solvent effects in the Stokes shift of acetone in water, J. Mol. Struct. (THEOCHEM) 632, 235 (2003).

[61] K. Coutinho, M. J. Oliveira e S. Canuto, Sampling configurations in the Monte Carlo simulation of solvent effects, Int. J. Quantum Chem. 66, 249 (1998).

[62] S. Canuto, K. Coutinho e D. Trzresniak, New developments in Monte Carlo/quantum mechanics methodology. The solvatochromism of betacarotene in different solvents, Adv. Quantum Chem. 41, 161 (2002). 
[63] J. F. Briesmeister, MCNP: A general Monte Carlo N-particle transport code, version 4A, 1993.

[64] R. V. Sole e J. Valls, Nonlinear phenomena and chaos in a Monte-Carlo simulated microbial ecosystem, Bull. Math. Bio. 54, 939 (1992).

[65] A. Achahbar e J. Marro, Phase-transitions in a driven lattice-gas in 2 planes, J. Stat. Phys. 78, 1493 (1995).

[66] H. Bekker, Unification of box shapes in molecular simulations, J. Comp. Phys. 18, 1930 (1997).

[67] D. P. Ehrenfest e T. Ehrenfest, The conceptual foundations of the statistical approach in mechanics, Cornell University Press, Ithaca, New York, 1959.

[68] R. K. Pathria, Statistical mechanics, Pergamon Press, Oxford, 1977.

[69] R. Kubo, Statistical mechanics, North-Holland, Amsterdam, 1965.

[70] J. E. Lennard-Jones, The determination of molecular fields. II. From the equation of state of a gas, Proc. R. Soc. Lon. 106, 463 (1924).

[71] K. Coutinho e S. Canuto, Dice (version 2.8): A general Monte Carlo program for liquid simulation, 2000.

[72] H. E. Fischer, A. C. Barnes e P. S. Salmon, Neutron and x-ray diffraction studies of liquids and glasses, Rep. Prog. Phys. 69, 233 (2006).

[73] P. Wernet, D. Nordlund, U. Bergmann, M. Cavalleri, M. Odelius, H. Ogasawara, L. A. Naslund, T. K. Hirsch, L. Ojamae, P. Glatzel, L. G. M. Pettersson e A. Nilsson, The structure of the first coordination shell in liquid water, Science 304, 995 (2004).

[74] C. Park, M. Saito, Y. Waseda, N. Nishiyama e A. Inoue, Structural study of Pd-based amorphous alloys with wide supercooled liquid region by anomalous X-ray scattering, Mat. Transac. 40, 491 (1999). 
[75] W. R. Rocha, K. Coutinho, W. B. de Almeida e S. Canuto, An efficient quantum mechanical/molecular mechanics Monte Carlo simulation of liquid water, Chem. Phys. Lett. 335, 127 (2001).

[76] C. Chatfield, The Analysis of Time Series: An Introduction, CRC Press LLC, Boca Raton, Florida, 2004.

[77] R. Krätschmer, K. Binder e D. Stauffer, Linear and nonlinear relaxation and cluster dynamics near critical-points, J. Stat. Phys. 15, 267 (1976).

[78] M. Born e J. R. Oppenheimer, Zur quantentheorie der molekeln, Annln. Phys. 84, 457 (1927).

[79] M. Born e K. Huang, Dynamical theory of cristal lattices, Oxford University Press, London, 1954.

[80] W. Pauli, The hydrogen spectrum from the standpoint of the new quantum mechanics, Z. Physik. 36, 336 (1926).

[81] D. R. Hartree, The wave mechanics of an atom with a non-Coulomb central field. Part I - Theory and methods, Proc. Camb. Phil. Soc. 24, 111 (1928).

[82] V. A. Fock, Näherungsmethode zur lösung des quantenmechanischen mehrkörperproblems, Z. Physik. 61, 126 (1930).

[83] J. C. Slater, The theory of complex spectra, Phys. Rev. 34, 1293 (1929).

[84] J. C. Slater, Note on Hartree's method, Phys. Rev. 35, 210 (1930).

[85] C. C. J. Roothaan, New developments in molecular orbital theory, Mod. Phys. 23, 69 (1951).

[86] J. D. Vianna, A. Fazzio e S. Canuto, Teoria quântica de moléculas e sólidos, Livraria da Física, São Paulo, 2004.

[87] P. O. Löwdin, Correlation problem in many-electron quantum mechanics. 1. Review of different approaches and discussion of some current ideas, Adv. Chem. Phys. 2, 207 (1959). 
[88] C. Møller e M. S. Plesset, Note on an approximation treatment for manyelectron systems, Phys. Rev. 46, 618 (1934).

[89] K. A. Brueckner, Many-body problem for strongly interacting particles. 2. Linked cluster expansion, Phys. Rev. 100, 36 (1955).

[90] J. Goldstone, Derivation of the Brueckner many-body theory, Proc. R. Soc. Lon. 239, 267 (1957).

[91] J. Č́žzek, On the correlation problem in atomic and molecular systems. Calculation of wavefunction components in ursell-type expansion using quantum-field theoretical methods, J. Chem. Phys. 45, 4256 (1966).

[92] J. Paldus e J. Č́žzek, Time-independent diagrammatic approach to perturbation theory of fermion systems, Adv. Quantum Chem. 9, 105 (1975).

[93] R. J. Bartlett, Many-body perturbation theory and coupled cluster theory for electon correlation in molecules, Ann. Rev. Phys. Chem. 32, 359 (1981).

[94] J. Č́žzek, Adv. Chem. Phys. 14, 35 (1969).

[95] M. Urban, J. Noga, S. J. Cole e R. J. Bartlett, Towards a full CCSDT model for electron correlation, J. Chem. Phys. 83, 4041 (1985).

[96] J. Noga e R. J. Bartlett, The full CCSDT model for molecular electronic structure, J. Chem. Phys. 86, 7041 (1987).

[97] L. H. Thomas, The calculation of atomic fields, Proc. Camb. Phil. Soc. 23, $542(1927)$.

[98] E. Fermi, Eine statistische methode zur bestimmung einiger eigenschaften des atoms und ihre anwendung auf die theorie des periodischen systems der elemente, Z. Physik. 48, 73 (1928).

[99] P. Hohenberg e W. Kohn, Inhomogeneous electron gas, Phys. Rev. 136, 864 (1964). 
[100] W. Kohn e L. J. Sham, Self-consistent equations including exchange and correlation effects, Phys. Rev. 140, 1133 (1965).

[101] R. G. Parr e W. Yang, Density functional theory of atoms and molecules, Oxford University Press, New York, 1989.

[102] T. Ziegler, Approximate density functional theory as a practical tool in molecular energetics and dynamics, Chem. Rev. 91, 651 (1991).

[103] C. T. Lee, W. T. Yang e R. G. Parr, Development of the ColleSalvetti correlation-energy formula into a functional of the electrondensity, Phys. Rev. B 37, 785 (1988).

[104] J. P. Perdew, Density-functional approximation for the correlation-energy of the inhomogeneous electron-gas, Phys. Rev. B 33, 8822 (1986).

[105] A. D. Becke, Density-functional exchange-energy approximation with correct asymptotic-behavior, Phys. Rev. A 38, 3098 (1988).

[106] A. D. Becke, Density-functional thermochemistry. III. The role of exact exchange, J. Chem. Phys. 98, 5648 (1993).

[107] J. P. Perdew, J. A. Chevary, S. H. Vosko, K. A. Jackson, M. R. Pederson, D. J. Singh e C. Fiolhais, Atoms, molecules, solids and surfaces applications of the generalized gradient approximation for exchange and correlation, Phys. Rev. B 46, 6671 (1992).

[108] P. J. Wilson, T. J. Bradley e D. J. Tozer, Hybrid exchange-correlation functional determined from termochemical data and ab initio potentials, J. Chem. Phys. 115, 9233 (2001).

[109] E. Runge e E. K. U. Gross, Density-functional theory for time-dependent systems, Phys. Rev. Lett. 52, 997 (1984).

[110] E. K. U. Gross e W. Kohn, Local density-functional theory of frequencydependent linear response, Phys. Rev. Lett. 55, 2850 (1985).

[111] T. Ando, Inter-subband optical absorption in space-charge layers on semiconductor surfaces, Z. Phys. B 26, 263 (1977). 
[112] A. Zangwill e P. Soven, Density-functional approach to local-field effects in finite systems: Photoabsorption in the rare gases, Phys. Rev. A 21, 1561 (1980).

[113] M. A. L. Marques e E. K. U. Gross, Time-dependent density functional theory, Ann. Rev. Phys. Chem. 55, 427 (2004).

[114] W. J. Hehre, R. F. Stewart e J. A. Pople, Self-consistent molecular-orbital methods. I. Use of gaussian expansions of Slater-type atomic orbitals, J. Chem. Phys. 51, 2657 (1969).

[115] T. H. Dunning, Gaussian-basis sets for use in correlated molecular calculations. 1. The atoms boron through neon and hydrogen, J. Chem. Phys. 90, 1007 (1989).

[116] R. Ditchfield, W. J. Hehre e J. A. Pople, Self-Consistent molecular-orbital methods. IX. An extended gaussian-type basis for molecular-orbital studies of organic molecules, J. Chem. Phys. 54, 724 (1971).

[117] W. J. Hehre, R. Ditchfield e J. A. Pople, Self-consistent molecular orbital methods. XII. Further extensions of gaussian-type basis sets for use in molecular orbital studies of organic molecules, J. Chem. Phys. 56, 2257 (1972).

[118] P. C. Hariharan e J. A. Pople, Accuracy of AH, equilibrium geometries by single determinant molecular orbital theory, Mol. Phys. 27, 209 (1974).

[119] M. S. Gordon, The isomers of silacyclopropane, Chem. Phys. Lett. 76, 163 (1980).

[120] A. D. McLean e G. S. Chandler, Contracted Gaussian basis sets for molecular calculations. I. Second row atoms, $\mathrm{Z}=11-18$, J. Chem. Phys. 72, 5639 (1980).

[121] R. Krishnan, J. S. Binkley, R. Seeger e J. A. Pople, Self-consistent molecular orbital methods. XX. A basis set for correlated wave functions, J. Chem. Phys. 72, 650 (1980). 
[122] D. E. Woon e T. H. Dunning Jr., Gaussian basis sets for use in correlated molecular calculations. III. The atoms aluminum through argon, J. Chem. Phys. 98, 1358 (1993).

[123] R. A. Kendall, T. H. Dunning Jr. e R. J. Harrison, Electron affinities of the first-row atoms revisited. Systematic basis sets and wave functions, J. Chem. Phys. 96, 6796 (1992).

[124] K. A. Peterson, D. E. Woon e T. H. Dunning Jr., Benchmark calculations with correlated molecular wave functions. IV. The classical barrier height of the $\mathrm{H}+\mathrm{H}_{2} \longrightarrow \mathrm{H}_{2}+\mathrm{H}$ reaction, J. Chem. Phys. 100, 7410 (1994).

[125] T. Helgaker, P. Jørgensen e J. Olsen, Molecular electroni-structure theory, Wiley, Chinchester, 2000.

[126] D. Feller, Application of systematic sequences of wave functions to the water dimer, J. Chem. Phys. 96, 6104 (1992).

[127] D. Feller, The use of systematic sequences of wave functions for estimating the complete basis set, full configuration interaction limit in water, J. Chem. Phys. 98, 7059 (1992).

[128] Y. Chuang e D. G. Truhlar, Geometry Optimization with an Infinite Basis Set, J. Phys. Chem. A 103, 651 (1999).

[129] A. Halkier, T. Helgaker, W. Klopper, P. Jørgensen e A. G. Császár, Comment on: Geometry optimization with an infinite basis set by Y. Chuang et al., Chem. Phys. Lett. 310, 385 (1999).

[130] S. B. Huh e J. S. Lee, Basis set and correlation dependent extrapolation of correlation energy, J. Chem. Phys. 118, 3035 (2003).

[131] S. Y. Park, S. B. Huh e J. S. Lee, Basis set convergence of correlated calculations on $\mathrm{HF}, \mathrm{H}_{2} \mathrm{O}, \mathrm{N}_{2}, \mathrm{CO}$, and Ne, J. Mol. Struct. (THEOCHEM) 586, 81 (2002).

[132] D. G. Truhlar, Basis-set extrapolation, Chem. Phys. Lett. 294, 45 (1998). 
[133] S. Y. Park e J. S. Lee, Basis set limit binding energies of dimers derived from basis set convergence of monomer energies, J. Chem. Phys. 116, 5389 (2002).

[134] R. J. Gdanitz, Accurately solving the electronic Schrödinger equation of atoms and molecules by extrapolating to the basis set limit. I. The helium dimer $\left(\mathrm{He}_{2}\right)$, J. Chem. Phys. 113, 5145 (2000).

[135] E. F. Laschuk e P. R. Livotto, Convergence of triples energy in $\operatorname{CCSD}(\mathrm{T})$ and $\mathrm{CC} 3$ calculations with correlation-consistent basis sets, J. Chem. Phys. 121, 12146 (2004).

[136] J. S. Lee, Accurate ab initio determination of binding energies for rare-gas dimers by basis set extrapolation, Theor. Chim. Acta 113, 87 (2005).

[137] B. J. C. Cabral e S. Canuto, The enthalpy of the O-H bond homolytic dissociation: Basis-set extrapolated density functional theory and coupled cluster calculations, Chem. Phys. Lett. 406, 300 (2005).

[138] S. Scheiner, Hydrogen bonding: A theoretical perspective, Oxford University Press, Oxford, 1997.

[139] S. F. Boys e F. Bernardi, Calculation of small molecular interactions by differences of separate total energies - Some procedures with reduced errors, Mol. Phys. 19, 553 (1970).

[140] G. C. Pimentel e A. L. Mc Clellan, The hydrogen bond, Freeman, San Francisco, 1960.

[141] D. A. Smith, editor, Modeling the hydrogen bond, ACS Publication, Washington, D.C., 1994.

[142] G. A. Jeffrey, An introduction to hydrogen bond, Oxford University Press, Oxford, 1997.

[143] D. Hadzi, editor, Theoretical treatments of hydrogen bonding, Wiley, Chichester, UK, 1997. 
[144] T. Malaspina, K. Coutinho e S. Canuto, Ab initio calculation of hydrogen bonds in liquids: A sequential Monte Carlo quantum mechanics study of pyridine in water, J. Chem. Phys. 117, 1692 (2002).

[145] R. Rivelino, V. Ludwig, E. Rissi e S. Canuto, Theoretical studies of hydrogen bonding in water-cyanides and in the base pair Gu-Cy, J. Mol. Struct. 615, $259(2002)$.

[146] K. Coutinho, N. Saavedra e S. Canuto, Theoretical analysis of the hydrogen bond interaction between acetone and water, J. Mol. Struct. (THEOCHEM) 466, 69 (1999).

[147] E. E. Fileti, R. Rivelino e S. Canuto, Rayleigh light scattering of hydrogen bonded clusters, J. Phys. B: At. Mol. Opt. Phys. 36, 399 (2003).

[148] S. Canuto e K. Coutinho, From hydrogen bond to bulk: Solvation analysis of the $n-\pi^{*}$ transition of formaldehyde in water, Int. J. Quantum Chem. 77, $192(2000)$.

[149] E. E. Fileti, K. Coutinho, T. Malaspina e S. Canuto, Electronic changes due to thermal disorder of hydrogen bonds in liquids. Pyridine in aqueous environment, Phys. Rev. E 67, 61504 (2003).

[150] R. Rivelino e S. Canuto, Theoretical investigation of hydrogen bonding in lactonitrile-water complexes., Int. J. Quantum Chem. 103, 654 (2005).

[151] E. E. Fileti, P. Chaudhuri e S. Canuto, Relative strength of hydrogen bond interaction in alcohol-water complexes, Chem. Phys. Lett. 400, 494 (2004).

[152] W. Caminati, P. Moreschini e P. G. Favero, The hydrogen bond between water and aromatic bases of biological interest: Rotational spectrum of pyridazine-water, J. Phys. Chem. A 102, 8097 (1998).

[153] S. Scheiner, T. Kar e Y. Gu, Strength of the (CH)-H-alpha ‥ O hydrogen bond of amino acid residues, J. Biol. Chem. 276, 9832 (2001). 
[154] H. S. Park, K. S. Oh, K. S. Kim, T. Chang e D. R. Spiegel, Change of internal hydrogen bonding of methyl red upon photoisomerization monitored by forced Rayleigh scattering, J. Phys. Chem. B 103, 2355 (1999).

[155] M. W. Feyereisen, D. Feller e D. A. Dixon, Hydrogen bond energy of the water dimer, J. Phys. Chem. 100, 2993 (1996).

[156] S. Tsuzuki, T. Uchimaru, K. Matsumura, M. Mikami e K. Tanabe, Effects of basis set and electron correlation on the calculated interaction energies of hydrogen bonding complexes: MP2/cc-pV5Z calculations of $\mathrm{H}_{2} \mathrm{O} \cdots \mathrm{MeOH}, \mathrm{H}_{2} \mathrm{O} \cdots \mathrm{Me} 2 \mathrm{O}, \mathrm{H}_{2} \mathrm{O} \cdots \mathrm{H}_{2} \mathrm{CO}, \mathrm{MeOH} \cdots \mathrm{MeOH}$ and HCOOH $\cdots$ HCOOH complexes, J. Chem. Phys. 110, 11906 (1999).

[157] G. M. Gale, G. Gaillot, F. Hache, N. Lascoux, S. Bratos e J. C. Leickman, Femtosecond dynamics of hydrogen bonds in liquid water: A real time study, Phys. Rev. Lett. 82, 1068 (1999).

[158] A. J. Stone, A. D. Buckingham e P. W. Fowler, Structure and spectroscopy of $(\mathrm{HCN})_{n}$ clusters: Cooperative and electronic delocalization effects in $\mathrm{C}-\mathrm{H} \cdots \mathrm{N}$ hydrogen bonding - Comment, J. Chem. Phys. 107, 1030 (1997).

[159] B. F. King e F. Weinhold, Structure and spectroscopy of $(\mathrm{HCN})_{n}$ clusters - Cooperative and electronic delocalization effects in $\mathrm{C}-\mathrm{H} \cdots \mathrm{N}$ hydrogen bonding, J. Chem. Phys. 103, 333 (1995).

[160] B. F. King, T. C. Farrar e F. Weinhold, Quadrupole coupling-constants in linear $(\mathrm{HCN})_{n}$ clusters. Theoretical and experimental evidence for coorperative effects in $\mathrm{C}-\mathrm{H} \cdots \mathrm{N}$ hydrogen bonding, J. Chem. Phys. 103, 348 (1995).

[161] E. D. Isaacs, A. Shukla, P. M. Platzman, D. R. Hamann, B. Barbiellini e C. A. Tulk, Covalency of the hydrogen bond in ice: A direct X-ray measurement, Phys. Rev. Lett. 82, 600 (1999). 
[162] T. K. Ghanty, V. N. Staroverov, P. R. Koren e E. R. Davidson, Is the hydrogen bond in water dimer and ice covalent?, J. Am. Chem. Soc. 122, $1210(2000)$.

[163] J. H. Guo, Y. Luo, A. Augustsson, J. E. Rubensson, C. Sathe, H. Ågren, H. Siegbahn e J. Nordgren, X-ray emission spectroscopy of hydrogen bonding and electronic structure of liquid water, Phys. Rev. Lett. 89, $137402(2002)$.

[164] G. Cornilescu, J. S. Hu e A. Bax, Identification of the hydrogen bonding network in a protein by scalar couplings, J. Am. Chem. Soc. 121, 2949 (1999).

[165] A. J. Dingley e S. Grzesiek, Direct observation of hydrogen bonds in nucleic acid base pairs by internucleotide ${ }^{2} \mathrm{~J}_{N N}$ couplings, J. Am. Chem. Soc. 120, 8293 (1998).

[166] B. Mennucci, J. M. Martinez e J. Tomasi, Solvent effects on nuclear shieldings: Continuum or discrete solvation model to treat hydrogen bond and polarity effects?, J. Phys. Chem. A 105, 7287 (2001).

[167] C. L. Perrin e J. B. Nielson, Strong hydrogen bonds in chemistry and biology, Ann. Rev. Phys. Chem. 48, 511 (1997).

[168] R. A. Provencal, R. N. Casaes, K. Roth, J. B. Paul, C. N. Chapo, R. J. Saykally, G. S. Tschumper e Schaefer III, Hydrogen bonding in alcohol clusters: A comparative study by infrared cavity ringdown laser absorption spectroscopy, J. Phys. Chem. A 104, 1423 (2000).

[169] J. H. Kim, H. J. Lee, E. J. Kim, E. J. Jung, Y. S. Choi, J. Park e C. J. Yoon, Hydrogen bonding ability of azabenzenes toward thioacetamide, acetamide and water, J. Phys. Chem. A 108, 921 (2004).

[170] P. Vishweshwar, N. J. Babu, A. Nangia, S. A. Mason, H. Puschmann, R. Mondal e J. A. K. Howard, Variable temperature neutron diffraction analysis of a very short $\mathrm{O}-\mathrm{H} \cdots \mathrm{O}$ hydrogen bond in 2,3,5,6pyrazinetetracarboxylic acid dihydrate: Synthon-assisted short $\mathrm{O}_{a c i d}{ }^{-}$ 
$\mathrm{H} \cdots \mathrm{O}$ water hydrogen bonds in a multicenter array, J. Phys. Chem. A 108, 9406 (2004).

[171] W. Caminati, L. B. Favero, P. G. Favero A. Maris e S. Melandri, Intermolecular hydrogen bonding between water and pyrazine, $A n$ gew. Chem. Int. Ed. 37, 792 (1998).

[172] F. H. Stillinger, Theory and molecular models for water, Adv. Quantum Chem. 31, 1 (1975).

[173] B. J. Smith, D. J. Swanton, J. A. Pople, H. F. Schaefer e L. Radom, Transition structures for the interchange of hydrogen-atoms within the water dimer, J. Chem. Phys. 92, 1240 (1990).

[174] S. Susuki, P. G. Green, R. E. Bumgarner, S. Dasgupta, W. A. Godard III e G. A. Blake, Benzene forms hydrogen bonds with water, Science 257, 942 (1992).

[175] P. Hobza e Z. Havlas, Blue-shifting hydrogen bonds, Chem. Rev. 100, $4253(2000)$.

[176] R. Rivelino, P. Chaudhuri e S. Canuto, Quantifying multiplebody interaction terms in $\mathrm{H}$-bonded $\mathrm{HCN}$ chains with many-body pertubation/coupled-cluster theories, J. Chem. Phys. 118, 10593 (2003).

[177] J. Gao, Monte-Carlo quantum mechanical-configuration interaction and molecular mechanics simulation of solvent effects on the $n-\pi^{*}$ blue-shift of acetone, J. Am. Chem. Soc. 116, 9324 (1994).

[178] C. C. Arnold e D. M. Neumark, Study of $\mathrm{Si}_{4}$ and $\mathrm{Si}_{4}^{-}$using threshold photodetachment (ZEKE) spectroscopy, J. Phys. Chem. 99, 3353 (1994).

[179] C. C. Arnold e D. M. Neumark, Threshold photodetachment zero-electron kinetic energy spectroscopy of $\mathrm{Si}_{3}^{-}$, J. Phys. Chem. 100, 1797 (1994).

[180] G. R. Burton e C. Xu, Photoelectron spectroscopy and zero electron kinetic energy spectroscopy of germanium cluster anions, J. Phys. Chem. 104, 2757 (1996). 
[181] M. J. Frisch, G. W. Trucks, H. B. Schlegel, G. E. Scuseria, M. A. Robb, J. R. Cheeseman, J. A. Montgomery, Jr., T. Vreven, K. N. Kudin, J. C. Burant, J. M. Millam, S. S. Iyengar, J. Tomasi, V. Barone, B. Mennucci, M. Cossi, G. Scalmani, N. Rega, G. A. Petersson, H. Nakatsuji, M. Hada, M. Ehara, K. Toyota, R. Fukuda, J. Hasegawa, M. Ishida, T. Nakajima, Y. Honda, O. Kitao, H. Nakai, M. Klene, X. Li, J. E. Knox, H. P. Hratchian, J. B. Cross, C. Adamo, J. Jaramillo, R. Gomperts, R. E. Stratmann, O. Yazyev, A. J. Austin, R. Cammi, C. Pomelli, J. W. Ochterski, P. Y. Ayala, K. Morokuma, G. A. Voth, P. Salvador, J. J. Dannenberg, V. G. Zakrzewski, S. Dapprich, A. D. Daniels, M. C. Strain, O. Farkas, D. K. Malick, A. D. Rabuck, K. Raghavachari, J. B. Foresman, J. V. Ortiz, Q. Cui, A. G. Baboul, S. Clifford, J. Cioslowski, B. B. Stefanov, G. Liu, A. Liashenko, P. Piskorz, I. Komaromi, R. L. Martin, D. J. Fox, T. Keith, M. A. Al-Laham, C. Y. Peng, A. Nanayakkara, M. Challacombe, P. M. W. Gill, B. Johnson, W. Chen, M. W. Wong, C. Gonzalez e J. A. Pople, Gaussian 03: Revision B.04, 2003.

[182] K. A. Brueckner, Nuclear saturation and two-body forces. II. Tensor forces, Phys. Rev. 96, 508 (1954).

[183] L. A. Curtiss, P. C. Redfern, K. Raghavachari, V. Rassolov e J. A. Pople, Gaussian-3 theory using reduced Møller-Plesset order, J. Chem. Phys. 110, 4703 (1999).

[184] S. H. Vosko, L. Wilk e M. Nusair, Accurate spin-dependent electron liquid correlation energies for local spin-density calculations - A critical analysis, Can. J. Phys. 58, 1200 (1980).

[185] E. F. C. Byrd, C. D. Sherrill e M. Head-Gordon, The theoretical prediction of molecular radical species: A systematic study of equilibrium geometries and harmonic vibrational frequencies, J. Phys. Chem. A 105, 9736 (2001).

[186] G. A. Jeffrey e W. P. Saenger, Hydrogen bonding in biological structures, Springer-Verlag, Berlin, 1991. 
[187] M. C. Belissent-Funel e J. C. Dore, editors, Hydrogen bond networks, Kluwer, Amsterdam, 1994.

[188] G. A. Hopkins, M. Maroncelli, J. W. Nibler e T. R. Dyke, Coherent Raman spectroscopy of HCN complexes, Chem. Phys. Lett. 114, 97 (1985).

[189] M. Kofranek, H. Lischka e A. Karpfen, Ab initio studies on hydrogenbonded clusters. I. Linear and cyclic oligomers of hydrogen cyanide, Chem. Phys. 113, 53 (1987).

[190] S. S. Xantheas e T. H. Dunning, Ab initio studies of cyclic water clusters $\left(\mathrm{H}_{2} \mathrm{O}\right)_{n}, n=1-6$. 1. Optimal structures and vibrational-spectra, J. Chem. Phys. 99, 8774 (1993).

[191] A. J. Fillery-Travis, A. C. Legon e L. C. Willoughby, Rotational spectrum and properties of the hydrogen-bonded heterodimer $\mathrm{H}_{2} \mathrm{O} \cdots \mathrm{HCN}$ from pulsed-nozzle, Fourier-transform microwave spectroscopy, Proc. R. Soc. Lon. 396, 405 (1984).

[192] R. Rivelino e S. Canuto, Theoretical study of mixed hydrogen-bonded complexes: $\mathrm{H}_{2} \mathrm{O} \cdot \mathrm{HCN} \cdot \cdot \mathrm{H}_{2} \mathrm{O}$ and $\mathrm{H}_{2} \mathrm{O} \cdot \cdot \mathrm{HCN} \cdot \cdot \mathrm{HCN} \cdot \cdot \mathrm{H}_{2} \mathrm{O}$, J. Phys. Chem. A 105, 11260 (2001).

[193] T. Malaspina, E. E. Fileti, J. M. Riveros e S. Canuto, Ab initio study of the isomers equilibrium of the $\mathrm{HCN} \cdots \mathrm{H}_{2} \mathrm{O}$ and $\mathrm{H}_{2} \mathrm{O} \cdots \mathrm{HCN}$ hydrogenbonded clusters, J. Phys. Chem. A 110, 10303 (2006).

[194] P. Ball, $\mathrm{H}_{2} \mathrm{O}:$ A biography of water, Orion Books Ltd., London, 2000.

[195] D. Eisenberg e W. Kauzmann, The structure and properties of water, Oxford University Press, London, 1969.

[196] F. Franks, Water: A comprehensive treatise, Plenum Press, New York, 1972.

[197] N. A. M. Besseling e J. Lyklema, Hydrophobic hydration of small apolar molecules and extended surfaces: A molecular model, Pure Appl. Chem. 67, $881(1995)$. 
[198] L. Senthilkumar, T. K. Ghanty e S. K. Ghosh, Electron density and energy decomposition analysis in hydrogen-bonded complexes of azabenzenes with water, acetamide, and thioacetamide, J. Phys. Chem. A 109, 7575 (2005).

[199] R. B. Zhang, K. R. F. Somer, E. S. Kryachko, M. T. Nguyen, T. ZeegersHuyskens e A. Ceulemans, Hydrogen bonding to $\pi$-systems of indole and 1-methylindole: Is there any $\mathrm{OH} \cdots$ phenyl bond?, J. Phys. Chem. A 109, 8028 (2005).

[200] V. Barone, Accurate vibrational spectra of large molecules by density functional computations beyond the harmonic approximation: The case of azabenzenes, J. Phys. Chem. A 108, 4146 (2004).

[201] A. D. Boese e J. M. L. Martin, Vibrational spectra of the azabenzenes revisited: Anharmonic force fields, J. Phys. Chem. A 108, 3085 (2004).

[202] M. S. Elioff, M. Fang e A. S. Mullin, Methylation effects in state resolved quenching of highly vibrationally excited azabenzenes $\left(\mathrm{E}_{v i b} 38500 \mathrm{~cm}^{-1}\right)$. I. Collisions with water, J. Chem. Phys. 115, 6990 (2004).

[203] P. Kok, E. J. J. Groenen, L. VanderMeer e W. Amersfoort, IR spectroscopy with FELIX. 2. Lowest triplet state of azabenzenes, J. Chem. Soc. Faraday Trans. 93, 1727 (1997).

[204] T. S. Zwier, The spectroscopy of solvation in hydrogen-bonded aromatic clusters, Ann. Rev. Phys. Chem. 47, 205 (1996).

[205] S. A. C. McDowell e A. D. Buckingham, On the Correlation between bond-length change and vibrational frequency shift in hydrogen-bonded complexes: A computational study of $\mathrm{YHCl}$ dimers $(\mathrm{Y}=\mathrm{N} 2, \mathrm{CO}, \mathrm{BF})$, J. Am. Chem. Soc. 127, 15515 (2005).

[206] M. Piacenza e S. Grimme, Van der Waals complexes of polar aromatic molecules: Unexpected structures for dimers of azulene, J. Am. Chem. Soc. 127, 14841 (2005). 
[207] E. E. Fileti e S. Canuto, Ab initio NMR study of the isomeric hydrogenbonded methanol-water complexes, Int. J. Quantum Chem. 102, 554 (2005).

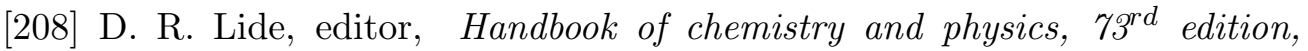
1992-1993, CRC-Pres, Boca Raton, 1992.

[209] W. L. Jorgensen e N. A. McDonald, Development of an all-atom force field for heterocycles. Properties of liquid pyridine and diazenes, J. Mol. Struct. (THEOCHEM) 424, 145 (1998).

[210] H. J. C. Berendsen, J. P. M. Postma e W. F. van Gunsteren, Intermolecular forces, Reidel, Dordrecht, 1981.

[211] K. Coutinho e S. Canuto, Solvent effects in emission spectroscopy. A sequential Monte Carlo-quantum mechanics study of the $n-\pi^{*}$ shift of formaldehyde in water, J. Chem. Phys. 113, 9132 (2000).

[212] M. J. Frisch, G. W. Trucks, H. B. Schlegel, G. E. Scuseria, M. A. Robb, J. R. Cheeseman, V. G. Zakrzewski, J. A. Montgomery, Jr., R. E. Stratmann, J. C. Burant, S. Dapprich, J. M. Millam, A. D. Daniels, K. N. Kudin, M. C. Strain, O. Farkas, J. Tomasi, V. Barone, M. Cossi, R. Cammi, B. Mennucci, C. Pomelli, C. Adamo, S. Clifford, J. Ochterski, G. A. Petersson, P. Y. Ayala, Q. Cui, K. Morokuma, D. K. Malick, A. D. Rabuck, K. Raghavachari, J. B. Foresman, J. Cioslowski, J. V. Ortiz, A. G. Baboul, B. B. Stefanov, G. Liu, A. Liashenko, P. Piskorz, I. Komaromi, R. Gomperts, R. L. Martin, D. J. Fox, T. Keith, M. A. Al-Laham, C. Y. Peng, A. Nanayakkara, C. Gonzalez, M. Challacombe, P. M. W. Gill, B. Johnson, W. Chen, M. W. Wong, J. L. Andres, C. Gonzalez, M. HeadGordon, E. S. Replogle e J. A. Pople, Gaussian 98: Revision A.7, 1998.

[213] J. E. D. Bene, W. B. Person e K. Szczepaniak, Properties of hydrogenbonded complexes obtained from the B3LYP functional with 6-31G(d,p) and $6-31+\mathrm{G}(\mathrm{d}, \mathrm{p})$ basis sets: Comparison with MP2/6-31+G(d,p) results and experimental data, J. Phys. Chem. 99, 10705 (1995). 
[214] J. K. Gregory e D. C. Clary, Quantum simulation of the benzene-water complex, Mol. Phys. 88, 33 (1996).

[215] D. Feller, Strength of the benzene-water hydrogen bond, J. Phys. Chem. A 103, 7558 (1999).

[216] J. Pitarch-Ruiz, J. Sanchez-Marin, A. S.Meras e D. Maynau, The vertical spectrum of $\mathrm{H}_{2} \mathrm{CO}$ revisited: (SC)2-CI and CC calculations, Mol. Phys. 101, 483 (2003).

[217] K. B. Wiberg, R. E. Stratmann e M. J. Frisch, A time-dependent density functional theory study of the electronically excited states of formaldehyde, acetaldehyde and acetone, Chem. Phys. Lett. 297, 60 (1998).

[218] K. Aidas, J. Kongsted, A. Osted e K. V. Mikkelsen, Coupled Cluster calculation of the $n-\pi^{*}$ electronic transition of acetone in aqueous solution, J. Phys. Chem. A 109, 8001 (2005).

[219] D. T. Co, T. F. Hanisco, J. G. Anderson e F. N. Keutsch, Rotational resolved absorption cross sections of formaldehyde in the $28100-28500 \mathrm{~cm}^{-1}$ (351-356 nm) Spectral region: Implications for in Situ LIF measurements, J. Phys. Chem. A 109, 10675 (2005).

[220] M. Staak, E. W. Gash, D. S. Venables e A. A. Ruth, The rotationallyresolved absorption spectrum of formaldehyde from 6547 to $6804 \mathrm{~cm}^{-1}$, J. Mol. Struct. 229, 115 (2005).

[221] J. C. D. Brand, The electronic spectrum of formaldehyde, J. Chem. Soc. 321, 858 (1956).

[222] A. Perrin, F. Keller e J. M. Flaud, New analysis of the $v_{2}, v_{3}, v_{4}$ and $v_{6}$ bands of formaldehyde $\mathrm{H}_{2}^{12} \mathrm{C}^{16} \mathrm{O}$ line positions and intensities in the 5-10 $\mu$ m spectral region, J. Mol. Struct. 221, 192 (2003).

[223] H. Lischka, M. Dallos e R. Shepard, Analytic MRCI gradient for excited states: formalism and application to $n-\pi^{*}$ valence and n- $(3 \mathrm{~s}, 2 \mathrm{p})$ Rydberg states of formaldehyde, Mol. Phys. 100, 1647 (2002). 
[224] K. B. Wiberg, A. E. Oliveira e G. Trucks, A comparison of the electronic transition energies for ethene, isobutene, formaldehyde e acetone calculated using RPA, TDDFT, and EOM-CCSD. Effect of basis sets, J. Phys. Chem. A 106, 4192 (2002).

[225] J. E. D. Bene, S. R. Gwaltney e R. J. Bartlett, Basic properties of $\mathrm{H}_{2} \mathrm{CO}$ in the excited $n-\pi^{*}$ State, J. Phys. Chem. A 102, 5124 (1998).

[226] J. B. Foresman, M. Head-Gordon e J. A. Pople, Toward a systematic molecular-orbital theory for excited-states, J. Phys. Chem. 96, 135 (1992).

[227] J. Tomasi e M. Persico, Molecular interactions in solution - An overview of methods based on continuous distributions of the solvent, Chem. Rev. 94, 2027 (1994).

[228] J. L. Rivail e D. Rinaldi, Quantum chemical approach to dielectric solvent effects in molecular liquids, Chem. Phys. 18, 233 (1976).

[229] J. Li, C. J. Cramer e D. G. Truhlar, Two-response-time model based on $\mathrm{CM} 2 / \mathrm{INDO} / \mathrm{S} 2$ electrostatic potentials for the dielectric polarization component of solvatochromic shifts on vertical excitation energies, Int. J. Quantum Chem. 77, 264 (2000).

[230] C. Zazza, L. Bencivenni, A. Grandi e M. Aschi, On the performance of time-dependent density funcional theory and polarizable continuum model in the study of aqueous formaldehyde, J. Mol. Struct. (THEOCHEM) 680, 117 (2004).

[231] S. A. Monte, T. Müller, M. Dallos, H. Lischka, M. Diedenhofen e A. Klamt, Solvent effects in electronically excited states using the continuum slvation model COSMO in combination with multireference configuration interaction with singles and doubles (MR-CISD), Theor. Chim. Acta 111, 78 (2004). 
[232] J. T. Blair, K. Krogh-Jespersen e R. M. Levy, Solvent effects on opticalabsorption spectra. The ${ }^{1} A_{1} \rightarrow^{1} A_{2}$ transition of formaldehyde in water, J. Am. Chem. Soc. 111, 6948 (1989).

[233] J. Kongsted, A. Osted e K. V. Mikkelsen, Solvent effects on the $n-\pi^{*}$ electronic transition in formaldehyde. A combined coupled cluster/molecular dynamics study, J. Chem. Phys. 121, 8435 (2004).

[234] A. Öhrn e G. Karlström, $\pi^{*}-n$ fluorescence transition in formaldehyde in aqueous solution: A combined quantum chemistry statistical mechanical study, J. Phys. Chem. A 110, 1934 (2006).

[235] S. J. Weiner, P. A. Kollman, D. A. Case, U. C. Singh, C. Ghio, G. Alagona, S. Profeta e P. Weiner, A new force field for molecular mechanical simulation of nucleic acids and proteins, J. Am. Chem. Soc. 106, 765 (1984).

[236] Y. Kawashima, M. Dupuis e K. Hirao, Monte Carlo microsolvation simulations for excited states using a mixed-Hamiltonian model with polarizable and vibrating waters: Applications to the blueshift of the $\mathrm{H}_{2} \mathrm{CO}$ $1\left(\pi^{*} \leftarrow \mathrm{n}\right)$ excitation, J. Chem. Phys. 117, 248 (2002).

[237] H. Fukunaga e K. Morokuma, Cluster and solution simulation of formaldehyde-water complexes and solvent effect on formaldehyde ${ }^{1}\left(n, \pi^{*}\right)$ transition, J. Phys. Chem. 97, 59 (1993).

[238] J. S. Bader, C. M. Cortis e B. J. Berne, Solvation and reorganization energies in polarizable molecular and continuum solvents, J. Phys. Chem. 106, 2372 (1997).

[239] B. Mennucci, R. Cammi e J. Tomasi, Excited states and solvatochromic shifts within a nonequilibrium solvation approach: A new formulation of the integral equation formalism method at the self-consistent field, configuration interaction, and multiconfiguration self-consistent field level, J. Chem. Phys. 109, 2798 (1998). 
[240] S. Ten-no, F. Hirata e S. Kato, Reference interaction site model selfconsistent field study for solvation effect on carbonyl compounds in aqueous solution, J. Chem. Phys. 100, 7443 (1994).

[241] M. E. Martín, M. L. Sánchez, F. J. O. del Valle e M. A. Aguilar, A multiconfiguration self-consistent field/molecular dynamics study of the $(n \longrightarrow$ $\left.\pi^{*}\right)^{1}$ transition of carbonyl compounds in liquid water, J. Chem. Phys. 113, $6308(2000)$.

[242] K. Naka, A. Morita e S. Kato, Effect of solvent fluctuation on the electronic transitions of formaldehyde in aqueous solution, J. Chem. Phys. 110, 3484 (1999).

[243] M. A. Thompson, QM/MMpol: A consistent model for solute/solvent polarization. Application to the aqueous solvation and spectroscopy of formaldehyde, acetaldehyde and acetone, J. Phys. Chem. 100, 14492 (1996). 


\section{Lista de Tabelas}

4.1 Parâmetros geométricos obtidos nos níveis de cálculo MP2/aug-cc-pVTZ e B3LYP/aug-cc-pVTZ, com distâncias em angstrom e ângulos em grau, para o singleto $\mathrm{AlP}_{3}$ nas simetrias $\mathrm{C}_{s}, \mathrm{C}_{2 v}$ e $\mathrm{C}_{3 v}$. . . . . . . . . . . . . . . 46

4.2 Freqüências vibracionais $\mathrm{em}^{-1}$, ZPE em kcal/mol, momento de dipolo em debye e energia total do sistema corrigida de ZPE em hartree. Resultados obtidos nos níveis de cálculo MP2/aug-cc-pVTZ e B3LYP/aug-cc-pVTZ, para o singleto $\mathrm{AlP}_{3}$ nas simetrias $\mathrm{C}_{s}, \mathrm{C}_{2 v}$ e $\mathrm{C}_{3 v}$. . . . . . . . . . . . . 46

4.3 Energias totais em hartree com correções para ZPE calculadas com a base aug-cc-pVTZ, a menos do modelo G3 emprega bases pré-estabelecidas, sobre as geometrias MP2/aug-cc-pVTZ, para os estados singleto do $\mathrm{AlP}_{3}$ nas simetrias $\mathrm{C}_{s} \mathrm{e}_{2 v} . \Delta E=E\left(C_{2 v}\right)-E\left(C_{s}\right) \mathrm{em} \mathrm{kcal} / \mathrm{mol}$. . . . . . . . . . 48

4.4 Energias relativas e energias extrapoladas incluido correção para ZPE, em $\mathrm{kcal} / \mathrm{mol}, \Delta E=E\left(C_{2 v}\right)-E\left(C_{s}\right)$ em vários níveis teóricos,obtidas a partir da geometria B3LYP/aug-cc-pVTZ. ${ }^{a}$ Esquema de extrapolação proposto na ref. [137] ${ }^{b}$ Esquema de extrapolação proposto na ref. [26]. . . . . . . . . . 50

4.5 Parâmetros geométricos obtidos para os agregados $\mathrm{HCN} \cdots \mathrm{HOH} \mathrm{e} \mathrm{H}_{2} \mathrm{O} \cdots \mathrm{HCN}$.

Para os funcionais utilizamos o conjunto de funções-base aug-cc-pVQZ e para o MP2 o conjunto aug-cc-pVTZ. . . . . . . . . . . . . . . 56

4.6 Momentos de dipolo, em debye, e ZPE, em kcal/mol, obtidos nas otimizações

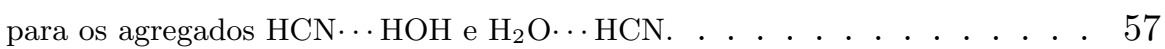


4.7 Energia de ligação, em $\mathrm{kcal} / \mathrm{mol}$, obtida para os agregados $\mathrm{HCN} \cdots \mathrm{HOH}$ e $\mathrm{H}_{2} \mathrm{O} \cdots \mathrm{HCN}$ nos níveis B3LYP, B3PW91, MP2, CCSD e CCSD(T) com o conjunto de funções-base aug-cc-pVXZ, X = 2,3,4 e extrapoladas para o limite de base infinita. ${ }^{a}$ Esquema de extrapolação proposto na ref. [137] ${ }^{b}$ Esquema de extrapolação proposto na ref. [26]. . . . . . . . . . . . . 59

4.8 Estatística de ligações de hidrogênio $(\mathrm{LH})$ formadas no líquido pirazina-água

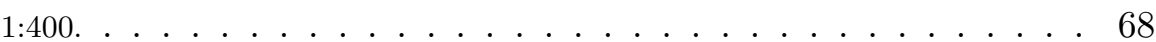

4.9 Parâmetros geométricos obtidos para os dois agregados de pirazina-água (1:1A e 1:1B segundo a figura 4.11) em nível MP2/aug-cc-pVDZ. . . . . . . 72

4.10 Distâncias, em angstrom, e ângulos, em grau, obtidos para os agregados 1:1 de pirazina-água do líquido obtidos em nível MP2/6-31+G(d). As incertezas são o desvio padrão das médias. Os subíndices nos valores médios indicam o número de configurações utilizados na obtenção do valor médio. . . . . . 73

4.11 Parâmetros geométricos obtidos para a estrutura pirazina-água 1:2 onde gasoso refere-se à estrutura otimizada em nível MP2/aug-cc-pVDZ e líquido refere-se a valores médios obtidos diretamente das estruturas do líquido. . .

4.12 Momentos de dipolo, $\mu$ em debye, calculados em nível MP2/6-31+G(d) das estruturas otimizadas e do líquido. As incertezas são o desvio padrão das médias e os números subscritos indicam o número de estruturas na média. 76

4.13 Energias de ligação, calculadas em nível MP2/6-31+G(d) sobre as estruturas otimizadas e do líquido. As incertezas são o desvio padrão das médias e os subscritos indicam o número de estruturas na média. . . . . . . . . . 78

4.14 Energias de interação de três e dois corpos para as estruturas pirazina-água 1:2 em fase gasosa e líquida. A figura acima identifica as moléculas A, B e C. 81

4.15 Distâncias em angstrom e ângulos em grau, obtidos em nível MP2/aug-ccpVDZ para as moléculas de formaldeído e água isoladas e para os agregados formaldeído-água $1: 1,1: 2 \mathrm{~A}$ e 1:2B. . . . . . . . . . . . . . . . 8 
4.16 Momentos de dipolo em debye, energias vibracionais de ponto zero em kcal $/ \mathrm{mol}$ e energias de ligação em kcal/mol corrigidas contra o erro de superposição de base e ZPE, obtidas em nível MP2/aug-cc-pVDZ para os agregados formaldeído-água 1:1, 1:2A e 1:2B. . . . . . . . . . . . . . . . . . . . 88

4.17 Energias de interação de dois e três corpos, obtidas em nível MP2/aug-ccpVDZ, para os agregados formaldeído-água 1:2A e 1:2B. As figuras acima identificam as moléculas A, B e C em cada agregado. . . . . . . . . . . . 91

4.18 Estatística de ligações de hidrogênio formadas no líquido formaldeído-água 1:400....................... 97

4.19 Valores médios do $\Delta E$ da transição $n \rightarrow \pi^{*}$ para as estruturas com uma, duas e três ligações de hidrogênio no líquido. Contribuição média de molécula de água para o deslocamento da banda de energia da transição $\mathrm{n} \rightarrow \pi^{*}$, onde $\delta E_{i}=\Delta E / i$ com $i=N^{o}$ de moléculas de água. . . . . . . . . . . . . . . 100

4.20 Valores médios do deslocamento da banda referente à transição $\mathrm{n} \rightarrow \pi^{*}$ do formaldeído em água, em $\mathrm{cm}^{-1}$ obtidos com TD-DFT para os funcionais B3LYP e B972 nas bases 6-311++G(d,p) para o formaldeído e 6-31G para as moléculas de água inclusas explicitamente nos cálculos quânticos. . . . 105

4.21 Valores para do deslocamento da banda referente à transição $\mathrm{n} \rightarrow \pi^{*}$ do formaldeído em água, em $\mathrm{cm}^{-1}$ obtidos na literatura. . . . . . . . . . . . 112 


\section{Lista de Figuras}

2.1 Ilustração da condição periódica de contorno, onde $\mathrm{r}_{c}$ é o raio de corte que evita que uma partícula interaja com a imagem de outra partícula. . . . . 9

2.2 Ilustração de uma função distribuição radial de pares, típica de um sistema líquido. . . . . . . . . . . . . . . . . . . 12

4.1 Ilustração das estruturas otimizadas do singleto $\mathrm{AlP}_{3}$ em três simetrias distintas obtidas em nível MP2/aug-cc-pVTZ. Da esquerda para a direita, apresentamos os isômeros $\mathrm{C}_{2 v}, \mathrm{C}_{3 v}$ e $\mathrm{C}_{s}$. . . . . . . . . . . . . 45

4.2 Extrapolação para o limite de base infinita da energia relativa dos dois isômeros, utilizando $\operatorname{CCSD}(\mathrm{T}) / \mathrm{cc}-\mathrm{pVXZ}$. . . . . . . . . . . . . 51

4.3 Hiper-superfície de energia potencial dos dois isômeros do singleto $\mathrm{AlP}_{3}$. . . 52

4.4 De cima para baixo, geometrias dos agregados $\mathrm{HCN} \cdots \mathrm{HOH}$ e $\mathrm{H}_{2} \mathrm{O} \cdots \mathrm{HCN}$ otimizadas em nível MP2/aug-cc-pVTZ. . . . . . . . . . . . . . . . . 54

4.5 Poço duplo de energia do agregado $\mathrm{H}_{2} \mathrm{O} \cdots \mathrm{HCN}$ em função do ângulo $\alpha$ formado entre a molécula de água e o HCN. Valores obtidos em nível MP2/6$311++\mathrm{G}(\mathrm{d}, \mathrm{p})$. A energia de referência tem o valor de -169,4877649 hartree . 56

4.6 Função de auto-correlação da energia do sistema líquido pirazina-água. . . 64

4.7 Função de distribuição radial determinada pelo átomo de nitrogênio da molécula de pirazina e átomos de hidrogênio das moléculas de água. . . . . . . . . . 65

4.8 Distribuição energética das estruturas do líquido de pirazina e água. As linhas tracejadas delimitam a distância e a energia máximas que caracterizam a formação de ligação de hidrogênio no líquido. . . . . . . . . . . . . . . 67 
4.9 Distribuição do ângulo N... OH nas estruturas de agregados do líquido com $\mathrm{R}_{N \ldots O} \leq 3,5 \AA$ e $\mathrm{E}_{l i g} \geq 2,5 \mathrm{kcal} / \mathrm{mol}$. . . . . . . . . . . . . . . . 67

4.10 Superposição de todas as estruturas que apresentam ligação de hidrogênio no líquido pirazina-água. . . . . . . . . . . . . . . . . . . . 68

4.11 Da esquerda para a direita, estruturas otimizadas em nível MP2/aug-ccpVDZ dos agregados pirazina-água, planar, agregado 1:1A e não-planar, agregado 1:1B. . . . . . . . . . . . . . . . . . . 71

4.12 Energia relativa, em kcal/mol, calculada em nível MP2/6-31+G(d) referente a rotação da molécula de água sobre o anel. . . . . . . . . . . . . . . . . 73

4.13 Estrutura otimizada em nível MP2/aug-cc-pVDZ do agregado pirazina-água $1: 2 . . . . . . . . . . . . . . . . . . . . .575$

4.14 Histograma dos momentos de dipolo calculados em nível MP2/6-31+G(d) das 67 estruturas $1: 1$ do líquido. . . . . . . . . . . . . . . . . 78

4.15 Convergência estatística das médias da energia de ligação obtidas das estruturas 1:1 (acima) e 1:2 (abaixo) do líquido. As barras de erro apresentadas correspondem ao erro estatístico presente nas médias. . . . . . . . . . . .

4.16 Agregados formaldeído-água otimizados em nível MP2-aug-cc-pVDZ. Acima, agregado 1:1, formaldeído e uma água interagindo por duas ligações de hidrogênio. Abaixo da esquerda para a direita, agregado 1:2A, formaldeído e duas águas interagindo por meio de quatro ligações de hidrogênio e agregado 1:2B, formaldeído e duas águas interagindo por meio de três ligações de hidrogênio. . . . . . . . . . . . . . . . . . . . . . 85

4.17 Função de auto-correlação da energia para o de líquido formaldeído em água. 94

4.18 Função de distribuição radial determinada pelas distâncias entre os átomos de oxigênio do formaldeído e das moléculas de água no líquido. . . . . . . .

4.19 Energia de interação em função da distância $\mathrm{O} \cdots$ O formaldeído-água no líquido. O gráfico em menor escala mostra o histograma de ocorrência da energia clássica de interação formaldeído-água. . . . . . . . . . . . . . 96

4.20 Distribuição do ângulo $\theta(\mathrm{O} \cdots \mathrm{OH})$ nas estruturas de agregados do líquido formaldeído-água, com $\mathrm{R}_{O \ldots O} \leq 3,5 \AA$ A e $\mathrm{E}_{\text {interação }} \leq-4,0 \mathrm{kcal} / \mathrm{mol}$. . . . . 9 
$4.21 \Delta E$ da transição $\mathrm{n} \rightarrow \pi^{*}$ do formaldeído em agregados do líquido contendo uma, duas e três moléculas de água fazendo ligação de hidrogênio, obtidas com os funcionais B3LYP e B972, ambos com a base 6-311++G(d,p). As barras de erro são o desvio padrão das médias. . . . . . . . . . . . . . . 99

4.22 Função distribuição radial de pares determinada entre os átomos de carbono do formaldeído e oxigênio da água no líquido. . . . . . . . . . . . . . . . 102

4.23 Ilustração da primeira camada de solvatação em torno do formaldeído em solução aquosa. . . . . . . . . . . . . . . . . . . 103

4.24 Convergência estatística do deslocamento da banda $\mathrm{n} \rightarrow \pi^{*}$ do formaldeído na primeira camada de solvatação. . . . . . . . . . . . . . . . . . . . . 104

4.25 Histograma dos deslocamentos das bandas referentes à transição $\mathrm{n} \rightarrow \pi^{*}$ obtidos com os funcionais B3LYP e B972, com as bases 6-311++G(d,p) para o formaldeído e 6-31G para as 18 moléculas de água inclusas explicitamente no cálculo quântico. . . . . . . . . . . . . . . . . . . 106

4.26 Saturação dos deslocamentos das bandas referentes à transição $\mathrm{n} \rightarrow \pi^{*}$ do formaldeído em água, em função do número de moléculas de água inclusas explicitamente no cálculo quântico. Valores obtidos com os funcionais B3LYP e B972, com as bases 6-311++G(d,p) para o formaldeído e 6-31G para as moléculas de água. As barras de erro representam o desvio padrão das médias obtidas. . . . . . . . . . . . . . . . . 108

4.27 Deslocamento da banda de energia da transição $\mathrm{n} \rightarrow \pi^{*}$ em função do estiramento da ligação $\mathrm{C}=\mathrm{O}$ do formaldeído isolado. Cálculos pontuais realizados com os funcionais B3LYP e B972 na base 6-311++G(d,p). . . . . . . . . . 110

4.28 Saturação do deslocamento da banda de energia da transição $\mathrm{n} \rightarrow \pi^{*}$ em função da distância entre o átomo de carbono do formaldeído e o oxigênio da água. Cálculos pontuais realizados em nível B3LYP/6-311++G(d,p), as moléculas de água entraram nos cáculos como cargas pontuais nos átomos. Da esquerda para a direita, os pontos incluem as cargas pontuais de 15, 35, 80, 180 e 210 moléculas de água. . . . . . . . . . . . . . . . 111 
Esta tese é baseada parcialmente nos seguintes trabalhos:

- Hydrogen bonds between pyrazine and water. Gas phase complex versus solvation, T. Malaspina e S. Canuto, em preparação.

- Ab initio study of the isomers equilibrium of the HCN $\cdots \mathrm{H}_{2} \mathrm{O}$ and $\mathrm{H}_{2} \mathrm{O} \cdots \mathrm{HCN}$ hydrogen-bonded clusters, T. Malaspina, E. E. Fileti, J. M. Riveros e S. Canuto, J. Phys. Chem. A, 11010303 (2006).

- The relative stability of the two isomers of AlP3, T. Malaspina, K. Coutinho e S. Canuto, Chem. Phys. Lett., 41114 (2005).

- Electronic changes due to thermal disorder of hydrogen bonds in liquids: Pyridine in aqueous environment, E. E. Fileti, K Coutinho, T. Malaspina e S. Canuto, Phys. Rev. E, 6761504 (2003).

\section{Publicação no mestrado:}

- Ab initio calculation of hydrogen bonds in liquids: A sequential Monte Carlo quantum mechanics study of pyridine in water, T. Malaspina, K. Coutinho e S. Canuto, J. Chem. Phys., 1171692 (2002). 
